\title{
THE EFFECT OF CRACKS AND GEO-MORPHOLOGY ON EVAPORATION FROM CLAY SOILS
}

\author{
A thesis submitted to the Faculty of Graduate and Postdoctoral Affairs \\ in Partial Fulfillment of the requirements for the degree of
}

\section{Master of Applied Science}

In

Environmental Engineering

\author{
by \\ Khalil Djalal, \\ B.Eng, Environmental Engineering
}
Department of Civil and Environmental Engineering Carleton University

Ottawa-Carleton Institute of Civil \& Environmental Engineering

May, 2014

C2014 Khalil Djalal 


\section{Abstract}

Crack development in soils and the associated potential for higher evaporation rates are pertinent to many agricultural and engineering applications. Many researchers have attempted to model crack formation though none have succeeded to comprehensively capture it. Chertkov's model is a commonly cited theory for describing crack initiation and development. This theory uses only two independent parameters to model crack development, which makes it a promising tool for engineering applications. This research sought to verify Chertkov's model, as well as to analyze the coupled effect of crack growth and evaporation. A large scale (1.29 by $1.45 \mathrm{~m}$ by $0.09 \mathrm{~m}$ in thickness) clay drying test was carried out where crack growth, rate of evaporation and surface suction were monitored. Volume change and crack development were tracked using a 2-D laser scanner mounted on a scanning control mechanism, as well as by pixel analysis of surface photographs. A fractrographic analysis was also executed to determine the nature of soil deformation at crack tip. The drying test has shown that crack surfaces contributed at most to $6 \%$ of total evaporation before the onset of de-saturation and up to $63.4 \%$ after de-saturation. Results have also shown that Chertkov's model could successfully model crack growth, though the parameters had somewhat unrealistic values. While the fractographic analysis showed that some of Chertkov's model assumptions were violated, in particular that plastic strains appeared to be important, it is not clear whether these violations rule out this model as a useful tool. 


\section{Acknowledgments}

I am grateful to God first and foremost. I would also like to extend my gratitude to my supervisor Dr. Paul H. Simms as well as to my mother. 


\section{Table of Contents}

Acknowledgments

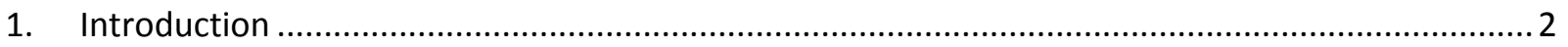

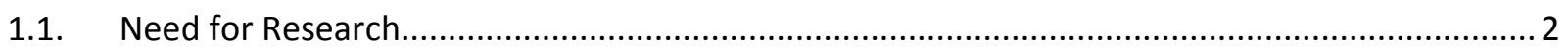

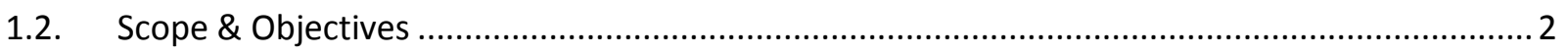

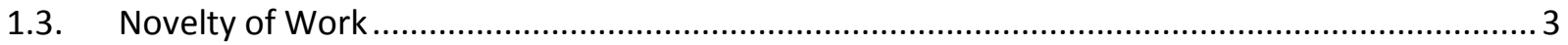

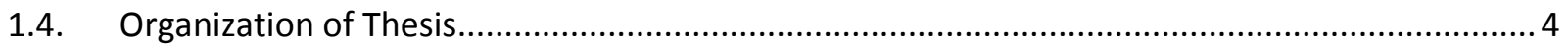

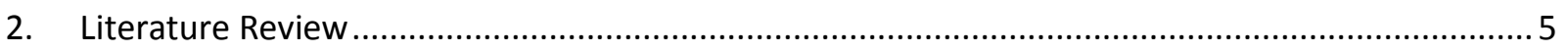

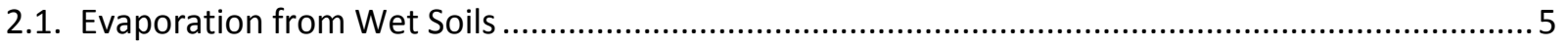

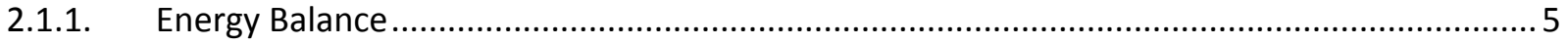

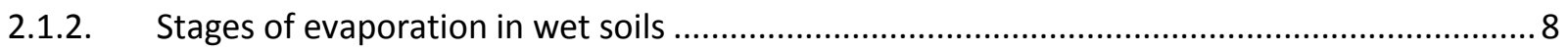

2.1.3. Evaporative mechanisms in cracked soils ..................................................................... 11

2.1.4. Evaporation and the soil water characteristic curve ....................................................... 12

2.1.5. Hydraulic Conductivity in saturated soils....................................................................... 15

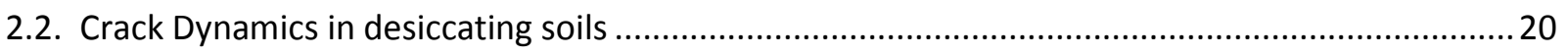

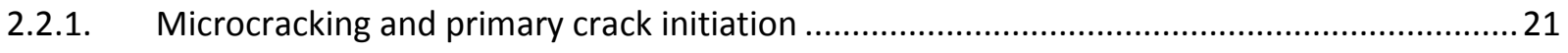

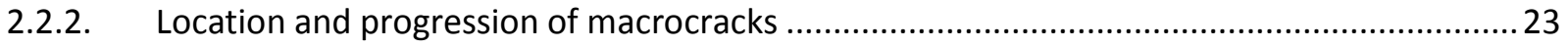

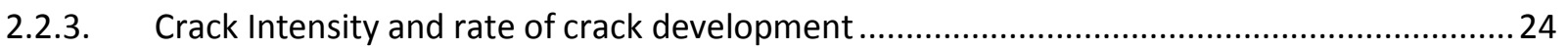

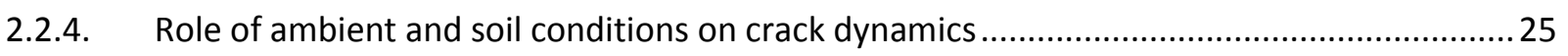

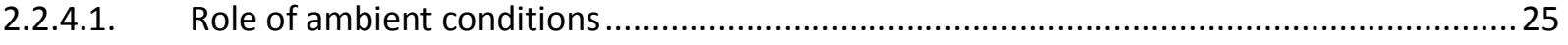

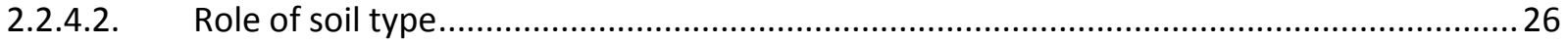

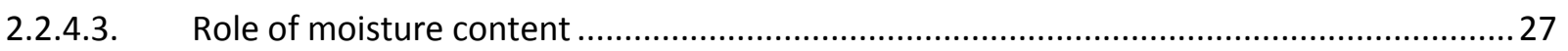

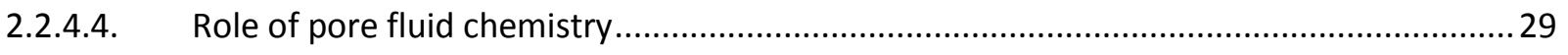

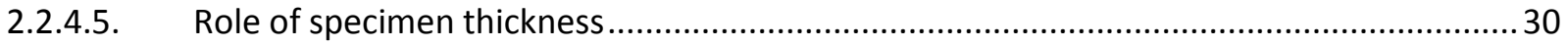

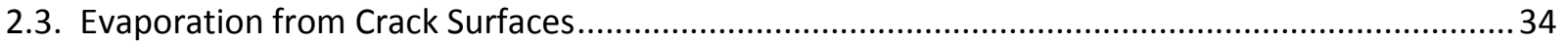


2.4. Role of surface roughness and geomorphology on evaporation.

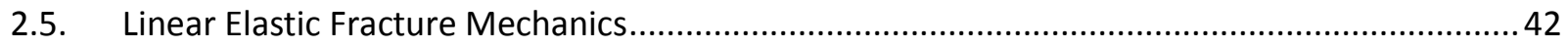

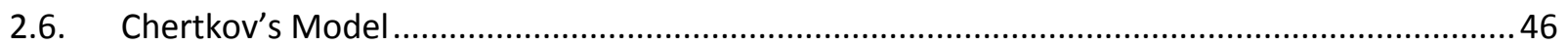

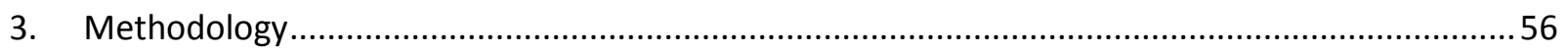

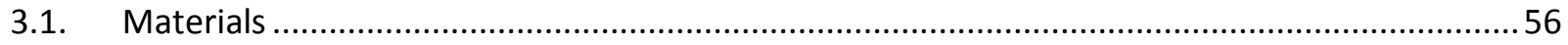

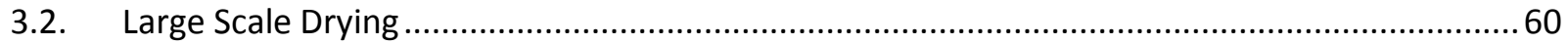

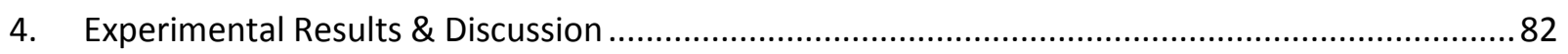

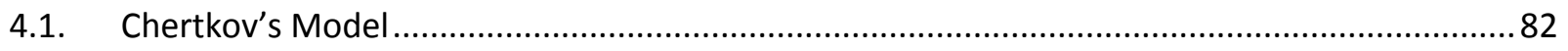

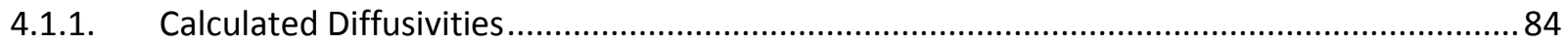

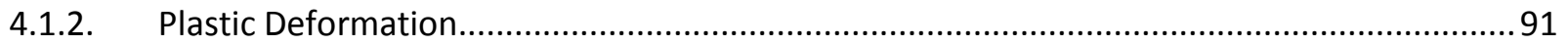

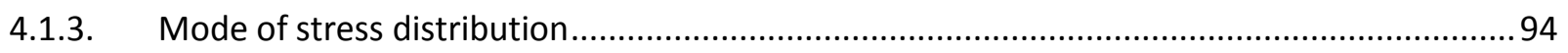

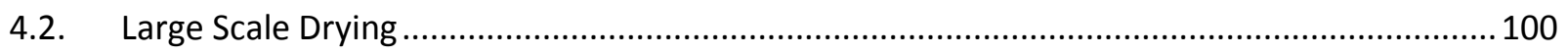

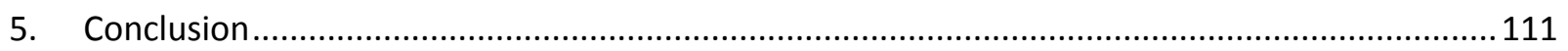

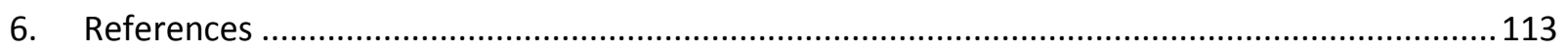

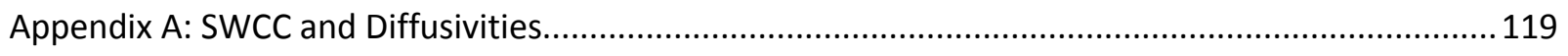

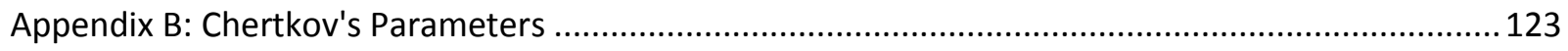

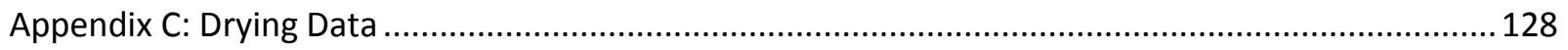




\section{List of Figures}

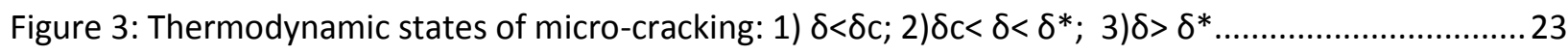

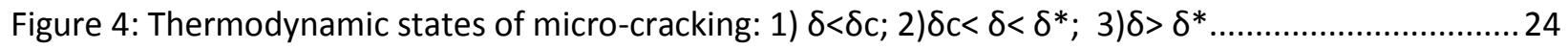

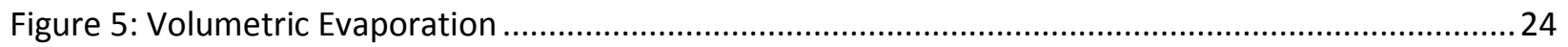

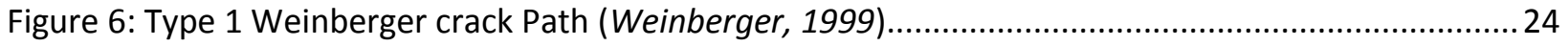

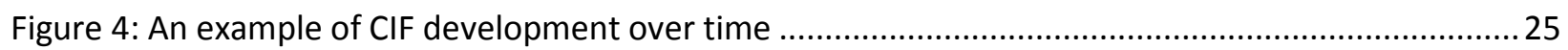

Figure 7: micro-crack jump of orientation: a) flocculated, b) dispersed ................................................2 27

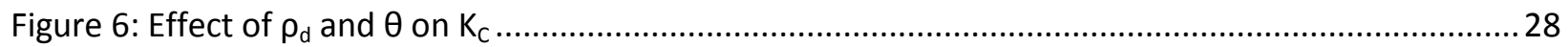

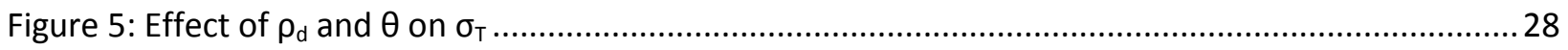

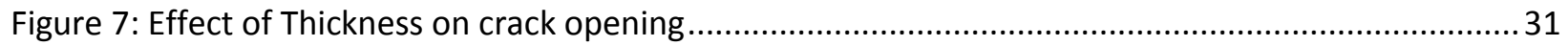

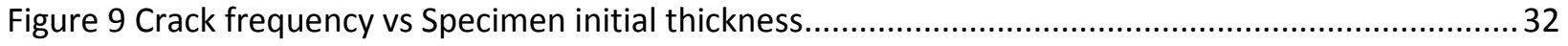

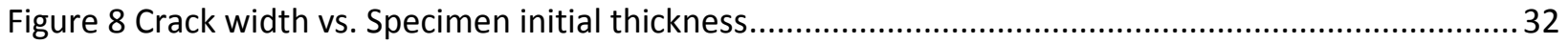

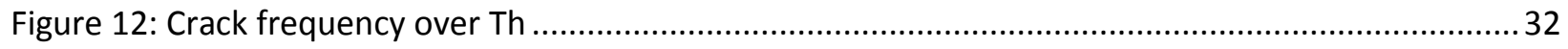

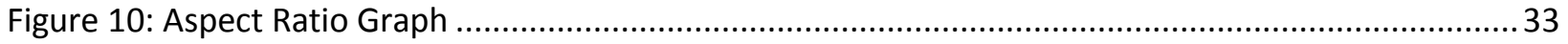

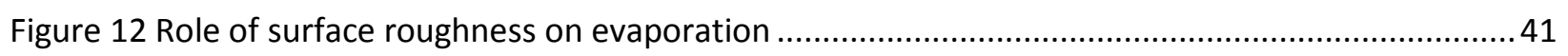

Figure 13 Role of variation in surface roughness on evaporation .......................................................... 42

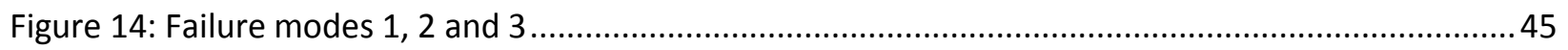

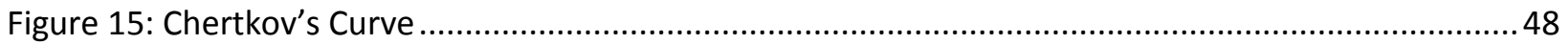

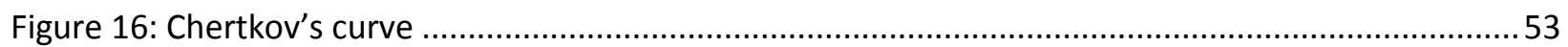

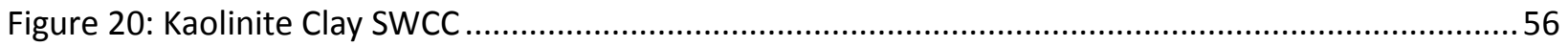

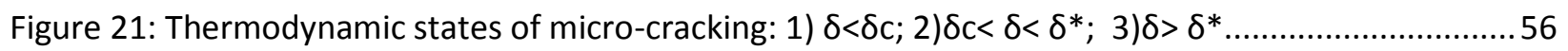

Figure 22: micro-crack jump of orientation: a) flocculated, b) dispersed ...............................................56

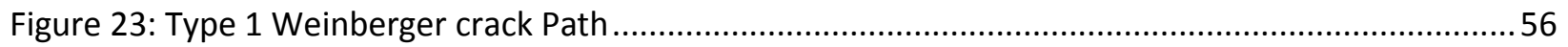

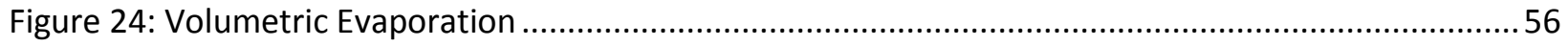

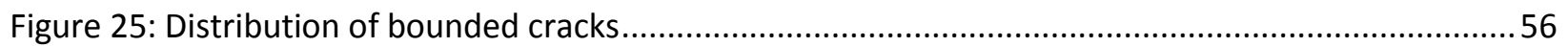

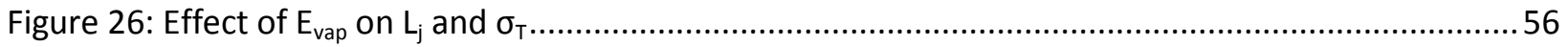

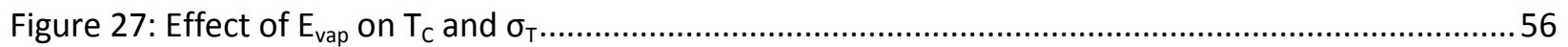

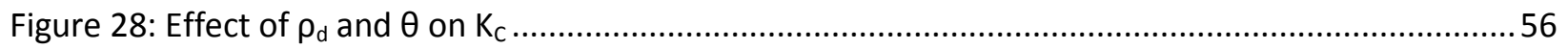

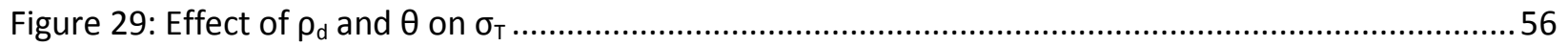

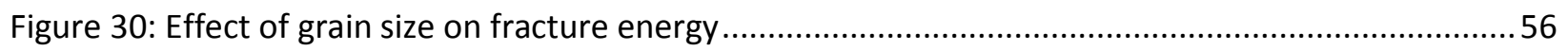

Figure 31: Effect of $1^{\text {st }}, 2^{\text {nd }}$ and $3^{\text {rd }}$ shrink/well cycles Shrinkage Crack Patterns.....................................5 56

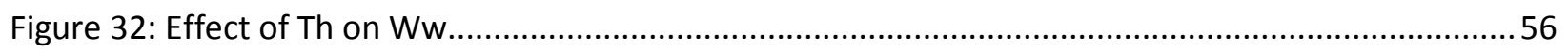

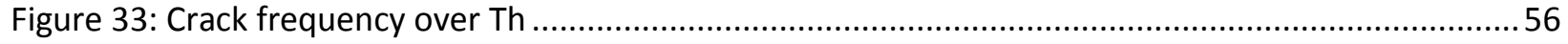

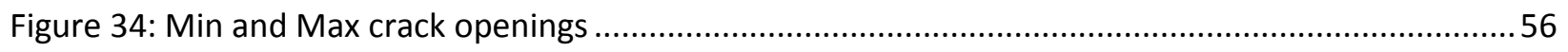

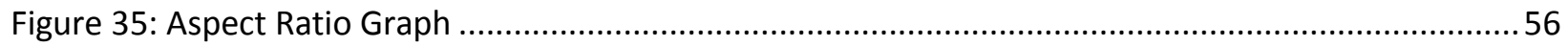

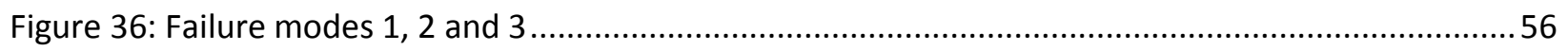

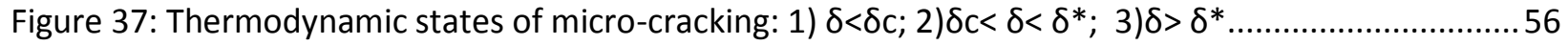

Figure 38: micro-crack jump of orientation: a) flocculated, b) dispersed ...............................................5 56

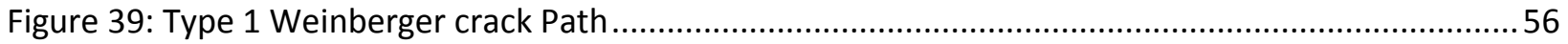

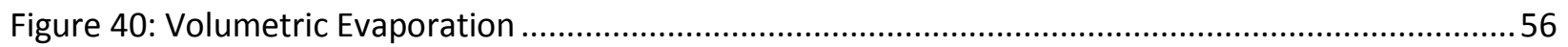




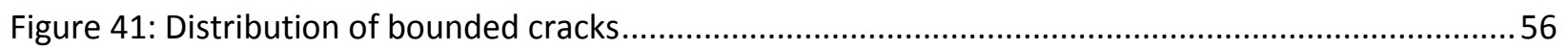

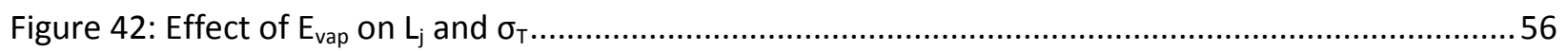

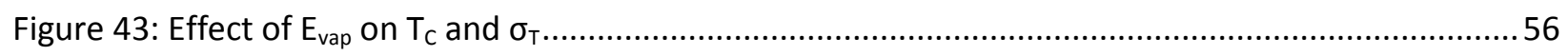

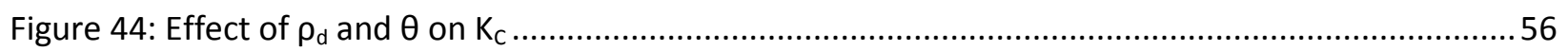

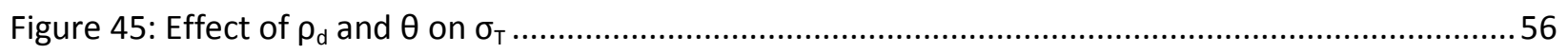

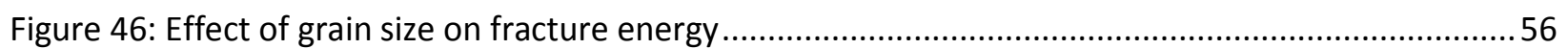

Figure 47: Effect of $1^{\text {st }}, 2^{\text {nd }}$ and $3^{\text {rd }}$ shrink/well cycles Shrinkage Crack Patterns...................................56

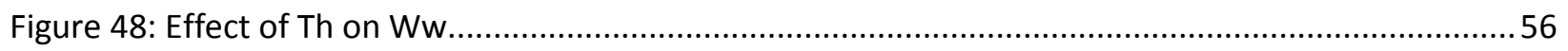

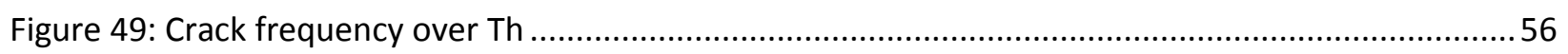

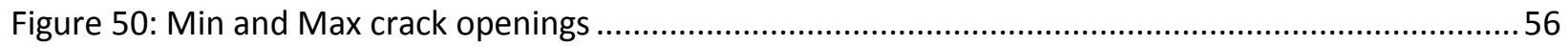

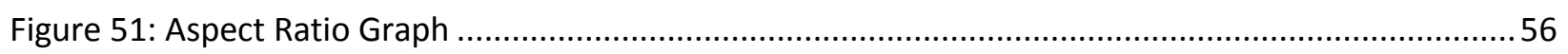

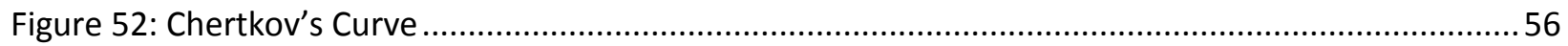

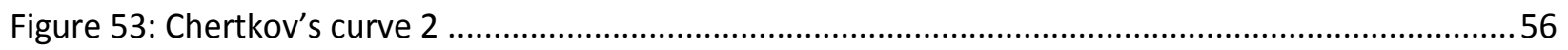

Figure 18 Metallic container which contained clay specimen $(2.7 \mathrm{mx1.5m \times 1 \textrm {m } )}$.................................5

Figure 19 Soil water characteristic curve (after Jayasinghe (2013)) ....................................................59

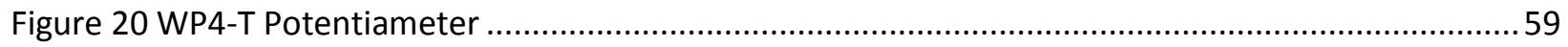

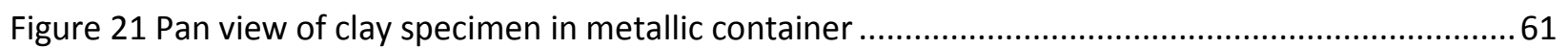

Figure 22 Corner view of clay specimen in metallic container ............................................................6. 61

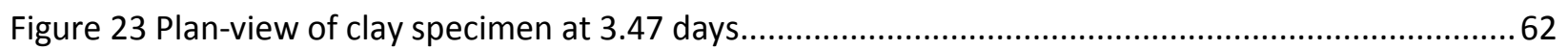

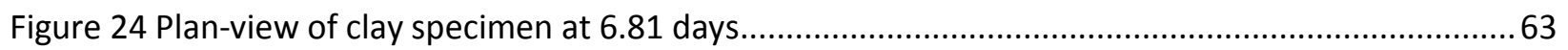

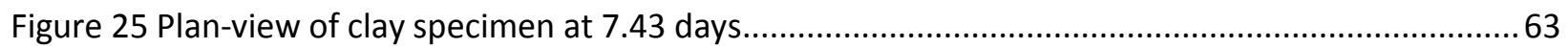

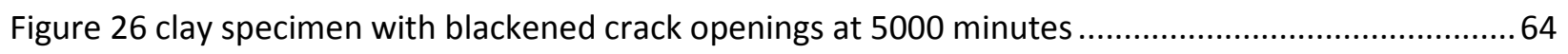

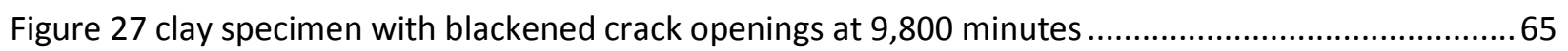

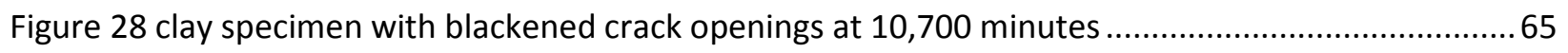

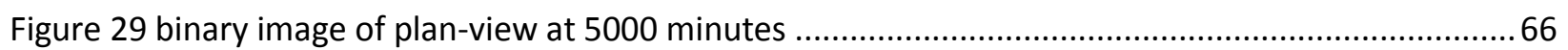

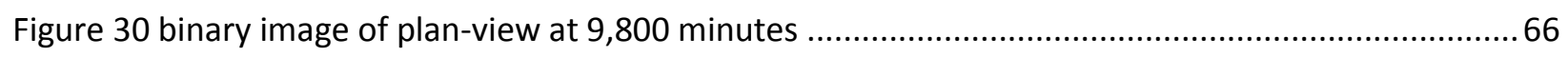

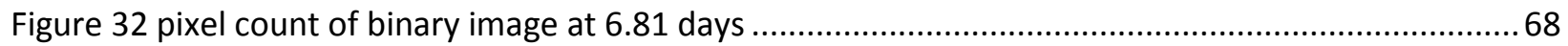

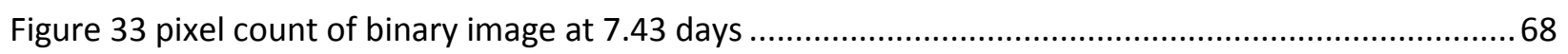

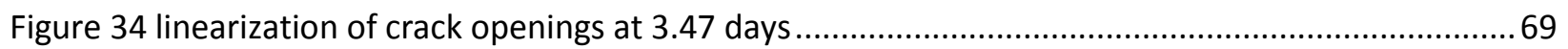

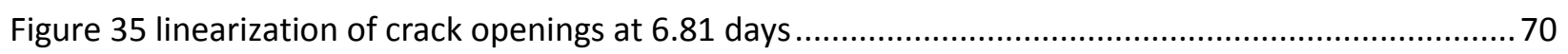

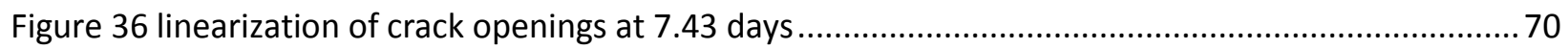

Figure 38 skeletalization of crack openings at 7.43 days.................................................................. 71

Figure 39 locations of surface clay samples for suction analysis at 3.47 days ....................................... 72

Figure 40 locations of surface clay samples for suction analysis at 6.81 days ...................................... 73

Figure 41 locations of surface clay samples for suction analysis at 7.43 days ....................................... 73

Figure 42 contour map of matric suction on clay specimen surface at 6.81 days.................................... 76

Figure 43 contour map of matric suction on clay specimen surface at 7.43 days................................... 77

Figure 45 colour coded contour map of matric suction on clay specimen surface at $7.43 \mathrm{~d}$ days .............79

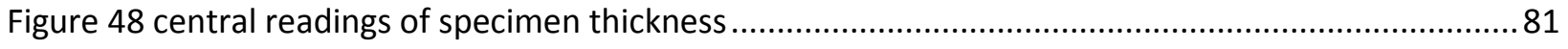

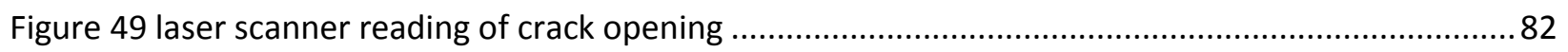

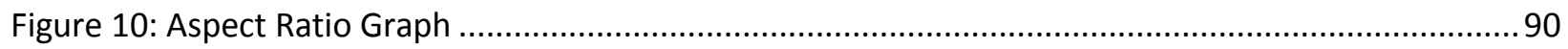

Figure 56 shear stress distribution for plastic deformation ............................................................ 92 
Figure 57 crack bifurcation along maximum shear stress directions ...................................................93

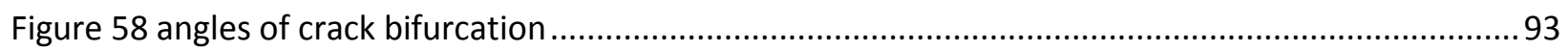

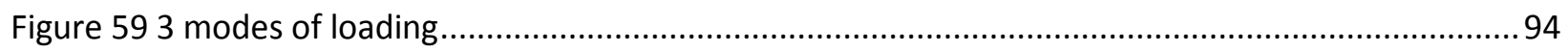

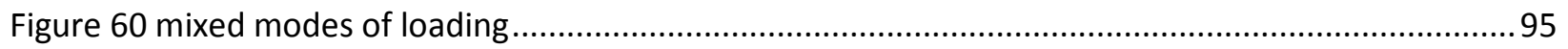

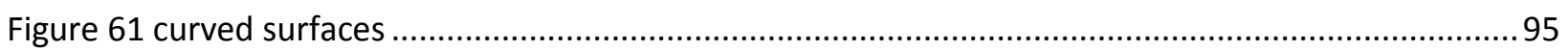

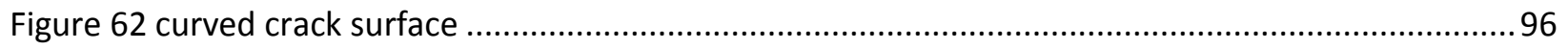

Figure 63 laser scanner rendering of curved crack surface ................................................................ 96

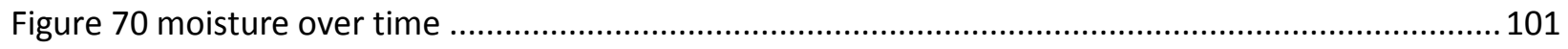

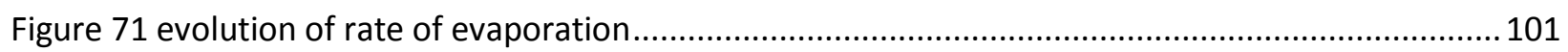

Figure 72 evolution of specimen thickness over time …................................................................... 103 


\section{List of Tables}

Table 2: Equations of Unsaturated Hydraulic Conductivity ............................................................... 14

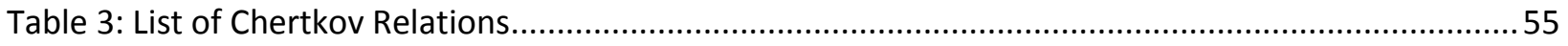

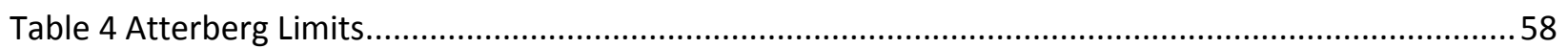

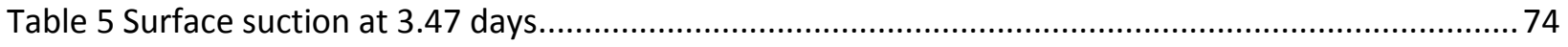

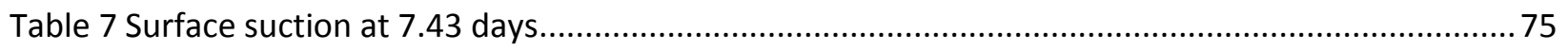

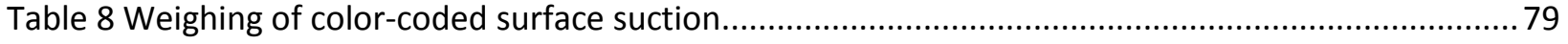

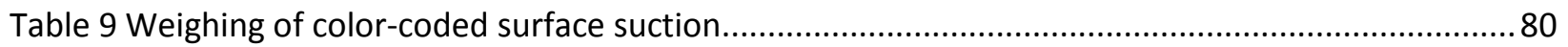

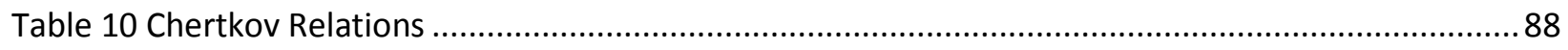

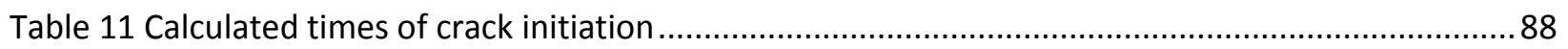

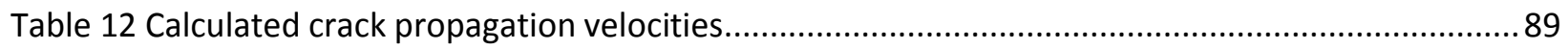

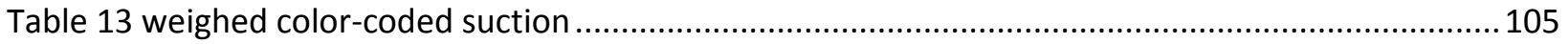

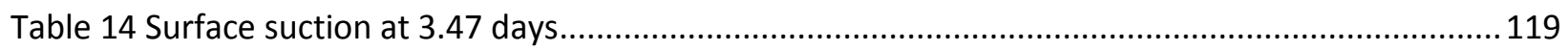

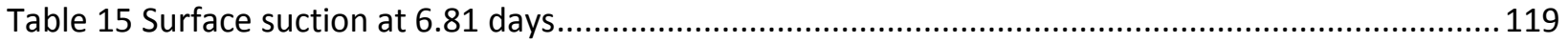

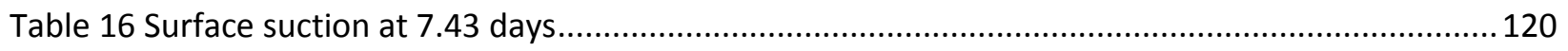




\section{Nomenclature}

\begin{tabular}{|c|c|c|c|}
\hline AEV & air entry pressure value [kPa] & $K I I$ & fracture toughness under mode 2 \\
\hline$A r$ & area emitting radiation [m2] & & failure, $[\mathrm{kNm}-1.5]$ \\
\hline$A T$ & area of the crack aperture [m2] & KIII & failure, $[\mathrm{kNm}-1.5]$ \\
\hline ATM & atmospheric pressure $[\mathrm{kPa}]$ & $K p$ & intrinsic permeability, [m2] \\
\hline CIF & crack intensity factor, [\%] & kSAT & $\begin{array}{l}\text { saturated hydraulic conductivity } \\
\text { [ms-1] }\end{array}$ \\
\hline Cs & shape factor & $I^{*}$ & minimum dimension for which \\
\hline$c V A$ & $\begin{array}{l}\text { atmosphere vapor concentration } \\
\text { at height } \mathrm{ZREf}(\mathrm{mol} / \mathrm{mol})\end{array}$ & IAVG & $\begin{array}{l}\text { macro-nucleation is possible, }[\mathrm{m}] \\
\text { mean depth of micro-crack which }\end{array}$ \\
\hline cVS & $\begin{array}{l}\text { vapor concentration of the soil } \\
\text { surface }(\mathrm{z} 0, \mathrm{Ts})(\mathrm{mol} / \mathrm{mol})\end{array}$ & IAVG & 'jumps' to primary crack, [m] \\
\hline$D$ & diffusivity, [m2s-1] & LAVG & beginning of initiation, [m] \\
\hline$D a$ & $\begin{array}{l}\text { free air diffusion coefficient of } \\
\text { water vapour in air }\end{array}$ & $L j$ & $\begin{array}{l}\text { actual depth of micro-crack which } \\
\text { 'jumps' to primary crack [m] }\end{array}$ \\
\hline De & effective grain size & $L j$ & actual depth of primary crack at \\
\hline Di & soil diameter & $M$ & molality of pure solution \\
\hline$E$ & modulus of elasticity, [kPa] & $P$ & pressure $[\mathrm{kPa}]$ \\
\hline$E$ & $\begin{array}{l}\text { evaporation, volumetric } \\
\text { evaporation, }[\mathrm{ms}-1],[\mathrm{m} 3 \mathrm{~s}-1]\end{array}$ & $q$ & heat transfer $[\mathrm{MJ} / \mathrm{d}]$ \\
\hline$e$ & void ratio & $Q D$ & mass flow rate [mass/time] \\
\hline$e a$ & actual vapor pressure $[\mathrm{kPa}]$ & $R$ & $\begin{array}{l}\text { universal gas constant, [Jmol-1K- } \\
\text { 1] }\end{array}$ \\
\hline es & saturate vapor pressure [kPa] & $R 1$ & portion of radiation reflected \\
\hline $\boldsymbol{F}$ & load, [kN] & & through albedo \\
\hline $\boldsymbol{F}$ & volume forces & ra & $\begin{array}{l}\text { radius of plastic deformation } \\
\text { zone, }[\mathrm{m}]\end{array}$ \\
\hline$f(u)$ & wind factor $[\mathrm{mm} / \mathrm{d} / \mathrm{kPa}]$ & Rdess & rate of desiccation, $[\mathrm{m} / \mathrm{hr}]$ \\
\hline $\boldsymbol{G}$ & ground heat flux [W/m2] & & {$[\mathrm{m} 3 / \mathrm{hr}]$} \\
\hline$g$ & gravity acceleration [ms-2] & RH & relative humidity, [\%] \\
\hline Gc & critical strain energy release rate, & $R H(s m a l l ~ H)$ & hydraulic radius \\
\hline & {$[\mathrm{Js}-1]$} & Rha & actual relative humidity \\
\hline Gc & $\begin{array}{l}\text { elastic strain energy release rate } \\
\text { [Js-1] }\end{array}$ & Rlongwave & net long wave radiation $[\mathrm{W} / \mathrm{m} 2]$ \\
\hline$H$ & sensible heat flux [W/m2] & $R N(s m a l l ~ N)$ & net radiation [W/m2] \\
\hline i & $\begin{array}{l}\text { Van't Hoff constant for } \\
\text { measurement of osmotic suction } \\
{[\mathrm{m} 2 \mathrm{~s}-2]}\end{array}$ & $\begin{array}{l}\text { Rs } \\
\text { rs }\end{array}$ & $\begin{array}{l}\text { radius of curvature of the } \\
\text { contractile } s k i n[\mathrm{~m}] \\
\text { soil resistance }[\mathrm{s} / \mathrm{m}]\end{array}$ \\
\hline i & Van't Hoff constant & Rshortwave & net short-wave radiation $[\mathrm{W} / \mathrm{m} 2]$ \\
\hline$\kappa$ & stress Intensity factor, [kPam-2] & $r V$ & aerodynamic resistance for water \\
\hline$\kappa$ & fracture toughness [kNm-1.5] & & vapor transfer $[\mathrm{s} / \mathrm{m}]$ \\
\hline$K^{*}$ & $\begin{array}{l}\text { ratio of linear dimension of crack } \\
\text { by crack depth }\end{array}$ & $S$ & $\begin{array}{l}\text { wetted surface area per unit } \\
\text { volume of particle material } \\
\text { [L2/L3] }\end{array}$ \\
\hline KO & shape factor of soil void channel & so & avg. distance between primary \\
\hline KC & $\begin{array}{l}\text { critical stress intensity factor (aka, } \\
\text { fracture toughness) [kNm-1.5] }\end{array}$ & Sn & cracks, $[\mathrm{m}]$ \\
\hline khyd & hydraulic conductivity [ms-1] & swce & soil water characteristic curve \\
\hline KI & $\begin{array}{l}\text { fracture toughness under mode } 1 \\
\text { failure, }[\mathrm{kNm}-1.5]\end{array}$ & $T$ & time, $[\mathrm{s}]$ \\
\hline
\end{tabular}


ua

Ustrain

Usurface

uw

V

vavg

$v W$

ZO

$\mathrm{Zm}$

$\alpha$

b

$r$

veff

vp

rw

$\varepsilon$

$\varepsilon r$

$\eta$

nad

$\vartheta$ time of formation of upper intensive cracking layer, [s]

temperature, $\left[{ }^{\circ} \mathrm{C}\right]$

time of crack nucleation (macro-

nucleation), [s]

specimen thickness, [m]

surface tension $[\mathrm{N} / \mathrm{m}]$

speed of depth propagation of

primary crack, [ms-1]

pore air pressure, [kPa]

strain energy [J]

crack surface energy [Jm-2]

pore water pressure, [kPa]

velocity $[\mathrm{m} / \mathrm{s}]$

average flow velocity $\mathrm{m}$ per $\mathrm{s}$

specific volume of water $[\mathrm{m} 3 / \mathrm{kg}]$

depth of upper intensive crack

layer, $[\mathrm{m}]$

maximum crack depth, $[\mathrm{m}]$

shrinkage coefficient

Bowen ratio

psychrometric constant

effective surface energy, [J]

plastic deformation energy [J]

fluid unit weight ${ }^{\wedge} \mathrm{kNém} 3 c ̧$

emissivity

ratio of mole weight of water to

air

dynamic viscosity of fluid $\mathrm{kg}$ per

$\mathrm{m}$ per $\mathrm{s}$

absolute viscosity of fluid

[Pa*sec]

gravimetric moisture content [\%] $\vartheta 0$

$\vartheta C$

ขf

vr

ชS

ЭTOP

$\lambda$

$\lambda E$

$\lambda f$

$\lambda g$

$\mu$

$\rho$

$\rho d$

pvapor

$\sigma c$

$\sigma e$

$\sigma s$

$\sigma T$

$\sigma \vartheta$

$\tau$

$\chi$

$\boldsymbol{\Psi}$

$\psi m$

$\psi 0$

$\Omega$

$\omega v$ initial moisture content, [\%]

gravimetric moisture content at

macro-nucleation, [\%]

final moisture content, [\%]

residual water content

saturated volumetric soil

moisture

soil moisture in the top $1 \mathrm{~cm}$

latent heat of vaporization $[\mathrm{kJ} / \mathrm{kg}]$

latent heat flux [W/m2]

So/Th

aspect ratio: specimen length/Th

poisson ratio

fluid density ^kgém3ç

dry density g per $\mathrm{cm} 3$

vapour density

critical tensile stress [ $\mathrm{kPa}]$

elastic stresses, [kPa]

Stefan-Boltzmann constant

$[\mathrm{MJ} / \mathrm{d} / \mathrm{m} 2 / \mathrm{K} 4]$

tensile strength of soil [kPa]

shrinkage stresses, [KPa]

minimal possible time of

desiccation for crack to initiate

error function

total suction, [kPa]

matric suction, [kPa]

osmotic suction, [kPa]

tortuosity

molecular mass of water vapour, [kgkmol-1] 


\section{Introduction}

\subsection{Need for Research}

Results from literature suggest that cracks can increase the rate of evaporation in soils (Adams and Hanks (1964), Kirkham and Selim (1970), Adams and Ritchie (1974) and Hatano et al. (1988)). Cracking in soils or other porous media is important to many applications. Cracks affect the stability of slopes, are often precursors for failure and affect the bearing capacity of cracked soil masses. Moreover, cracks form preferential flow routes, compromising clayey barriers in landfills and leading to nutrient loss and water pollution in agriculture. In management of fine grained tailings, desiccation is relied upon to contribute to densification and improve the strength of tailings deposits (BGC, 2010). Cracking in tailings depositions however, can lead to the infusion of oxygen into the soil matrix which can react with sulfide minerals and water and generate acid mine drainage, which should be avoided. Understanding their initiation and propagation is therefore a priority for many sectors of the economy.

\subsection{Scope \& Objectives}

An experiment was designed to study both crack development, and the influence of cracks on evaporation. The experiment involved drying a kaolin clay from above its liquid limit. The initial thickness of the clay layer was $0.09 \mathrm{~m}$, and the drying test was 
conducted in a steel box with a test surface area $1.29 \mathrm{~m}$ by $1.4 \mathrm{~m}$. The geometry of crack development was monitored by a 2-d laser scanner, and by pixel analysis of photographs. Evaporation is directly measured by scales under the box. Totals suction and water content are measured in the top $1 \mathrm{~cm}$ of the specimen.

With respect to crack dynamics, the purpose of the experiment is to assess the validity of Chertkov's model (Chertkov, 2002.a) of crack formation. Chertkov's model was chosen because it is widely cited in the literature, and has only two free parameters and therefore has potential for use as an engineering tool. With respect to evaporation, the goal of the experiment was to observe correlations between evaporation and crack morphology, if any.

\subsection{Novelty of Work}

The main novelty of the work is:

1. The use of a laser scanner to image crack morphology

2. To independently test Chertkov's model for predicting crack development, and its applicability as an engineering tool.

3. To correlate evaporation with surface measurements of total suctions, taken across a relatively large plan area. 


\subsection{Organization of Thesis}

Chapter 2 will review general knowledge of stages of evaporation and evaporative mechanisms. An overview of the stages of crack formation and the role of ambient conditions will follow, as well as a summary of reported relations between evaporation and crack formation. The literature review will conclude with a review of the roles of surface roughness and geomorphology on total evaporation. Chertkov's model (Chertkov, 2002.a) is reviewed and a description of experimental methods and materials (Chapt.3) will then be followed by a discussion of the experimental results (Chapt.4). These will be capped by concluding remarks (Chapt.5), references (Chapt.6) and appendices. 


\section{Literature Review}

\subsection{Evaporation from Wet Soils \\ 2.1.1. Energy Balance}

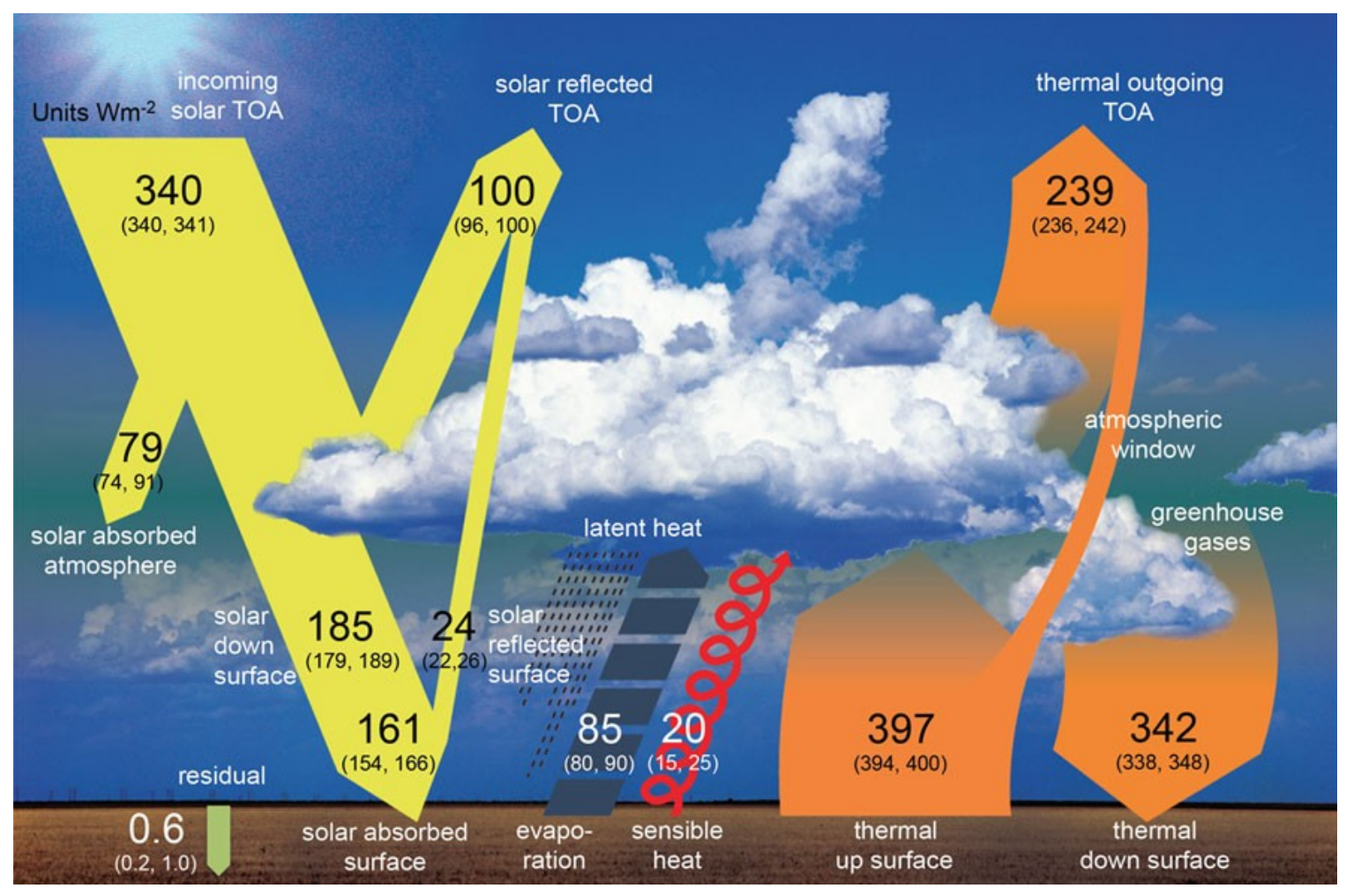

Figure 1 Global Energy Balance (Pontius, Fred, 2012)

Evaporation is the process of converting a unit mass of water from its liquid state to a vapour state. The amount of thermal energy that must be input into the liquid to achieve this transformation is called the Latent Heat of Vaporization $\lambda[\mathrm{kJ} / \mathrm{kg}]$. Latent Heat of Vaporization depends on air temperature $\mathbf{T}[\mathrm{C}]$ (equation 1) and can be found in steam tables for specific pressures and temperatures.

$$
\lambda=2501-2.3601 \cdot T
$$

Equation 1 
The heat required to evaporate water from the earth's surface is provided by the sun in the form of radiation. Thermal energy is transmitted through electromagnetic waves emitted from the sun. A portion of that radiation is absorbed by the atmosphere and converted into heat while a portion is reflected back into space and another portion is reflected towards the earth surface. An estimated $48 \%$ of the incoming solar radiation reaches the ground surface. Of this energy, a portion is reflected back towards the sky through the albedo effect (R1), a portion is absorbed into the soil as heat (G), a portion heats the air right above the ground surface $(\mathbf{H})$, and finally, a portion of that energy is used to vaporize pore water as quantified by the mass rate of evaporation and the Latent Heat of Vaporization $\boldsymbol{\lambda}[\mathrm{kJ} / \mathrm{kg}]$.

The 'albedo effect' refers to the partial reflectance of solar radiation. It is dependent on angle of incidence as well as the reflecting surface and has range of 0.02-0.08 for water and $0.05-0.31$ for soils. Generally accepted averages for water and soil are 0.05 and 0.18 respectively.

Energy transfer through radiation is defined by wavelength and is dependent on the thermal energy contained in the emitting body. Wavelength is an inverse function of temperature and so radiation emitted from the sun, with its surface temperature of $5800 \mathrm{~K}$, will be much shorter (0.015-4 microns) than radiation emitted by colder bodies like clouds, surface water or soil (4-50 microns). This relationship is described by the Stefan-Boltzmann equation (equation 2) where emissivity $\boldsymbol{\varepsilon}$ is the ratio of radiation from the actual surface to that from an 'ideal' radiation surface where $\boldsymbol{\varepsilon}$ would be 1 . 


$$
\frac{q}{A}=\varepsilon^{\prime} \sigma T^{4}
$$

\section{Equation 2}

$\mathrm{q}[\mathrm{MJ} / \mathrm{d}]:$ heat transfer

$A$ [m2]: area emitting radiation

$\mathrm{T}[\mathrm{K}]$ : absolute temperature of object emitting radiation

$\boldsymbol{\sigma}\left[\mathrm{MJ} / \mathrm{d} / \mathrm{m}^{2} / \mathrm{K}^{-4}\right]$ : Stefan-Boltzmann constant

$\boldsymbol{\varepsilon}$ [dimensionless]: emissivity

The energy balance at ground surface is characterized by the Heat Balance Equation (eq.3). Net radiation $\mathbf{R}_{\mathbf{N}}\left[\mathrm{W} / \mathrm{m}^{2}\right]$ does work on the soil surface by converting into heat. This heat is portioned in three different ways; 1 ) Sensible Heat Flux $\mathbf{H}\left[\mathrm{W} / \mathrm{m}^{2}\right]$ which is a heat flux emitted from the ground surface and which heats the air above the surface through convection and advection, 2) Latent Heat Flux $\lambda \mathrm{E}\left[\mathrm{W} / \mathrm{m}^{2}\right]$ which the heat of vaporization required for surface evaporation and finally 3) Ground Heat Flux $\mathbf{G}\left[\mathrm{W} / \mathrm{m}^{2}\right]$ which is the movement of heat below the soil surface either towards or away from the ground surface. The net radiation $\mathbf{R}_{\mathbf{N}}\left[\mathrm{W} / \mathrm{m}^{2}\right]$ itself is the difference between net shortwave radiation emitted by the sun and net long wave radiation emitted by the earth.

$$
\begin{aligned}
& R_{N}=\lambda E+H+G \\
& R_{N}=R_{\text {ShortWave }}-R_{\text {Equation } 3}
\end{aligned}
$$

$\mathrm{R}_{\mathrm{N}}\left[\right.$ Watts $\left./ \mathrm{m}^{2}\right]$ : Net Radiation at ground surface

$R_{\text {Short.Wave }}\left[\right.$ Watts $/ \mathrm{m}^{2}$ ]: Net Short-wave Radiation

$\mathrm{R}_{\text {Long.Wave }}\left[\right.$ Watts $\left./ \mathrm{m}^{2}\right]$ : Net Long-wave Radiation

$\Lambda \mathrm{E}\left[\right.$ Watts $\left./ \mathrm{m}^{2}\right]:$ Latent Heat Flux

$\mathrm{H}\left[\right.$ Watts $/ \mathrm{m}^{2}$ ]: Sensible Heat Flux

G [Watts $\left./ \mathrm{m}^{2}\right]$ : Ground Heat Flux 
Most of the energy from net radiation usually converts into Latent Heat Flux and Sensible Heat Flux. Ground heat flux is often of a magnitude lower than latent and sensible heat fluxes. The important relationship for predicting evaporation then becomes the ratio of energy available for a sensible heat flux to that available for a latent heat flux, known as the Bowen Ratio $\boldsymbol{\beta}$ [unitless] (equation 4).

$$
\beta=\frac{H}{\lambda E}=\gamma \cdot \frac{\Delta T}{\Delta e}
$$

\section{Equation 4}

The Bowen Ratio $\boldsymbol{\beta}$ can be predicted from temperature $\boldsymbol{\Delta} \mathbf{T}$ and vapour pressure gradients $\Delta \mathbf{e}$ above the surface between two heights of measurement. The psychrometric constant $\boldsymbol{v}$, which is also required for this equation (Equation 5), is directly dependent on total atmospheric pressure $\mathbf{P}[\mathrm{kPa}]$ and inversely dependent on $\boldsymbol{\lambda}$ $[\mathrm{kJ} / \mathrm{kg}]$ and $\varepsilon_{\mathrm{R}}$ which is the ratio of mole weight of water to air and is equal to 0.622 .

$$
\gamma=C_{p m} \cdot \frac{P}{\varepsilon_{R} \lambda}
$$

$$
\text { Equation } 5
$$

\subsubsection{Stages of evaporation in wet soils}

Evaporation in soils occurs in two stages (Barbour et al., 1997). The first stage is characterized by an actual evaporation that is roughly equal to potential evaporation as calculated by Dalton (1802) (equation 6 ) where $\mathbf{f}(\mathbf{u})$ is the wind factor, $\mathbf{e}_{\mathbf{s}}$ is saturated vapor pressure $[\mathrm{kPa}]$ and $\mathbf{e}_{\mathrm{a}}$ is actual vapor pressure $[\mathrm{kPa}]$ This stage is located in the saturated phase and ends at the point of air entry. 


$$
E=f(u)\left(e_{s}-e_{a}\right)
$$

\section{Equation 6}

The second stage is one of a falling rate of evaporation and begins at a surface total suction of $3 \mathrm{MPa}$ which corresponds to air entry value. The relationship between rate of evaporation and total suction in that stage (figure 2) is independent of soil texture, water content and rate of evaporation.

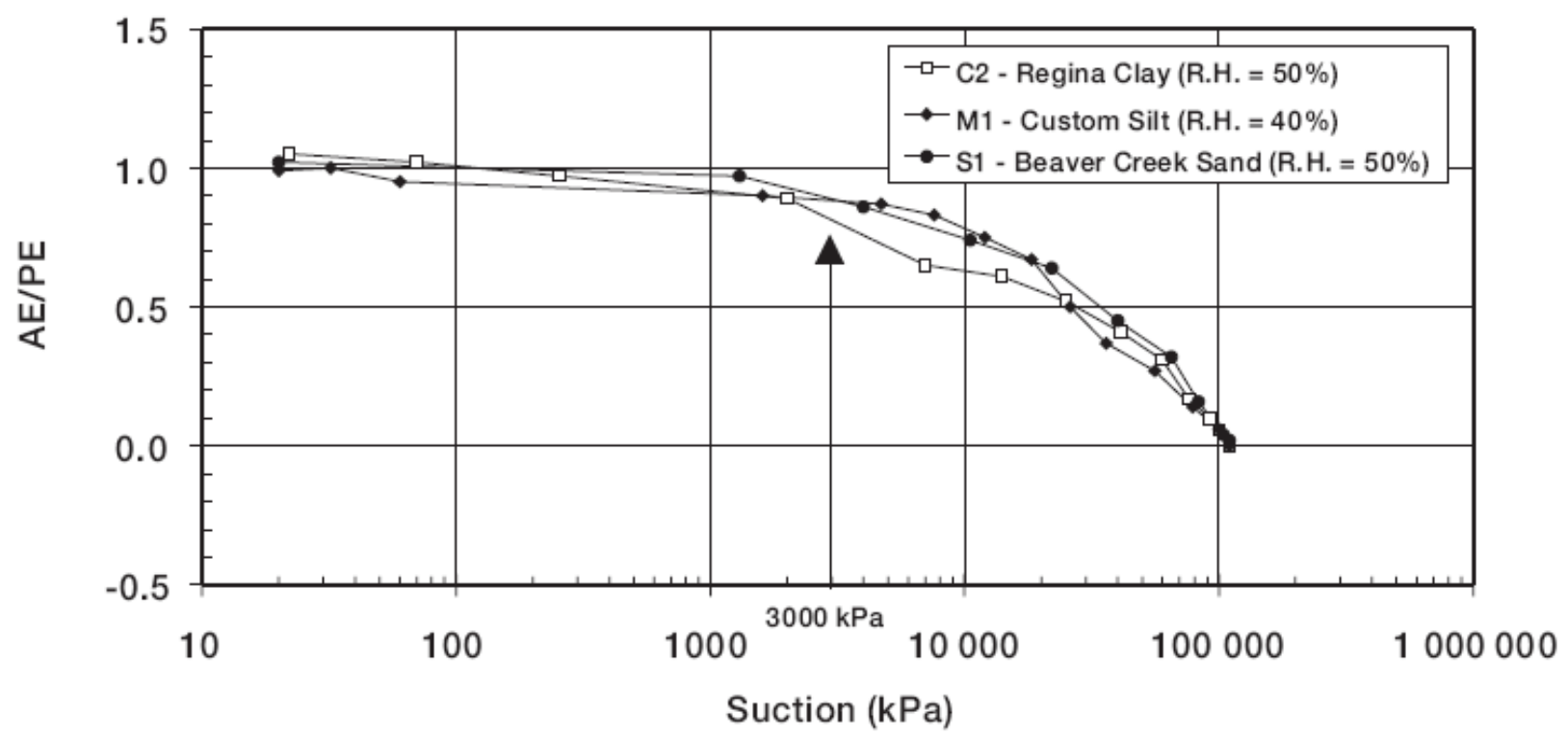

Figure 2 Effect of Total Suction on Evaporation (Barbour et al., 1997)

The second stage of evaporation can be modelled by Wilson et al.'s (1994) modification of Penman's equation where the surface total suction is taken into account as the controlling factor in total evaporation (Equation 7).

$$
E_{\text {theoretical }}\left[\frac{m m}{d}\right]=f(w) e_{a}\left(\frac{1}{R H_{A}}-\frac{1}{R H_{S}}\right)
$$

Equation 7 
$\mathbf{R} \mathbf{H}_{\mathbf{A}}$ is the relative humidity of ambient air while $\mathbf{R} \mathbf{H}_{\mathbf{S}}$ is relative humidity inside soil pores. Relative humidity in soil pores is related to total suction $\boldsymbol{\Psi}$, absolute temperature $\mathbf{T}$, the universal gas constant $\mathbf{R}$ and the molecular weight of water $\boldsymbol{\omega}$ as seen in Equation 8.

$$
\begin{aligned}
& R H=e^{\frac{\Psi \omega v}{R T}} \\
& \text { Equation } 8
\end{aligned}
$$

Equation 7, however, may overestimate evaporation. A further coefficient must be applied to Equation 7, either in the form of a resistance term $\mathbf{r}_{\mathbf{s}}[\mathrm{s} / \mathrm{m}$ ] (Bitelli et al., 2008)(Camillo and Gurney, 1986), or by applying a coefficient to further decrease the RH at the surface, beyond that predicted the total suction. Camillo and Gurney (1986) define soil surface resistance $\mathbf{r}_{\mathbf{s}}[\mathrm{s} / \mathrm{m}]$ as a function of actual volumetric soil moisture $\boldsymbol{\theta}_{\text {TOP }}$ and the saturated volumetric soil moisture $\boldsymbol{\theta}$ s, of the first $1 \mathrm{~cm}$ top surface layer (equation 9):

$$
\begin{gathered}
r_{S}=805+4140 \bullet\left(\theta_{S}-\theta_{T O P}\right) \\
\text { Equation } 9 \\
E=\frac{1}{r_{V}+r_{S}}\left(\frac{c_{V A}-c_{V S}}{z_{R E F}-z_{0}}\right) \\
\text { Equation 10 }
\end{gathered}
$$

$\mathbf{r}_{\mathbf{s}}$ is embedded in the above Equation (equation 10) where a large $\mathbf{r}_{\mathbf{s}}$ lowers the evaporation and a low $\mathbf{r}_{\mathbf{s}}$ increases evaporation rate. In Equation $10, \mathbf{E}$ is the evaporation rate $\left(\mathrm{kg} / \mathrm{m}^{2} / \mathrm{s}\right), \mathbf{r}_{\mathbf{v}}$ is the aerodynamic resistance for water vapor transfer $(\mathrm{s} / \mathrm{m}), \mathbf{r}_{\mathbf{s}}$ is the 
soil surface resistance for water vapor transfer $(\mathrm{s} / \mathrm{m}), \mathrm{c}_{\mathrm{VA}}$ is the atmosphere vapor concentration at height $\left(\mathbf{z}_{\mathrm{REF}}\right)(\mathrm{mol} / \mathrm{mol}), \mathbf{c}_{\mathrm{VS}}$ is the vapor concentration of the soil surface $\left(\mathrm{z}_{0}, \mathrm{Ts}\right)(\mathrm{mol} / \mathrm{mol})$. (Bitelli et al., 2008)

\subsubsection{Evaporative mechanisms in cracked soils}

Theoretically, the wind-activated ventilation of crack openings is explained as a result of a pressure gradient between atmospheric air under a wind current, and relatively static air in a crack opening. At ground level following Bernoulli's equation at sea level, static pressure is equal to atmospheric pressure (ATM) minus dynamic pressure, where $\mathbf{V}$ is the velocity of air. When a wind current increases air velocity, dynamic energy increases and static pressure decreases. This decrease in static pressure creates a gradient between that very air current at sea level and the air below in the soil crack volume, inducing evaporation.

$$
P=A T M-\frac{\rho V^{2}}{2}
$$

Equation 11

Weisbrod et al. (2011) showed that a wind velocity of $0.5 \mathrm{~m} / \mathrm{s}$ would result in a pressure gradient of $0.1625 \mathrm{~Pa}$ assuming air density of $1.3 \mathrm{~kg} / \mathrm{m}^{3}$. This difference in pressure, when inputted into Darcy's equation, resulted in an advective vapour flux of $0.58 \mathrm{~m} / \mathrm{s}$, when compared to the theoretical diffusive flux for the same geometry and ambient conditions, the ratio of advective flux to diffusive flux was over 10,000 , indicating the relative insignificance of diffusion when wind is applied. 
Overall, the three phenomena driving crack evaporation are 1) upward vapour diffusion, 2) wind-generated 'forced convection' within crack volumes, and 3) thermal-density gradients as elaborated by Weisbrod et al. (2005).

Upward diffusion of crack vapour is driven by a vapour density gradient between a denser and moist air within crack volume and the lighter and drier atmospheric air above soil surface. This upward flux is explained by Fick's law as follows (equation 12):

$$
\begin{gathered}
Q_{D}=A_{T} D\left(\frac{\partial \rho_{\text {vapor }}}{\partial z}\right) \\
\text { Equation } 12
\end{gathered}
$$

$Q_{D}$ (mass/time) being the mass flow rate out of the fracture opening, $A_{T}$ is the area of the crack aperture, $\mathbf{D}$ is the free air diffusion coefficient of water vapour in air, $\mathbf{z}(\mathbf{L})$ is the vertical coordinate and $\rho$ VAPOR is the vapour density.

\subsubsection{Evaporation and the soil water characteristic curve}

As explained in section 2.1.2, the AE/PE ratio is a function of total suction at the soil surface. Total suction is the total negative potential of water with respect to atmospheric conditions, and it arises both due to capillary interactions between water, air, and particles in an unsaturated state (matric suction), as well as the content of dissolved mass in the pore-fluid (osmotic suction). Total suction is the sum of matric suction and osmotic suction, as per Equation 14. Osmotic suction can be defined by van 
Hoff's Equation (equation 13). Total suction can be related to pore-air vapour pressure at equilibrium through Equation 15 - the Kelvin equation.

$$
\begin{gathered}
\psi_{o}=i M R T \\
\text { Equation } 13
\end{gathered} \quad \psi=\psi_{m}+\psi_{o}=\left(u_{a}-u_{w}\right)+\psi_{o} \quad \psi=-\frac{R T}{v_{w o} \omega_{v}} \ln (R H)
$$

As seen in Van't Hoff equation (equation 13), osmotic suction $\Psi_{\mathrm{o}}$ increases with ionic strength as the addition of solutes decreases vapour pressure by strengthening intermolecular fluid bonds through hydration. $\Psi_{\mathrm{o}}$ also depends upon the Van't Hoff constant $\mathbf{i}$, molality of pure solution $\mathbf{M}$ and universal gas constant $\mathbf{R}$ (Rao and Shivananda, 2005).

Matric suction $\Psi_{M}$ is responsible for the capillary effect whereby water is vertically pulled up through pore channels due to particle-fluid adhesion and surface tension Ts $[\mathrm{N} / \mathrm{m}] . \Psi_{M}$ has been directly related to the surface tension acting on the fluid-air interface, and the radius of curvature of the contractile skin $\mathbf{R}_{\mathbf{s}}[\mathrm{m}]$ (equation 16).

$$
\begin{aligned}
& \psi_{m}=\frac{2 T_{s}}{R_{s}} \quad \text { Ts: Surface Tension }[\mathrm{N} / \mathrm{m}] \\
& \text { Equation } 16
\end{aligned}
$$

The curve relating moisture content and matric suction is termed the Soil Water Characteristic Curve (SWCC) and from it, can be derived the hydraulic conductivity of the unsaturated soil (Fredlund and Rahardjo, 1993). The SWCC is experimentally determined and then fitted to a function (table 1) from which constants may be derived 
and inputted into the concordant hydraulic conductivity equation as per table 2 below in section 2.1.5.5.

Brooks and Corey, 1964 Van Genutchen, 1980

Fredlund and Xing, 1994

Campbell, 1985

$$
\frac{\theta-\theta_{r}}{\theta_{s}-\theta_{r}}=\left(\frac{A E V}{\psi}\right)^{\lambda} \quad \theta=\theta_{r}+\frac{\theta_{s}-\theta_{r}}{\left[1+(\alpha \psi)^{n}\right]^{n}} \quad \theta=\frac{\theta_{s}}{\left\{\ln \left[e+\left(\frac{\psi}{a}\right)^{b}\right]\right\}^{c}} \quad \psi=A E V\left(\frac{\theta}{\theta_{s}}\right)^{-d}
$$

For $\psi>$ AEV

e, natural log; $\lambda, \alpha, m, n, a, b, c$ and $d$ are empirical constants; $\theta_{r}$, residual water content

Table 1: Equations of SWCC

Brooks and Corey, 1964

Genutchen, 1980

Campbell 1985

$$
k_{\text {hyd }}=k s\left(\frac{A E V}{\psi_{m}}\right)^{\beta}
$$

$$
k_{\text {hyd }}=\frac{\left\{1-\left(a \psi_{m}\right)^{n-1}\left[1+\left(a \psi_{m}\right)^{n}\right]^{-m}\right\}^{2}}{\left[1+\left(a \psi_{m}\right)^{n}\right]^{m / 2}}
$$

For $\psi>$ AEV

$k_{\text {sat, }}$ relative permeability; Constants $a, n, m$ and $d$ correspond to those in equations in table 1

Table 2: Equations of Unsaturated Hydraulic Conductivity

These fitted equations (table 2) pose several problems: they erroneously assume a constant mono-modal pore size distribution throughout the SWCC test. While they are accurate for coarse-grained soils, care must be taken with their application to fine grained soils where significant volume change occurs during shrinkage (Simms and Yanful, 2005). It should also be noted that actual $\mathbf{k}_{\text {hyd }}$ can be significantly larger then a theoretically derived $\mathbf{k}_{\text {hyd, }}$ which doesn't account for micro and macro cracks. $\mathbf{k}_{\text {hyd }}$ is in fact highly dependent upon crack opening and upon spacing between cracks (Ayad and Konrad, 1997.a). 
Total suction $\psi[\mathrm{kPa}$ ](equation 15 ) is the state of free energy of the soil's pore water and is a function of temperature $\mathbf{T}[\mathrm{K}]$, universal gas constant $\mathbf{R}\left[\mathrm{J} \cdot \mathrm{mol}^{-1} \cdot \mathrm{K}^{-1}\right]$, specific volume of water $\mathbf{v}_{\mathbf{w o}}\left[\mathrm{m}^{3} \mathrm{~kg}^{-1}\right]$, molecular mass of water vapour $\boldsymbol{\omega}_{\mathbf{v}}\left[\mathrm{kgkmol}^{-1}\right]$ and pore vapour relative humidity RH (Fredlund and Rahardjo, 1993). In practical terms, total suction represents the amount of extra energy required to pull water out of the soil matrix through evaporation as compared to a baseline case of evaporating free pure water without the influence of external solid adhesive forces or ionic solutes dissolved into the water.

\title{
2.1.5. Hydraulic Conductivity in saturated soils
}

\subsubsection{Darcy's Law and Saturated Hydraulic Conductivity}

Darcy's law (Equation 24) explains the flow of water through porous mediums. It shows that water flow is governed by pressure gradients and flows from high pressure to low pressure.$$
k_{\text {hyd }}=-\frac{K_{p} \rho g}{\mu} \cdot \frac{d h}{d l}
$$$$
\text { Equation } 19
$$$$
k_{\text {hyd }}[\mathrm{m} / \mathrm{s}] \text { : hydraulic conductivity }
$$$$
\mathrm{K}_{\mathrm{p}}\left[\mathrm{m}^{2}\right] \text { : intrinsic permeability }
$$$$
\rho\left[\mathrm{kg} / \mathrm{m}^{3}\right] \text { : fluid density }
$$$$
\mathrm{g}\left[\mathrm{m} / \mathrm{s}^{2}\right] \text { : gravity }
$$$$
\mathrm{dh}[\mathrm{m}] \text { : pressure differential }
$$$$
\text { dl [m]: distance between pressure points }
$$ 
Saturated hydraulic conductivity $\mathbf{k}_{\text {sat, }}$ is the flow rate exhibited when the pores are fully saturated. $\mathbf{k}_{\text {sat }}$ is directly dependent on intrinsic permeability (Equation 25). It can be calculated using intrinsic permeability in the following manner:

$$
\begin{gathered}
k_{\text {sat }}=K_{p} \bullet \frac{\gamma_{w}}{\eta_{a d}} \\
\text { Equation } 20
\end{gathered}
$$

Coefficient of permeability (or hydraulic conductivity) $\mathbf{k}_{\text {sat }}[\mathrm{cm} / \mathrm{s}]$ is a function of intrinsic permeability $\boldsymbol{K}_{\mathbf{p}}\left[\mathrm{cm}^{2}\right]$, fluid unit weight $\boldsymbol{\gamma}_{\mathbf{w}}\left[\mathrm{kN} / \mathrm{m}^{3}\right]$, and absolute viscosity of fluid $\boldsymbol{\eta}_{\mathrm{ad}}$ $[\mathrm{Pa} * \mathrm{sec}]$

\subsubsection{Intrinsic Permeability \& the Role of Grain Morphology}

Saturated soils contain two components; the solids that are the soil grains, and pore water. The pore water moves through the channels that are formed by the interconnected pore spaces created between adjacent grains. The degree to which a fluid may flow through these pore channels is characterized by intrinsic permeability $\mathbf{K}_{\mathbf{p}}$ $\left[\mathrm{m}^{2}\right]$. Intrinsic permeability is a factor of two variables; the hydraulic radius $\mathbf{R}_{\mathbf{H}}$, and the shape factor $\mathbf{C}_{\mathbf{s}}$. The $\mathbf{R}_{\mathbf{H}}$ represents the extent of contact between channel surface area and fluid volume. It is taken from a representative cross section of the channel and is calculated as flow divided by wetted channel perimeter (Equation 26).

$$
R_{H}=\frac{\text { AreaofFlow }}{\text { WettedPerimeter }}
$$

Equation 21 


$$
\begin{gathered}
K=C_{S} \bullet R_{H}^{2} \bullet n \\
\text { Equation 22 }
\end{gathered}
$$

The shape factor is a product of grain size, sorting, grain shape and porosity. Intrinsic permeability $\mathbf{K}_{\mathbf{p}}$ is independent of fluid and exclusively represents the permeability of a porous matrix. It also depends on porosity $\mathbf{n}$ as seen in Equation 27. For granular soils, Intrinsic permeability has also been described as the product of shape factor $\mathbf{C}_{\mathbf{S}}$ and effective grain size $\mathbf{D}_{\mathbf{e}}$ (Equation 28 ). The effective grain size is usually between $\mathbf{D}_{\mathbf{5}}$ and $\mathbf{D}_{10}$ meaning that $5-10 \%$ of all soil grains, by mass, have lower particle diameters than $D_{5}-D_{10}$. It is in this lower range because it is the smaller particles which control the size of the pore channels.

$$
K=C_{S} \bullet D_{e}^{2}
$$

Equation 23

\subsubsection{Hydraulic Conductivity \& the Role of Pore Fluid}

Although two identical pore mediums will exhibit the same $\boldsymbol{K}_{\mathbf{p}}$, if they contain different fluids, they will exhibit different coefficients of permeability $\mathbf{k}_{\text {hyd }}[\mathrm{cm} / \mathrm{s}]$. The coefficient of permeability $\boldsymbol{k}_{\text {hyd }}$ depends on the unit weight $\boldsymbol{\gamma}_{\mathbf{w}}[\mathrm{kN} / \mathrm{m} 3]$ of the fluid and the viscosity of the fluid. Fluid viscosity is the resistance of a fluid to flow. Hydraulic conductivity can hence be described as Equation 25.

Pore fluid chemistry can have a significant effect on the permeability of clay soils whose particles have negatively charged surfaces which interact with polar compounds and ionic substances. For example, the relation between $\mathbf{k}_{\text {sat }}$ and void ratio for three types of clays were different for two types of fluids. With water as a fluid, kaolinite's $\mathbf{k}_{\text {hyd }}$ was 
200,000 times greater than that of montmorrilite at the same void ratio. Montmorrilite contains the smallest grains while kaolinite, the largest of the three. Montmorrilite was also arranged in a flocculated fashion due to the electrostatic interaction with polar water molecules, while kaolinite was much more dispersed. When the fluid was changed to nonpolar benzene and carbon tetrachloride, the three e- $k_{\text {hyd }}$ curves collapsed into a single curve. (Terzaghi, 1967) This is due to a re-arrangement of clay particle plates into a more dispersed structure because nonpolar fluids geochemically promote the aggregation of clay particles. In the saturated phase, coefficient of permeability is a function of void ratio. (Fredlund and Rahardjo 1993).

\subsubsection{The Kozeny-Carman Equation}

Given that the coefficient of permeability in the saturated stage is often varies as a function of void ratio, size, shape and tortuosity, the Kozeny-Carman equation (equation 29) directly ties void ratio e to $\mathbf{k}_{\text {hyd. }}$

$$
k_{\text {hyd }}=\left[\left(\frac{1}{\mathrm{~K}_{0} \Omega^{2}}\right)\left(\frac{1}{S^{2}}\right)\left(\frac{e^{3}}{1+e}\right)\right] \bullet S_{n} \bullet \frac{\gamma_{w}}{\eta}
$$

Equation 24

\footnotetext{
$K_{\text {hyd }}$ : coefficient of permeability [cm/s]

E: void ratio [unitless]

$\mathrm{K}_{0}$ : shape factor of soil void channel [unitless]

$\Omega$ : tortuosity factor

$\mathrm{S}$ : wetted surface area per unit volume of particle material $\left[\mathrm{L}^{2} / \mathrm{L}^{3}\right]$

$\gamma_{w}:$ unit weight of fluid $\left[\mathrm{kN} / \mathrm{m}^{3}\right]$

$\eta$ : dynamic viscosity of fluid $[\mathrm{kg} / \mathrm{m} / \mathrm{s}]$

$\mathrm{S}_{\mathrm{n}}$ : degree of saturation [unitless]
} 
This is based on Poiseuille's law for flow in circular tubes which provides an average flow velocity $\mathbf{v}_{\text {avg }}$ (equation 30 ). When $\mathbf{v}_{\text {avg }}$ is multiplied by cross sectional area of a tube, a total flow $\mathbf{q}$ is attained (equation 31). The Kozeny-Carman equation is attained by substituting tube radius $\mathbf{R}[\mathrm{cm}]$ by hydraulic radius $\mathbf{H R}[\mathrm{cm}]$ and by replacing the circular cross section shape factor $C_{s}$ of $1 / 2$ by a constitutive equation for $C_{s}$ where $\boldsymbol{\Omega}$ is a tortuosity factor and $\boldsymbol{K}_{\mathbf{0}}$ is a shape factor for the soil void channel.

$$
\begin{gathered}
v_{a v g}=\frac{\gamma R^{2}}{8 \eta_{a d}} i_{h} \\
\text { Equation } 25 \\
q=\left(v_{\text {avg }}\right)(a)=\left(\frac{\gamma R^{2}}{8 \eta_{a d}} i_{h}\right)(a) \\
\text { Equation 26 }
\end{gathered}
$$

When the material's void channels are assumed to be identical in shape and dimension then the $C_{s}$ value $C_{S}=\left(\kappa_{0} \Omega^{2}\right)^{-1}$ becomes approximately $1 / 5$. Assuming that the material is composed of identical soil particles, spherical in shape and with a common diameter $\mathbf{D}_{\mathbf{i}}$, than $\mathbf{S}$ can be reduced to 6/D. Finally, when the fluid is taken as water with unit weight $\mathbf{\gamma}$ and dynamic viscosity $\eta$ taken for $20^{\circ} \mathrm{C}$ temperature, the Kozeni-Carmen equation in its extensive form (equation 29) can be reduced to Equation 32 where particle diameter $\mathbf{D}_{\mathbf{i}}$ is usually taken as $\mathbf{D}_{10}$, which is the greatest particle diameter out of the lower (by particle diameter) $10 \%$ of sample by weight. (McCarthy, 2007)

$$
\begin{aligned}
& k_{\text {hyd }}=(555)\left(D^{2}\right)\left[\frac{e^{3}}{1+e}\right] \\
& \text { Equation } 27 \\
& \mathrm{~K}_{\text {hyd }} \text { coefficient of permeability [cm/s] } \\
& \text { D: particle diameter [cm] } \\
& \text { E: void ratio [unitless] }
\end{aligned}
$$


This simplified version of the Kozeni Carman equation underestimates tortuosity factor $\boldsymbol{\Omega}$ and $\mathbf{S}$, the wetted surface area per unit volume of particle material $\left[\mathrm{L}^{2} / \mathrm{L}^{3}\right]$ by assuming uniform particle and uniform void shape and sizes. This results in an underestimation of $\mathbf{k}_{\text {hyd }}[\mathrm{cm} / \mathrm{s}]$. Equation 32 however is used to estimate the order of magnitude of $\mathbf{k}_{\text {hyd }}$ at various void ratios e. This equation may be applied for sands and silts but not for clays which are too complex in micro-structure and geochemical behaviour to be modelled by this approach.

\subsection{Crack Dynamics in desiccating soils}

The general literature agrees upon three phases of cracking, i) Initiation and development of Primary Cracking, ii) Secondary cracking, when the zones of soil delineated by primary cracks are, in turn, subdivided by new cracks and iii) tertiary cracks, where the zones delineated by secondary cracks are in turn fractured (Tuk-Ki and Nhat, (2008.a), Liu et al. (2008), Barbour et al. (2000)). Crack formation reduces a soil's shrinkage potential. Primary cracks consequently reach the greatest widths and depths, followed by secondary and tertiary cracks (Tuk-Ki and Nhat, 2008.b). Each set of successive cracks propagate linearly until approaching another crack whereby this path is altered in order that the intersection be at a right angle (Liu et al., 2008).

Tertiary cracks are often difficult to distinguish from secondary cracks. They are smaller than secondary crack and form between two cracks (either primary or secondary). They 
are ultimately differentiated from secondary cracks based on time of crack initiation (Kodikara and Nahlawi, 2006). The crack surface opening will continue to expand, though minimally and very shortly until crack dynamics cease and a final set of crack geometries and pattern is established (Chertkov, 2002.a).

In general, cracking initiates when the soils tensile strength is exceeded by tensile stress. Tensile strength is generally accepted to be a function of innate soil properties as well as moisture content and / or stress state (overburden stress and matric suction) (Miller and Snyder, (1985), Causarano, (1993)).

\subsubsection{Microcracking and primary crack initiation}

As mentioned in the introduction, Chertkov's model was chosen to analyze crack development in this thesis, due to its relatively few free parameters. Chertkov's model (Chertkov (2002a), Chertkov (2002b)) divides the evolution of cracks into a number a phases; micro-cracking, macro-crack initiation (or jump), crack growth at a constant rate, and a quick decline in crack growth. 'Delay' $\left(\mathbf{T}_{\mathbf{C}}\right)$ refers to the duration of time between initial deposition of soil and macro-crack initiation. During this period of crack delay, drying of a soil induces tensile stresses. The tensile stresses arise as the tendency of the soil to shrink near the ground surface is restrained either by wetter or stiffer soil at a depth, or by horizontal and vertical boundaries. When these stresses exceed some tensile strength $\sigma_{\mathrm{T}}$, they are dissipated through cracking. Micro-cracks form, grow, interact and eventually nucleate into macro-cracks. A micro-crack is defined as a fissure 
whose growth can be arrested by elements or properties of the soil matrix. Chertkov (2002.a) uses this definition of minimum micro-crack dimension to predict primary crack initiation. The tensile strength is subsumed in the definition of minimum micro-crack length. Chetkov's model will be reviewed in the final section of the literature review.

Macro-crack growth is arrested by 'means or measures at a larger scale than the material' (van Mier, 2008). Said otherwise, by the interception of other cracks or specimen boundaries. Micro-cracks can appear in water contents as high as above the liquid limit (Chertkov, 2002.a) and although their growth is inhibited by energy dissipation while in the visco-plastic range, they may still grow and coalesce in that range until initiation of macro-cracks occurs (Chertkov, 2002.a).

Micro-cracks have been observed to nucleate in weaker regions at first and then propagate and coalesce to form macro-cracks (Chen et al., 2001). In ductile materials, this growth development is gradual, and culminates in macro-cracks (Belyaev and Naimark, 1989).

Macro-nucleation only materializes if micro-cracks are in high enough frequency and reach sufficiently large dimension. The developmental regime prior to macro-nucleation is self accelerating free of additional loading. Three different modes of micro-crack growth have been recognized: subcritical, critical and supercritical (figure 4) (Belyaev and Naimark, 1989).The subcritical mode (curve 3 figure 4$)$ describes a stable $(\delta<\delta c)$ material reaction to 'weakly interacting' micro-crack growth. This reaction is seen as thermodynamically reversible and features dispersed nucleation and growth. 


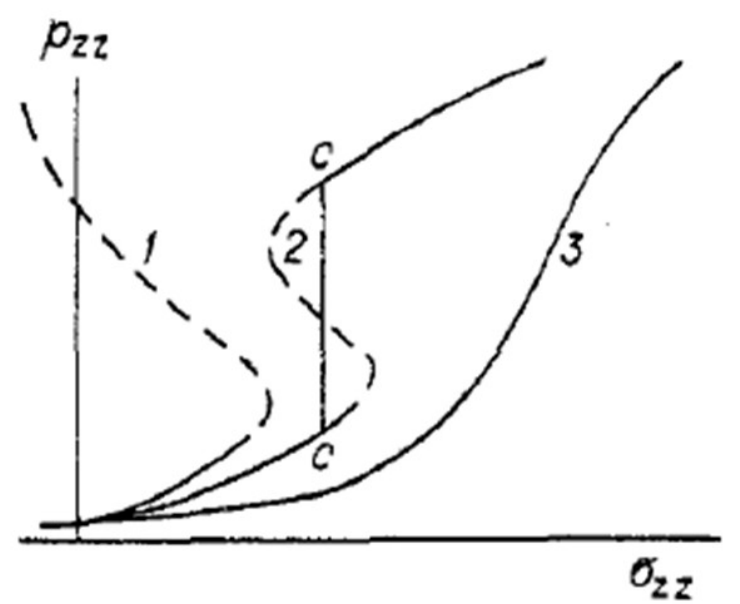

Figure 3: Thermodynamic states of micro-cracking: 1) $\delta<\delta c ; 2) \delta c<\delta<\delta * ; 3) \delta>\delta^{*}$ (Belyaev and Naimark, 1989)

Parameter $\delta$ is conditioned by average dimension of micro-crack and by the radius of micro-crack process zone of intensified stress field. The critical mode (figure 3, curve 2) describes the transition across a threshold of explosive instability and the subsequent formation of micro-crack coalescent networks that will serve as nucleation sites for macro-nucleation. This self-accelerated macro-nucleation is due to a spontaneous ordering/re-orientation in the system of micro-cracks. The supercritical mode (a.k.a. peaking regime) (figure 3, curve 1) describes a completely unstable state where macrocracks are almost instantaneously nucleated and propagate.

\subsubsection{Location and progression of macrocracks}

Liu et al. (2008) found that cracks nucleated at independent and random positions. Costa and Kodikara, (2008) reported a more ordered process where macro-nucleation occurred in the middle of the specimen as opposed to the boundaries, this was, however, for a longitudinal specimen (long and narrow). The same was observed 
regardless of specimen thickness (Kodikara and Nahlawi, 2006). Weinberger's (2001) primary mud cracks created a uniform polygonal network but unlike Kodikara and Nahlawi (2006), his secondary cracks subdivided the primary aggregates unevenly hence creating a non-self-similar polygonal network reminiscent of Horgan and Young's (2000) simulation of crack networks. Patterns of pentagons, heptagons (Ayad and Konrad, 1997.a) and hexagons (Weinberger, 2001) have been reported, the most prominent being the latter (Fang, 1997). Curved cracks were attributed to adhesion at soil-mould boundary (Kodikara and Nahlawi, 2006). Soil surfaces are most favourable for crack initiation as they exhibit maximal matric suction and low-self weight stresses (Miller et al., 1998), though some cases of crack initiation have been reported at the bottom of soil layers, where grain size segregation occurs in that soil (Weinberger, 1999).

\subsubsection{Crack Intensity and rate of crack development}

Crack Intensity Factor (CIF) [\%] is defined as crack surface area over total surface area. Miller et al., (1998) reported two stages of CIF development; a short and intense period of crack propagation lasting 19 hours where $90 \%$ of the CIF was achieved, and a long secondary period lasting 130 hours where the remaining $10 \%$ was achieved (figure 4). Suction changed by $40(4000 \mathrm{kPa})$ bars in the first period and only by 2 bars ( $200 \mathrm{kPa})$ in the latter. Such observation of intense cracking period corresponds with Costa and Kodikara's (2008) observations of rapid secondary and tertiary crack formation following primary initiation. This was partly explained by the fact that once cracking had begun, 
adhesion at the base had significantly decreased hence allowing 'free-shrinkage'-like behaviour as the strain vectors redirected towards the center of the cells (Costa and Kodikara, 2008).

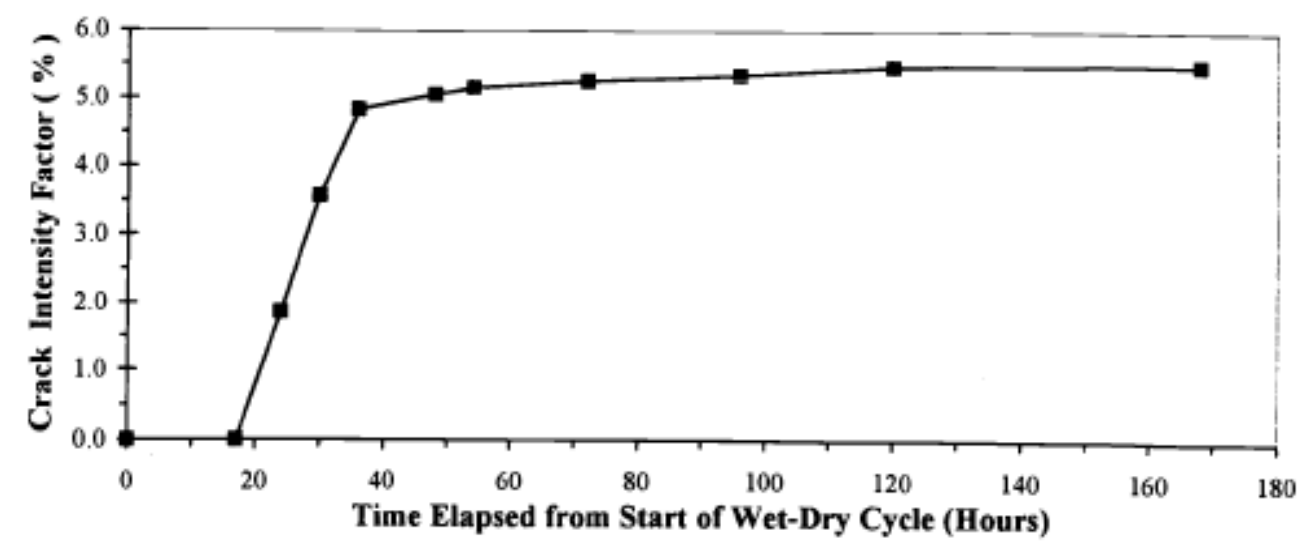

Figure 4: An example of CIF development over time (Miller et al., 1998)

Similarly, Ayad and Konrad, (1997.b) observed that though it took 17 hrs for primary crack initiation to occur, only 5 hrs later, a whole and complete network of cracks had developed through the secondary cracks, which split the aggregates relatively symmetrically into halves.

\subsubsection{Role of ambient and soil conditions on crack dynamics}

\subsubsection{Role of ambient conditions}

When the desiccating specimen is restrained, the reaction forces located at the constraints are proportional to the liquid removal front (Hu et al., 2007), which can be presented by evaporative flux and is related to hydraulic diffusivity. 'Over-dried' 
samples exhibited more irregular crack patterns then samples dried by ambient air (Fang, 1997). For soils, the maximum number of cracked cells is recognized as being dependent upon drying environment and 'basal adhesion properties' (Costa and Kodikara, 2008).

Liu et al. (2008) found that crack length, width, aggregate area and their corresponding probability density functions are all altered with temperature. In their study, as temperature was increased from 30 to 40 and then 50 degrees centigrade, the number of polygon intersections, the number of crack segments and the CIF all decreased from 107-58, 171-94 and 14.14\%-12.92\% respectively (Liu et al., 2008). Meanwhile, the average crack length, crack width and aggregate area all increased (Liu et al., 2008).

\subsubsection{Role of soil type}

Fracture Toughness (K), tensile strength, hydraulic conductivity and susceptibility to cracking are all related to soil characteristics such as dry density, clay mineral content and wilting point. Clay minerals usually have a residual negative charge. They are highly reactive and strongly favour soil cracking (Inci, 2008). Most soil minerals are from the phyllosilicates mineral family and the addition of a small amount of water to such minerals creates significant plasticity (Inci, 2008). Greater plasticity in turn increases shrinkage (and swelling) potential which in turn encourages shrinkage cracking (Inci, 2008). By this logic, lower fines content (less clay) lead to less cracking and vice-versa. Poorly compacted soils result in greater shrinkage potential and thus more cracking. 
Well compacted soils are usually nearer optimum water content and crack less (Inci, 2008). Yanful et al. (2007) have shown that greater plasticity led to greater crack dimensions.

Soil heterogeneity favours stable growth of micro-cracks and therefore a large time to initiation. However, adding sand to clay soils and therefore increasing heterogeneity was found to increase crack intensity (Colina and Roux, 2000).

\subsubsection{Role of moisture content}

Cracking occurs when tensile stress surpasses tensile strength. These tensile stresses are brought about by differential desiccation. Cracking should, therefore, simply be a function of water content (Kodikara and Nahlawi, 2006). As discussed previously, this is not the case as the cracking water contents differ with respect to rate of desiccation $R_{\text {dess, }}$ and as will be discussed later on page 33 .

$\sigma_{t}$ decreased linearly with increases in water content (figure 5), (Chiu et al., 2007). This behaviour proved contradictory and agreeable with various researches in literature (Chiu et al., 2007) highlighting an area in need of clarification. 


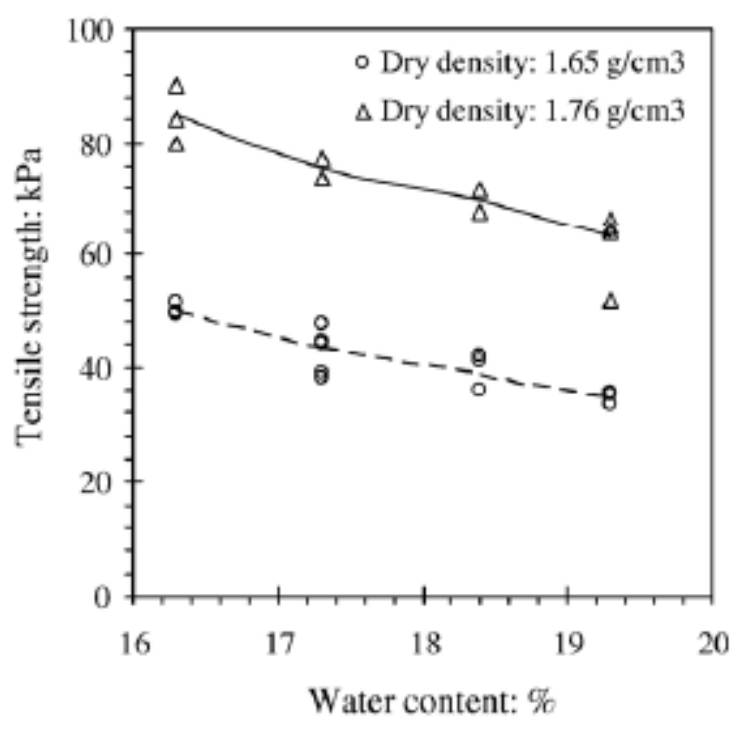

Figure 5: Effect of $\rho_{d}$ and $\theta$ on $\sigma_{T}$ (Chiu et al., 2007)

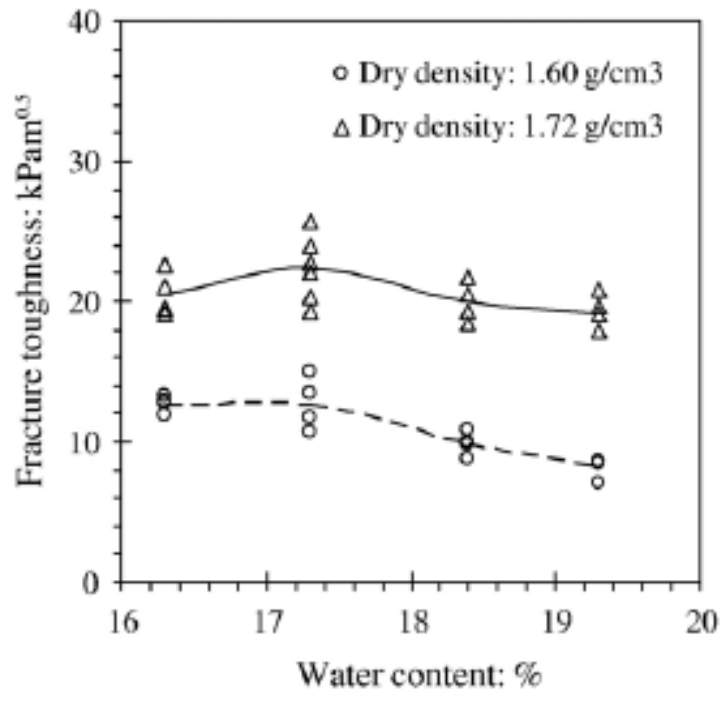

Figure 6: Effect of $\rho_{d}$ and $\theta$ on $K_{c}$ (Chiu et al., 2007)

Costa and Kodikara, (2008) found that for clay specimens drying from initial water content near liquid limit, crack development took place in conditions of or near saturation. This contradicts Hu et al.'s (2007) finding that crack initiation only began at de-saturation or near de-saturation and then develop in the unsaturated desiccating soil. Chertkov (2002.b) makes the same assertion as Costa and Kodikara (2008) for his model.

Kodikara and Nahlawi (2006) established a relation between the water content at crack initiation and desiccation rate $\left[R^{2}=-1.345, R^{2}=-0.66\right]$ showing cracking water content decreased as desiccation rate increased. Kodikara and Nahlawi (2006) explain this behaviour by the fact that tensile strength of a soil changes, and increases as desiccation rate increases. As a result, soil matric suction would have to be even greater than usual 
(ie. Lower moisture content) in order reach that new and higher tensile strength. Another explanation was that adhesion at the base of the clay increases and applies greater internal restraints as desiccation rates increase (Kodikara and Nahlawi, 2006).

Spacing between primary cracks $\mathbf{S}_{\mathbf{0}}$ is related to soil type as well as initial moisture content. For example, Ayad and Konrad 1997.b) found that a Saint Alban clay yielded cracks with spacings in the range of $\mathbf{S}_{0}=20-24 \mathrm{~cm}$ at an initial moisture content $103 \%$ whereas the nearby weathered clay produced cracks with spacings in the range of $S_{0}=10-12 \mathrm{~cm}$ at $50 \%$ initial moisture content (Ayad and Konrad, 1997.b).

\subsubsection{Role of pore fluid chemistry}

Pore fluid may play a critical role in micro-crack dynamics. Not only is fracture toughness lower in wet rock than in dry rock, but crack propagation velocity is faster as chemical deterioration results in an increase in crack propagation velocity and stress corrosion factor (Chen et al., 2001). Pore fluid chemistry can induce such corrosion and lead to 'stress corrosion cracking' (Chen et al., 2001). Such cracking was found to be most favoured under zero-zeta-potential; a point at which tensile strength reaches its minimum (Chen et al., 2001). Compressive strength is reduced by the presence of water. This effect is minimized at neutral $\mathrm{pH}$ and increased by any increase or decrease from $\mathrm{pH}=7$ (Chen et al., 2001). Volatility and vapour pressure of pore fluid are thus instrumental in crack dynamics. 
The rate of evaporation is greatly dependent upon the pore fluid and may present a complex problem for mixed fluids whereby the more volatile fraction evaporates at a greater rate leading to continuous changes in the pore fluid mixture ratio and related characteristics during desiccation (Hu et al., 2007).Pore fluids affect pore structure by inducing either flocculated or dispersed particle orientations. Flocculated structures lead to larger crack areas then dispersed structures (Inci, 2008). Higher ionic strengths increase flocculated structure orientation and decrease dispersed arrangements, whereas temperature, size of hydrated ion, $\mathrm{pH}$ value and anion adsorption all decrease flocculated orientations and increase dispersed orientations (Fang, 1997).

In a comparative analysis of shrinkage with three pore fluids; water, ethanol and ethylene-glycol, it was found that water which had the highest surface tension, consistently exhibited the highest shrinkage and that ethanol, with the lowest surface tension, the lowest shrinkage (Hu et al., 2007). Glycol exhibited the slowest drying rate (0.4g/hr v.s. 3.5 for water and 4.6 for ethanol) there was a clear correlation between pore fluid vapour pressure and drying rate (Hu et al., 2007).Elastic strain energy release rate $\mathbf{G}_{\mathbf{e}}$ increases with soil salinity. More saline soils must expend more $\mathbf{G}_{\mathbf{e}}$ for crack propagation (Hallet and Yoshida 2008).

\subsubsection{Role of specimen thickness}

Specimen thickness Th increases shrinkage potential (Tuk-Ki and Nhat, 2008.a) and is one of the most important factors in crack dynamics. Th also increases the time and 
distance travelled by pore water to the specimen surface. As such, rate of crack desiccation depends highly on specimen thickness. Thicker specimens crack earlier and faster than thinner specimens (Costa and Kodikara, 2008).

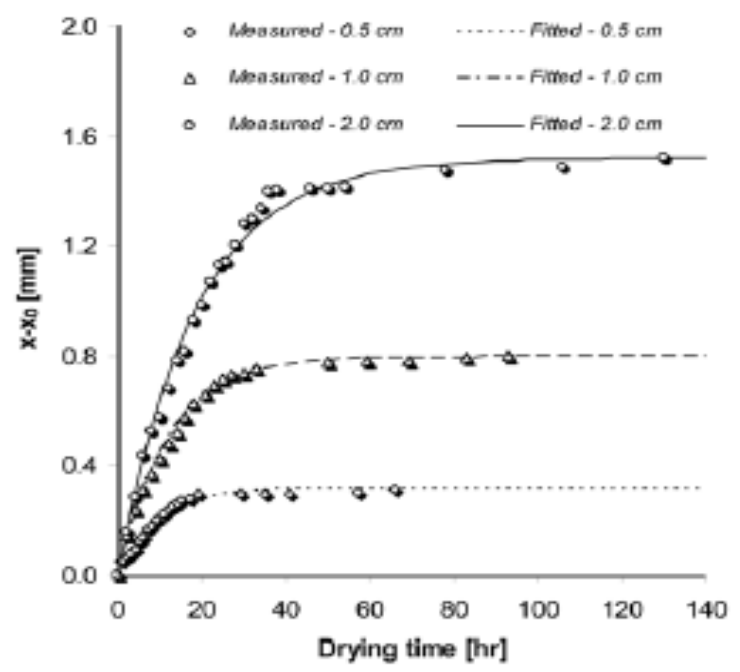

Figure 7: Effect of Thickness on crack opening (Tuk-Ki and Nhat, 2008.a)

Kodikara and Nahlawi (2006) controlled rate of desiccation by vary sample thickness under constant evaporation. Lower Th corresponded to lower cracking water contents. Kodikara and Nahlawi (2006) inferred that the higher rate of desiccation result in more differential shrinkage with depth and hence induction of stresses. This trend is also reported by Corte and Higashi (1960).

Liu et al.'s (2008) showed that thinner soil layers increased in average crack length, aggregate area, and crack intensity factor CIF. A trend was also found where cracking water content increased as Th increased. (Kodikara and Nahlawi, 2006). Crack openings and distribution of crack openings change with respect to thickness of cracks (Tuk-Ki and Nhat, 2008.a). 


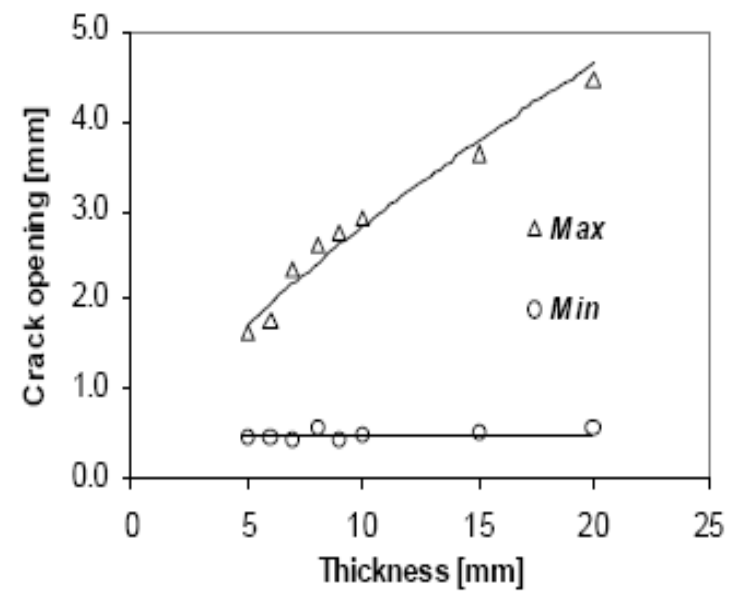

Figure 8 Crack width vs. Specimen initial thickness

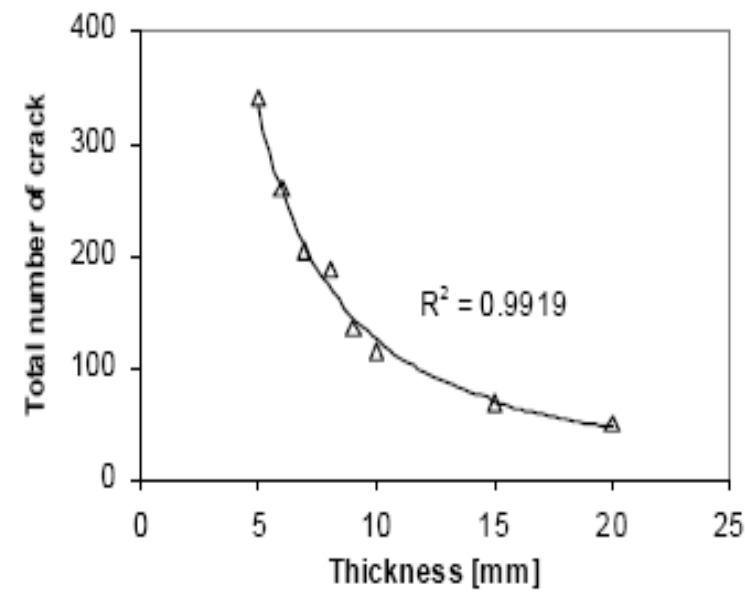

Figure 9 Crack frequency vs Specimen initial thickness

Greater thickness meant larger maximum crack widths (figure 8) (Tuk-Ki and Nhat, 2008.b). Minimal crack opening was constant throughout thickness (figure 8) and total number of cracks decreased by a power relation as thickness increased (figure 9). The highest amount of cracks corresponded with the smallest crack openings (Tuk-Ki and Nhat, 2008.b).

Colina and Roux, (2000) and Acker and Colina (2000) found that mean spacing between cracks over initial specimen thickness $\lambda \mathbf{f}$ (figure 10) decreased with a power relation as aspect ratio $\lambda \mathbf{g}$ (length over thickness) increased. This relation held true regardless of absolute specimen thickness. Two asymptotes exist; one at $\lambda \mathrm{g}=1$ (of cubic dimension) and the other at a given $\lambda f=A$ which is found experimentally and depends on the soil. The soil used was a layer of paste made of clay, sand and water. This graph was not replicated for other types of soils. 


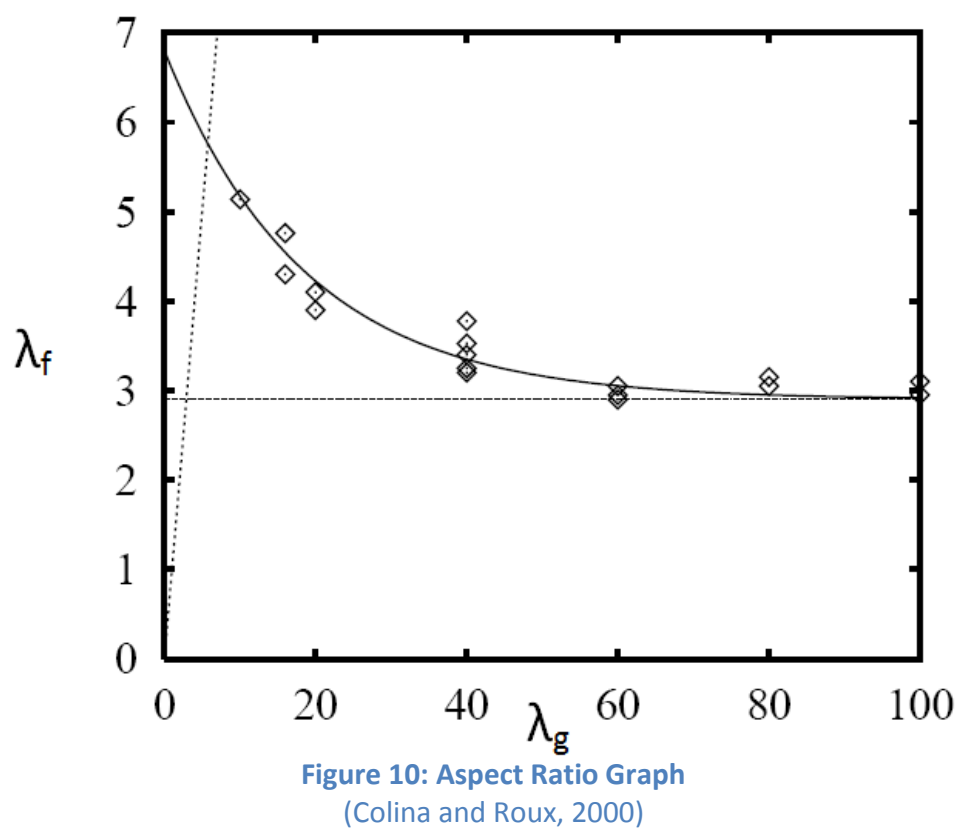

Below the minimal ratio of $\lambda \mathbf{g}=1$, macro-nucleation cannot take place. (Colina and Rioux, 2000) (Acker and Colina, 2000). Figure 10 shows that for specimen $\lambda f$ and by extension, average distance between cracks $\mathbf{S}_{0}$, becomes constant. This corresponds to Chertkov's semi-infinite medium where the soil system is of ever-expanding length L>>thickness (Chertkov, 2002.a).

Most cracks initiate in the early stages of desiccation (Costa and Kodikara, 2008). Acker and Colina (2000) found a linear relationship between gravimetric water content and time over thickness (figure 11). This straight line changed slopes at instant of crack initiation, representing an increase in gravimetric rate of evaporation. Carrying out a simple small scale drying experiment will provide $\tau=T_{c} / T h$. This parameter can be multiplied by whichever intended large scale thickness Th of deposit and the $\mathbf{T}_{c}$ can be obtained. 


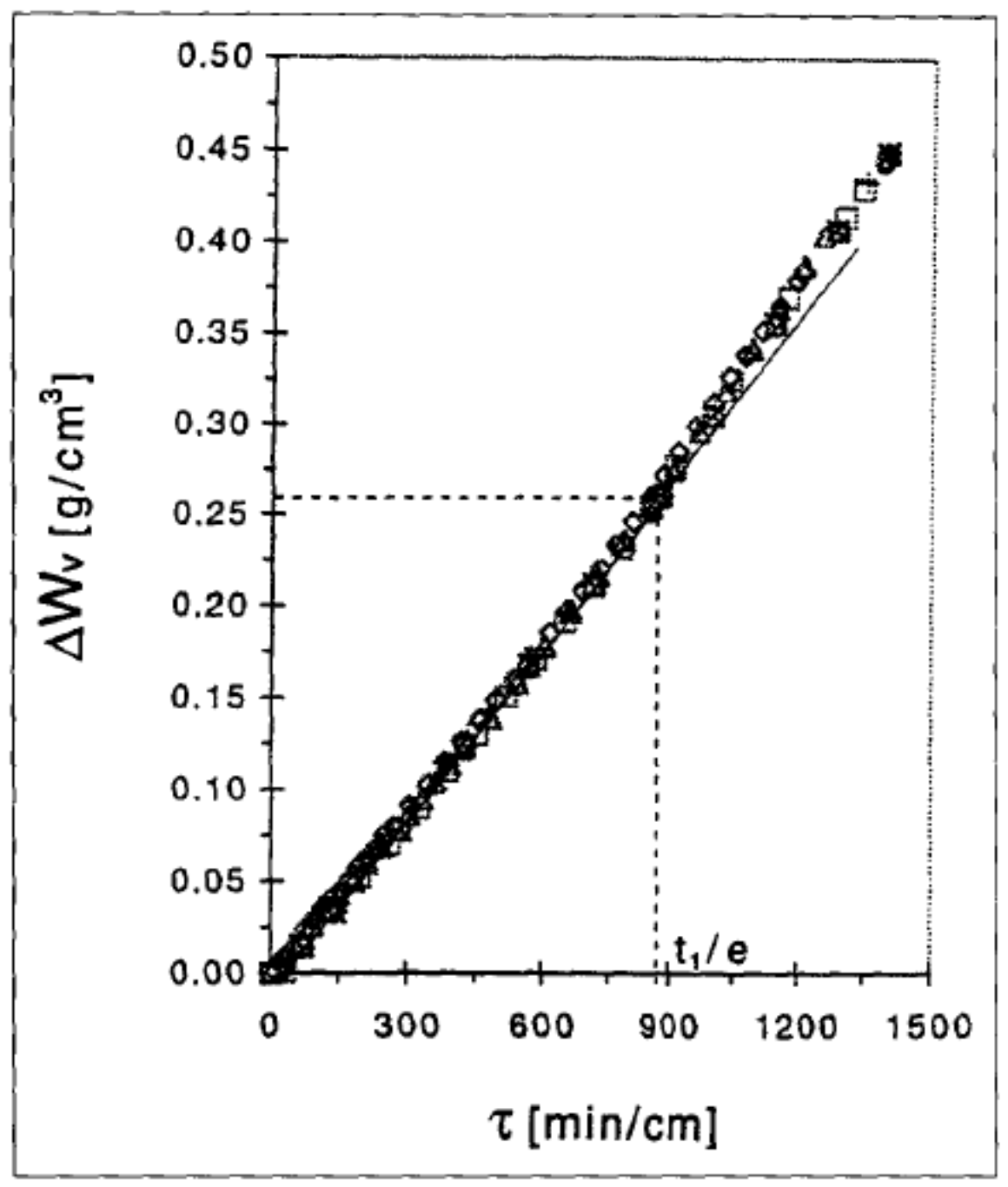

Figure 11 Evaporation as function of time over initial thickness

(Acker and Colina, 2000)

\subsection{Evaporation from Crack Surfaces}

Cracks drastically increase total exposed surface area. Crack surface to top surface ratios ranged from 2.9 to 4.6 in agricultural fields (Adams \& Hanks, 1964) while cracking 
increased total exposed area by over $350 \%$ in desiccating mine tailings (Fujiyasu et al., 2000).

When crack width reached $30-70 \mathrm{~mm}$, a sharp vertical profile of evaporation along the crack surface was observed (Ritchie et al., 1969). In this range of crack-width, $60-70 \%$ of evaporation occurred in the top half of the crack surface. The $30-70 \mathrm{~mm}$ width threshold possibly represents the minimal width at which turbulent air currents within cracks become important. (Ritchie et al., 1969)

Adams and Hanks (1964) showed that introducing wind velocity (25mph) to an artificial crack in a wind tunnel resulted in evaporation increases of $570 \%$ at 2 in depth and ever lower increases at lower depths with only $100 \%$ increase at a depth of 18 inches, again, demonstrating the importance of being able to model the turbulent wind current within crack volume as it relates to crack depth (Adams \& Hanks, 1964).

Suspending moist samples at varying depths of cracks in atmometers in agricultural fields, Adams and hanks (1964) observed moisture losses of only $55 \%$ of that lost at the surface in the first 19 hours. While soil in atmometers suspended within the top 12 inches saw moisture loss ration decrease from $55 \%$ to $17 \%$ in $44 \mathrm{hrs}$. (Adams \& Hanks, 1964) In order words, this study showed lower rates of evaporation in cracks compared to the top surface.

In desiccating tailings, Fujiyasu et al. (2000) observed re-orientation of evaporative profile on crack surface once the top surface started to de-saturate. While the top of the soil remained saturated the evaporation profile was linear with greatest evaporation at 
the top of the crack and lowest at the bottom. After desiccation at the top surface of the soil began de-saturating, the profile became triangular shaped, with low evaporation at the top of the crack surface, gradually increasing to a peak evaporation rate, below which evaporation rates decreased until one reached the bottom of the crack surface. What was also interesting is that evaporation rates near the center of the crack depth had actually increased as compared to recorded rates (from before top de-saturation) of a month prior to that sampling. Overall, evaporation from cracks only became significant after top surface de-saturation began, a period characterized by the formation of a desiccation crust on the surface. Following the beginning of surface de-saturation, evaporation from crack surfaces eventually represented over $80 \%$ of total evaporation.

Ritchie et al. (1969) dried two artificial crack surfaces in a wind tunnel with constant temperature and humidity. The variation of crack width $(1-7 \mathrm{~cm})$, depth $(3-6 \mathrm{~cm})$ and wind velocity $(0-8.9 \mathrm{~m} / \mathrm{s})$ resulted in immense variability in crack evaporation, up to a $3600 \%$ increase. They found, however, that the coupled effect of crack geometry (width and depth) and wind velocity, could explain $99.1 \%$ of this variation. Unexpectedly, Adams and Hanks (1964) observed an increase in total evaporation when crack width was decreased from 2.75 to $1.75 \mathrm{in}$.

Kirkham and Selim (1970) reinforced our understanding of the coupled effect of crack geometry and wind velocity. A $0.64 \mathrm{~cm}$ wide crack in moist soils increased total evaporation by $12-16 \%$ depending on soil type, while a slight increase in that crack width to $1.91 \mathrm{~cm}$ doubled it to a $30 \%$ increase in total evaporation for all soil types. 
Turbulent air convections were thus high enough to decrease the importance of soil type and equalize all increases in evaporation to $30 \%$ relative to un-cracked soils in identical drying conditions. Kirkham and Selim (1970) also showed the significant effect a slight increase in width could have to the coupled crack -wind interaction that produces turbulent air convections within crack openings (Kirkham and Selim, 1970).

When identical cracks carved out of 3 soil types were dried without effect of wind, the evaporative pull from crack surfaces caused lateral movement of water towards crack surface varying at a distance between 4 and $5 \mathrm{~cm}$, depending on the soil type (excluding sand). When the same experiment was repeated with wind as an addition, lateral movement of water reached $5 \mathrm{~cm}$, regardless of soil type, again indicating that the effect of a turbulent air current within crack openings superseded any effects of soil type by its magnitude. (Kirkham and Selim, 1970) The moisture flux towards crack surfaces has been shown to increase salt concentration near the crack surface (Weisbrod et al, 2000)

Again showing how crack volume and geometry must be coupled with wind velocity in order to actualize the advantage of increased surface-volume ratio, a difference in soil temperature was witnessed between cracked soils and un-cracked soils. Cracked soils were $1-2 \mathrm{C}$ lower than un-cracked soils under wind-drying conditions. While no such distinction was found between cracked and un-cracked soils when wind was removed, indicating that there was no turbulent air current to remove the soils heat within the crack. (Kirkham and Selim, 1970) 
Shrinkage cracks have the geometrical effect of decreasing the distance between soil matrix particles and soil-atmosphere interfaces. This geometric effect was demonstrated with a soil drying experiment by Kirkham and Selim (1970) whereby two sets of soils were dried by irradiation. The set of soils with cracks and hence, with greater surface to volume ratio, ended up having average soil temperature 5-10C greater than that of soils without cracks, which had access to less soil-light interface.

Ayad and Konrad (1997.b) have reported that moisture loss per top unit area was constant prior to primary crack initiation (at 18hrs) only to drop at instant of primary crack initiation and then increase to surpass its pre-crack initiation value due to the development of 3-dimensional evaporation due to cracks. Interestingly, at instant of secondary crack initiation ( $72 \mathrm{hrs})$ the same pattern repeated itself. These secondary cracks had the effect of accelerating crack widening, a phenomenon attributed to the onset of 3-dimensional evaporation from total polygons surfaces (Ayad and Konrad, 1997.b).

Evaporation eventually decreased. This Ayad and Konrad (1997.b) attributed to a decrease in hydraulic conductivity. That the period before primary crack initiation is characterized by a constant rate of volumetric evaporation which is only disrupted upon crack nucleation has also been reported by Acker and Colina (2000), Menziani et al. (1999) and Arya et al.(2006).

TOUGH2, a simulator of non-isothermal multiphase flow for fractured porous matrices was updated with the EWASG (Battistelli et al., 1997) module which incorporates salt 
movement and precipitation into the code. Graham (2005) used the TOUGH2 simulator with the EWASG module to combine the effects of 3 dimensional crack geometry, wind velocity, ambient conditions and salt accumulation. He was able to model Adam and Ritchie's (1974) field evaporation experiments within 7-15\% of field results. He modelled an overall increase in total evaporation from crack surfaces of $21 \%$ which was below published values and found that surface accumulation and precipitation of salts reduced total evaporation by $7-12 \%$, depending on initial pore water salt concentration.

In 2005, Weisbrod (2005) showed the coupled effect of cracking and salt-accumulation on evaporation, demonstrating that diurnal convective venting entrains cold, dry and dense atmospheric air into the crack volume while ejecting its moist and warmer air. This dryer air exerts an evaporative pull from the crack surface which increases lateral water movement through its surface leading to salt accumulation and precipitation. This precipitated salt in turns lowers crack surface evaporation by up to half of its initial rate. It has been reported that even in relatively salt free soils a salt crust would form which would inhibit evaporation. By removing the top $1-2 \mathrm{~mm}$ soil layer the previous evaporation rate can be restored. (Gardner and Hillel, 1962)

Evaporation by vapour diffusion is a minor contributor to total evaporation in part because of the relatively small area of crack opening AT(L2) but largely because of the relatively greater force exerted by the two other mechanisms of crack evaporation; wind-generated convection and diurnal thermal density gradients. For example, Weisbrod et al. (2000) recorded a total crack evaporation rate of $2.3 \times 10^{-2} \mathrm{~g}^{*} \mathrm{~cm}^{-2} * \mathrm{day}^{-1}$ 
but applying the equation of diffusivity showed that diffusivity could only account for an evaporative flux on the order of $10^{-4} \mathrm{~g}^{*} \mathrm{~cm}^{-2} \mathrm{day}^{-1}$, a minor contribution. Crack experiments in this research were held inside a laboratory so Weisbrod's diurnal thermal density gradient is not expected to be a phenomenon of any significance.

\subsection{Role of surface roughness and geomorphology on evaporation}

Kishii and Sugita (2002) varied the surface morphology and constant water table levels for 33 soil specimens and found a causative link between surface roughness and evaporation. The greater the surface roughness, the greater was the evaporation. It was surmised that this was due to greater turbulence being generated by the larger number of ridges.

This was true for all specimens except for those exhibiting the minimal distance between ridges of $0.025 \mathrm{~m}$. It was suggested that the ridge density was so high that upon reception of the wind current, the specimen surface acted as a smooth surface with a certain displacement height. The effect of surface roughness was reduced when the water table was lowered and the surface found itself in the unsaturated zone. 


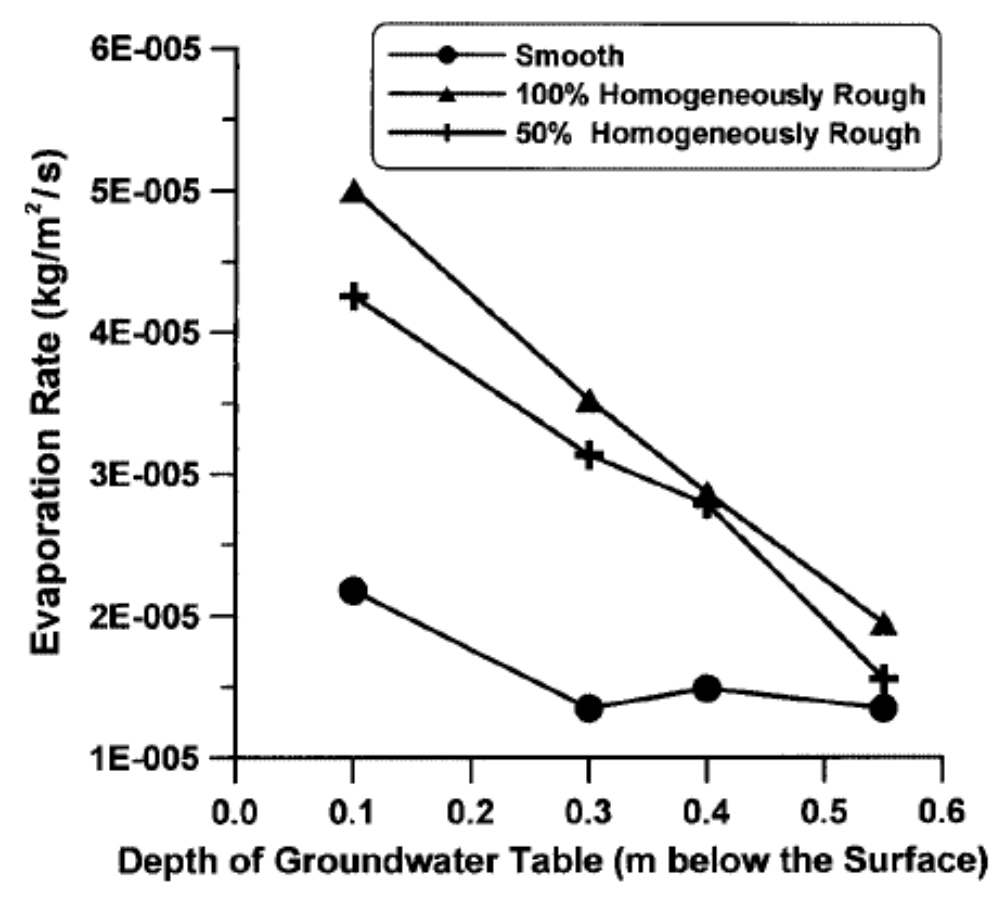

Figure 12 Role of surface roughness on evaporation

(Kishii and Sugita, 2000)

Kishii and Sugita (2000) also varied the amount and distribution of ridges on the surfaces. Greater numbers of ridges generated greater rates of evaporation while higher standard deviations in ridge distribution resulted in greater evaporation due to greater turbulence. This was true when the roughness spacing to height ratio was more than unity. 


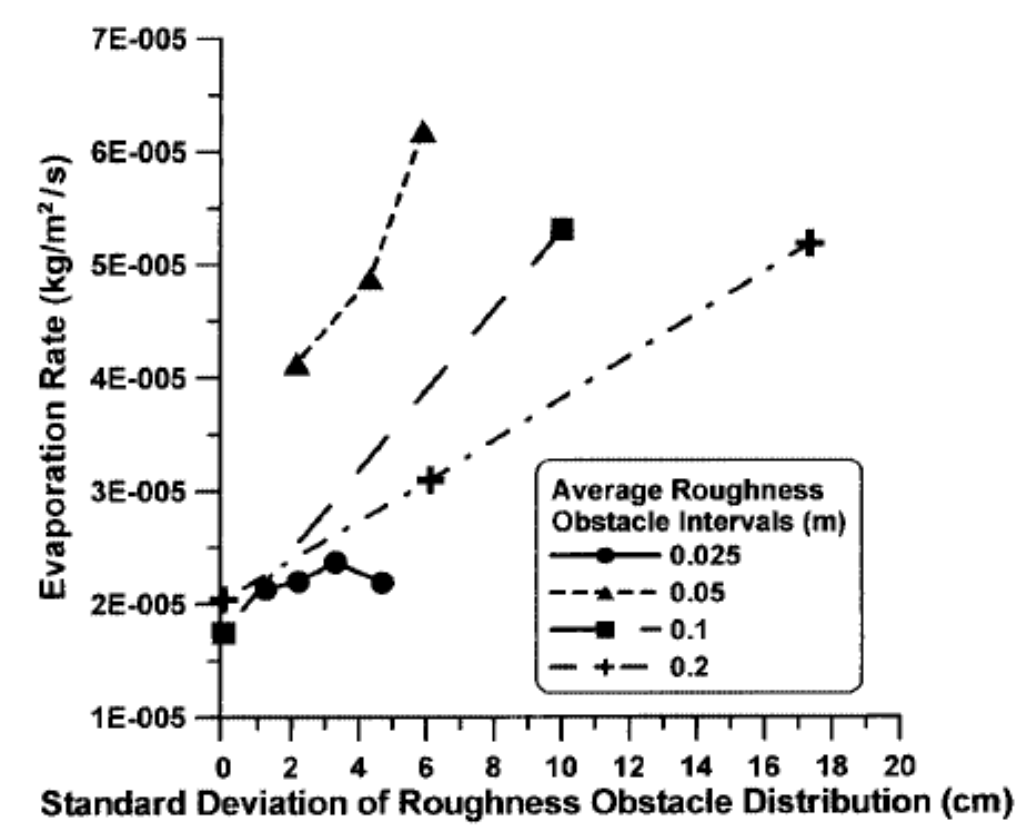

Figure 13 Role of variation in surface roughness on evaporation

(Kishii and Sugita, 2000)

\subsection{Linear Elastic Fracture Mechanics}

Linear elastic fracture mechanics assumes an ideally elastic medium (Pratt, 2008) and zero-net lateral strain prior to crack propagation (Ayad and Konrad, 1997.a). A microcrack is held to propagate if the accumulated strain energy is great enough to compensate for the energy lost in the creation of new surfaces. The surface energy is initially small due to the small dimension of the micro-crack whereas the strain energy is much greater in magnitude. Cracks are considered to have a length of 2 a to represent both surfaces of the crack. As the crack of length 2 a grows, the crack surface tension $\boldsymbol{\gamma}_{\mathbf{s}}$ increases and the strain energy $\mathbf{U}_{\text {strain, }}$ which is utilized and consumed in its creation, decreases (equation 33). Crack reaches equilibrium and cease propagating when the 
surface energy created over propagation area increment da becomes greater than the available strain energy (equation 34). By solving Equation 34 at condition of equilibrium, critical tensile stress $\boldsymbol{\sigma}_{\mathbf{c}}$ can be obtained in terms of modulus $\mathbf{E}$, crack surface tension $\boldsymbol{\gamma}_{\mathbf{s}}$ and initial micro-crack dimension a. Equation 35 assumes that critical tensile stress $\boldsymbol{\sigma}_{\mathrm{c}}$ is perpendicular to and uniformly distributed across the crack of length $\mathbf{2 a}$. If plane deformation exists as opposed to plain stress, modulus $E$ becomes $E=E /\left(1-\mu^{2}\right)$ where $\boldsymbol{\mu}$ is the poisson's ratio (Pratt, 2008).

$$
\begin{array}{ccc}
\Delta U=U_{\text {surface }}-U_{\text {strain }} & & \\
\Delta U=4 a t \gamma_{s}-\frac{\pi \sigma^{2} a^{2} t}{E} & \frac{d \Delta U}{d a} \geq 0 & \sigma_{c} \leq \sqrt{\frac{2 E \gamma_{s}}{\pi a}} \\
\text { Equation 33 } & \text { Equation 34 } & \text { Equation 35 }
\end{array}
$$

Griffith's Equation (equation 35) however under calculates the value of $\boldsymbol{\sigma}_{\mathrm{c}}$ as compared to experimental data. Irwin henceforth introduced the element of strain deformation to explain this discrepancy. $\mathbf{U}_{\text {strain }}$ is now expended into both $\boldsymbol{v}_{\mathbf{s}}$ and plastic deformation at small region of crack tip $\boldsymbol{\gamma}_{\mathrm{p}}$ (equation 36). Importantly, this effective surface energy $\boldsymbol{V}_{\mathrm{eff}}$ is no longer strictly a function of soil type as is $\boldsymbol{\gamma}_{\mathbf{s} .}$ (Pratt, 2008). In his work "Analysis of

$$
\begin{array}{lll}
\gamma_{\text {eff }}=\gamma_{s}+\gamma_{p} & \sigma_{i j}=\frac{K}{2 \pi r} f_{i j}(\theta) & G_{c}=\frac{K_{c}^{2}}{E_{1}}=2 \gamma \\
\text { Equation 36 } & \text { Equation 37 } & \text { Equation 38 }
\end{array}
$$

stresses and strains near the end of a crack traversing a plate." Irwin showed that the stress distribution at the crack tip, the principal part of any stress tensor $\sigma_{\mathrm{ij}}$ is dependent on $\mathbf{K}$, distance at the given point from crack tip $\mathbf{r}$ and $\mathbf{f}_{\mathrm{ij}}(\boldsymbol{\theta})$ which is a factor of both $\mathbf{r}$ and 
concordant polar angle $\boldsymbol{\theta}$ (equation 37). It was also demonstrated that critical strain release rate $\mathbf{G}_{\mathbf{c}}$ is related to critical stress intensity factor $\mathbf{K}_{\mathbf{c}}, \mathbf{E}$ and $\boldsymbol{\gamma}$ (equation 38). Once $\mathbf{K}=\mathbf{K}_{\mathbf{c}}$, the crack propagates without further increase in applied stress (Ayad and Konrad, 1997.a).

Irwin's parameters $\mathbf{K}$ and $\mathbf{G}_{\mathbf{c}}$ especially differ from Griffith's approach in that they are proportional to load and reach their peak values at crack initiation, after which load decreases along with $\mathbf{K}$ and $\mathbf{G}_{\mathbf{c}}$. This initially increasing load later becomes critical for the description of micro-cracks and their eventual nucleation into primary cracks. Griffith's theory on the other hand, presents cracking as an instantaneous event occurring as soon as $\mathbf{d U}_{\text {strain }}$ surpasses $\mathbf{d a}$ (Yarema, 1995). Crack initiation is categorized into mode 1 , mode 2 and mode 3 in LEFM. Mode 1 is induced by tensile stresses and is an 'opening displacement', mode 2 is induced by shear stresses and is a transverse displacement and mode 3 is induced by torsion and is a longitudinal shear crack. They each produce their respective $\mathbf{K}$ values (equation 39$)$

$$
\begin{gathered}
K_{I}=\sqrt{2 \pi} \lim _{r \rightarrow 0} \sqrt{r} \sigma_{n} \quad K_{I I}=\sqrt{2 \pi} \lim _{r \rightarrow 0} \sqrt{r} \tau_{n} \quad K_{I I I}=\sqrt{2 \pi} \lim _{r \rightarrow 0} \sqrt{r} \tau_{l} \\
\text { Equation } 39
\end{gathered}
$$

The strength of LEFM is that it links micro-crack size with fracture criterion $\mathbf{K}_{\mathbf{c}}$ (Hallet and Yoshida, 2008) which is a characteristic of the cracking material (Ayad and Konrad, 1997.a). Its weakness is that may not accurately predict crack propagation dynamics as the assumed linear elastic behaviour does not cover larger scale regions whereas it has 
been observed for clayey soils for example, that 'large scale yielding' does indeed occur (Hallet and Yoshida, 2008).
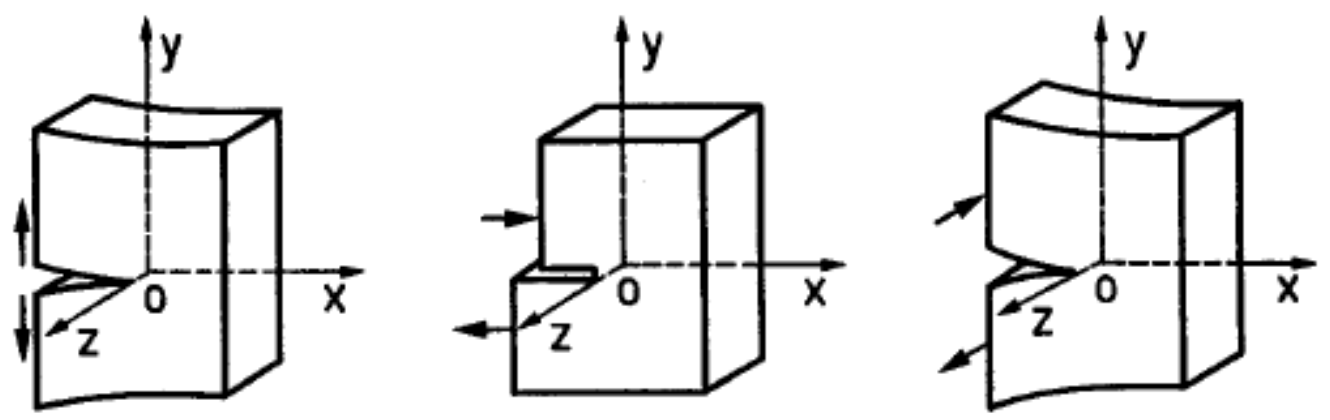

Figure 14: Failure modes 1,2 and 3

(Gdoutos, 2005)

Under mode $1, \mathbf{K}_{\mathbf{c}}$ can be expressed by Equation 42 where $\mathbf{r}_{\mathbf{a}}$ represents the radius of the plastic deformation zone and $\mathbf{Y}$ is dimensionless and accounts for specimen geometry (Dexter et al., 1995). This only applies for a crack propagating in one direction; if the crack is propagating in both directions then crack dimension $\mathbf{2 a}$ is to be divided into 2 so as to consider that the stress field will now be divided into 2 crack tips (Dexter et al., 1995). At plain stress conditions of an infinite plate of negligible thickness where only $\sigma_{\mathbf{y}}$ is significant $\left(\sigma_{y y}=\sigma_{y}, \sigma_{x x}=\sigma_{z z}=0\right)$, Equation 41 becomes true (NealSturgess, 2008). Irwin (1957) also expressed K in terms of a (equation 42) for the stress field at the end of a surface crack of length 2a propagating in both directions. All of the above assume a uniformly distributed stress field $\sigma_{c}$ which is perpendicularly distributed across the crack length 2a (Yarema, 1995).

$$
K_{C}=Y \sigma_{c}\left(2 a+r_{a}\right)^{1 / 2} \quad \sigma_{c}=\frac{K_{C}}{(2 \pi r)^{1 / 2}} \quad K=\sigma \sqrt{\pi 2 a}
$$


$\mathbf{K}$ changes with respect to micro-crack length and stress distribution along micro-crack reaching a maximum $\mathbf{K}$ at a particular length before gradually decreasing (Ayad and Konrad, 1997.a). Although $\mathbf{K}$ increases with decreases in moisture content $\boldsymbol{\theta}$ (Hallet and Yoshida 2008), it has been shown that regardless of moisture content or specimen dimension, $\mathbf{K}$ will increase if initial fracture size is decreased (Pratt, 2008). There is a minimal length at which propagation may occur (Ayad and Konrad, 1997.a) corresponding to Chertkov's minimal crack dimension $\mathbf{I}_{*} . \mathbf{K}$ has been shown to be linear with respect to tensile strength $\sigma_{\mathbf{T}}$ (Chiu et al., 2007). As suction at crack tip is inversely proportional to radius of voids, fine grained soils become more susceptible-than coarse grained soils to micro-crack nucleation and growth (Mitchell, 1993) (Holtz et al., 1981).

\subsection{Chertkov's Model}

The principal premise upon which Chertkov's model is based is that for given stresses at the surface of a crack, the crack will only grow, if its length is greater then a specific minimum length I*. This is supported by Irwin's (1957) assertion that there exists a minimum crack length below which cracks cannot develop (as cite by Chertkov, 2002.a). Chertkov's model (Chertkov, 2002.a) is based on a differential distribution of water content that leads to shrinkage stresses and eventually cracking. His model assumes constant liquid water diffusivity, elastic properties, strength and shrinkage properties of materials within a saturated range of desiccation $\theta_{1} \leq \theta \leq \theta_{0} . I_{*}$ is related by Chertkov, to: diffusivity, elastic modulus, strength and shrinkage properties of materials. 


\section{What the Model Does}

Chertkov identifies 4 distinct stages of crack development: 1) crack Delay, 2) crack Jump/initiation, 3) Stable Crack Growth and 4) Rapid End. These stages are characterized by duration of stage, crack depth, velocity of crack propagation, and mean spacing between primary cracks $\mathbf{S}_{0}$. The most important aspect of this model's contribution is that it requires only two input parameters; minimum crack dimension I*, and soil water diffusivity $\mathbf{D}$. Multiple tests to determine $\mathbf{E}, \boldsymbol{\mu}, \mathbf{K c}$ and a host of other parameters are hence 'obviated'. This simple and direct input-output arrangement allows for a detailed description of the 4 stages of development as represented in Figure 15 where $l_{*}$ is the characteristic minimum dimension of cracks capable of developing in a quasi-brittle soil at shrinkage, $I_{a v}$ is the average initial crack depth, $I_{20}$ is the initial crack depth corresponding to crack depth after jump equal to $z_{0}, I_{\tau}$ is the dimension of initial crack that corresponds with minimum delay time, $z_{0}$ is the thickness of an upper layer of intensive cracking at the quasi-steady state, $L_{a v}$ is, $z *$ is the upper boundary of a depth range where the velocity of cracks approaching $z_{m}$ quickly decreases to zero and $z_{m}$ is the maximum crack depth. 


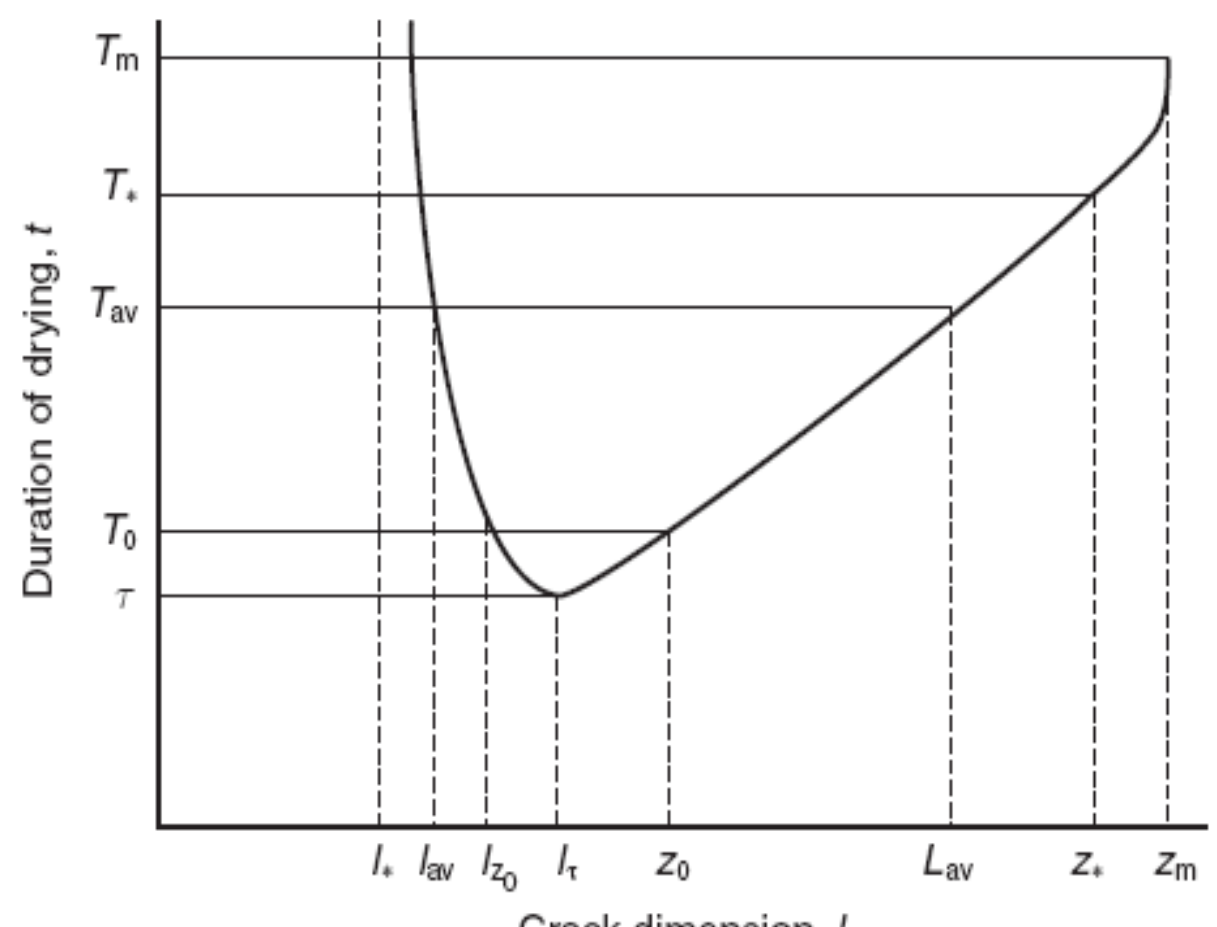

Crack dimension, $I$

Figure 15: Chertkov's Curve

(Chertkov, 2002.a)

As seen in Figure 15, dimension $I_{*}$ forms an asymptotic limit of depth of micro-crack which may develop into primary crack. This is supported by Irwin (1957) who asserts that fracture toughness is dependent on both load $\mathbf{P}$ and micro-crack dimension I. Micro-crack dimension $\mathbf{K} \mathbf{I}_{*}$ is thus so small that no load $\mathbf{P}$ or duration of desiccation ' $\mathbf{t}$ ' can satisfy $\mathbf{K}_{\mathbf{l}} \geq \mathbf{K}_{\mathbf{I C}}$ and only micro-cracks of dimension $\mathbf{I} \geq \mathbf{I}^{*}$ may develop into primary cracks. No crack will develop unless a minimal desiccation time $\boldsymbol{\tau}$ is satisfied.

During stage 1 (Delay), of duration $\mathbf{T}_{\mathrm{av}}$, micro-cracks in the range of $\mathbf{I}^{*}<\mathbf{I} \leq \mathrm{I}_{\mathbf{\tau}}$ grow at a moving equilibrium and connect to form micro-aggregate networks. At time $\mathbf{T}_{a v}, \mathbf{K}_{\mathbf{l}} \geq \mathbf{K}_{\mathbf{I C}}$ is satisfied, the system becomes unstable and the crack networks (of average depth $I_{a v}$ ) undergo sudden and sharp growth (described as a 'jump') into primary cracks, of 
average depth $\mathbf{L}_{\mathbf{a v}}$ and spacing $\mathbf{S}_{\mathbf{0}}$. The crack system is thus no longer unstable as the cracks have 'jumped' to a new moving equilibrium. This sudden formation of primary cracks represents stage 2 (crack Jump) of Chertkov's model and involve cracks of range $\mathrm{I}_{\boldsymbol{\tau}}<\mid<\approx \mathrm{L}_{\mathrm{av}}$. Subsequent to the jump, an upper intensive cracking layer of thickness $\mathbf{z}_{\mathbf{0}}$ forms where the distance between surface cracks is close to $\mathbf{z}_{\mathbf{0}}$, this assertion becomes important later on. At stage 3 (Stable Crack Growth), the water table decreases stably and the crack grows at a near constant velocity $\mathbf{u}$ until it reaches depth $\mathbf{z}$ *and time $\mathbf{T} *$ at which the water table has stabilized. This stage occurs between $\mathbf{z}_{\mathbf{0}} \approx<\mathbf{1}<\approx \mathbf{Z} *$. Stage 4 (Rapid End) is the terminal stage of crack growth. In the range $\mathbf{z} \approx \approx<1 \leq \mathbf{z}_{\mathrm{m}}$, crack growth experiences rapid deceleration and ultimately halts at depth $\mathbf{z}_{\mathbf{m}}$ and time $\mathbf{T}_{\mathbf{m}}$. Desiccation is what drives crack growth; when the crack opening tip approaches the stabilized constant water table, where desiccation no longer occurs (at quasi-brittle range 'the saturated range'), tensile stresses are no longer great enough to keep driving the energy-crack-growth. $\mathbf{T} *$ and $\mathbf{z} *$ are the only parameters not solved though the model establishes that $\mathbf{z}_{\mathbf{m}} \approx \mathrm{z}^{*}$.

\section{Model Assumptions and Development}

Chertkov's model applies for desiccation at the visco-plastic range $(\theta \geq \theta p)(\theta p=$ plastic limit). It differs from Irwin's approach in that it assumes a semi-infinite medium of infinite horizontal extension but limited depth. The model functions in the water content range $\boldsymbol{\theta}_{1} \leq \boldsymbol{\theta} \leq \boldsymbol{\theta}_{0}$ where both $\boldsymbol{\theta}_{1}$ and $\boldsymbol{\theta}_{0}$ are above $\boldsymbol{\theta}_{\mathrm{s}}$ (shrinkage limit), where $\boldsymbol{\theta}_{0}$ is the initial $\boldsymbol{\theta}$ of the whole body $(t=0)$ and where $\boldsymbol{\theta}$ varies both spatially and temporally, 
gradually decreasing until reaching the constant and minimal $\theta_{1}$ at surface. Shock drying is assumed at the surface such that as soon as $t>0$, surface $\boldsymbol{\theta}=\boldsymbol{\theta}_{\mathbf{1}}$. This is important as this shock drying phenomenon immediately imposes the greatest stresses (over range $\left.\theta_{1} \leq \theta \leq \theta_{0}\right)$ and corresponding $\left.\right|_{*}$. Hence, $I^{*}$ is indeed present at $t \approx 0$ at the shock dried surface. $\Delta \theta\left(\theta_{0^{-}} \theta_{1}\right)$ corresponds to the highest $\Delta \theta$ from $\theta_{t=0}$ to $\theta_{t}$ where shrinkage coefficient $\alpha$ is constant. Within this range of $\Delta \theta, D, K, E$ and $v$ are also considered to be constant. A 'shock drying layer' is formed immediately at $\mathrm{t}=0$ where the initial water content $\theta_{0}$ at the surface is equal to the minimum and ultimate water content $\theta_{\mathrm{f}} . \boldsymbol{\theta}_{0}=\boldsymbol{\theta}_{\mathrm{f}}$. Perhaps most importantly, Chertkov assumes that the micro-cracks have depths I equal to the dimension ' $2 a$ ' (from Irwin) of their crack opening. Dimensions of the soil body are presumed to play no part in micro-crack formation. The development of Chertkov's model is here divided into two phases; first the theoretical establishment of the timelength relationship as seen in Figure 15, and secondly the parameterization of key development stage-points strictly in terms of $\mathbf{I}_{*}$ and $\mathbf{D}$, as summarized in table 2 .

\section{Phase 1:}

The model is based on moisture distribution $\nabla \theta$ from which concordant stresses and propagation dynamics are determined. Through assumption of constant $\mathbf{D}$, the water content distribution takes the form of Fick's second diffusion equation (equation 46) thus relating it to time. Two stresses are recognized as acting upon a desiccating soil; shrinkage stresses $\sigma^{\theta}$ (equation 43 ), and elastic stresses $\sigma^{e}$. Total stress $\sigma_{\boldsymbol{T}}$ related to crack opening is the sum of these two (equation 44). By establishing condition of 
equilibrium (equation 45) the equation of theory of elasticity (equation 46) may be derived.

$\begin{array}{cccc}\sigma^{\theta}=-k \alpha\left(\theta-\theta_{0}\right) \delta y & \sigma_{T}=\sigma^{\theta}+\sigma^{e} & \frac{\partial \sigma_{T}}{\partial x}=0 & F=-k \alpha \nabla \theta \\ \text { Equation 43: Shrinkage Stress } & \begin{array}{c}\text { Equation 44: Total } \\ \text { Stress }\end{array} & \begin{array}{c}\text { Equation 45: Condition of } \\ \text { Equilibrium }\end{array} & \text { Equation 46: } \\ & & & \text { Theory of Elasticity }\end{array}$

This Equation (equation 46) provides the volume forces for $\boldsymbol{\sigma}^{\mathbf{e}}$. Therefore, the problem was solved separately according to moisture concentration. Fick's second diffusion equation was substituted into equation of theory of elasticity (equation 46). This produced the resultant stress $\sigma_{\mathrm{yy}}$ (equation 48 ) along the crack line and related it to both time $\mathbf{t}$ and depth $\mathbf{z}$. $\boldsymbol{\sigma}_{\mathrm{c}}$ (equation 47 ) is the maximum stress exerted at the crack surface (under shock drying conditions) and with stress decreasing down the crack depth. $\boldsymbol{\chi}$ is an error function.

$$
\begin{gathered}
\sigma_{c}=\frac{E \alpha}{3(1-v)}\left(\theta_{0}-\vartheta_{1}\right) \quad \sigma_{y y}(z, t)=\sigma_{*}\left[1-\chi \frac{z}{2 \sqrt{D t}}\right] \\
\text { Equation } 47 \\
\text { Equation } 48
\end{gathered}
$$

Substituting Equation 48 into Cherepanov's stress intensity factor function (equation 49): where $\sigma_{y y}(z, t)=p(z)$ relates intensity factor $K_{\mathbf{l}}$ to $\mathbf{I}$, $\mathbf{t}$ and $\boldsymbol{\sigma}_{\mathbf{c}}$. When this $K_{l}\left(I_{*}, I, t \sigma_{*}\right)$ is substituted into Equation 50 for $\sigma_{c}, \sigma_{c}$ cancels out and the solution is solved as $\mathbf{t}$ can be related to $\mathbf{I}$ and $\mathrm{I}_{*}$. The resultant Equations (equations 56-60) form the relationship seen in Figure 16. 


$$
\begin{array}{ccc}
K_{I}=\frac{2 \sqrt{l}}{\sqrt{\pi}} \int_{0}^{l} \frac{p(z) d z}{\sqrt{l^{2}-z^{2}}} & \sigma_{*}=\frac{K_{I C}}{\left(\pi d_{*}\right)^{1 / 2}} & \sigma_{*}=\frac{K_{I C}\left(\sigma_{*}, l, t\right)}{\left(\pi l_{*}\right)^{1 / 2}} \\
\text { Equation } 49 & \text { Equation } 50 & \text { Equation } 51 \\
t=\frac{l_{*}^{2}}{4 D} * \frac{1}{\beta^{2}(F(\beta))^{4}} & F(\beta)=\frac{2}{\pi} \int_{0}^{l} \frac{1-\phi(\beta \varepsilon)}{\sqrt{1-\varepsilon^{2}} d \varepsilon} \quad \beta=\frac{1}{2 \sqrt{D t}} \\
\text { Equation } 52 & \text { Equation } 53
\end{array}
$$

Equation 52 develops into Equation 56 when $\beta\langle\langle 1$ and into Equation 57 when $\beta\rangle\rangle 1$. These form the descending and ascending lines in Figure 16. When Equations 56 and 60 are equated, minimal time of delay $\tau$ and its corresponding crack length $I_{\tau}$ (equation 58 ) may be obtained. When ascending (equation 57) and descending (equation 56) equations are equated, a direct relationship between micro-crack length $\mathbf{I}_{\mathbf{j}}$ and corresponding macro-crack length (after jump) $\mathbf{L}_{\mathbf{j}}$ may be derived (equation 60 ).
$t=\frac{16}{\pi^{3} D}$
Equation 56
$t=\frac{\pi^{3} l_{*} l}{16 D}$
$\tau \cong 2.77 \frac{l_{*}^{2}}{D}$
$l_{\tau} \cong 1.43 l_{*}$
$l_{j}=\left(\frac{16}{\pi^{3}}\right)^{2} \frac{l_{*}^{3}}{\left(L_{j}-l_{*}\right)^{2}}$
Equation 57
Equation 58
Equation 59
Equation 60 


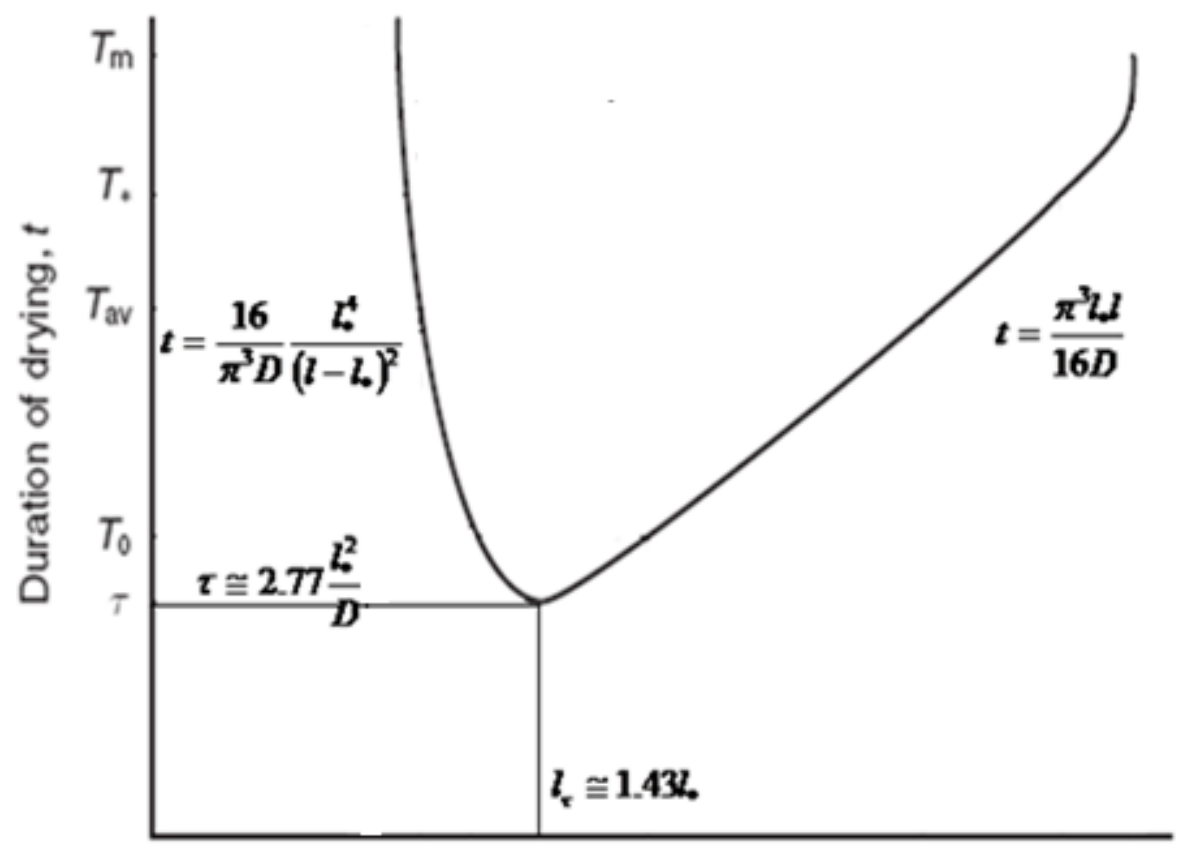

Crack dimension, I

Figure 16: Chertkov's curve

Adapted from (Chertkov, 2002.a)

\section{Phase 2:}

In phase 2 , the $t(l)$ equations are modified so as to recognize: a) the soil nonhomogeneities on a scale comparable to the growing crack, and b) establish a maximum crack depth as related to a stabilizing water table. Point $b$ establishes the semi-infinite nature of the soil medium as it now incorporates a bottom boundary to the soil layer. Micro-cracks of length $\sim$ I* grow wider and deeper until they connect to one another and form crack networks. According to Chertkov (1998), these crack networks have a mean dimension of $\left(\mathrm{K}^{*}+1\right) I^{*} . \mathrm{K}^{*}$, the critical ratio of the mean linear dimension of an area 
taken by an initial surface crack with respect to the crack depth. According to Zhurkov (1977), ratio $K^{*}$ is $\approx 5$ for soils. The resultant mean dimension of $61^{*}$ must coincide, according to Chertkov, to mean spacing between cracks $S_{0}$, hence $S_{0}=61_{*}$.

$\mathbf{z}_{0}$, the depth of intensive cracking layer is characterized by average spacing between cracks $d\left(Z_{0}\right)=Z_{0}$. The intensive crack layer is directly dependent upon $z_{m}$ (the maximum crack layer at the moment) and their ratios range from an initial $z_{0} / z_{m} \approx 0.2$ to a final $\mathrm{z}_{0} / \mathrm{z}_{\mathrm{m}} \approx 0.1$ as determined by Chertkov and Ravina (1998). $\mathrm{z}_{0}$ is solved by assuming that an initial intensive crack layer $\left(a t z_{0} / z_{m}=0.2\right)$ forms from primary cracks of both depth and distance $\mathbf{S}_{\mathbf{0}}$. This layer then undergoes secondary cracking which divides the mean spacing between surface cracks by two. The secondary cracks are shallower then the primary and have depths equal to the new mean distance between cracks $\left(S_{0} / 2\right)$ hence $z_{0}=S_{0} / 2$. From relations $z_{0} / z_{m} \approx 0.1$ and $z_{0}=S_{0} / 2, z_{m}$ is solved in terms of $I_{*}$ as $z_{m}=\left.30\right|_{*}$ (table 3). The average length of micro-crack $l_{\text {avg }}$ to jump is taken as the average length between $I_{\tau}$ and $I_{*}$ and is thus expressed as $I_{\text {avg }}=\left.1.22\right|^{*}$. $I_{\text {avg }}$ is subbed into Equation 56 to solve for $T_{\text {avg }}\left(T_{\text {avg }}=\left.11.10\right|^{2} * / D\right)$. In turn $T_{\text {avg }}$ is plugged into Equation 57 to solve for average crack depth of primary cracks at initiation $L_{\text {avg }}$ as $L_{a v g}=5.721^{*}$. $T_{0}$ is obtained by plugging in $z_{0}$ into Equation 57 and the corresponding micro-crack length $I_{z_{0}}$ is determined by subbing $\mathbf{T}_{0}$ into Equation 46. 


\section{Forms of Final Equations}

\begin{tabular}{|c|c|c|}
\hline $\begin{array}{c}\text { Base } \\
\text { Parameters }\end{array}$ & $\begin{array}{c}\text { Derived } \\
\text { Parameters }\end{array}$ & Transformation \\
\hline \multirow{11}{*}{ * } & $\mathrm{S}_{0}$ & $S_{0}=\left.\left(K_{*}+1\right)\right|_{*} \approx 6 I_{*}$ \\
\hline & $\mathbf{z}_{0}$ & $\mathrm{z}_{0} \approx \mathrm{S}_{0} / 2 \approx 0.1 \mathrm{Z}_{\mathrm{m}}$ \\
\hline & $\mathbf{z}_{\mathrm{m}}$ & $\mathrm{z}_{\mathrm{m}} \approx 30 \mathrm{I}_{*}$ \\
\hline & $I_{\text {avg }}$ & $\mathrm{I}_{\mathrm{avg}}=1.22 \mathrm{I}_{*}$ \\
\hline & $\mathbf{L}_{\text {avg }}$ & $\mathrm{L}_{\mathrm{avg}} \approx 5.72 \mathrm{I}_{*}$ \\
\hline & $I_{20}$ & $I_{\mathrm{z} 0} \approx 1.31 I_{*}$ \\
\hline & $I_{\tau}$ & $I_{\tau} \approx 1.43 I_{*}$ \\
\hline & $\mathbf{T}_{0}$ & $T_{0} \approx\left(\pi^{3} / 16\right)\left(I_{*} z_{0} / D\right)$ \\
\hline & $\mathbf{T}_{\text {avg }}$ & $\mathrm{T}_{\mathrm{avg}}=11.10\left(\mathrm{I}^{2} * / \mathrm{D}\right)$ \\
\hline & $\mathbf{T}$ & $\left.\tau \approx 2.77\right|^{2} * / D$ \\
\hline & $\mathbf{U}$ & $u=16 D /\left(\pi^{3} I_{*}\right)$ \\
\hline
\end{tabular}

Table 3: List of Chertkov Relations

As demonstrated in this literature review multiple factors affect crack formation, it is therefore formidable that a single model can model crack propagation with only two dimensions; minimal crack length $\mathbf{I}_{*}$ and soil water diffusivity. It was therefore the objective of this thesis to verify Chertkov's claims and test his model. The aim was also to test the effect of crack formation on total evaporation. 


\section{Methodology}

\subsection{Materials}

The primary piece of equipment used in this research is the scanCONTROL 2810 laser scanner seen below (figure 17). This laser scanner provided two-dimensional readings of the desiccating clay surface and its crack incisions. The head of the scanner emits a laser beam whose reflection is received back into it and is converted into a two dimensional reading. The bottom piece is called the monitor.

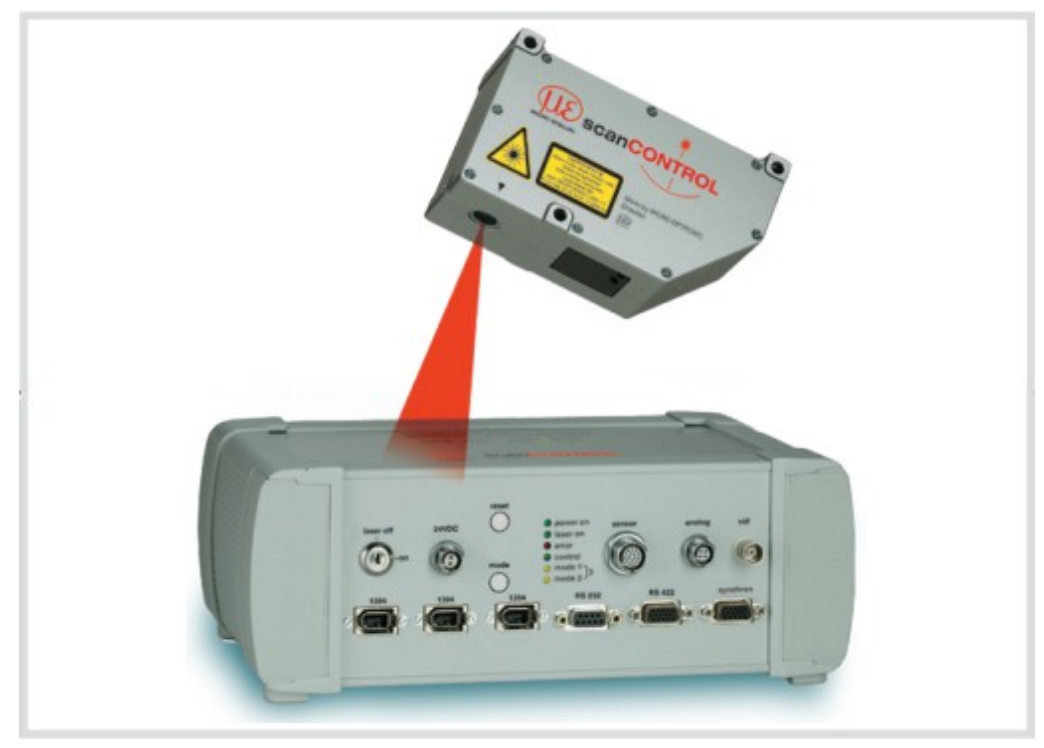

Figure 17 laser scanner

This laser scanner had to scan an area of clay deposited inside a $2.7 \times 1.5 \times 1 \mathrm{~m}$ metallic tank. In order to hold and move the laser scanner above this area for scanning, a metallic Laser Support System (LSS) was built with three main pieces (figure 18). The axial beam is the metallic beam which spans both sides of the tank. It is equipped with 
plastic wheels which allow it to roll along the tank sides. The slider is the central piece which holds the vertical metallic arm. Its function is to move the metallic arm axially along the axial beam. It also holds the scanCONTROL's monitor atop of it. The metallic arm is pierced with holes along its length which are used as entry points by a pin to hold the beam at different depths along the slider. The bottom of the arm holds the head of the laser scanner and is equipped with a spherical joint which lends it 3 dimensional movements.

Scan readings were taken in two ways; through an excel graph of the surface line and through a scanControl video of the line beam over time. In the beginning of crack development, 2-dimensional readings were analyzed through excel. Later on, as the crack openings became more complex it was important to take the scan images through video scanning to ensure the full depth of the crack was reached and recorded by the beam.

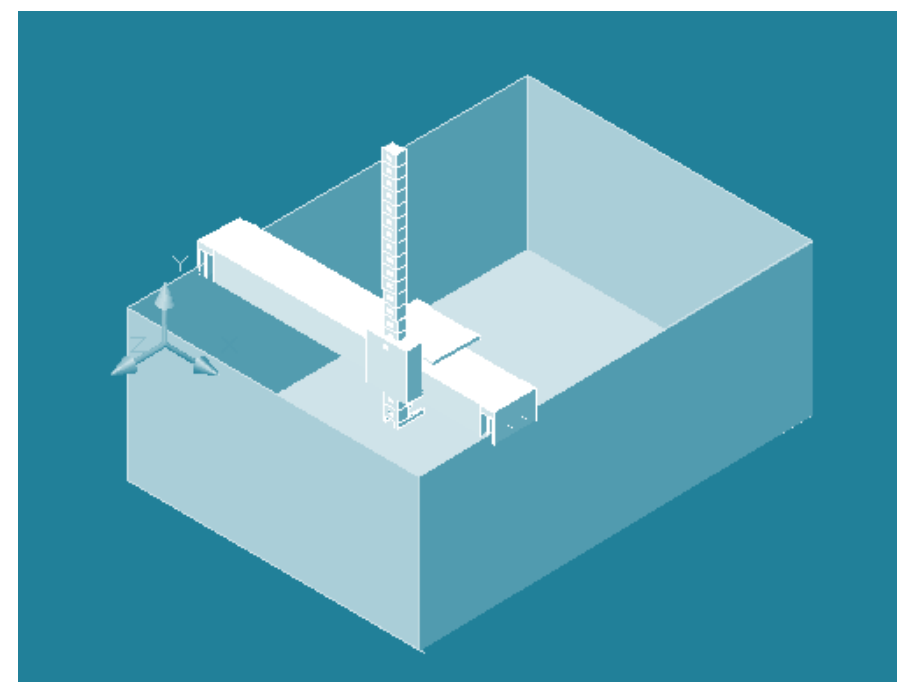

Figure 18 Metallic container which contained clay specimen $(2.7 \mathrm{~m} \times 1.5 \mathrm{~m} \times 1 \mathrm{~m})$ 
Four load scales (2272.73kg capacity, Artech industries Inc.) underlet each corner of the tank to measure weight loss. Two fans (Hawaiian Breeze 16" 3-Speed Oscillating Stand Fan) were placed on both sides of the clay deposition and were activated at intensity levels of $3.219 .9 \mathrm{~kg}$ of wet Kaolinite clay was deposited in this space at $60 \%$ initial moisture content. The clay had the following characteristics:

\begin{tabular}{|l|l|}
\hline \multicolumn{2}{|l|}{ Atterberg Limits: } \\
\hline Dry density & 1.6 \\
\hline Plastic Limit & $34.8 \%$ \\
\hline Liquid Limit & $46 \%$ \\
\hline Shrinkage Limit & $19.6 \%$ \\
\hline \multicolumn{2}{|c|}{ Table 4 Atterberg Limits }
\end{tabular}

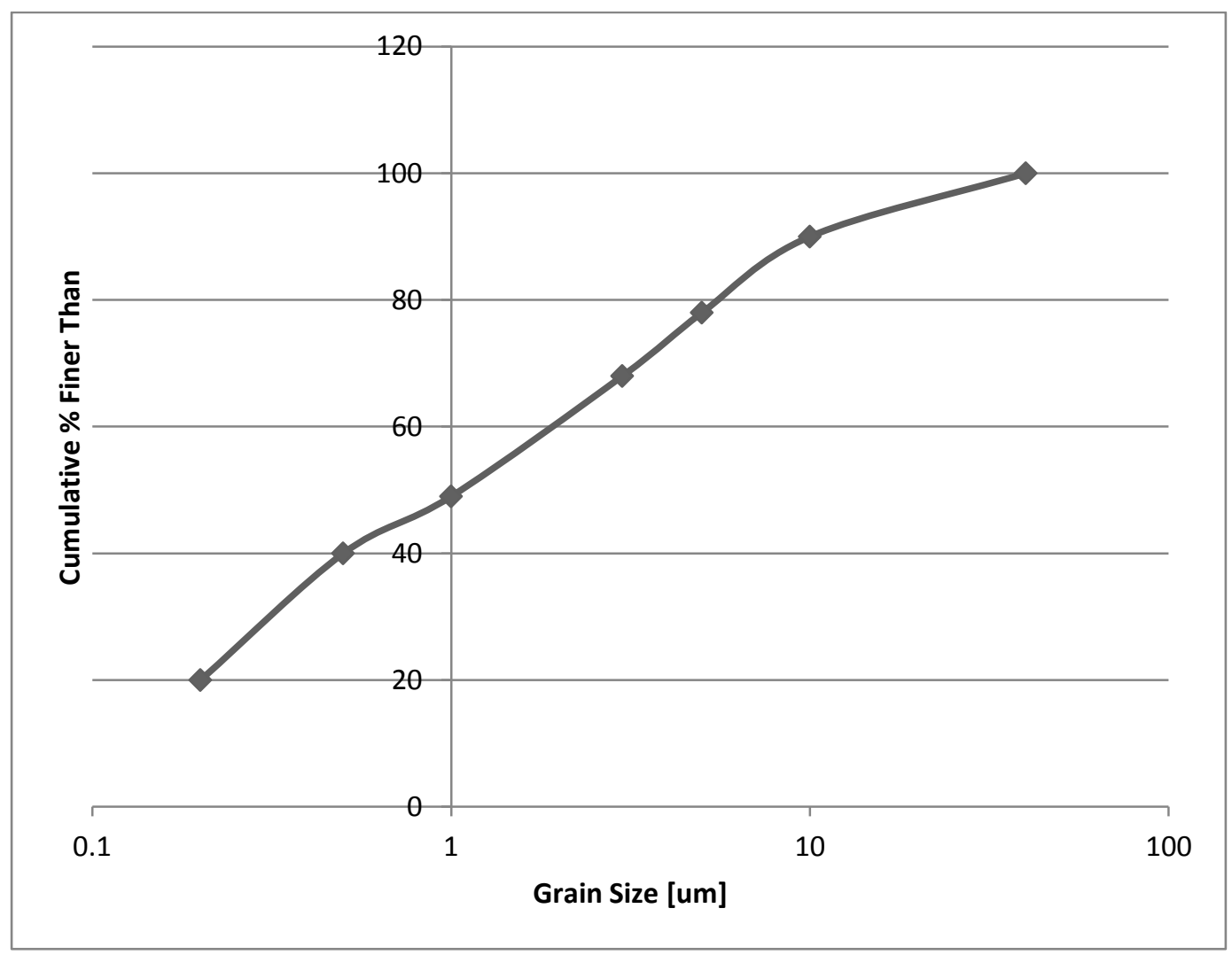

Figure 19 Grain Size Distribution 


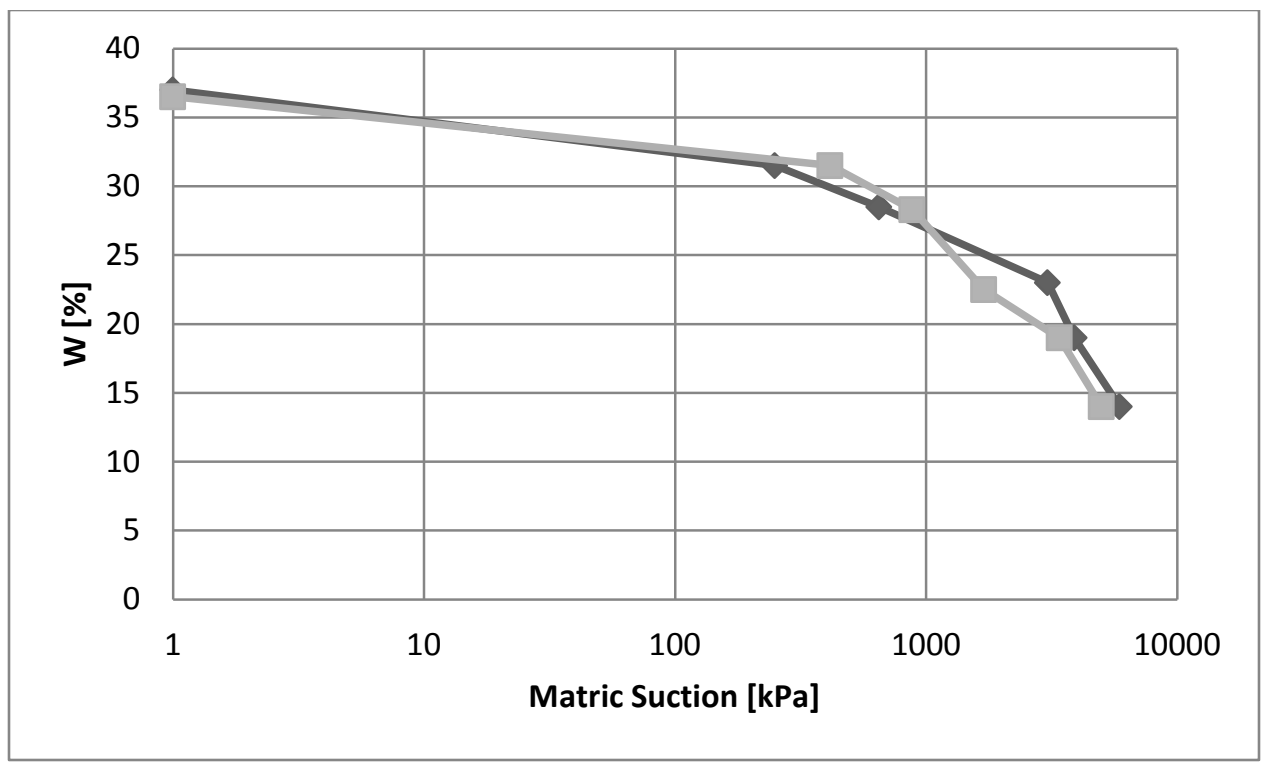

Figure 20 Soil water characteristic curve (after Jayasinghe (2013))

Total suction readings of samples taken from the clay surface were taken by the WP4-T Dewpoint Potentiameter (figure 21) seen below while relative humidity and temperature readings were taken by an RH logger (OMEGA ENGINEERING OM-EL-USB-2LCD). Images of the desiccating clay surface were taken with a Sony NEX3N camera. Clay samples were dried in an oven to determine gravimetric water content.

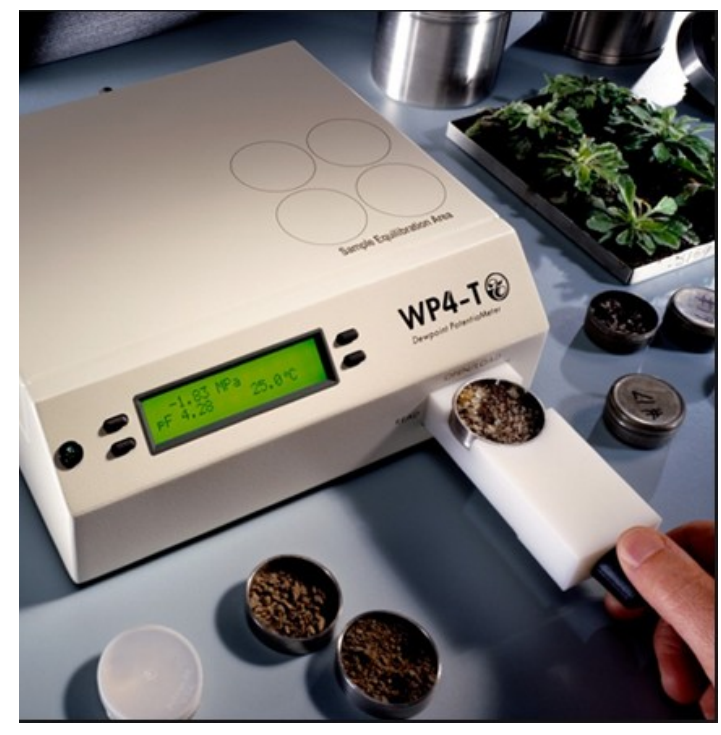

Figure 21 WP4-T Potentiameter 


\section{2. $\quad$ Large Scale Drying}

The wet clay was desiccated at the bottom of a $2.7 \times 1.5 \times 1 \mathrm{~m}$ metallic tank equipped with the Laser Support System (LSS) (figure 18) and with two fans at both longitudinal ends. The LSS exhibits three dimensional mobility at the laser head. Water loss was determined from 4 load scales (2272.73kg capacity, Artech industries Inc.) underlying each corner of the tank. Within the tank, two panels of wood $(145 \times 20 \mathrm{~cm})$ were placed at the bottom, enclosing an area $20 \mathrm{~cm}$ high by $145 \mathrm{~cm}$ length by $129 \mathrm{~cm}$ width. $219.9 \mathrm{~kg}$ of wet Kaolinite clay was deposited in this space at $60 \%$ initial moisture content (figures $21,22)$. The clay specimen dimension was $8.99 \times 129 \times 145 \mathrm{~cm}$. The clay was prepared by mixing dry kaolin clay with water and leaving to settle overnight. $60 \%$ moisture content was chosen to assure it was above the liquid limit as was the case with the soil cited by Chertkov. An initial thickness of $9 \mathrm{~cm}$ was chosen to approach the thickness used by Fisseha's experiment (2008) so as to make a valid comparison. The two fans were tu00rned on to level 3 while the RH logger was turned on, recording temperature and relative humidity every 5 minutes. 


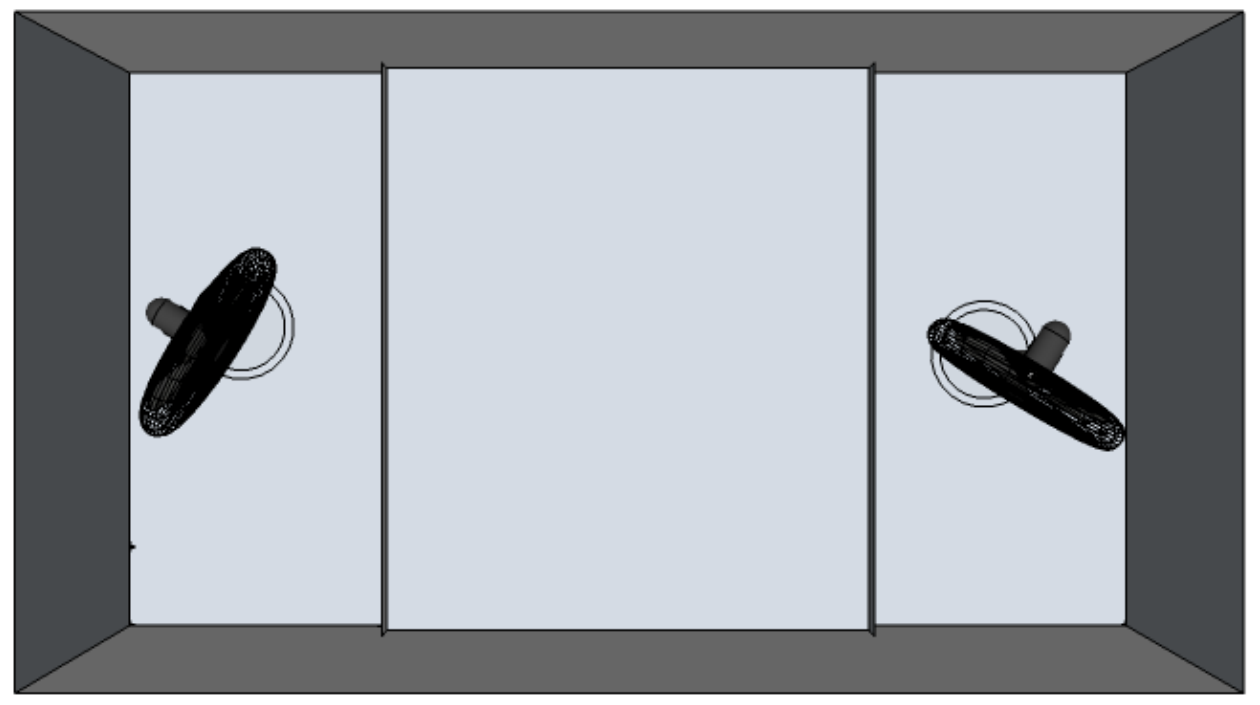

Figure 22 Pan view of clay specimen in metallic container

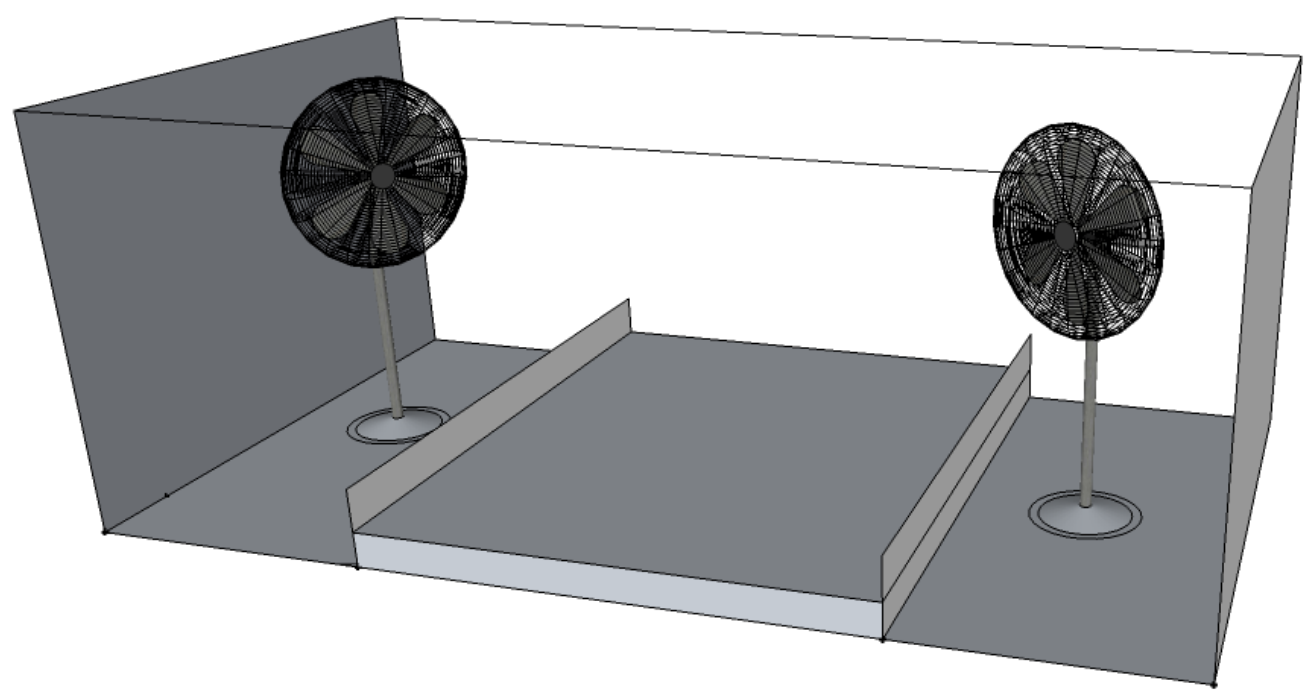

Figure 23 Corner view of clay specimen in metallic container

Planar camera-images were taken daily and then processed through Matlab for further analysis of crack propagation. The purpose was to derive Crack Intensity readings, defined as the ratio of the planar surface covered by cracks to that covered by intact 
clay surface. These Matlab processes also sought to determine the total length of cracks and the spatial distribution of total suction on the clay surface. The first task was to create black-white images of the planar pictures for further Matlab analysis. Figures 24, 25 and 26 show 3 examples of raw planar pictures taken of the desiccating clay at 3.47 days, 6.81 days and 7.43 days respectively. It should be noted that due to lack of perspective from the camera, the sides of the image were bent and had to be cut off for image analysis, as a result, crack lengths were slightly overestimated.

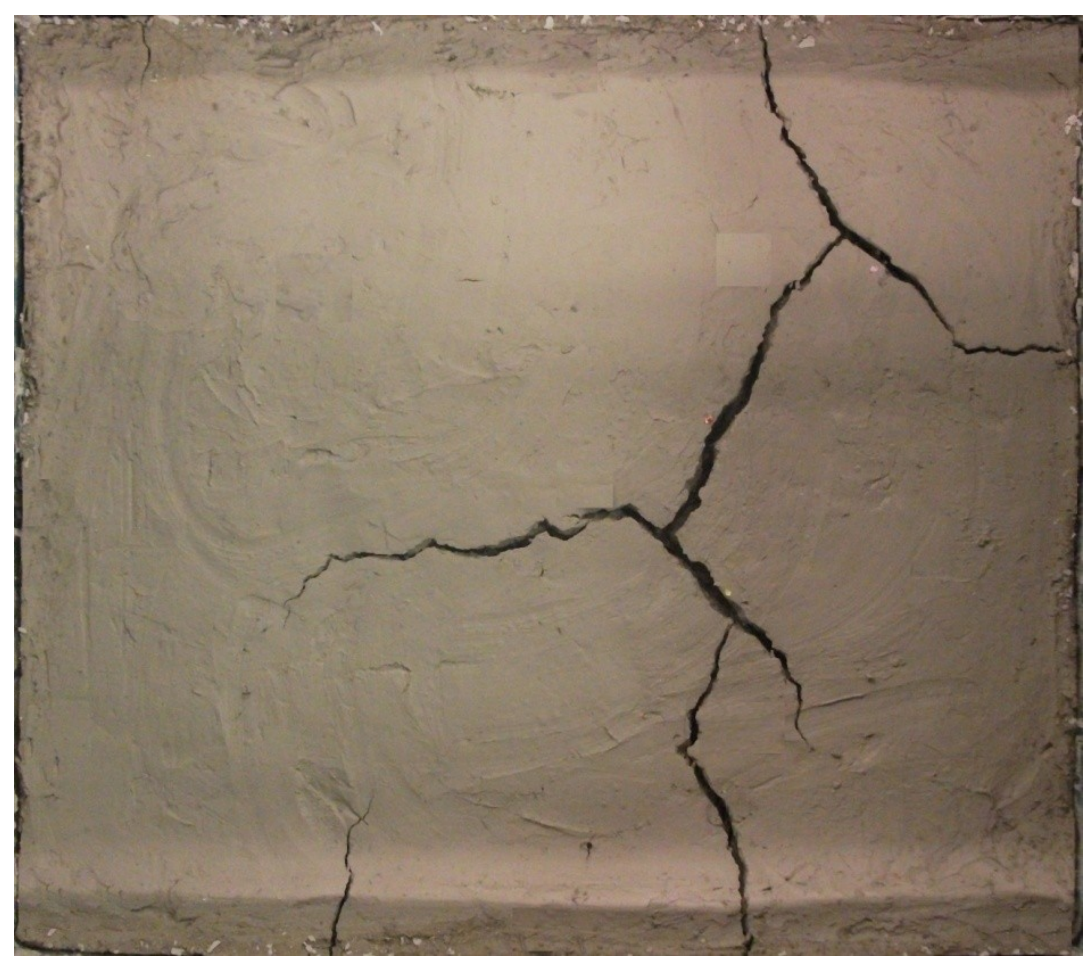

Figure 24 Plan-view of clay specimen at 3.47 days 


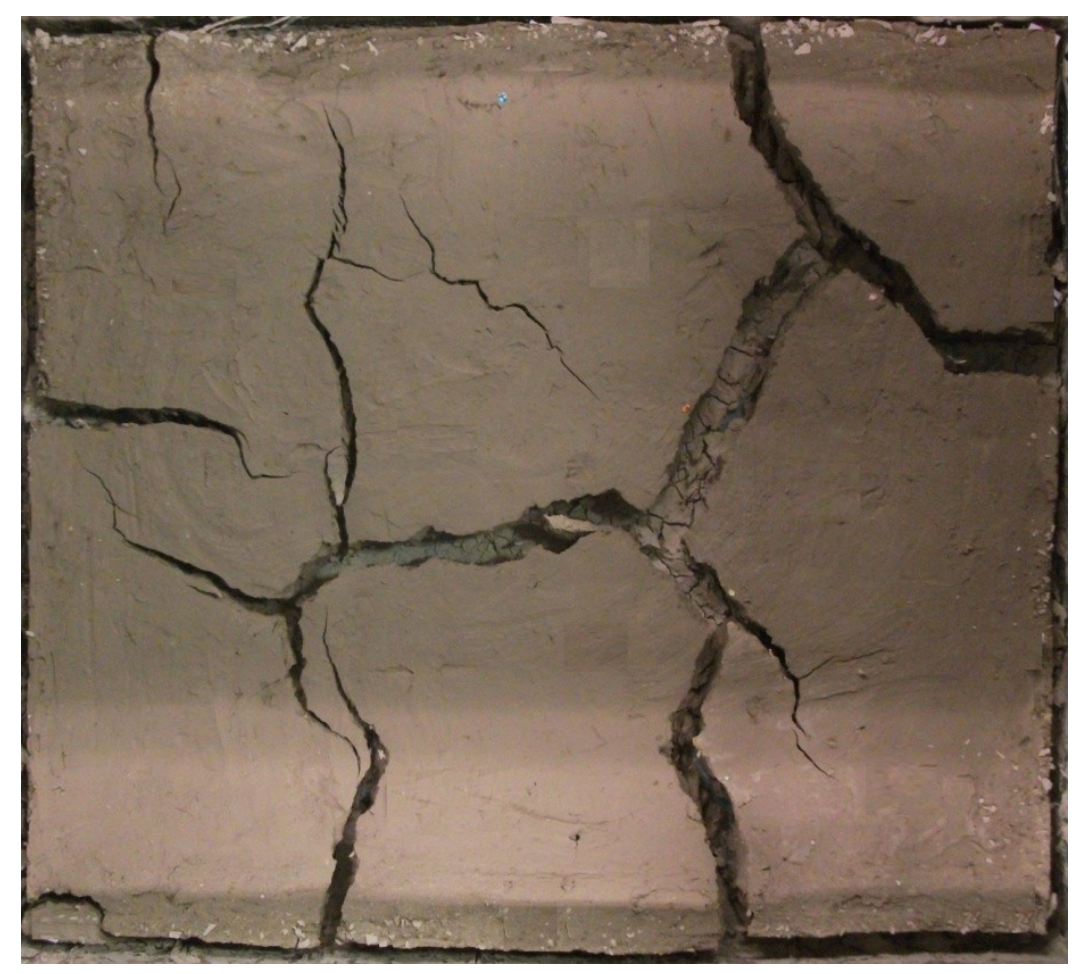

Figure 25 Plan-view of clay specimen at 6.81 days

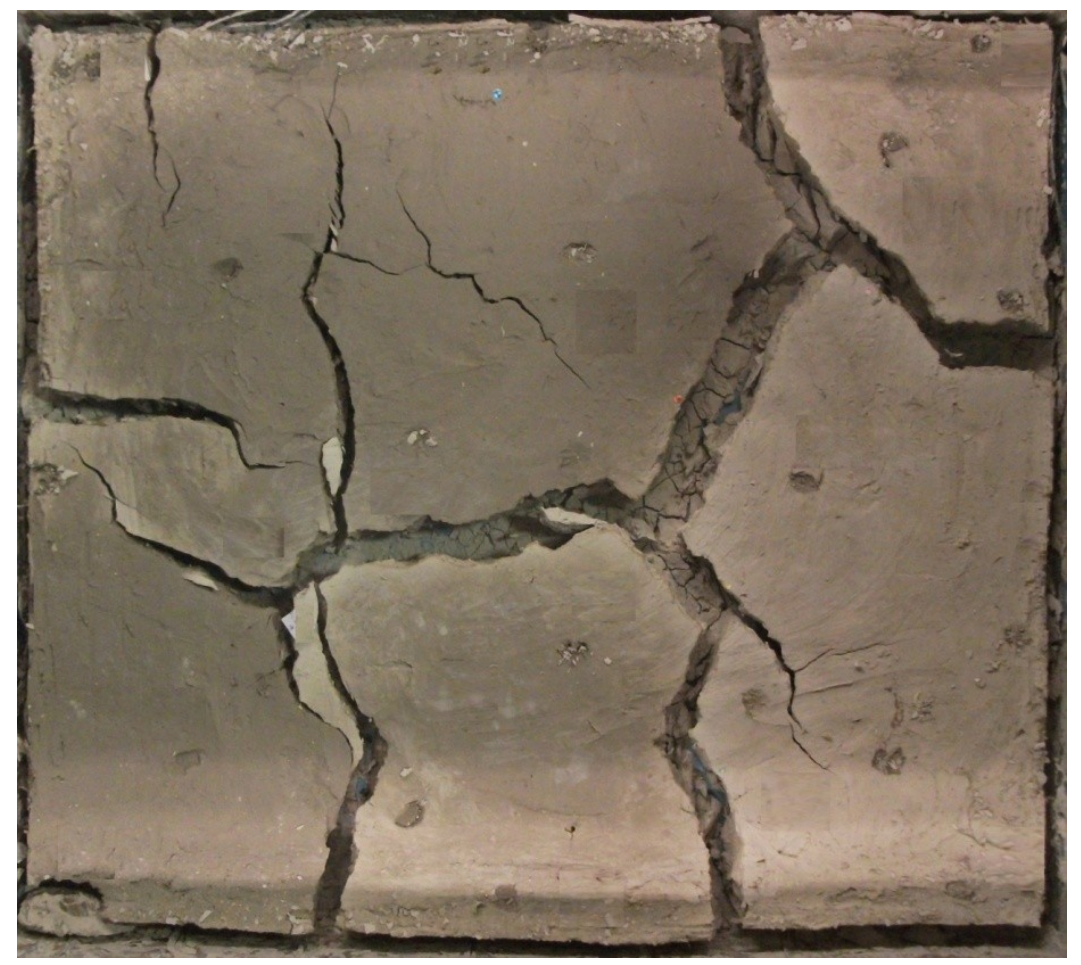

Figure 26 Plan-view of clay specimen at $\mathbf{7 . 4 3}$ days 
The strategy was to convert the images into a grayscale using the following Matlab function (I=rgb2gay(RGB)) where 'RGB' is the name of the coloured image to be converted into image 'I'. To convert the grayscale images ('I') into binary black white images, the following Matlab function was used $B W=i m 2 b w(I$, level) where ' $I$ ' is the name of the image to be transformed and 'level' is the threshold applied. The problem was that the all grayscale thresholds (level) for binary conversion could not accurately distinguish between crack openings and intact clay surface due to variations in lighting, shade and color. All images were therefore transferred to the Paint software where the crack openings were overlaid with black (figures $27,28,29$ ), converted into a grayscale and from thereon, converted into binary images (figures 30,31,32).

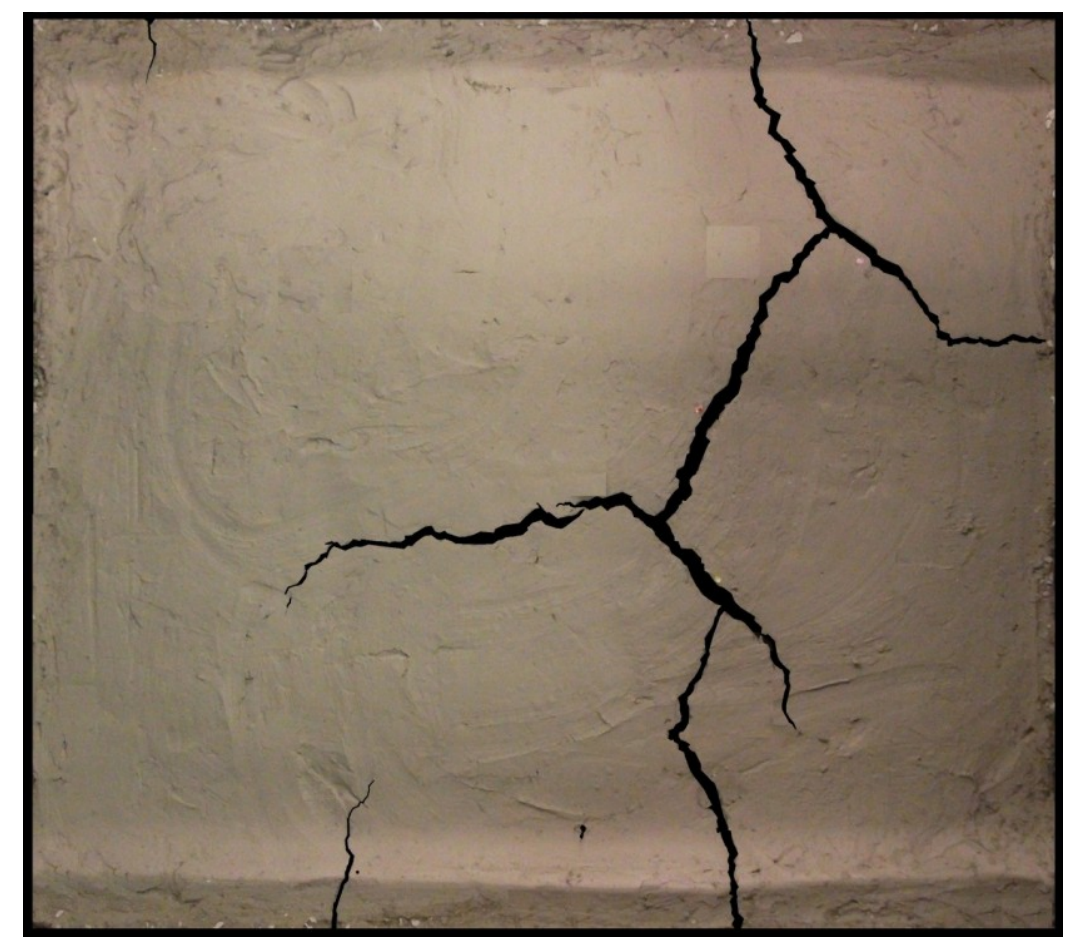

Figure 27 clay specimen with blackened crack openings at 5000 minutes 


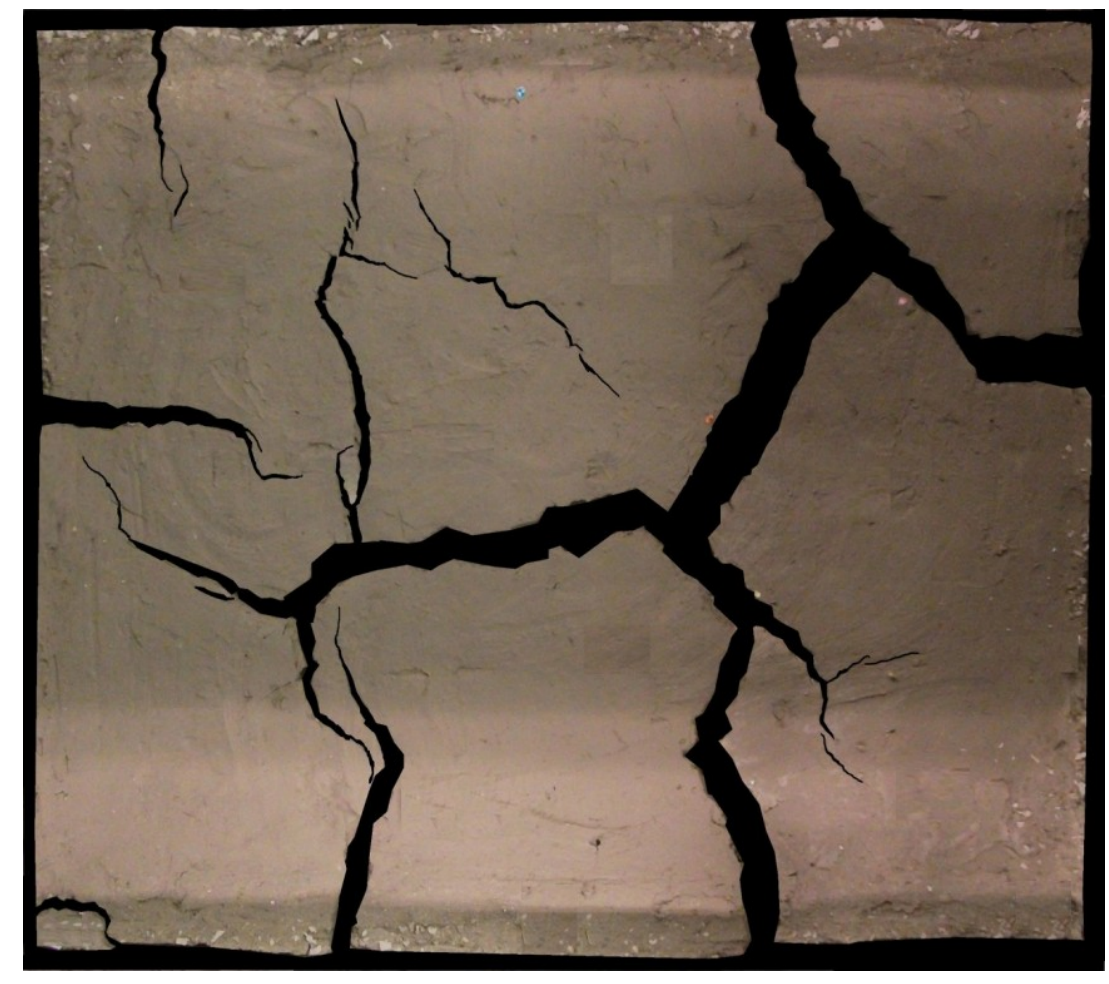

Figure 28 clay specimen with blackened crack openings at 9,800 minutes

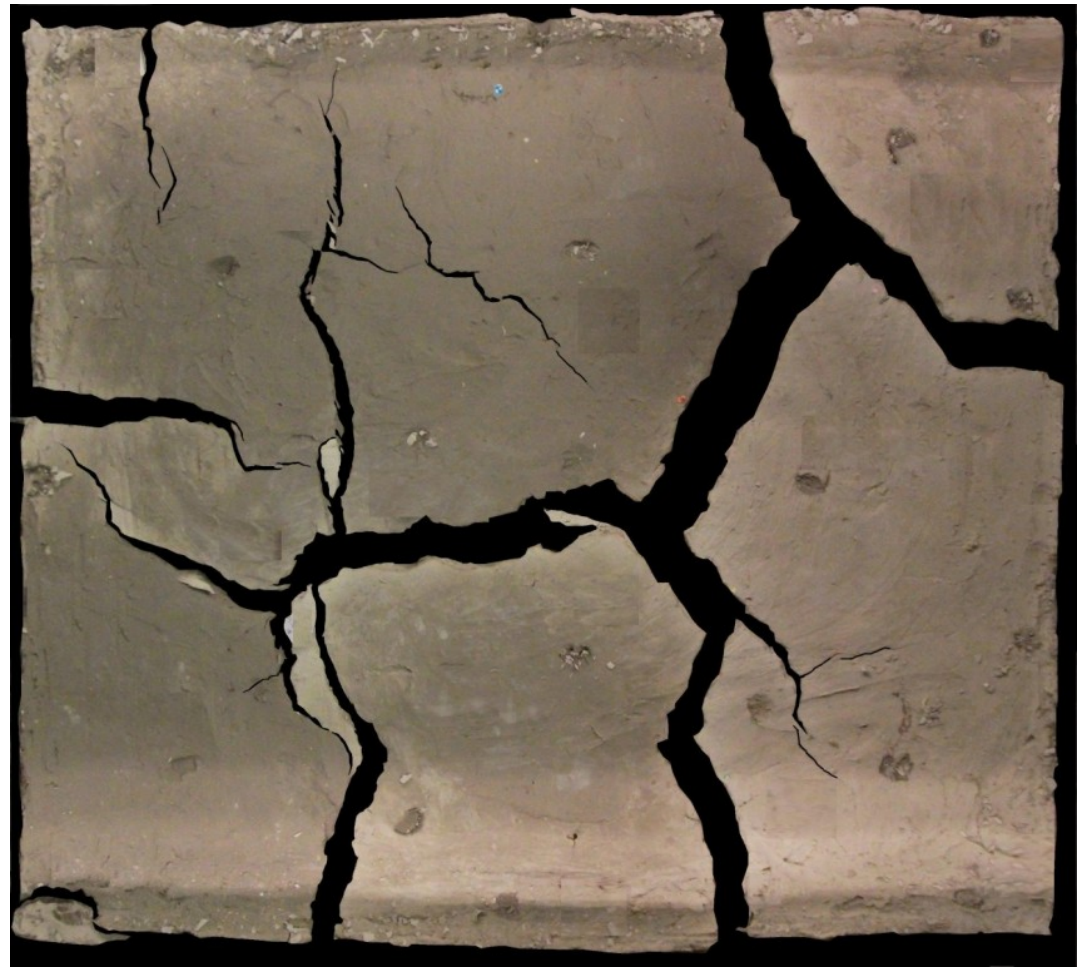

Figure 29 clay specimen with blackened crack openings at 10,700 minutes 


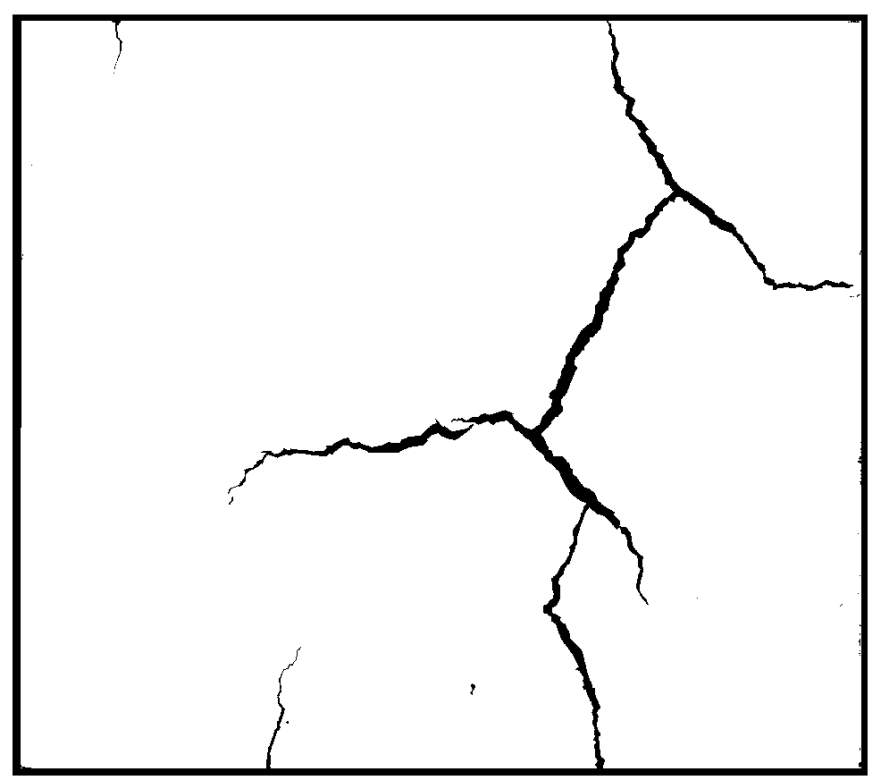

Figure $\mathbf{3 0}$ binary image of plan-view at $\mathbf{5 0 0 0}$ minutes

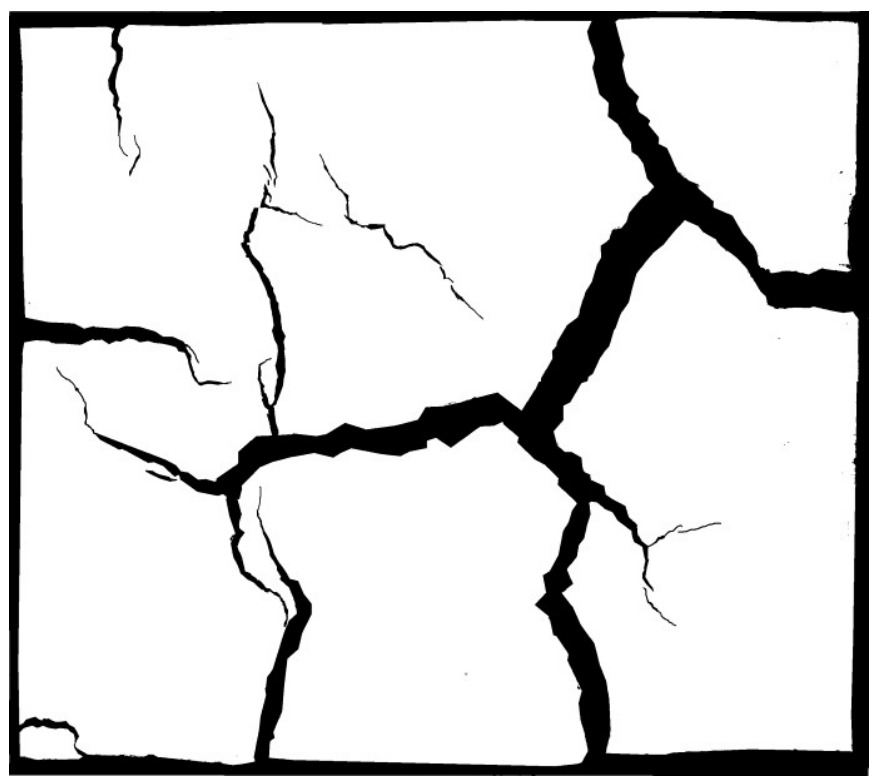

Figure 31 binary image of plan-view at 9,800 minutes 


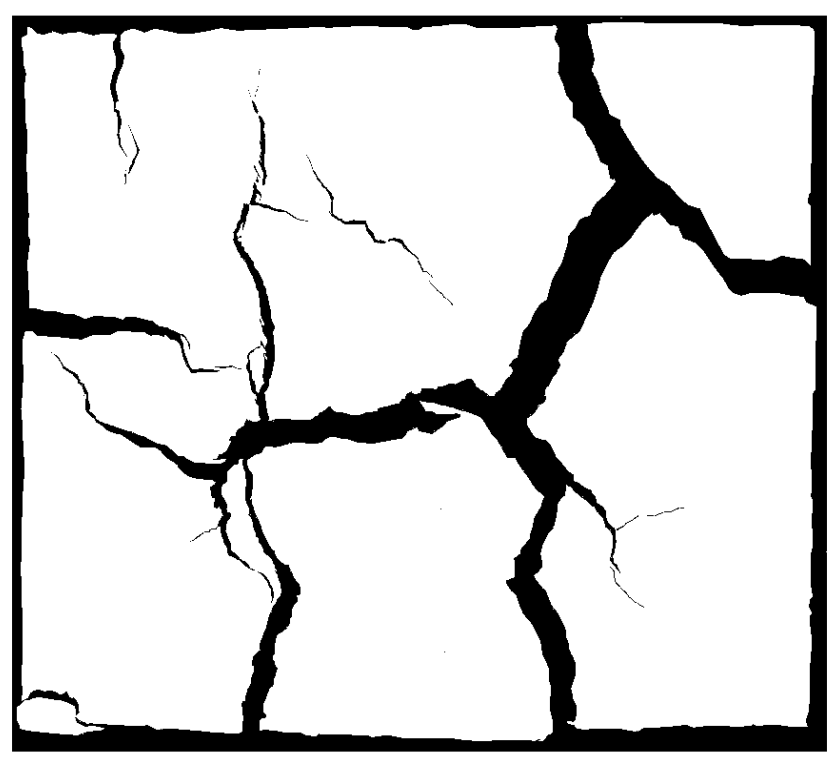

Figure 32 binary image of plan-view at 10,700 minutes

The following Matlab function for histograms ( $x$ =imhist(image) ) was used to determine the amount of black pixels and white pixels. 'image' is the name of the image to be analyzed while ' $x$ ' is the name of the histogram produced. The pixel count, in turn, was used to determine the proportion of the planar surface which was covered by crack openings and covered by intact surface. 


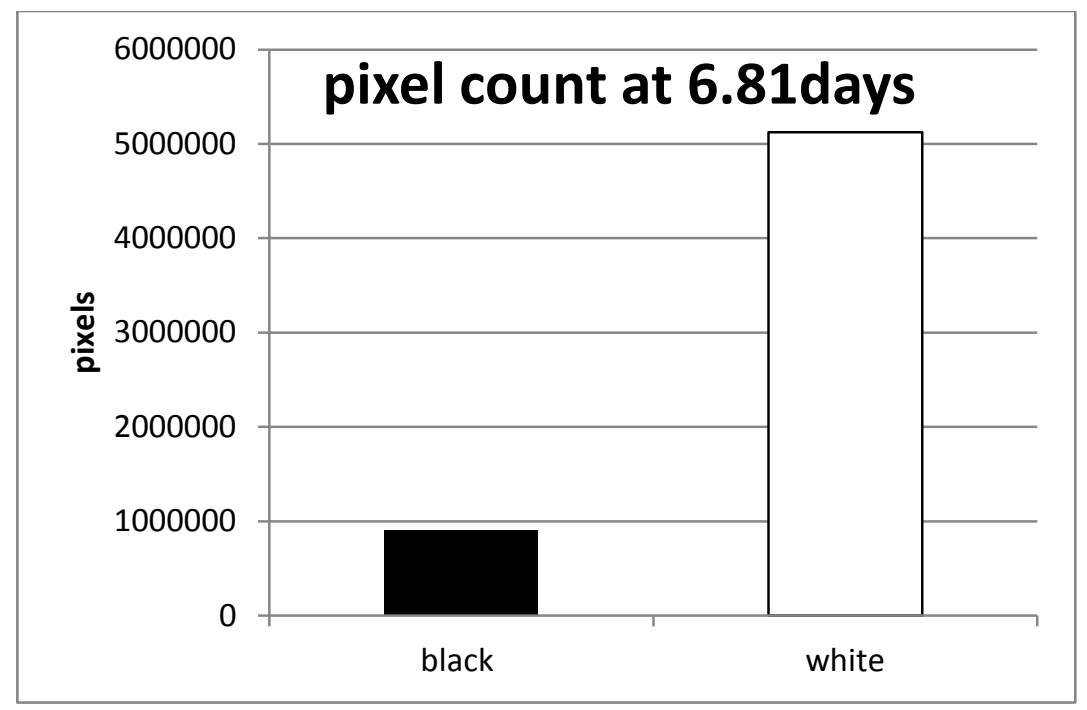

Figure 33 pixel count of binary image at 6.81 days

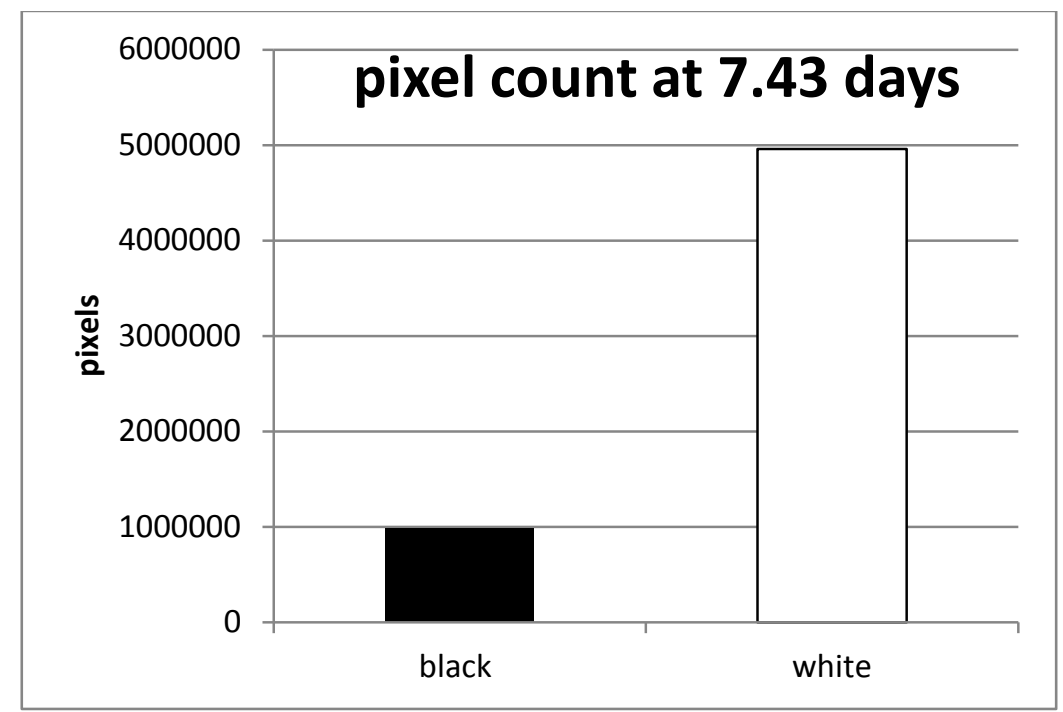

Figure 34 pixel count of binary image at 7.43 days

The next step was to determine the length of cracks for the three sample days at 3.47 days, 6.81 days and 7.43 days respectively. This was done by first overlaying the cracks with straight rectangular lines using the Paint program (figures 35, 36). These images were then converted into grayscale using Matlab function (I=rgb2gay(RGB)) where 'RGB' 
is the name of the image to be transformed and 'I' is the transformed image. These were then converted into binary images using the Matlab function (BW=im2bw(l, level)) where 'I' is the image to be transformed, 'level' is the threshold and 'BW' is the new image. These were then skeletalized using the Matlab function (BW3 = bwmorph(BW,'skel',Inf)) where 'BW' is the image to be transformed and 'BW3' is the transformed image. The number of pixels were then counted to determine the length of the cracks. It was assumed that the skeletal lines resulting from the straightened crack delineations were an accurate representation of real crack length.

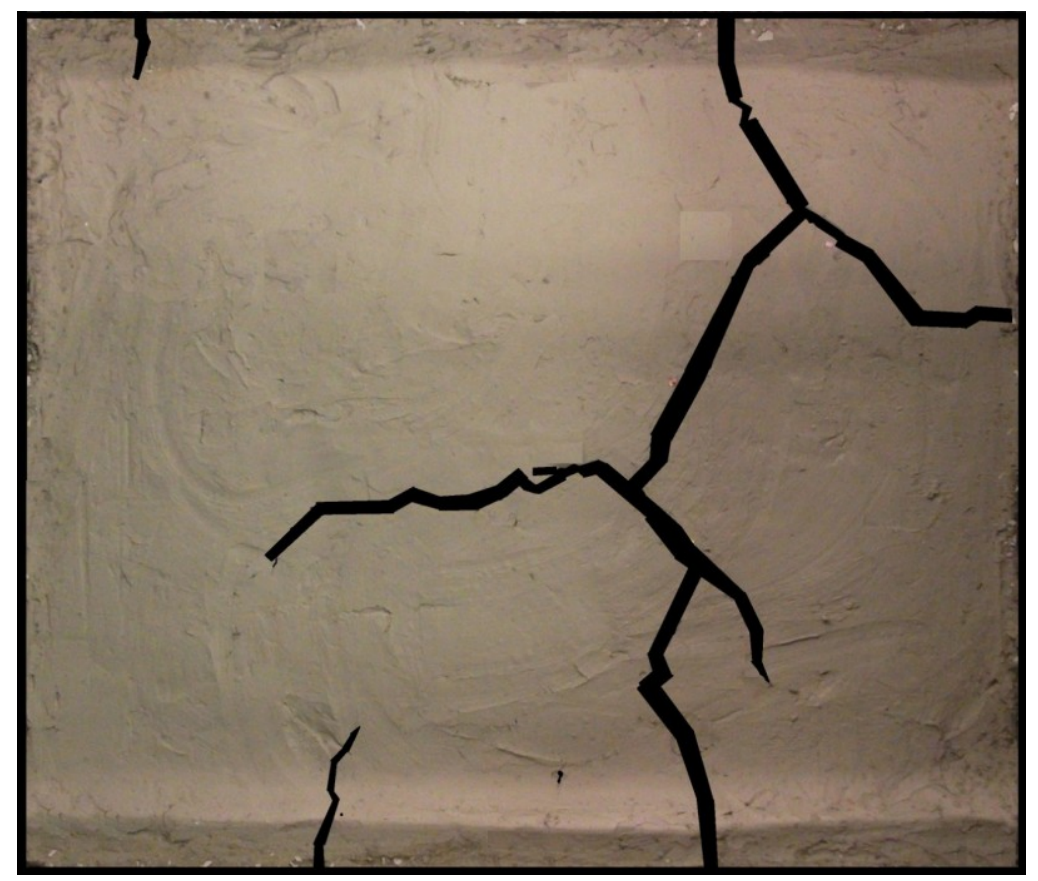

Figure 35 linearization of crack openings at 3.47 days 


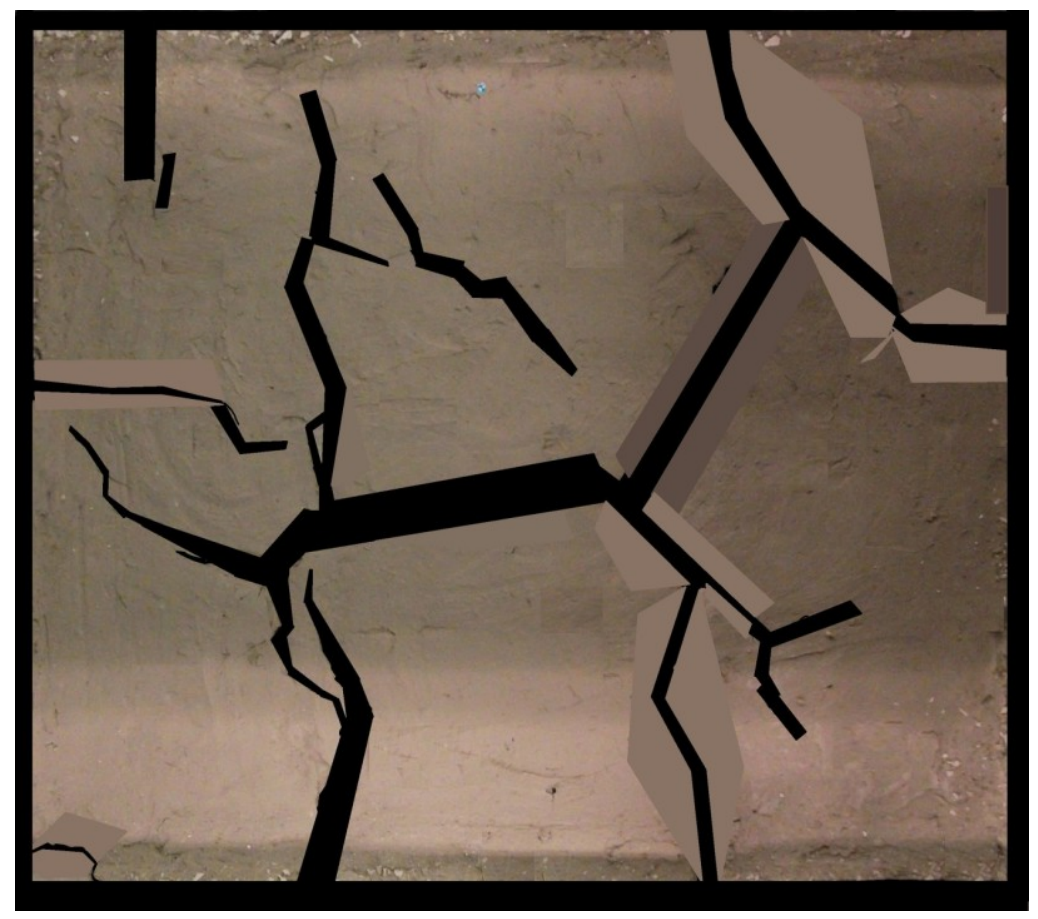

Figure 36 linearization of crack openings at 6.81 days

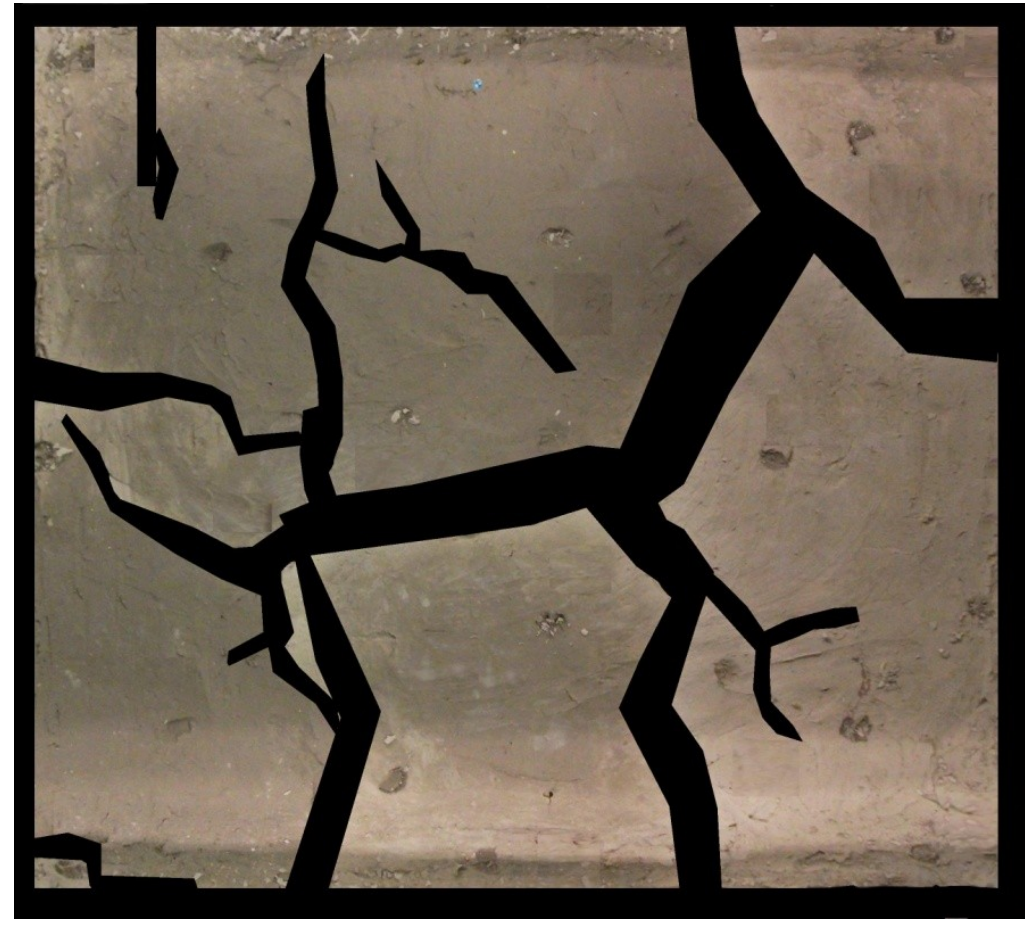

Figure 37 linearization of crack openings at $\mathbf{7 . 4 3}$ days 


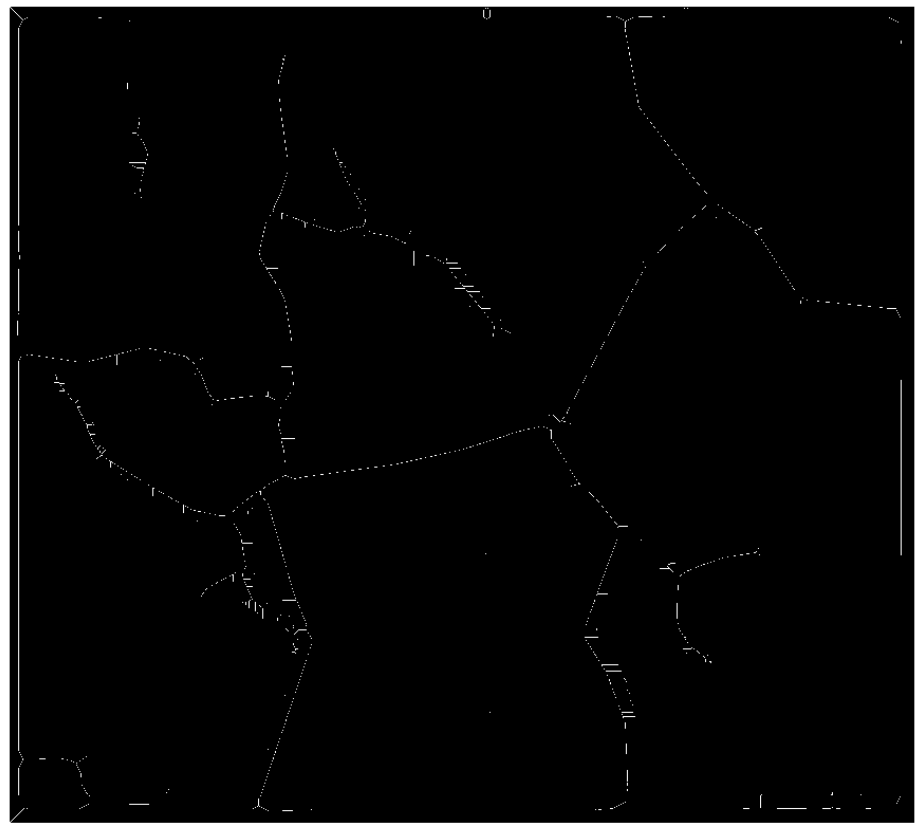

Figure 38 skeletalization of crack openings at 6.47 days

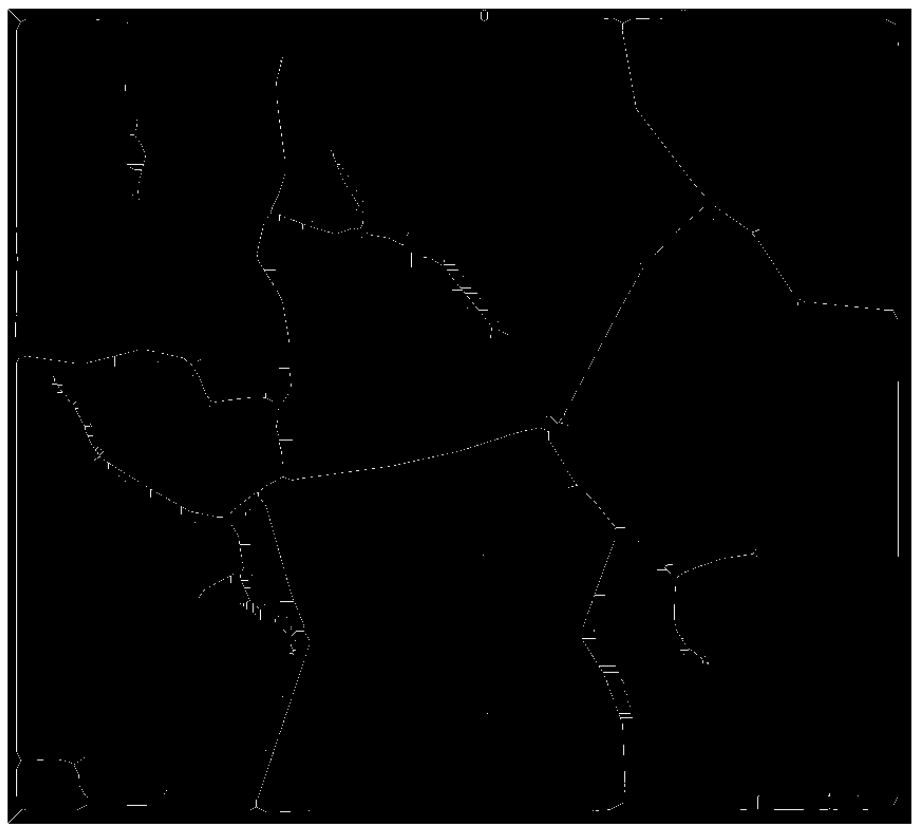

Figure 39 skeletalization of crack openings at 7.43 days 
At 3.47 days, 6.81 days and 7.43 days, an average of 24 surface samples were taken from the drying specimen and tested into the suction machine (WP4-T Dewpoint Potentiameter) for readings of total suction. These were then put into ovens for determination of moisture content. The location of these surface soil samples were marked and photographed.

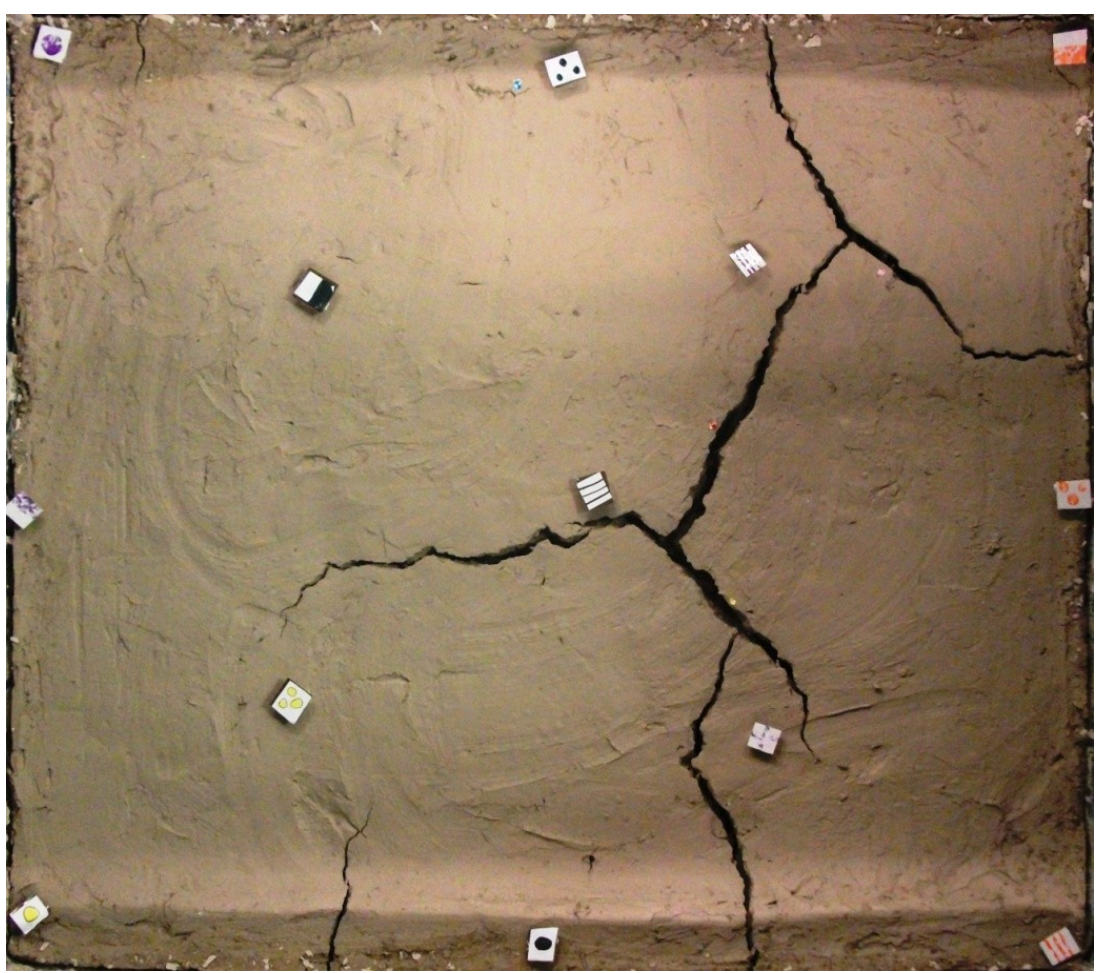

Figure $\mathbf{4 0}$ locations of surface clay samples for suction analysis at $\mathbf{3 . 4 7}$ days 


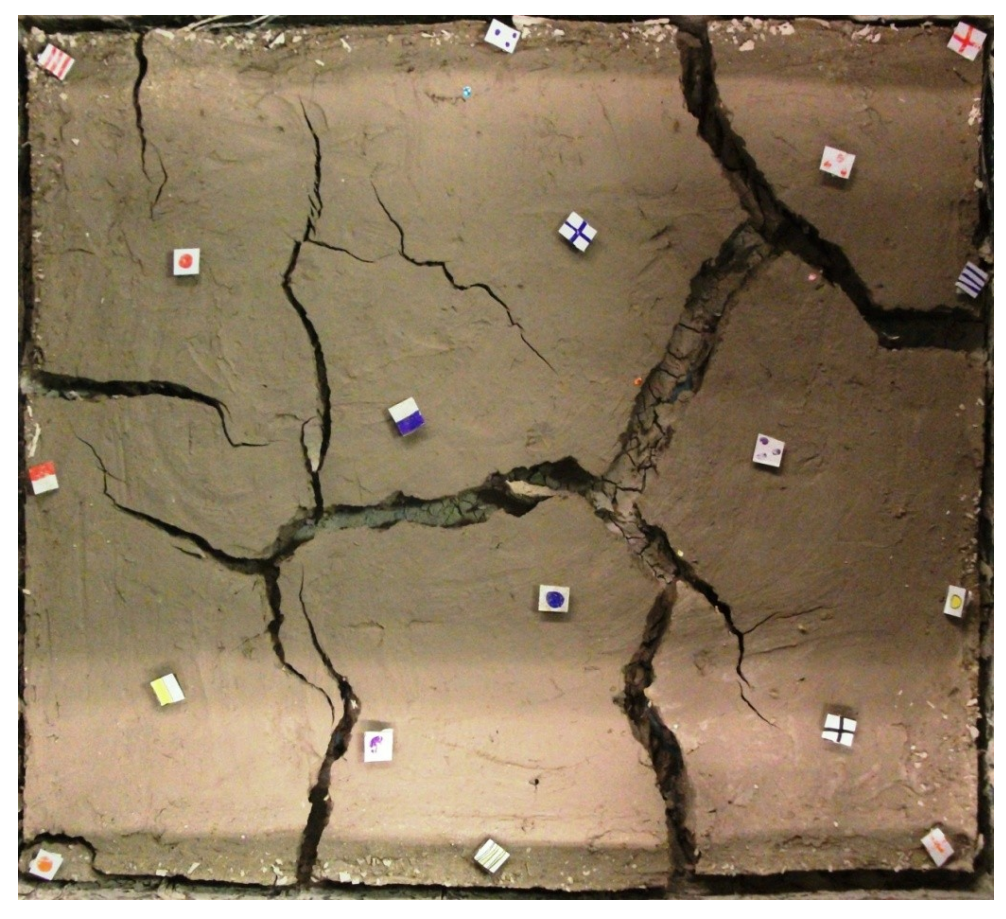

Figure 41 locations of surface clay samples for suction analysis at 6.81 days

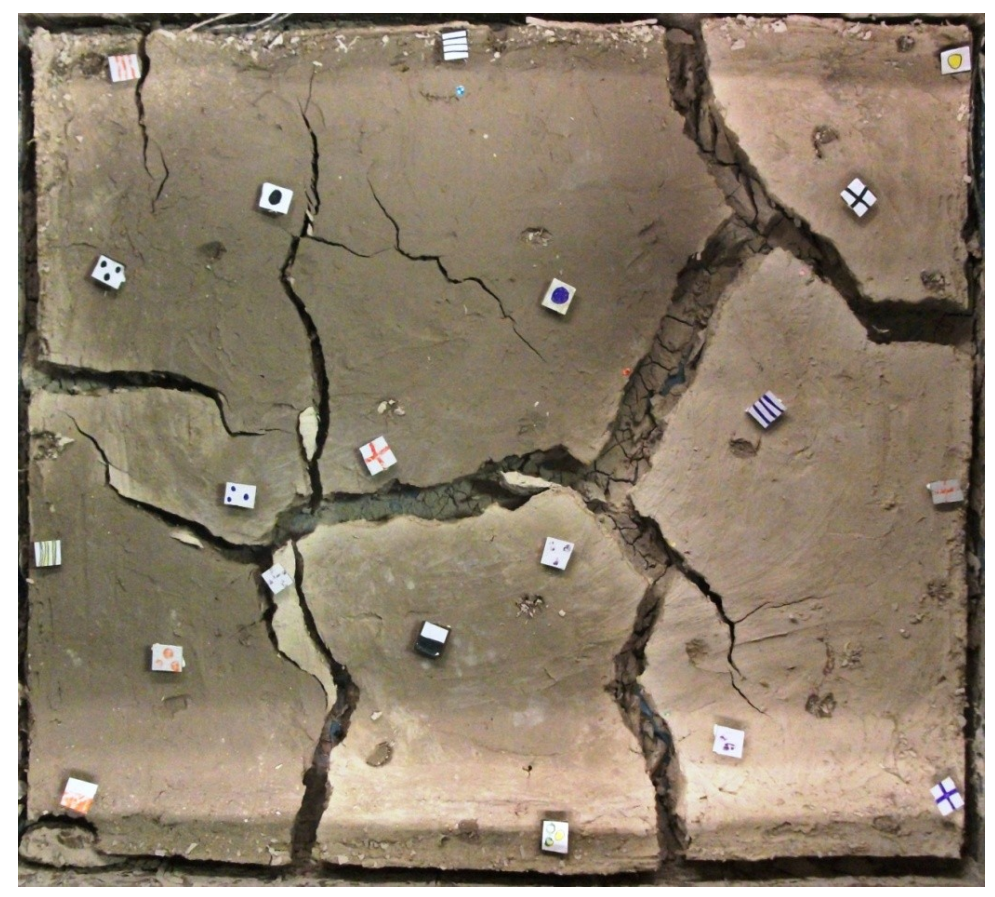

Figure 42 locations of surface clay samples for suction analysis at 7.43 days 


\begin{tabular}{|lrc|}
\hline \# & $\boldsymbol{\Psi}[\mathrm{Mpa}]$ & $\mathbf{w} \%$ \\
\hline 1 & 0.06 & 36.10921 \\
\hline 2 & 0 & 41.06833 \\
\hline 3 & 0.21 & 9.762406 \\
\hline 4 & 0 & 43.79511 \\
\hline 5 & 0.09 & 41.73656 \\
\hline 6 & 0.02 & 44.82161 \\
\hline 7 & 0.1 & 42.21883 \\
\hline 8 & 0.05 & 36.80456 \\
\hline 9 & 0.45 & 42.22087 \\
\hline 10 & 0 & 41.47721 \\
\hline 11 & 0.11 & 39.77981 \\
\hline 12 & 0.05 & 40.80765 \\
\hline 13 & 0.4 & 34.95823 \\
\hline
\end{tabular}

Table 5 Surface suction at 3.47 days

\begin{tabular}{|rrr|}
\hline \# $\boldsymbol{\Psi}$ & $\begin{array}{c}\boldsymbol{\Psi} \\
\text { [Mpa] }\end{array}$ & \multicolumn{1}{c|}{$\mathbf{w} \%$} \\
\hline 1 & -2.5 & 24.90566 \\
\hline 2 & -5.69 & -200 \\
\hline 3 & -1.67 & 27.98982 \\
\hline 4 & -5.35 & 22.58065 \\
\hline 5 & -4.09 & 24.50495 \\
\hline 6 & -2.1 & 27.8826 \\
\hline 7 & -4.73 & 23.7069 \\
\hline 8 & -3.58 & 24.73958 \\
\hline 9 & -5.24 & 22.22222 \\
\hline 10 & -5.18 & -293.333 \\
\hline 11 & -4.21 & 21.8638 \\
\hline 12 & -2.24 & 26.72897 \\
\hline 13 & -1.16 & 29.06977 \\
\hline 14 & -1.45 & 28.96936 \\
\hline 15 & -1.92 & 25.37879 \\
\hline 16 & -1.77 & 24.89177 \\
\hline 17 & -1.26 & 26.97368 \\
\hline 18 & -2.46 & 26.19048 \\
\hline
\end{tabular}

Table 6 Surface suction at 6.81 days 


\begin{tabular}{|rrr|}
\hline \multirow{4}{*}{$\boldsymbol{\Psi}$} & $\begin{array}{c}\boldsymbol{\Psi} \\
{[\mathbf{M p a}]}\end{array}$ & $\mathbf{w} \%$ \\
\hline 1 & -6.68 & 15.70827 \\
\hline 2 & -5.9 & 19.58637 \\
\hline 3 & -6.03 & 16.66667 \\
\hline 4 & -4.19 & 24.11765 \\
\hline 5 & -2.6 & 25.5688 \\
\hline 6 & -4.57 & 23.64621 \\
\hline 7 & -5.33 & 21.09005 \\
\hline 8 & -6.69 & 16.16314 \\
\hline 9 & -5.57 & 19.21296 \\
\hline 10 & -3.9 & 23.94068 \\
\hline 11 & -5.66 & 19.11469 \\
\hline 12 & -3.6 & 25.03277 \\
\hline 13 & -4.99 & 20.67594 \\
\hline 14 & -6.13 & 18.93333 \\
\hline 15 & -4.32 & 24.0458 \\
\hline 16 & -3.32 & 25.07837 \\
\hline 17 & -4.77 & 23.58318 \\
\hline 18 & -3.03 & 25.44379 \\
\hline 19 & -5.32 & 23.02905 \\
\hline 20 & -5.35 & 22.22222 \\
\hline Table 7 Surface suction at 7.43 days
\end{tabular}

The suction readings were then overlayed onto the image according to its recorded location. A contour map of suction was then generated through Matlab and the average surface suction was calculated by weighing the color-coded contours on matlab. The first step in creating the contour map was inserting the $x$ and $y$ data for the suction sampling points as $x=[x 1, x 2, x 3 \ldots]$ and $y=[y 1, y 2, y 3 \ldots]$. The suction values were input as the $z$ values $z=[z 1, z 2, z 3 \ldots]$. A meshgrid to contain this data was then created by first creating the $x$ axis $(x x=$ linspace $(1,2570,2570))$ and $y$ axis $(y y=l i n s p a c e(1,2286,2286))$. 2570 was the pixel width of the specimen image while 2286 was its pixel length. Meshgrid was then created as $[X, Y]=$ meshgrid( $x x, y y)$. The suction data was then input as 
height $Z(Z=$ griddata $(x, y, Z, X, Y))$. The contour map was then created by the Matlab function (contour $(X, Y, Z, 9)$ ) which created line-based contour maps of the sampling surface at 6.81 days (figure 43) and 7.43 days (figure 44). It was unnecessary to further analyse the specimen surface at 3.47 days because all suction values were nearly at zero, and so theoretically, evaporation was still roughly equivalent to potential evaporation.

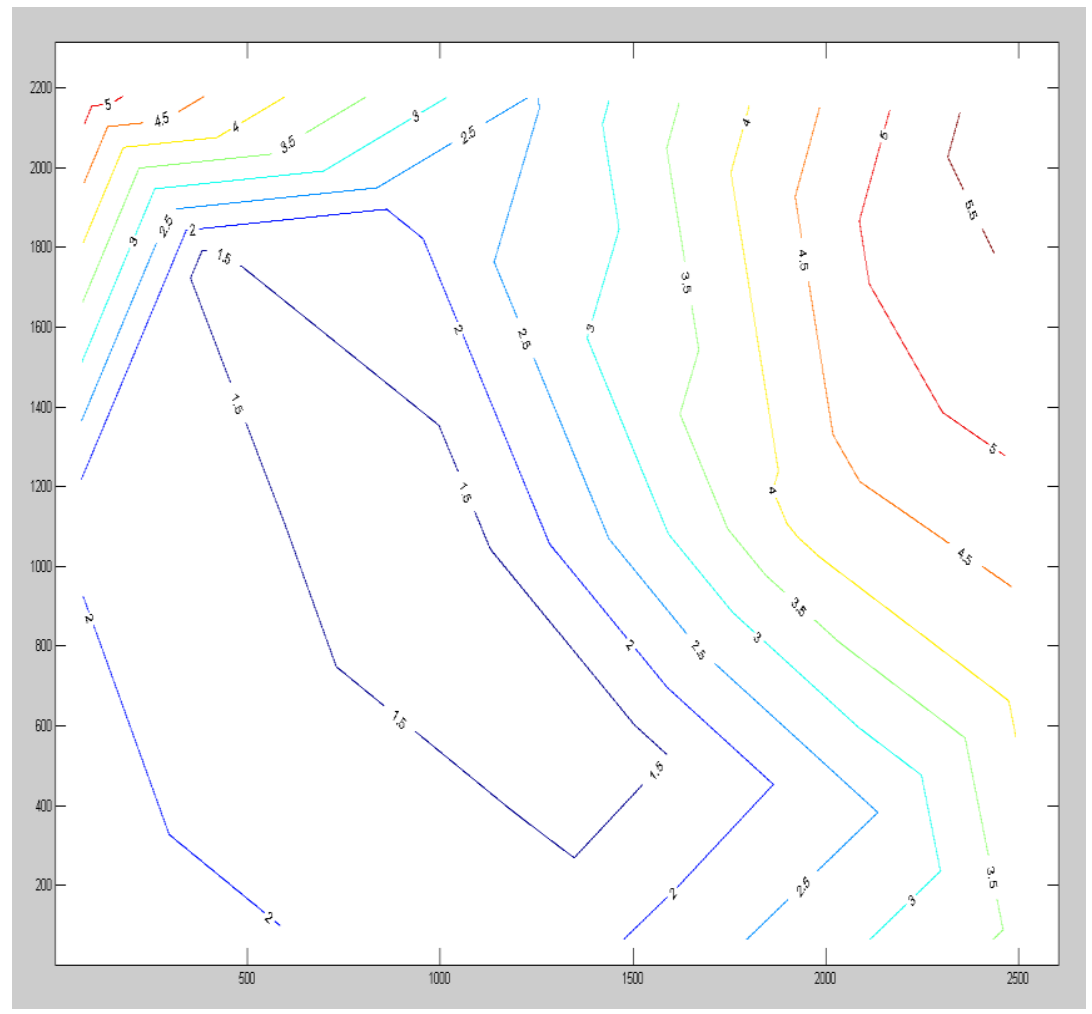

Figure 43 contour map of matric suction on clay specimen surface at 6.81 days 


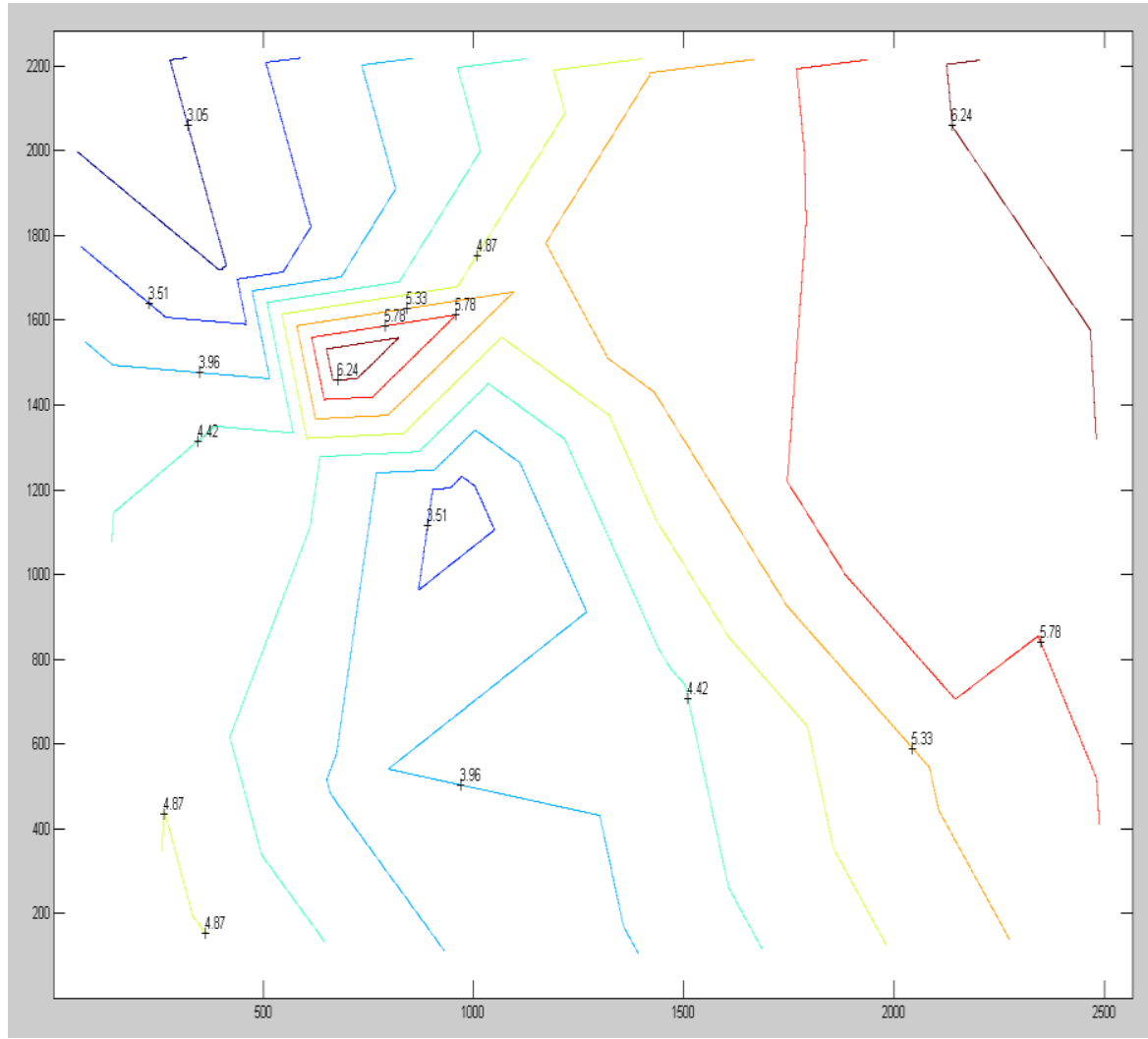

Figure 44 contour map of matric suction on clay specimen surface at 7.43 days 
The objective of the contour maps is to determine what the average surface suction was at time 9,800 minutes and 10,700 minutes. The contour maps were therefore overlaid onto the planar binary specimen images and the spaces between contour lines were filled with their respective colours (figures 45,46 ), depending on the suction value. Histograms were generated (figures 47,48 ) that calculated the pixel area of each colour was and the colour-coded suction was weighted and averaged to determine the total average suction (tables 8,9 ) for the surface at these times. Given that the boundary lines were black, they were voided in the readings for total suction, this had the effect of underestimating total surface suction.

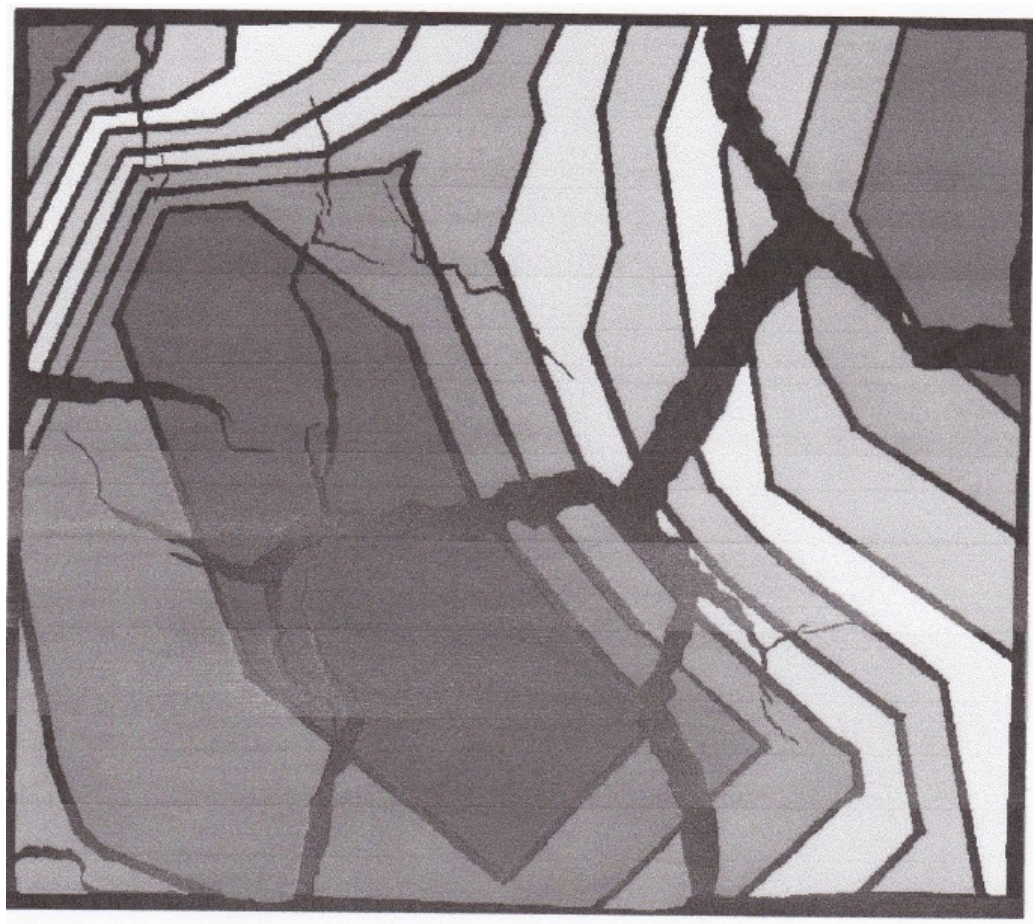

Figure 45 colour coded contour map of matric suction on clay specimen surface at 6.81 days 


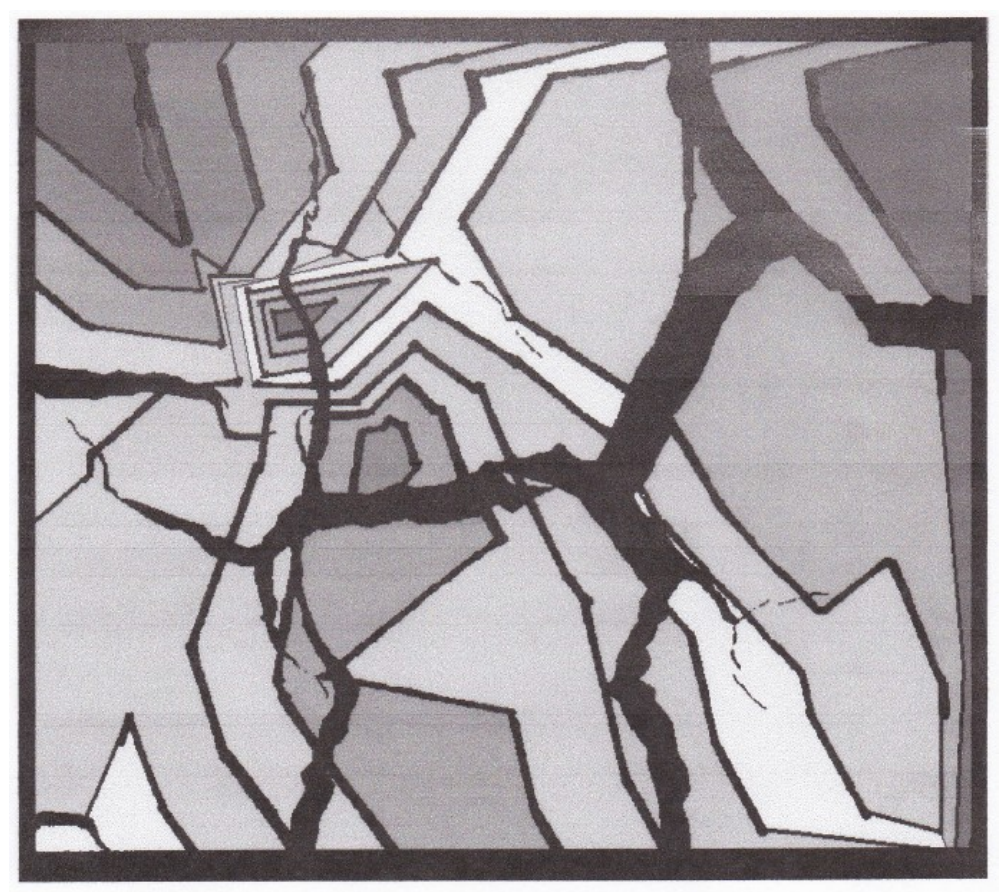

Figure 46 colour coded contour map of matric suction on clay specimen surface at $\mathbf{7 . 4 3 d}$ days
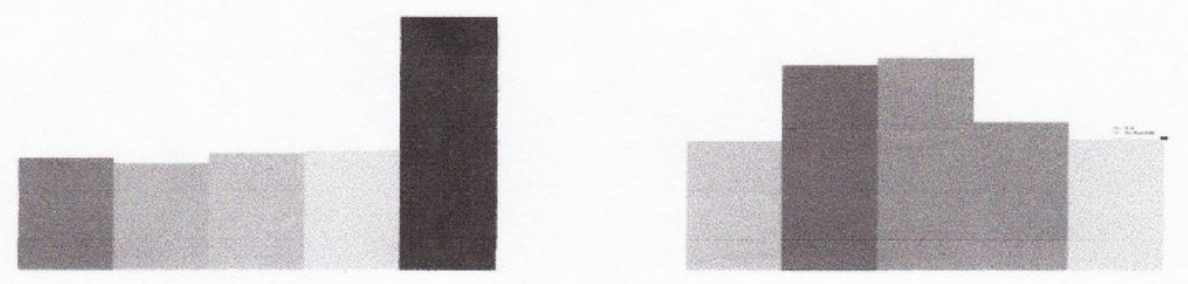

Figure 47 color histogram of color coded suction contour map at 6.81 days

\begin{tabular}{|c|c|c|c|c|c|c|c|c|c|c|c|c|c|}
\hline & $\begin{array}{l}\text { Color } \\
1\end{array}$ & $\begin{array}{l}\text { Color } \\
2 \\
\end{array}$ & $\begin{array}{l}\text { Color } \\
3 \\
\end{array}$ & $\begin{array}{l}\text { Color } \\
4 \\
\end{array}$ & $\begin{array}{l}\text { Color } \\
5 \\
\end{array}$ & $\begin{array}{l}\text { Color } \\
6 \\
\end{array}$ & $\begin{array}{l}\text { Color } \\
7 \\
\end{array}$ & $\begin{array}{l}\text { Color } \\
8 \\
\end{array}$ & $\begin{array}{l}\text { Color } \\
9\end{array}$ & $\begin{array}{l}\text { Color } \\
10 \\
\end{array}$ & $\begin{array}{l}\text { Color } \\
11 \\
\end{array}$ & $\begin{array}{l}\text { Color } \\
12 \\
\end{array}$ & total \\
\hline pt. $2 \Psi$ & 5.5 & 5 & 4.5 & 4 & 0 & 0 & 0 & 3.5 & 1.5 & 2 & 2.5 & 3 & \\
\hline $\begin{array}{l}\text { pt. } 2 \\
\text { pixel }\end{array}$ & 0.44 & 0.4198 & 0.4618 & 0.4769 & 0 & 0 & 0 & 0.5124 & 0.8098 & 0.8404 & 0.5875 & 0.5248 & 5.0734 \\
\hline$\%$ pixel & 0.08673 & 0.08275 & 0.09102 & 0.094 & 0 & 0 & 0 & 0.101 & 0.15962 & 0.165648 & 0.1158 & 0.103441 & \\
\hline $\begin{array}{l}\text { weighted } \\
\Psi\end{array}$ & 0.477 & 0.41373 & 0.40961 & 0.376 & 0 & 0 & 0 & 0.35349 & 0.23943 & 0.331297 & 0.2895 & 0.310324 & 3.200369 \\
\hline
\end{tabular}

Table 8 Weighing of color-coded surface suction 

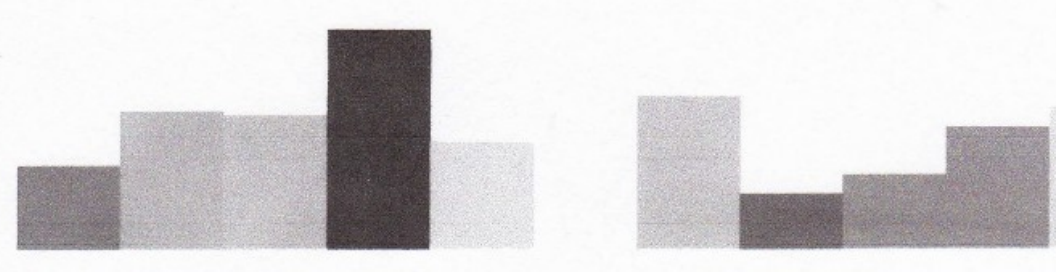

Figure 48 color histogram of color coded suction contour map at 7.43 days

\begin{tabular}{|c|c|c|c|c|c|c|c|c|c|c|c|c|}
\hline & $\begin{array}{l}\text { Color } \\
1 \\
\end{array}$ & $\begin{array}{l}\text { Color } \\
2 \\
\end{array}$ & $\begin{array}{l}\text { Color } \\
3 \\
\end{array}$ & $\begin{array}{l}\text { Colo } \\
\text { r } 4 \\
\end{array}$ & $\begin{array}{l}\text { Color } \\
5 \\
\end{array}$ & $\begin{array}{l}\text { Color } \\
6 \\
\end{array}$ & $\begin{array}{l}\text { Color } \\
7 \\
\end{array}$ & $\begin{array}{l}\text { Color } \\
8 \\
\end{array}$ & $\begin{array}{l}\text { Color } \\
9 \\
\end{array}$ & $\begin{array}{l}\text { Color } \\
10 \\
\end{array}$ & $\begin{array}{l}\text { Color } \\
11 \\
\end{array}$ & total \\
\hline pt. $3 \Psi$ & 6.24 & 5.78 & 5.33 & null & 4.87 & null & 4.42 & 3.05 & 3.51 & 3.96 & 4.42 & \\
\hline $\begin{array}{l}\text { pt. } 3 \\
\text { pixel }\end{array}$ & 0.3758 & 0.6269 & 0.6122 & 0 & 0.4878 & 0 & 0.6974 & 0.2496 & 0.3356 & 0.5575 & 0.6581 & 4.6009 \\
\hline$\%$ color & $\begin{array}{r}0.0816 \\
8\end{array}$ & $\begin{array}{r}0.1362 \\
6\end{array}$ & $\begin{array}{r}0.1330 \\
6\end{array}$ & 0 & $\begin{array}{r}0.1060 \\
2\end{array}$ & 0 & $\begin{array}{r}0.1515 \\
8\end{array}$ & $\begin{array}{r}0.0542 \\
5\end{array}$ & $\begin{array}{r}0.0729 \\
4\end{array}$ & $\begin{array}{r}0.12117 \\
2\end{array}$ & $\begin{array}{r}0.14303 \\
7\end{array}$ & \\
\hline $\begin{array}{l}\text { weighte } \\
\text { d } \Psi\end{array}$ & $\begin{array}{r}0.5096 \\
8\end{array}$ & $\begin{array}{r}0.7875 \\
6\end{array}$ & $\begin{array}{r}0.7092 \\
2\end{array}$ & 0 & $\begin{array}{r}0.5163 \\
3\end{array}$ & 0 & $\begin{array}{r}0.6699 \\
8\end{array}$ & $\begin{array}{r}0.1654 \\
6\end{array}$ & $\begin{array}{r}0.2560 \\
3\end{array}$ & $\begin{array}{r}0.47984 \\
1\end{array}$ & $\begin{array}{r}0.63222 \\
5\end{array}$ & $\begin{array}{r}4.72632 \\
1\end{array}$ \\
\hline
\end{tabular}

Table 9 Weighing of color-coded surface suction

In tables 8 and 9, the succession of the colors in the color row is in line with the succession of the colors in their respective histograms above. The black, grey and white bars did not represent any suction value, but rather the contour lines themselves or blank spaces. Their respective suction values were given as nill and they were not taken into account into the weighting calculations. Average surface suction was then used to determine theoretical evaporation of intact horizontal surface. By knowing the total evaporation from the scales, evaporation from vertical surface of cracks was calculated by subtracting theoretical evaporation of intact horizontal surface from total evaporation.

The next stage consisted of taking regular readings of specimen thickness and of monitoring the deepening of cracks. The former was done daily for the duration of the whole experiment and an example reading taken with the laser scanner can be seen in Figure 49. The latter was achieved roughly every second hour. An example of the laser 
scanner's 2-dimensional reading of a crack opening can be seen in figure 50 . The laser scanner can sense the depth as the distance between the laser head and the surface reached by the laser beam. The greater the distance between the laser head and the surface, the greater the spread between data points and the wider the beam-line which hits the surface. As a result, as shrinkage progressed, the width of the laser beam which was read increased.

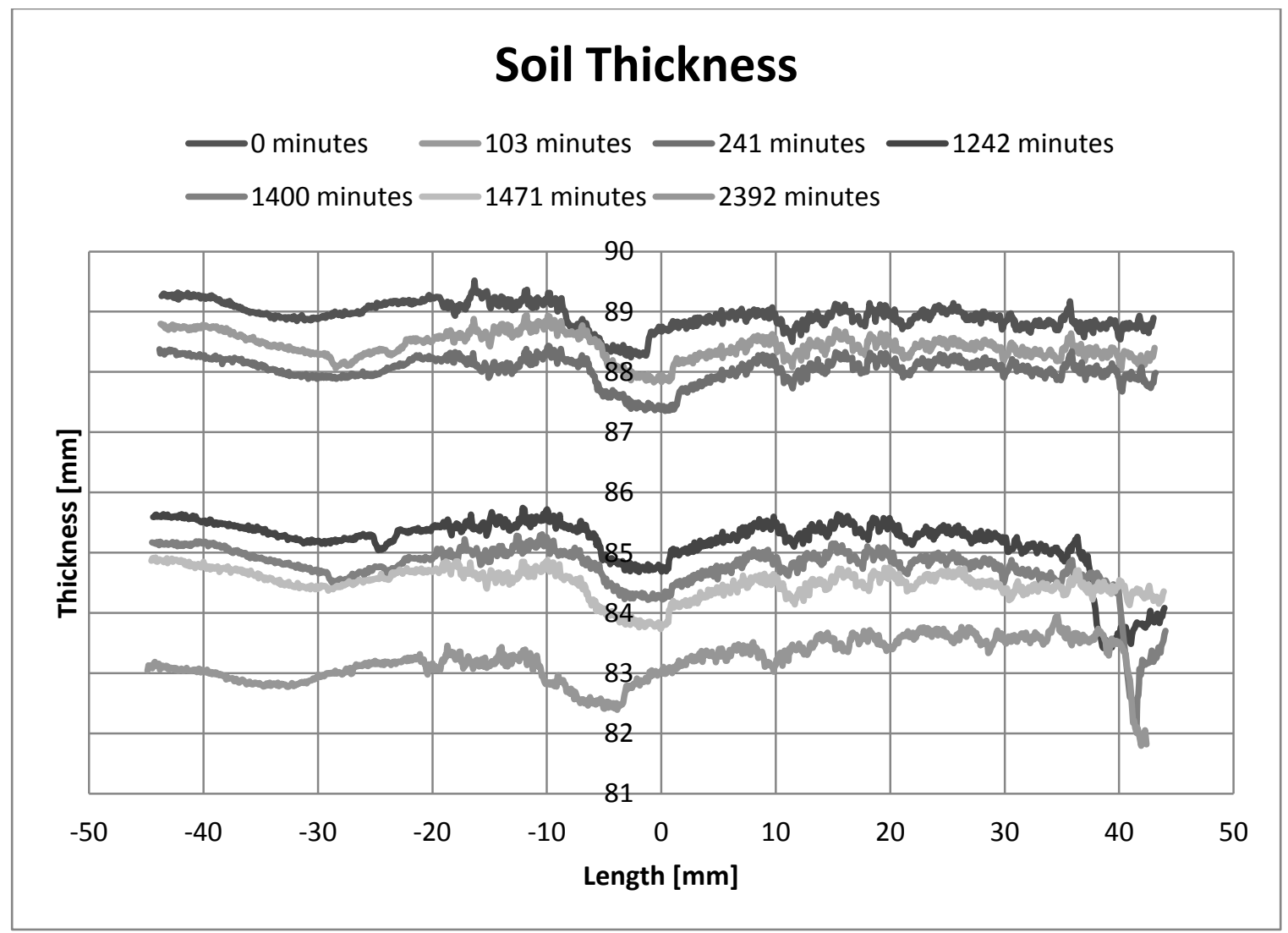

Figure 49 central readings of specimen thickness 


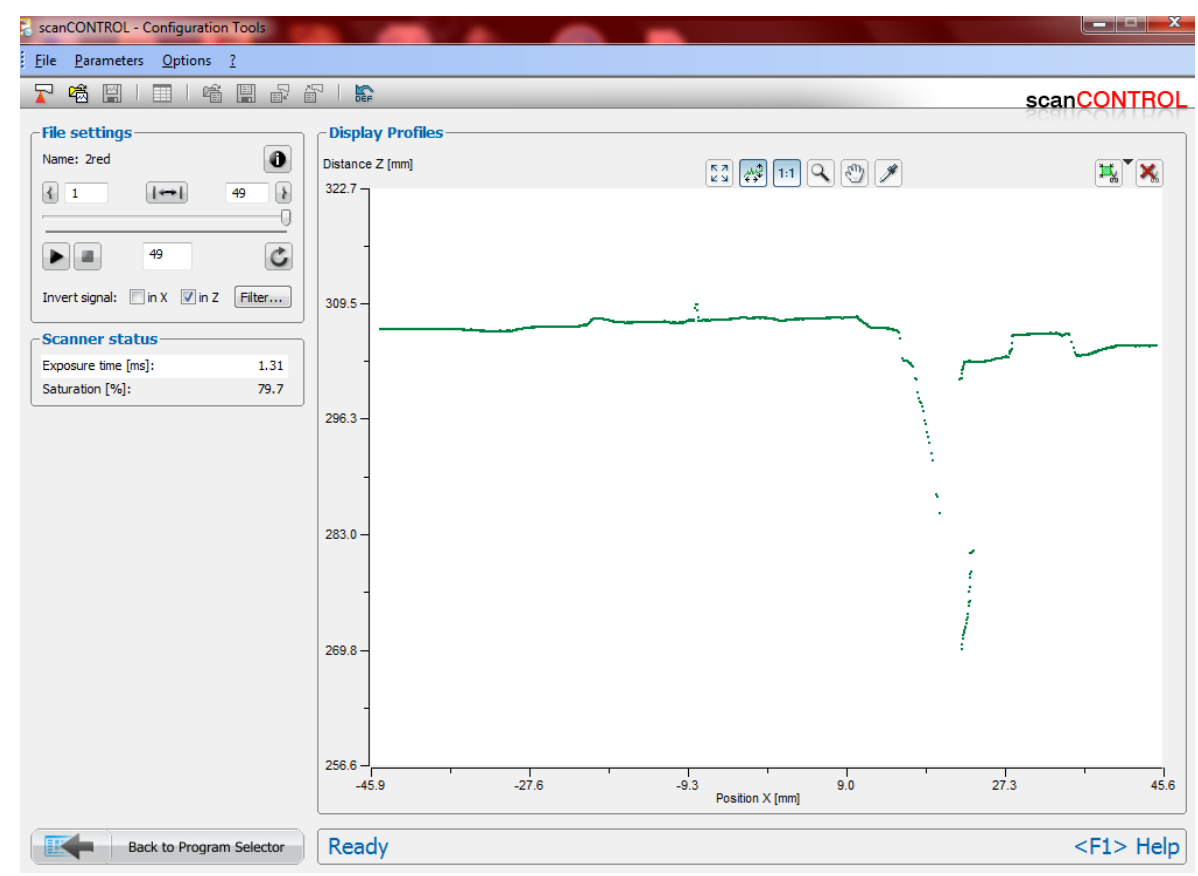

Figure 50 laser scanner reading of crack opening

\section{Experimental Results \& Discussion}

\subsection{Chertkov's Model}

Five cracks were color-coded and monitored with the laser scanner. Chertkov's curve, which has evolving crack depth as an abscissa and time as the ordinate, was created using the collected data on crack evolution. The sensitivity analysis has shown the great dependence of the modeled crack propagation on diffusivity. When the lower limit of crack depth $I_{*}$ (minimum crack dimension) was taken as $1 \mathrm{~mm}$. Based on various equations provided by Chertkov (2002.a), I* could be estimated as a function of crack spacing, or crack depth after initial jump $\left(L_{a v}=5.72 I_{*}, L_{a v}\right.$ taken to be the first visually 
detectable crack. This gave an $\mathbf{I}_{*}$ anywhere from 0.3 to $6 \mathrm{~mm}$. However, $\mathbf{I}_{*}$ should also be smaller than any crack after jump, so a value of $1 \mathrm{~mm}$ was chosen.

The value of diffusivity corresponding to the state of the clay during crack development was determined from the in-situ SWCC (as determined by samples of totals suction and GWC taken at the surface) for the range less than $1 \mathrm{MPa}$ (appendix A), and using values of hydraulic conductivity of kaolinite clay taken from the literature (For example, Chertkov, 2002.a). This gave a range of diffusivity of $0.6-6 \mathrm{~mm}^{2} / \mathrm{min}$ corresponding to a range of hydraulic conductivity values from $10^{-9}$ to $10^{-10} \mathrm{~m} / \mathrm{s}$. .

Crack development was predicted using Equation 57 from the literature review.

$$
\begin{aligned}
& t=\frac{\pi^{3} l_{*} l}{16 D} \\
& \text { Equation } 85
\end{aligned}
$$

However, when the range of diffusivity estimated in the previous section (0.6-6 $\mathrm{mm}^{2} / \mathrm{min}$ ) was used to predict the speed of crack propagation, the predicted rate of crack development was much faster than measured. The same was true when the diffusivity used by Chertkov for drying clays $\left(15 \mathrm{~mm}^{2} / \mathrm{min}\right)$ was used. However, when the diffusivity was decreased by one order of magnitude to $0.06 \mathrm{~mm}^{2} / \mathrm{min}$, a good fit was obtained for all five cracks, despite there being a range of crack initiation times.

As seen below, Chertkov's equation failed to accurately model the observed evolution of cracks for acceptable diffusivities. Reasons for this are discussed below. It can be noted that in some data points in the graphs below, crack length seems to decrease over time. 
This was evidently not the case, rather the laser scanner's laser beam was blocked by soil irregularities and hence failed to penetrate the full depth of cracks in these instances. The general evolution of the propagating crack is however clear to see from the totality of the graphs. The cracks were color coded on the clay surface and were named according to their respective color (figure 51).

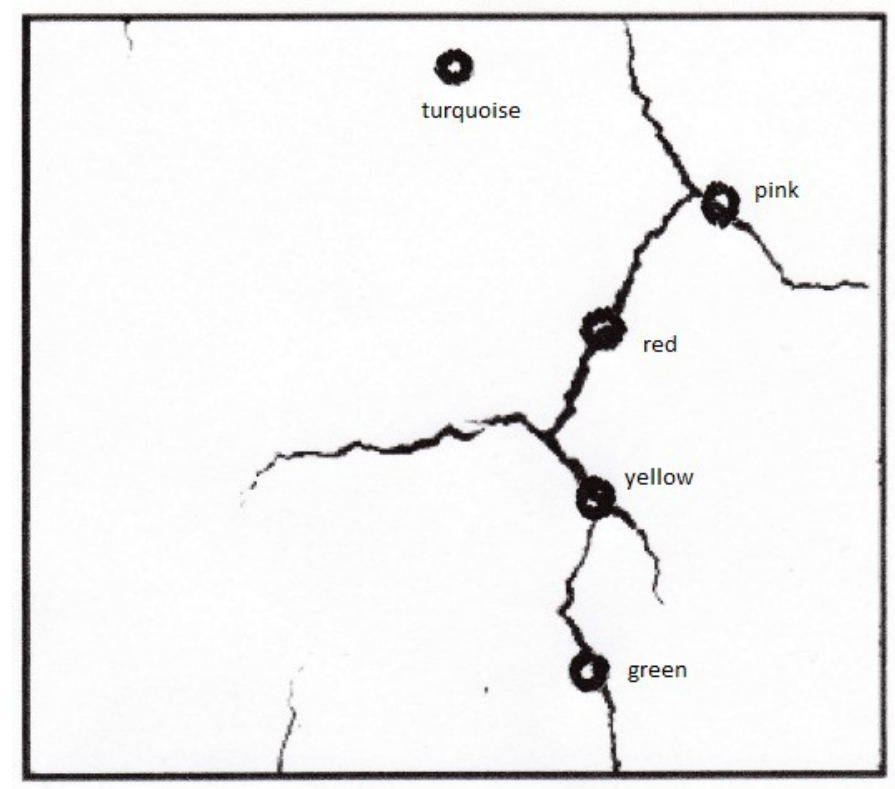

Figure 51 locations of observed cracks

\subsubsection{Calculated Diffusivities}

Below, Chertkov's model was graphed according to 3 diffusivities; the one given by Chertkov for drying Kaolinite clay, the one calculated from the data according to Gardner and Hillel's (1962) method and the diffusivity calculated by dividing saturated hydraulic conductivity by the slope of moisture over suction. The three diffusivities respectively are $222.1 \mathrm{~cm}^{2} / \mathrm{d}, 86.4 \mathrm{~cm}^{2} / \mathrm{d}$ and $0.8 \mathrm{~cm}^{2} / \mathrm{d}$. It should be noted that the last diffusivity was obtained by using a saturated hydraulic conductivity that is one 
magnitude lower than the average range for kaolinite clays. As seen below, when both of the first two diffusivities were applied, Chertkov's model (Chertkov, 2002.a) failed to represent the empirical data. When the final diffusivity was applied, however, it accurately represented the experimental data.

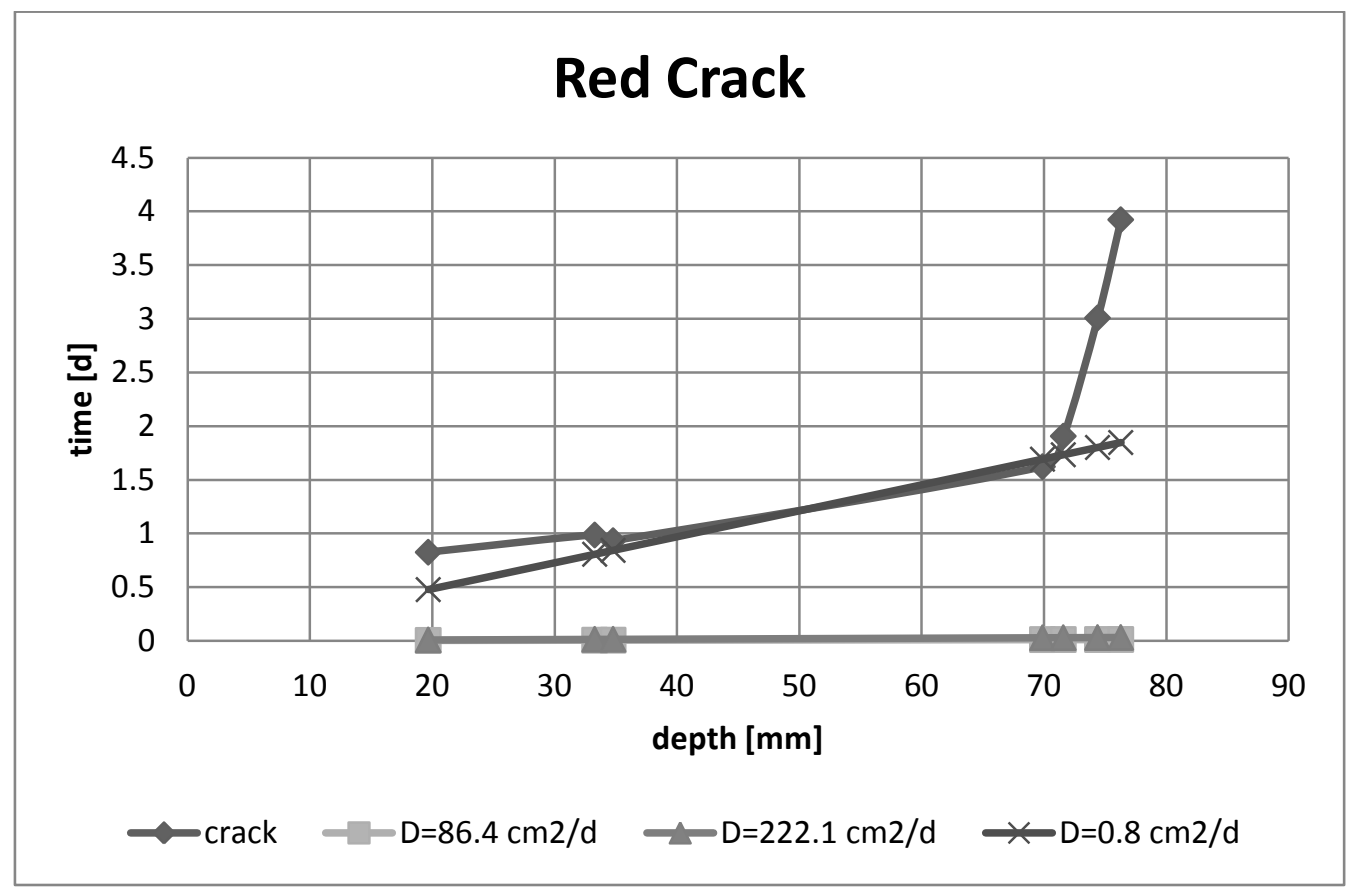

Figure 52 Chertkov's model applied to the red crack 


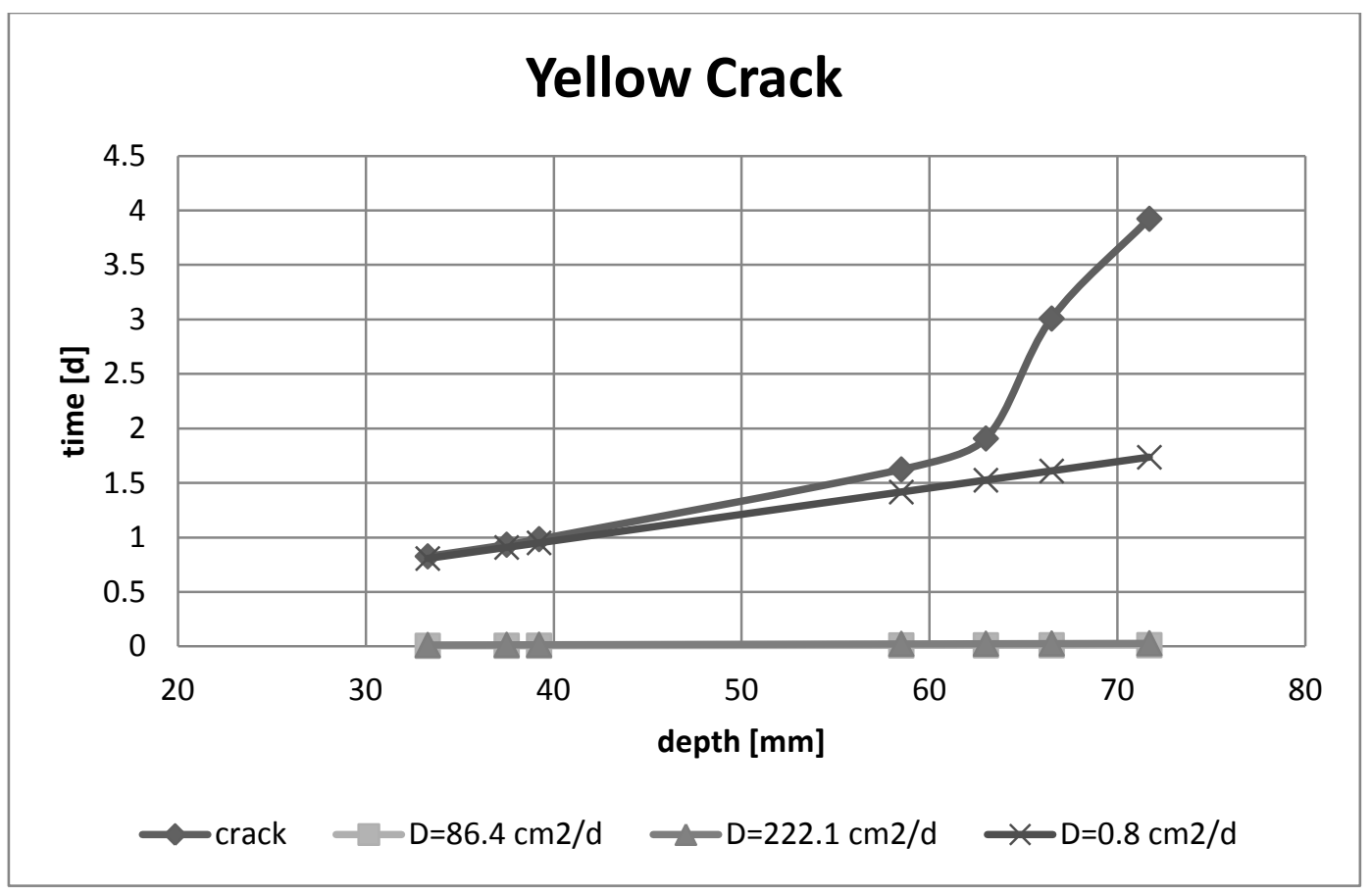

Figure 53 Chertkov's model applied to the yellow crack

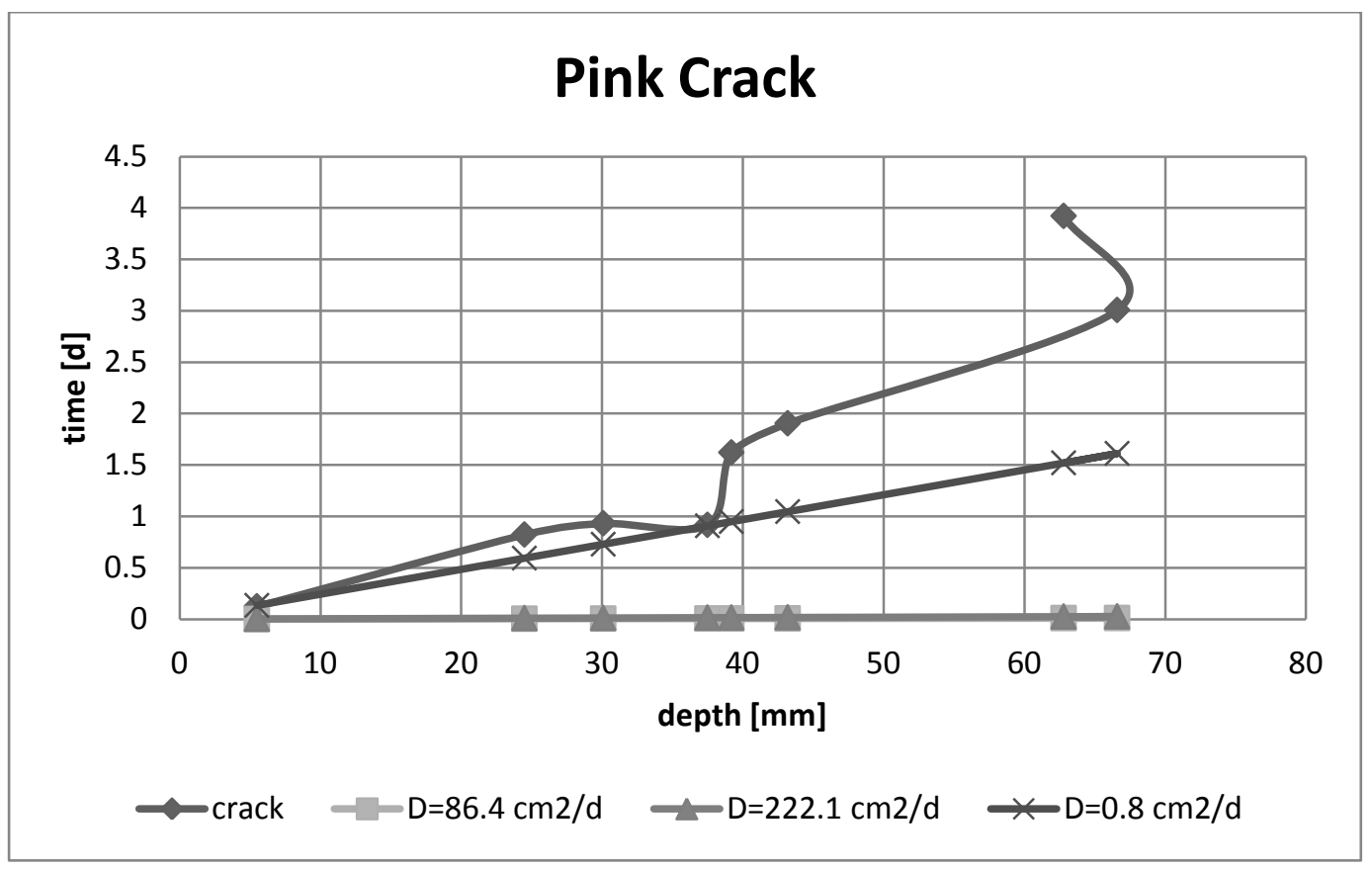

Figure 54 Chertkov's model applied to the pink crack 


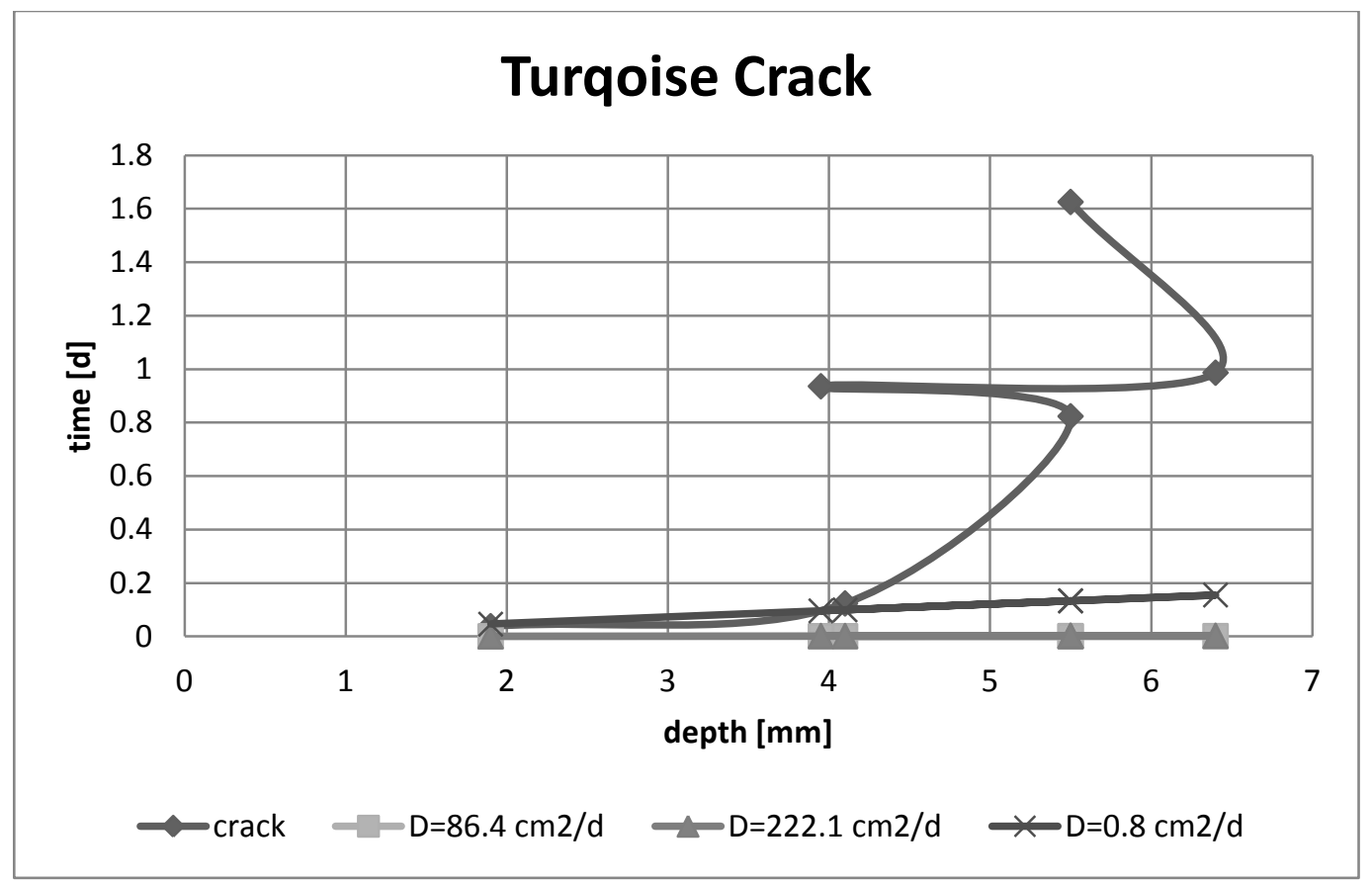

Figure 55 Chertkov's model applied to the turqoise crack

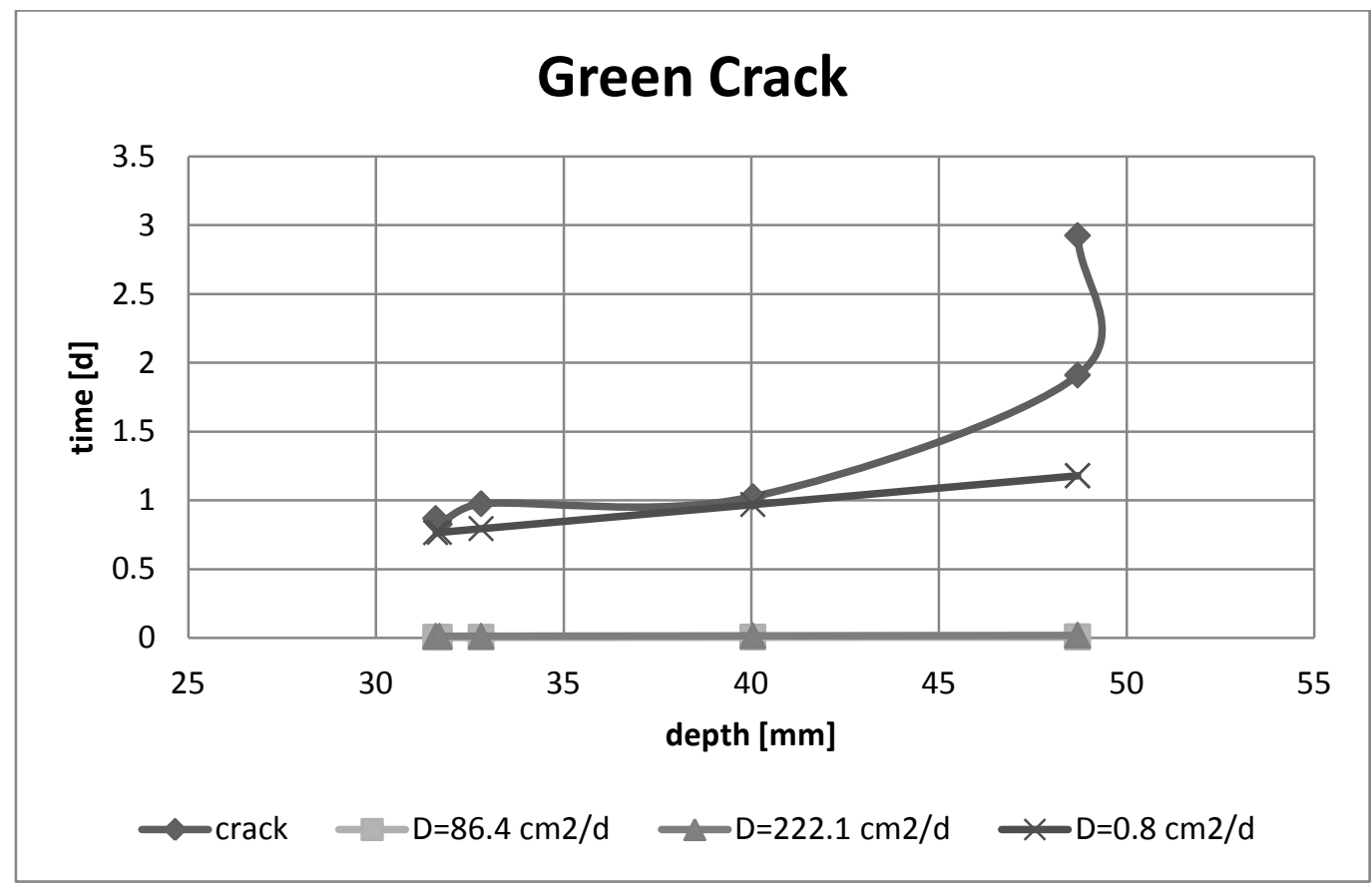

Figure 56 Chertkov's model applied to the green crack 
Four parameters which can be calculated from diffusivity and minimum crack dimension according to Chertkov's equations were verified, these were average distance between primary cracks $S_{0}$, average initial crack depth $\mathbf{L}_{\text {avg, }}$ average time of crack initiation $\mathbf{T}_{\text {avg }}$ and the velocity of vertical crack propagation $\mathbf{U}$.

\begin{tabular}{cl}
\hline $\begin{array}{c}\text { Derived } \\
\text { Parameters }\end{array}$ & \multicolumn{1}{c}{ Transformation } \\
\hline $\mathrm{S}_{0}$ & $\mathrm{~S}_{0}=\left(\mathrm{K}_{*}+1\right) \mathrm{I}_{*} \approx 6 \mathrm{I}_{*}$ \\
$\mathrm{~L}_{\mathrm{avg}}$ & $\mathrm{L}_{\mathrm{avg}} \approx 5.72 \mathrm{I}_{*}$ \\
$\mathrm{~T}_{\mathrm{avg}}$ & $\mathrm{T}_{\mathrm{avg}}=11.10\left(\mathrm{I}^{2} / \mathrm{D}\right)$ \\
$\mathrm{u}$ & $\mathrm{u}=16 \mathrm{D} /\left(\pi^{3} \mathrm{I}_{*}\right)$ \\
\hline
\end{tabular}

Table 10 Chertkov Relations

The average crack depth at initiation ( $L_{\text {avg }}$ ) was $18.398 \mathrm{~mm}$ (appendix b). A minimum crack dimension of $1 \mathrm{~mm}$ yielded an $\mathrm{L}_{\mathrm{avg}}$ of $5.75 \mathrm{~mm}$. Average time at crack initiation was 772.4 minutes or 0.563 days. Calculated $\mathbf{T}_{\text {avg }}$ varied from 0.72 minutes to 200 minutes, all of which are far off from the experimental value.

\begin{tabular}{|c|c|}
\hline $\begin{array}{l}\text { D } \\
{\left[\mathrm{mm}^{2} / \mathrm{min}\right]}\end{array}$ & $\begin{array}{l}\text { Tavg } \\
\text { [min] }\end{array}$ \\
\hline 15.4 & 0.72 \\
\hline 6 & 1.85 \\
\hline 0.0556 & 200 \\
\hline
\end{tabular}

Table 11 Calculated times of crack initiation

Initial velocities were calculated in Appendix B and yielded an average velocity of 0.026 $\mathrm{mm} / \mathrm{min}$. It should be noted that velocities were not uniform which counters the validity of Chertkov's model (Chertkov, 2002.a). The velocity produced by Chertkov's model 
ranged from a high $7.96 \mathrm{~mm} / \mathrm{min}$ for a diffusivity of $15.4 \mathrm{~mm} / 2 \mathrm{~min}$ to $0.029 \mathrm{~mm} / \mathrm{min}$, which was very close to the experimental average.

\begin{tabular}{rr}
\hline$D$ & $U$ \\
{$\left[\mathrm{~mm}^{2} / \mathrm{min}\right]$} & {$[\mathrm{mm} / \mathrm{min}]$} \\
\hline 15.4 & 7.96 \\
$\mathbf{6}$ & 3.1 \\
0.0556 & 0.029 \\
\hline
\end{tabular}

Table 12 Calculated crack propagation velocities

Both the diffusivity calculated using Garnder and Hillel's (1962) method and the diffusivity given by Chertkov produced $\mathbf{T}_{\text {avg }}$ 's and $\mathbf{U}$ 's that were far removed from the actual $\mathbf{T}_{\text {avg }}$ and $\mathbf{U}$. When diffusivity was set at $0.0556 \mathrm{~mm}^{2} / \mathrm{min}$, the $\mathbf{T}_{\text {avg }}$ and $\mathbf{U}$ approached actual values.

Chertkov's model (Chertkov, 2002.a) also predicts spacing between primary cracks $\mathbf{S}_{\mathbf{0}}$. $\mathbf{S}_{\mathbf{0}}$ was calculated by measuring the average distance between primary crack nucleation sites circled in Figure 50, yielding an $S_{0}$ of $29 \mathrm{~cm}$ (appendix B). This compared poorly to the calculated $S_{0}$ of $0.6 \mathrm{~cm}$ for a minimum crack dimension of $1 \mathrm{~mm}$. When a minimum crack dimension of $30 \mathrm{~mm}$ is used, the simulated $\mathbf{S}_{0}$ value is $180 \mathrm{~mm}$. It should be noted however that specimen dimension affects spacing between cracks as demonstrated below by Colina and Roux (2000) (figure 10) . 


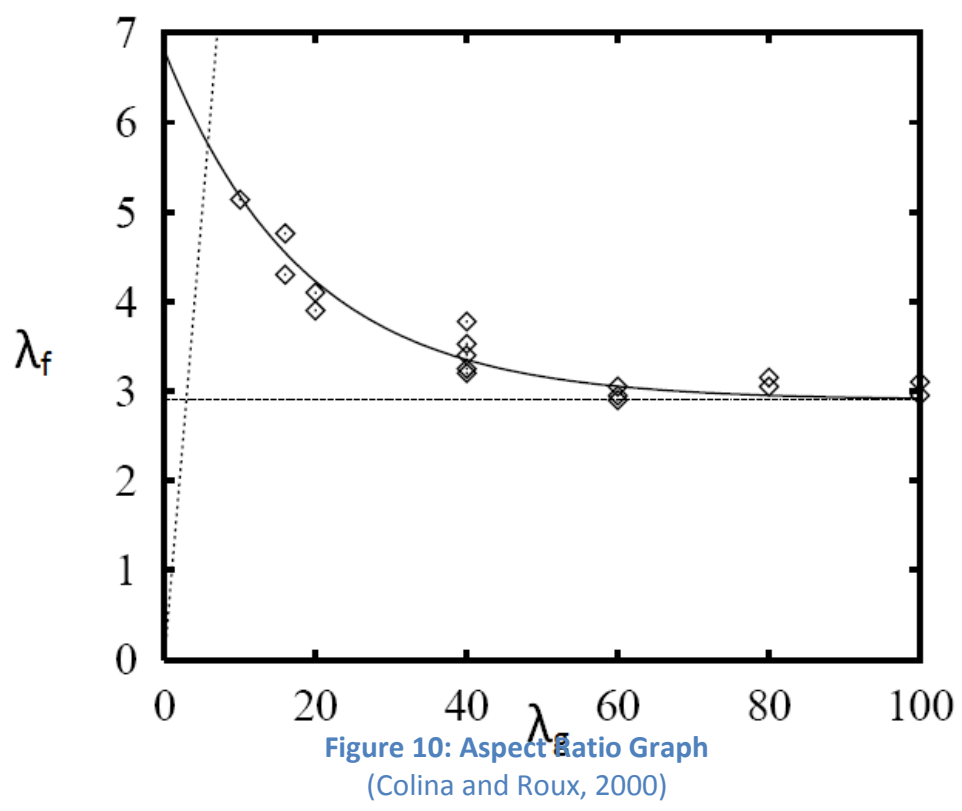

In Figure $10, \lambda_{f}$, which represents spacing between cracks over initial specimen thickness, decreases as $\boldsymbol{\lambda}_{\mathrm{g}}$ increases. $\boldsymbol{\lambda}_{\mathrm{g}}$ represents length of specimen over initial thickness. Chertkov (2002.b) assumes that specimen length is much higher than specimen thickness. $\lambda_{\mathbf{f}}$, which represents $\boldsymbol{S}_{\mathbf{0}}$ over thickness, is therefore corrected to properly represent the conditions Chertkov intended his model for. An $\lambda_{\mathrm{g}}$ of 60 is chosen. An adaptation of this graph is used for our experimental data where $\boldsymbol{\lambda}_{\mathrm{f}}$ at 60 is equal to 2. Multiplying $\lambda_{f}\left(\lambda_{f}=2\right)$ by the initial specimen thickness of $9 \mathrm{~cm}$ provides a corrected $S_{0}$ value of $180 \mathrm{~mm}$ which is much closer to the measured $S_{0}\left(S_{0}=290 \mathrm{~mm}\right)$ and is equal to the simulated $S_{0}$ value of $180 \mathrm{~mm}$.

This suggests that had we used specimen dimensions that satisfied Chertkov's assumption of semi-infinite lateral extension, our measured $\mathbf{S}_{\mathbf{0}}$ value would have been equal to the simulated $\mathbf{S}_{\mathbf{0}}$ value. This puts into question the validity of our experimental data as crack dynamics would have been different had we used a larger specimen. 
In a fourth scenario, a hydraulic conductivity within the range of published hydraulic conductivities for kaolinite clay is used, yielding a diffusivity of $1.65 \mathrm{~mm} 2 / \mathrm{d}$. Moreover, minimum crack dimension is set to $I^{*}=30 \mathrm{~mm}$. In order to accept this $I^{*}$, which is larger than the initial crack depth $(1.9 \mathrm{~mm})$ of the turquoise crack, the turquoise crack as a data set must be disregarded. This is acceptable given that the turquoise crack did not horizontally expand and its maximum crack depth was very shallow, its status as a 'jumped' crack is therefore questionable. This new set of parameters created a Chertkov curve that fit the data. The resultant $\mathrm{T}_{\text {avg }}$ was 370 minutes which was closer to the recorded 772.4 minutes than the other generated values for $T_{\text {avg. }}$. The velocity of crack propagation $U$ was $0.028 \mathrm{~mm} / \mathrm{min}$ which was very close to the recorded $0.026 \mathrm{~mm} / \mathrm{min}$. $L_{\text {avg }}$ was $171.6 \mathrm{~mm}$ which is much higher than the recorded $18.4 \mathrm{~mm}$ and finally, $\mathrm{S}_{0}$ was $18 \mathrm{~cm}$ which was much closer to the recorded $29 \mathrm{~cm}$ than other generated values. This set of values, however, generates a maximum depth $z_{m}$ of $90 \mathrm{~cm}$ (appendix b). Chertkov doesn't assume bottom boundary condition. Due to the tank and the initial specimen deposition geometry, the thickness of the specimen and maximum depth of cracks was $9 \mathrm{~cm}$.

\subsubsection{Plastic Deformation}

Linear elastic fracture mechanics, the model applied by Chertkov, assumes that cracking occurs in an elastic material where plastic deformation is confined to an infinitesimally small plastic zone at the crack tip which can be ignored. As seen below, plastic deformation in advancing cracks is characterized by plastic flow at crack tip with shear 
deformation where maximal shear stress typically occurs at $45^{\circledR}$ angles at the crack tip (figure 57). Note that Figure 56 shows a crack advancing in depth.

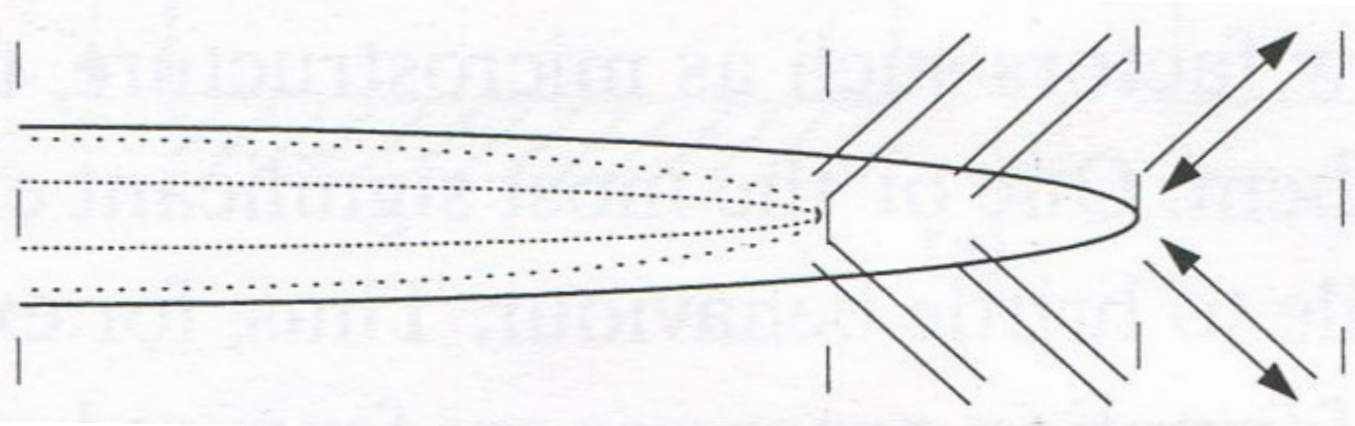

Figure 57 shear stress distribution for plastic deformation

(Hull, 1999)

As observed in the experiment, some cracks, at the peak of their advancing velocity, bifurcated into the directions of maximal shear stress (figure 56), thus indicating the influence of shear stresses characteristic of plastic deformation. This indicates that plastic deformation, and not linear elastic deformation, was responsible for crack evolution. This means that Chertkov should have applied the theory of Plastic-Elastic Fracture Mechanics and its concordant equations for the case of drying kaolinite clay soils as opposed to Linear-Elastic Fracture Mechanics. As seen below, the angles of bifurcation diverged from the optimal $45^{\circledR}$ as they were $74.8^{\circledR}$ on the left and $83.6^{\circledR}$ on the right (figures 57. 58). 


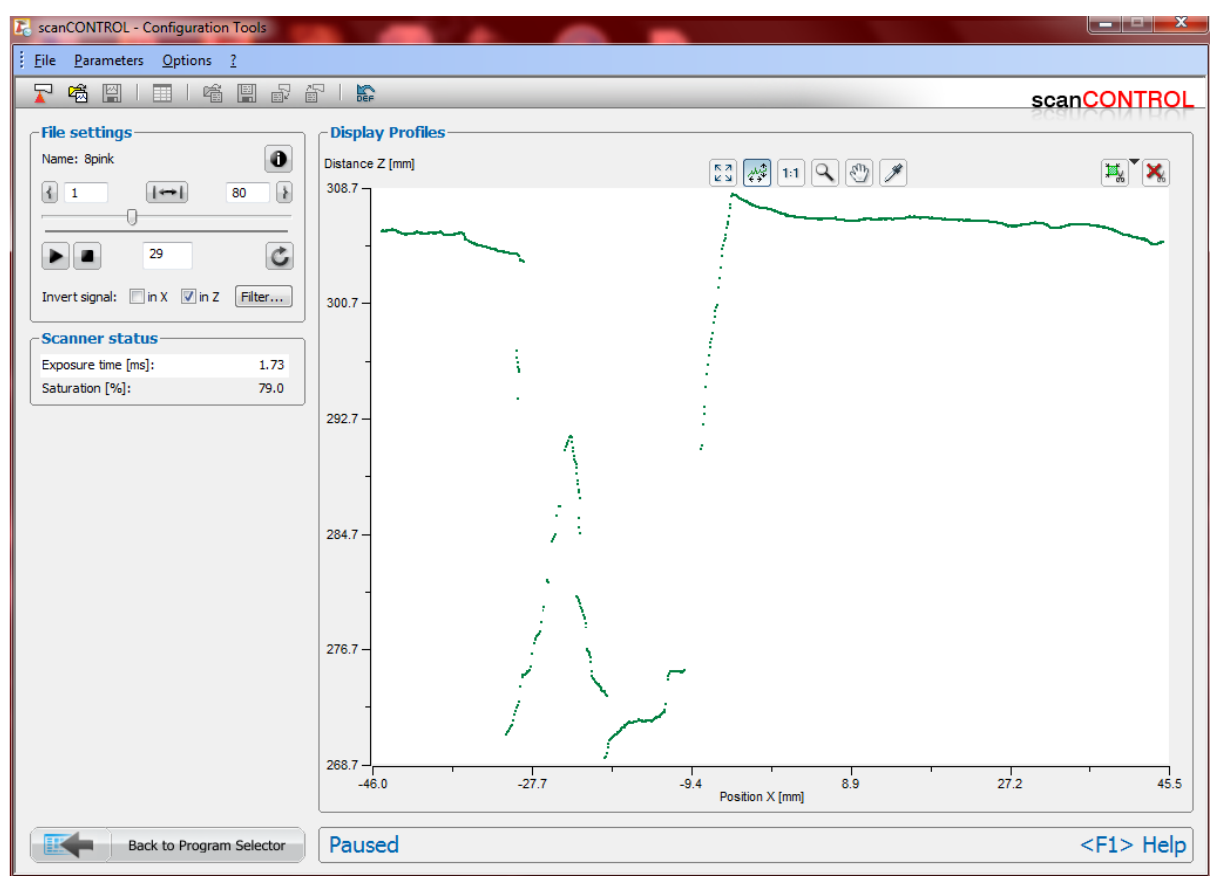

Figure 58 crack bifurcation along maximum shear stress directions

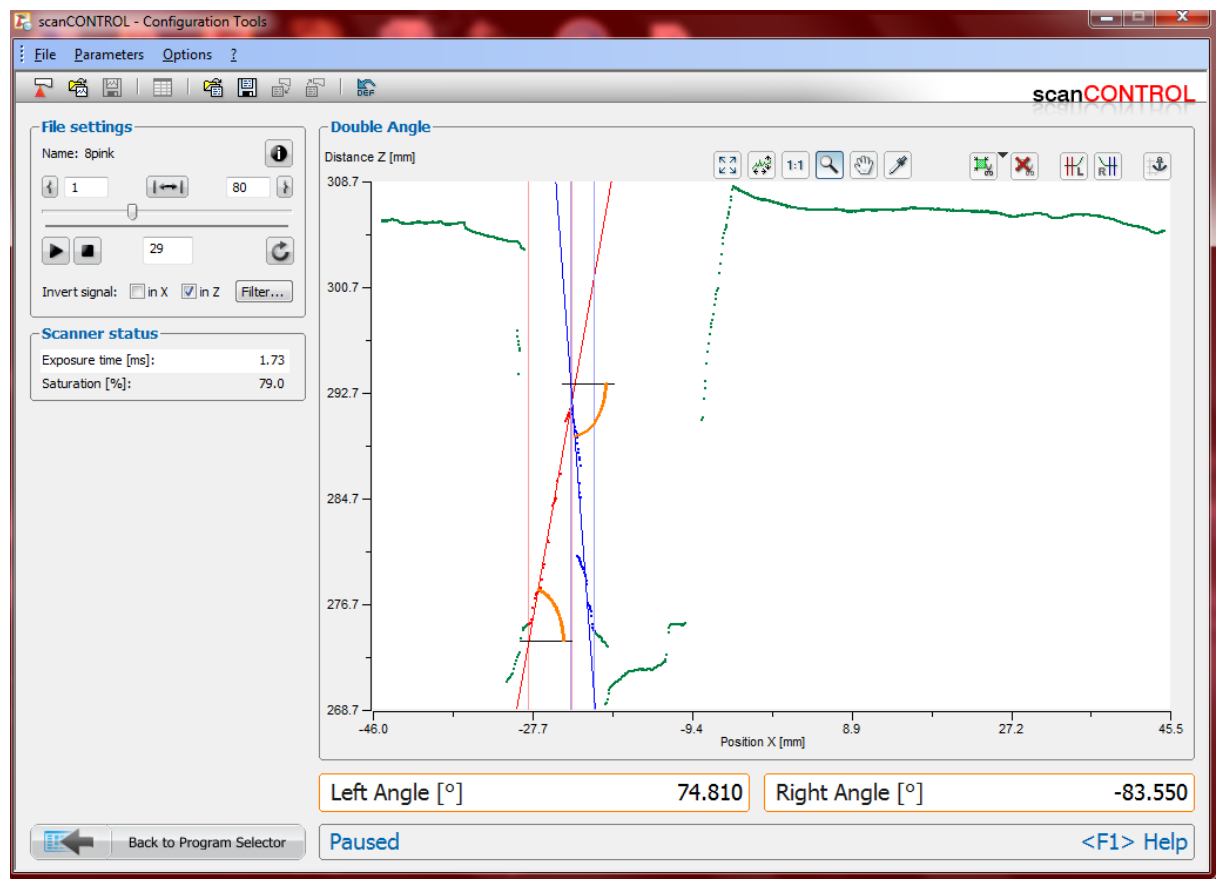

Figure 59 angles of crack bifurcation 


\subsubsection{Mode of stress distribution}

As seen below, there are three modes of loading for crack propagation. As mentioned in the literature review, mode 1 is induced by tensile stresses while mode 2 is induced by shear stresses and finally, mode 3 is induced by torsion (figure 60). Chertkov's model assumes a simple mode 1 opening of cracks.

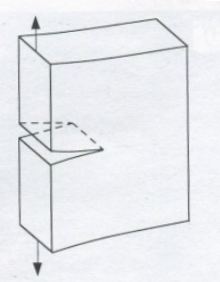

(a)

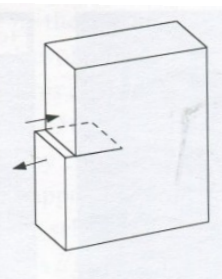

(b)

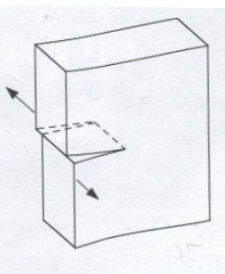

(c)

Figure 603 modes of loading

(Hull, 19990

In cracking mediums, it is also possible to observe mixed mode $\mathrm{I} / \mathrm{II}$ and $\mathrm{I} / \mathrm{III}$ loading (figure 60). 3-dimenionally curved crack surfaces (figures 62,63) are the result of mixed mode loading which requires a different set of equations than those applied by Chertkov (Chertkov, 2002.a) which assume mode I loading. As seen in Figures 63 and 64, curved surfaces were present, even frequent, in the experiment, showing that the use of mode I loading equations was erroneous. 


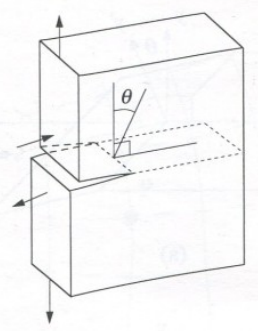

(a)

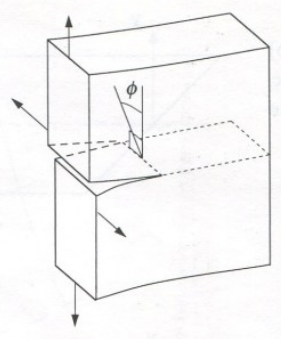

(b)

Figure 61 mixed modes of loading

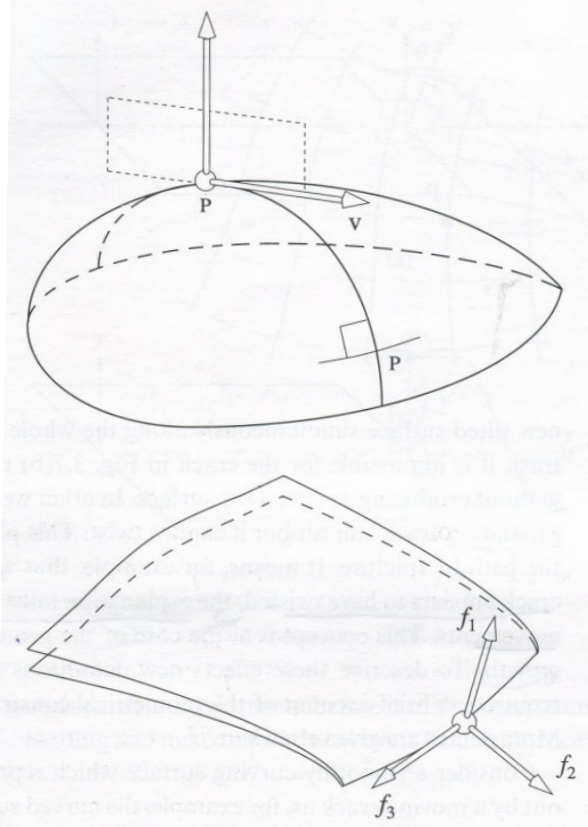

Figure 62 curved surfaces 


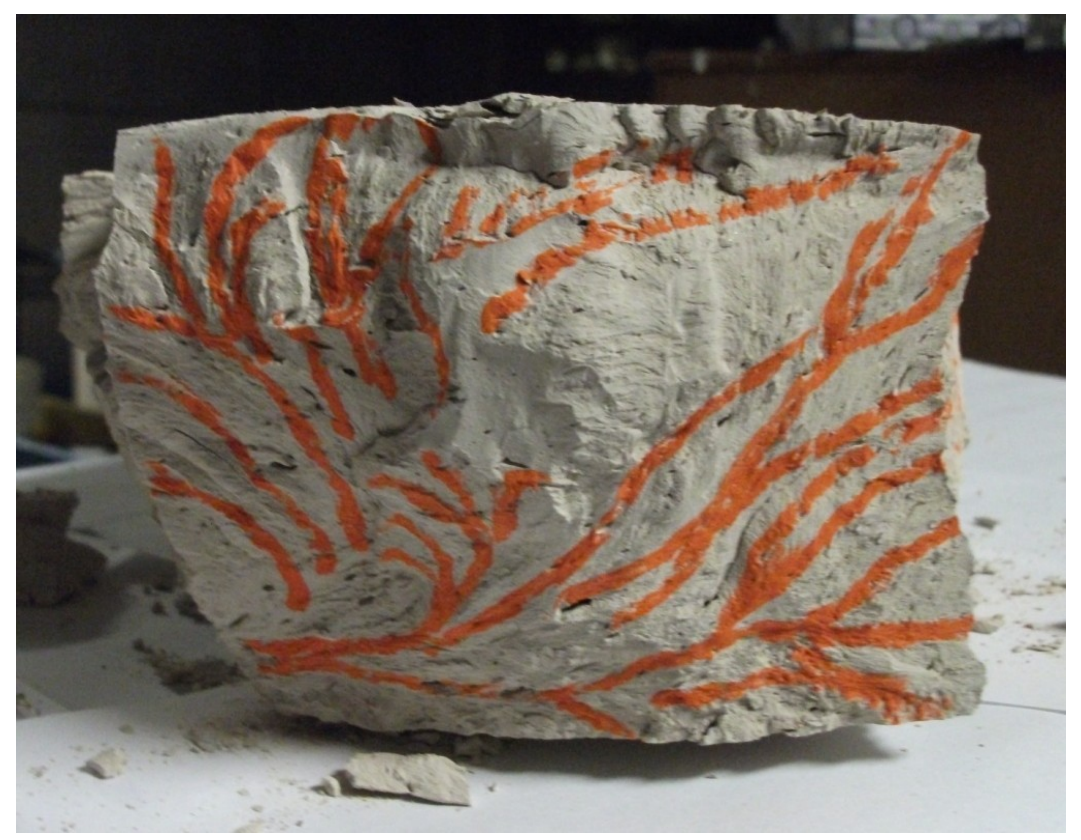

Figure 63 curved crack surface

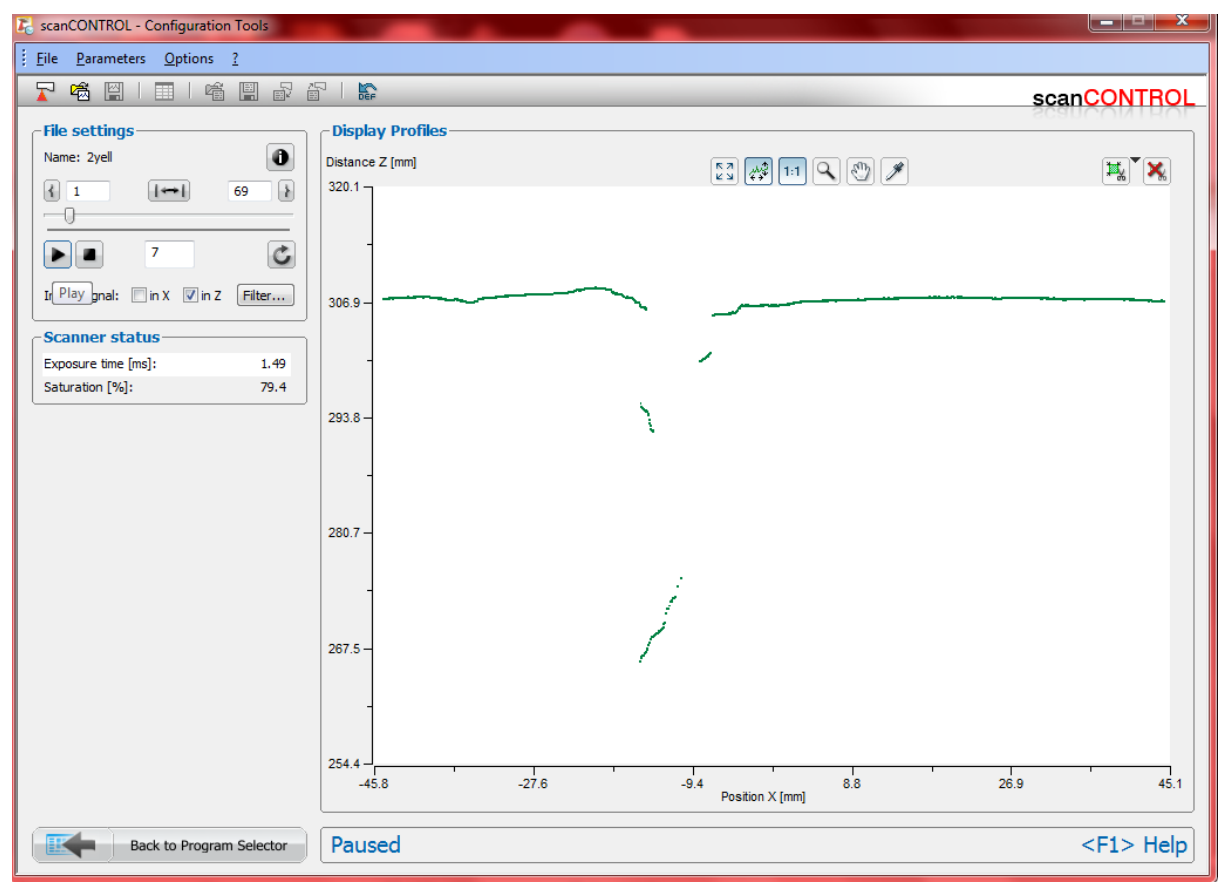

Figure 64 laser scanner rendering of curved crack surface

The fractographic analysis therefore found that there are at least two reasons for the failure of Chertkov's model; first, plastic deformation was the driving mechanism of crack propagation as opposed to linear elastic deformation, and secondly, mixed mode 
loading drove the crack propagation as opposed to mode I loading. Both of these facts require the use of a different set of equations to model crack propagation. On the other hand, the specimen dimensions were too small to satisfy Chertkov's assumption of semiinfinite lateral extension and so the crack dynamics change. For example, had we used a larger specimen, the average distance between primary crack nucleation sites would have been smaller. Chertkov's model is best tested in large scale experiments with depths of over $1 \mathrm{~m}$ and lengths of over $60 \mathrm{~m}$. The physico-chemical composition is also significant as the greater the fines content, the greater the shrinkage potential which leads to greater crack widths.

Crack widths were also monitored and yielded divergent rates of expansion as seen below where the slopes of the graphs are the velocities of crack width expansion.

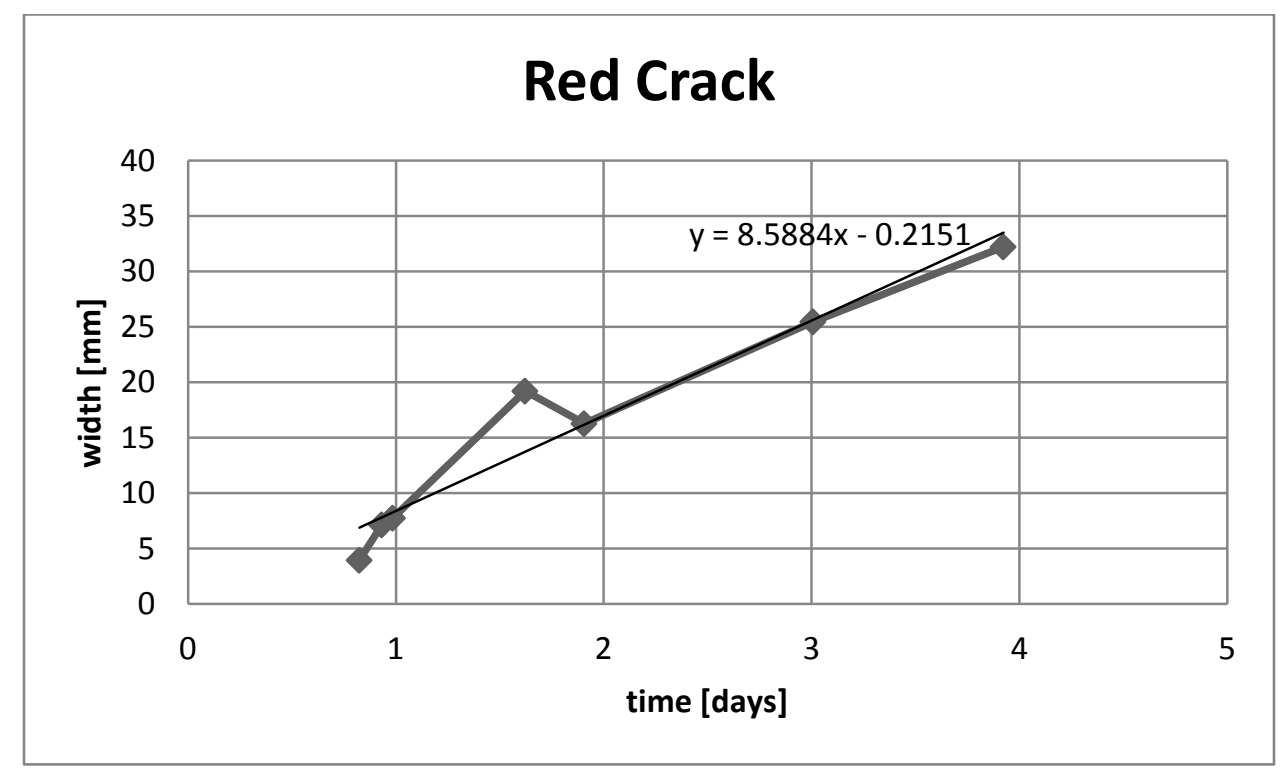

Figure 65 red crack width over time 


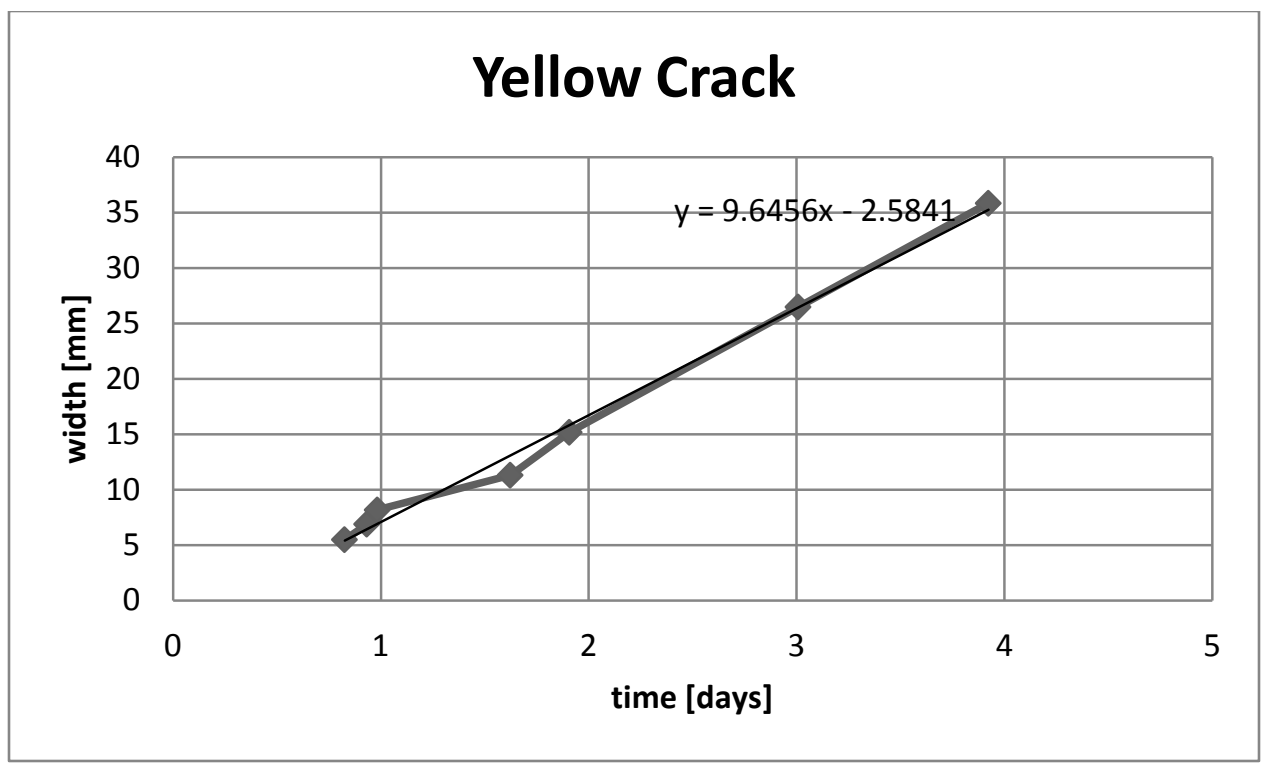

Figure 66 yellow crack width over time

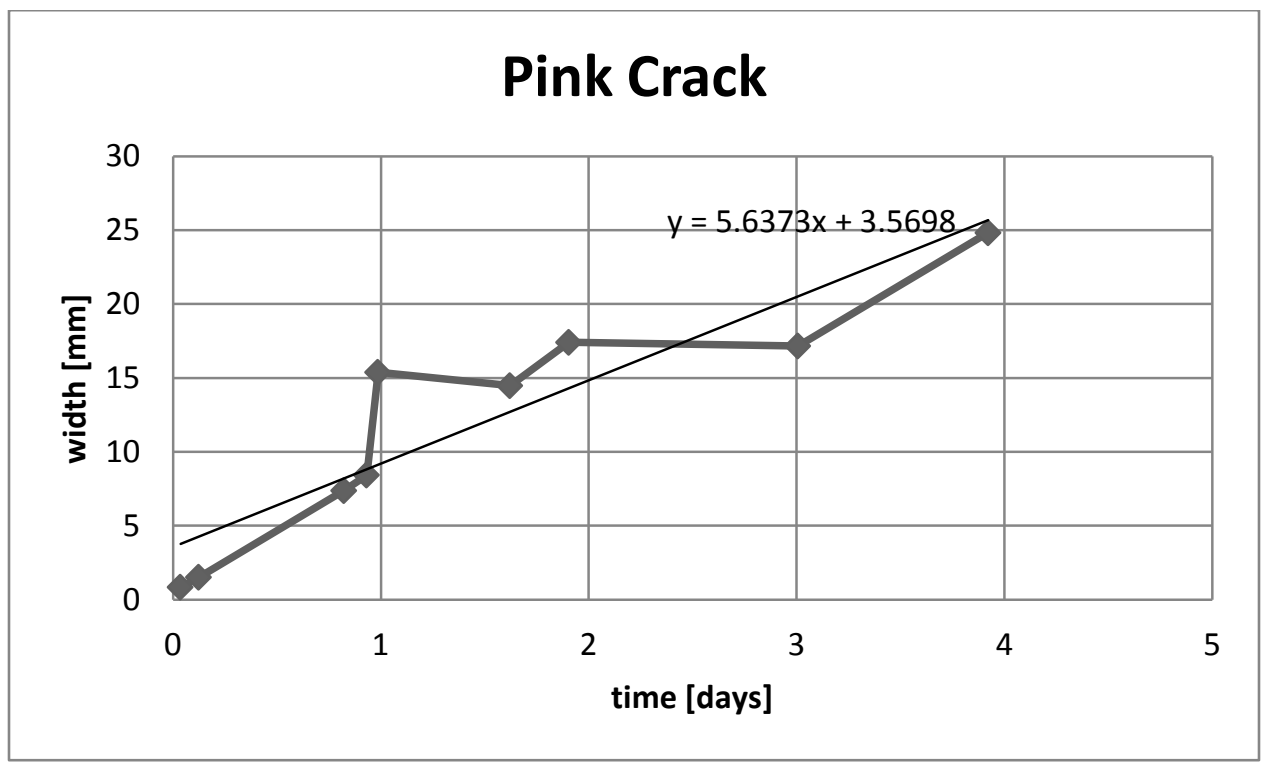

Figure 67 pink crack width over time 


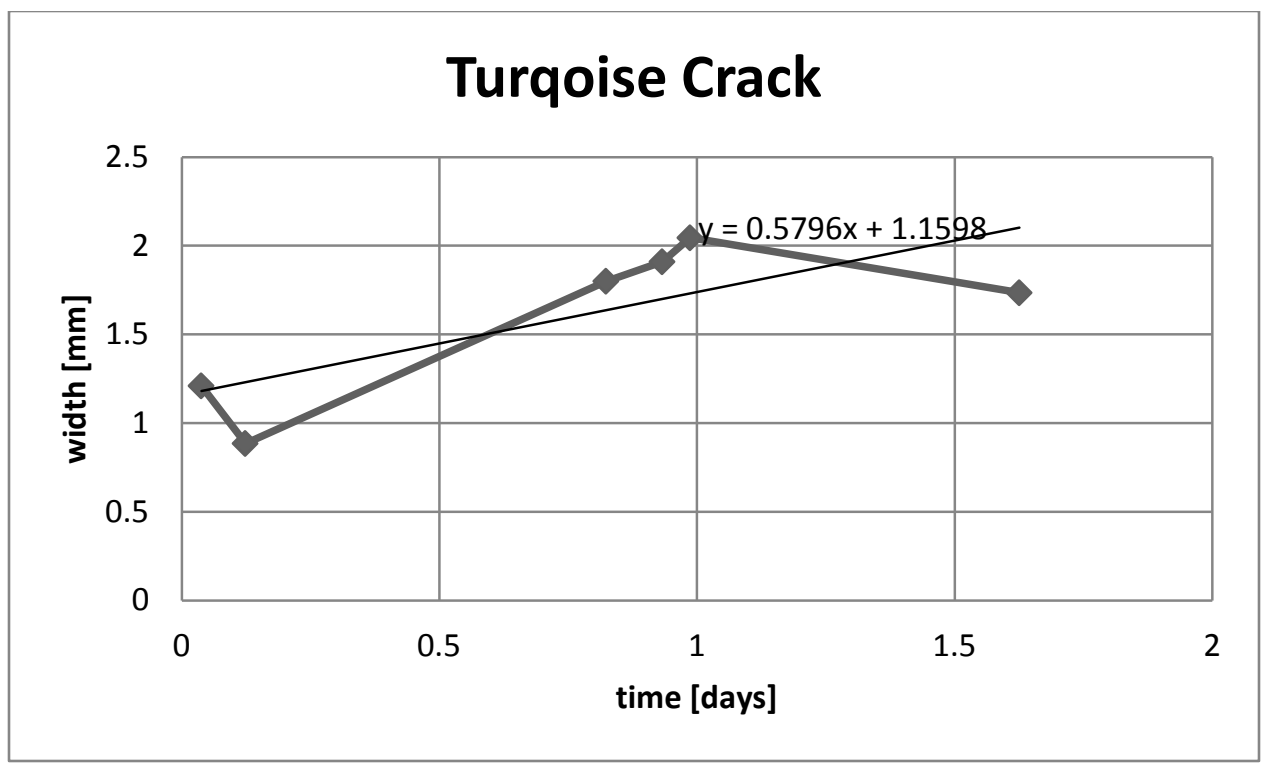

Figure 68 turquoise crack width over time

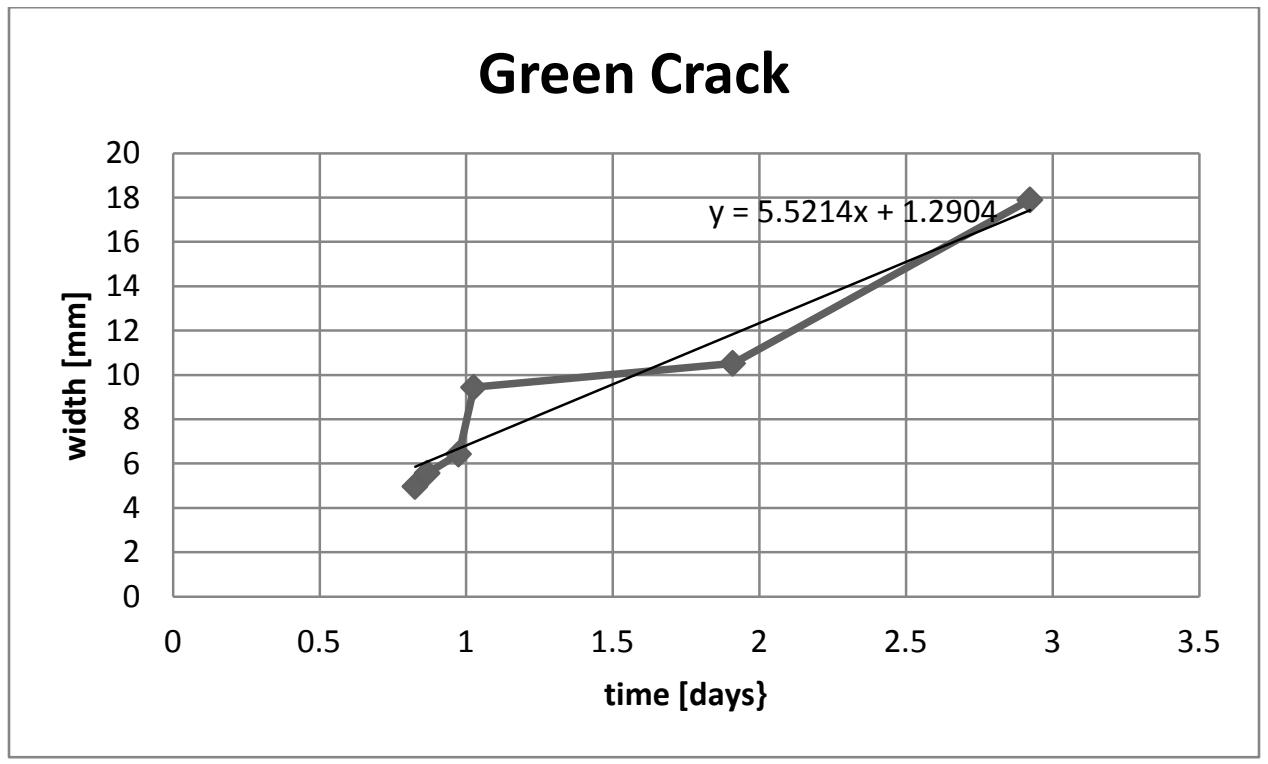

Figure 69 green crack width over time 


\section{2. $\quad$ Large Scale Drying}

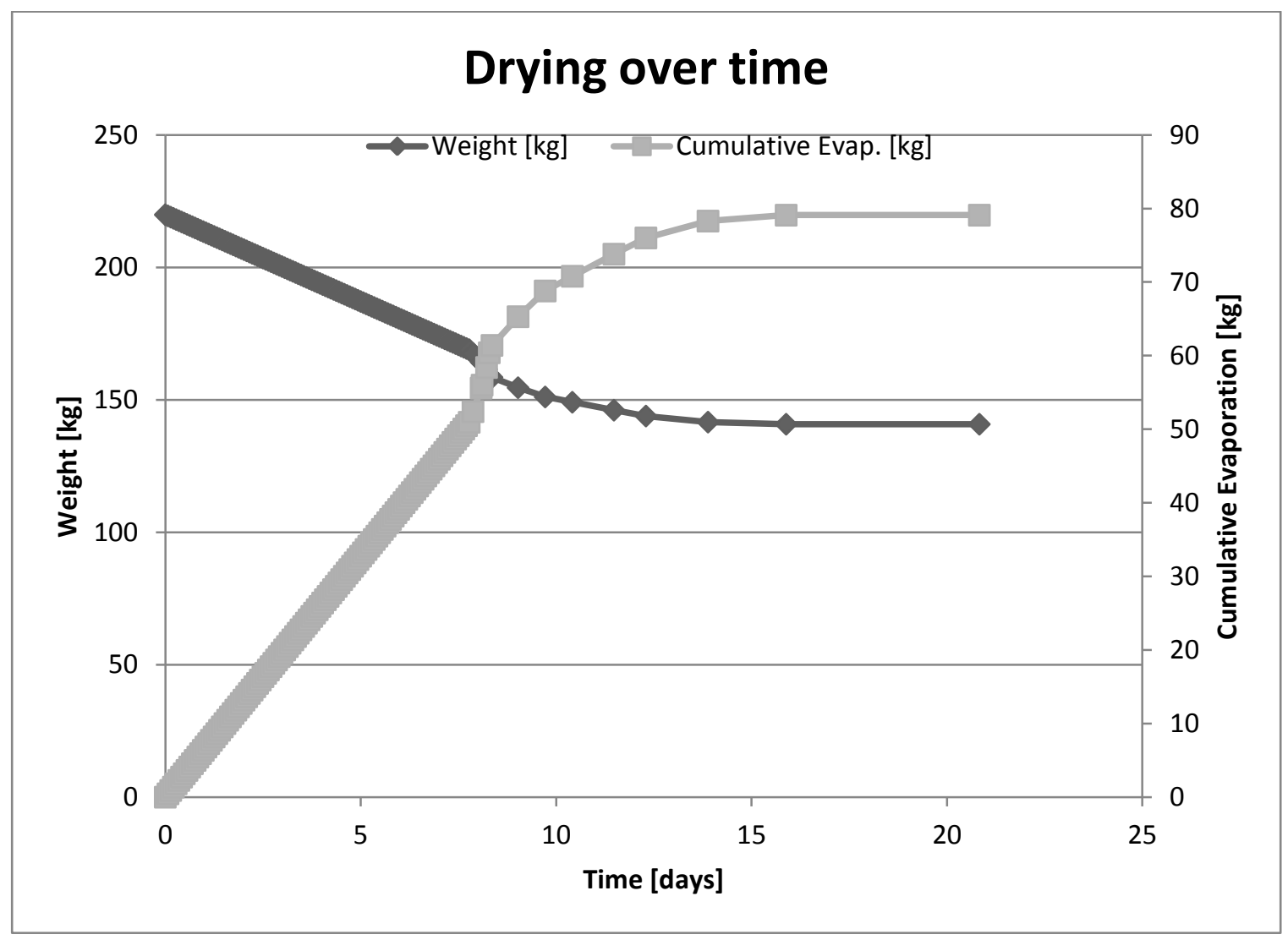

Figure 70 drying over time

The rate of weight loss over time was constant for the first stage of evaporation. When surface de-saturation commenced after 6.94 days, a sharp increase in the rate of weight loss was observed. This sharp increase gave way to a slower and slowing rate of weight loss over time after 8.33 days. 


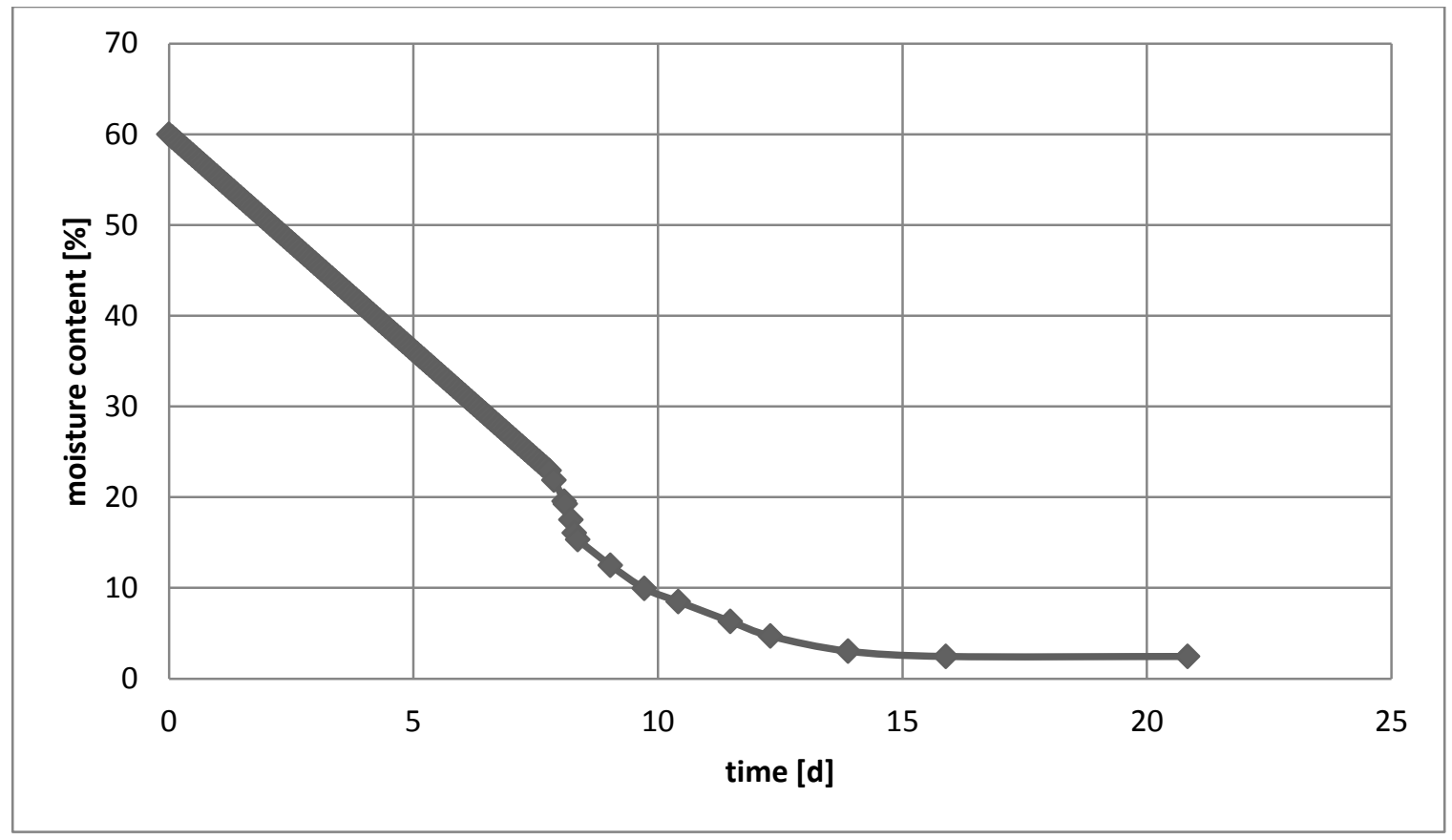

Figure $\mathbf{7 1}$ moisture over time

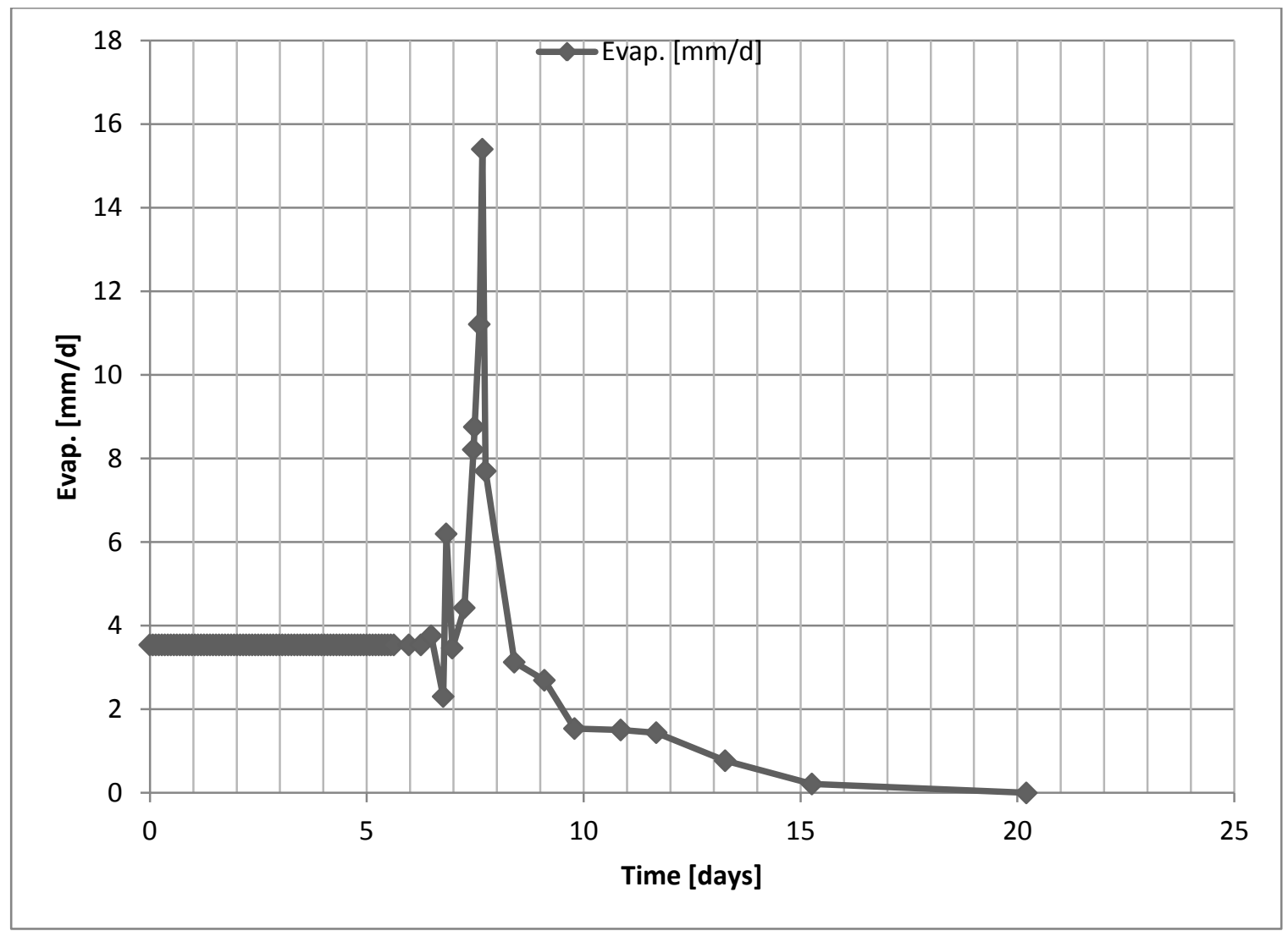

Figure 72 evolution of rate of evaporation 
At 6.94 days, corresponding to point of de-saturation, total rate of evaporation suddenly increases multiplying from $3.54 \mathrm{~mm} / \mathrm{d}$ to $11.54 \mathrm{~mm} / \mathrm{d}$ at 7.85 days. The surface area from which the evaporation is presumed to take place is the top planar surface area of $129 \mathrm{~cm} \times 145 \mathrm{~cm}$. It ignores both crack surface area and the voided surface area created by crack openings. This demonstrates that at point of de-saturation, evaporative moisture flow within the soil matrix was in part redirected laterally towards the crack surfaces.

For a known gravimetric evaporation, the rate of evaporation was determined from three possible surface area configurations; the square planar area from tank geometry, the top area of the crack blocks and the total exposed area (top and crack areas). Readings of relative humidity, temperature and calculated potential evaporation can be found in Appendix C.

Potential evaporation at time of evaporation peak was relatively low at $3.45 \mathrm{~mm} / \mathrm{d}$ at 7.08 days and $3.87 \mathrm{~mm} / \mathrm{d}$ at 7.92 days. This shows that the sudden increase in total evaporation was not driven by ambient conditions. 


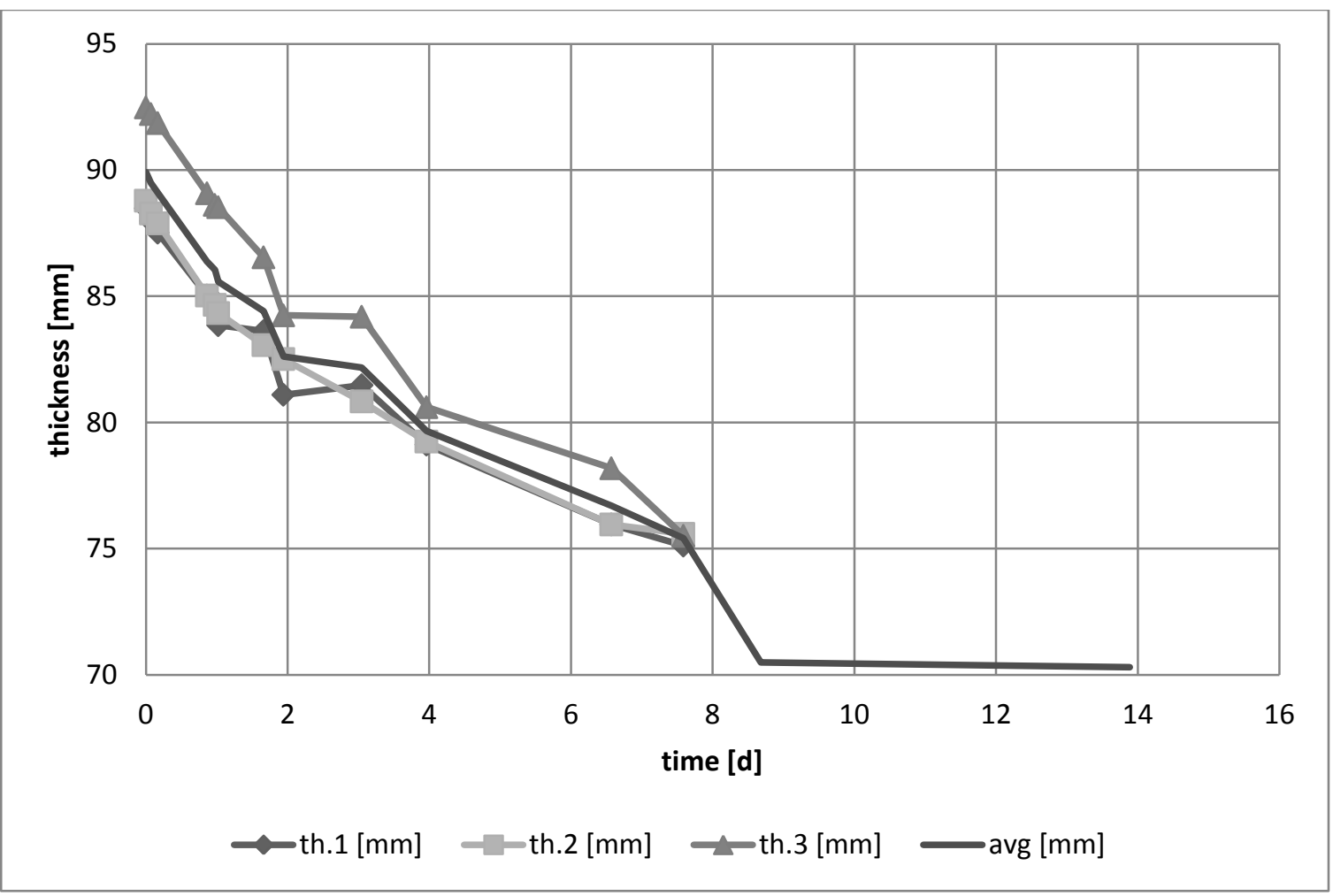

Figure 73 evolution of specimen thickness over time

Vertical shrinkage continued unabated during the sudden increase in evaporation. Images were taken each day and the surface area and volume were determined thereof through matlab processing for the top surface area and the measured thickness. It was assumed that the cracks were completely hollow and penetrated directly into the tank bottom, orthogonal to it. These volumes were used to calculate void ratio (figure 74) and evaporation based on apparent volume changes (figure 75). 


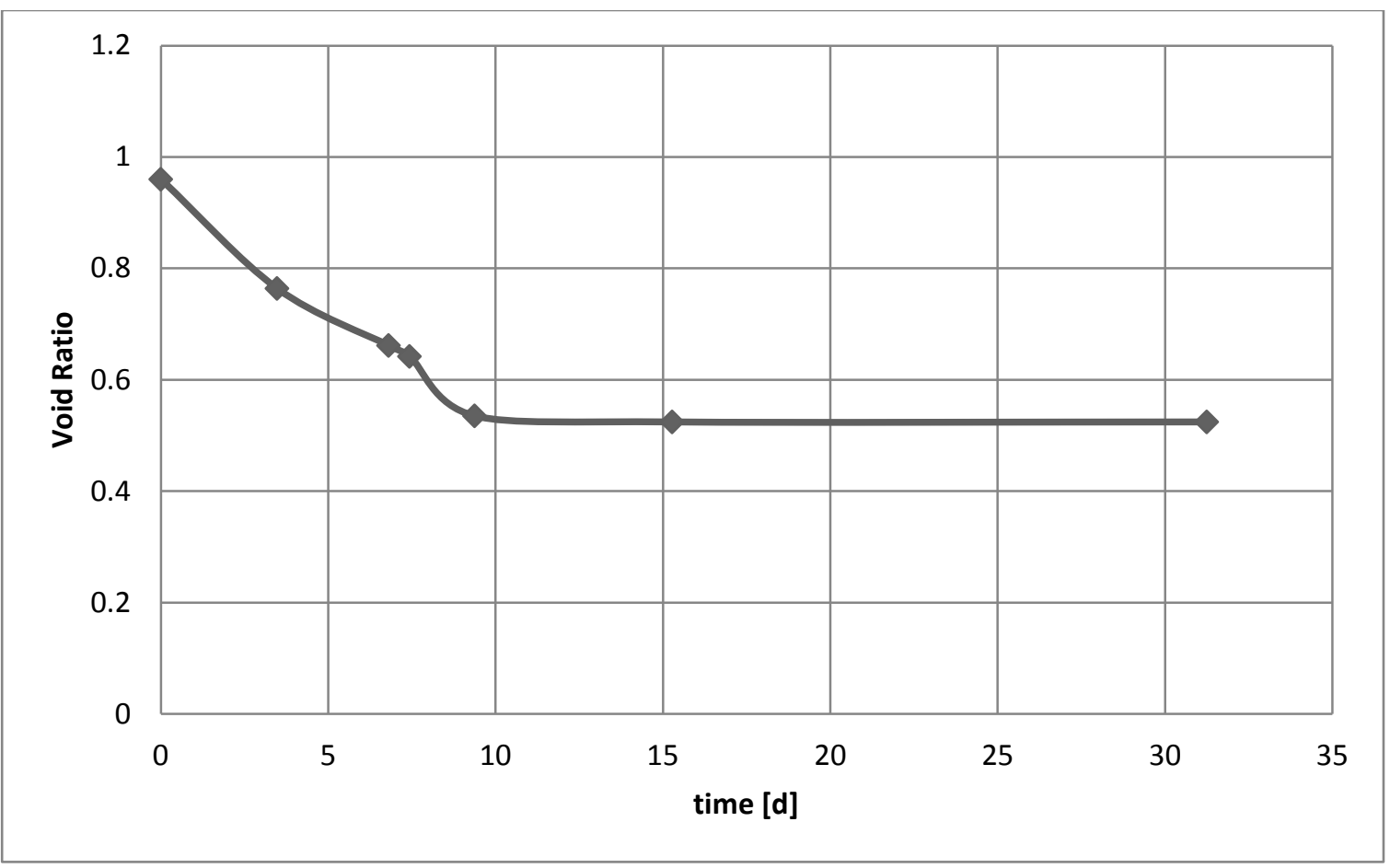

Figure $\mathbf{7 4}$ Void ratio over time

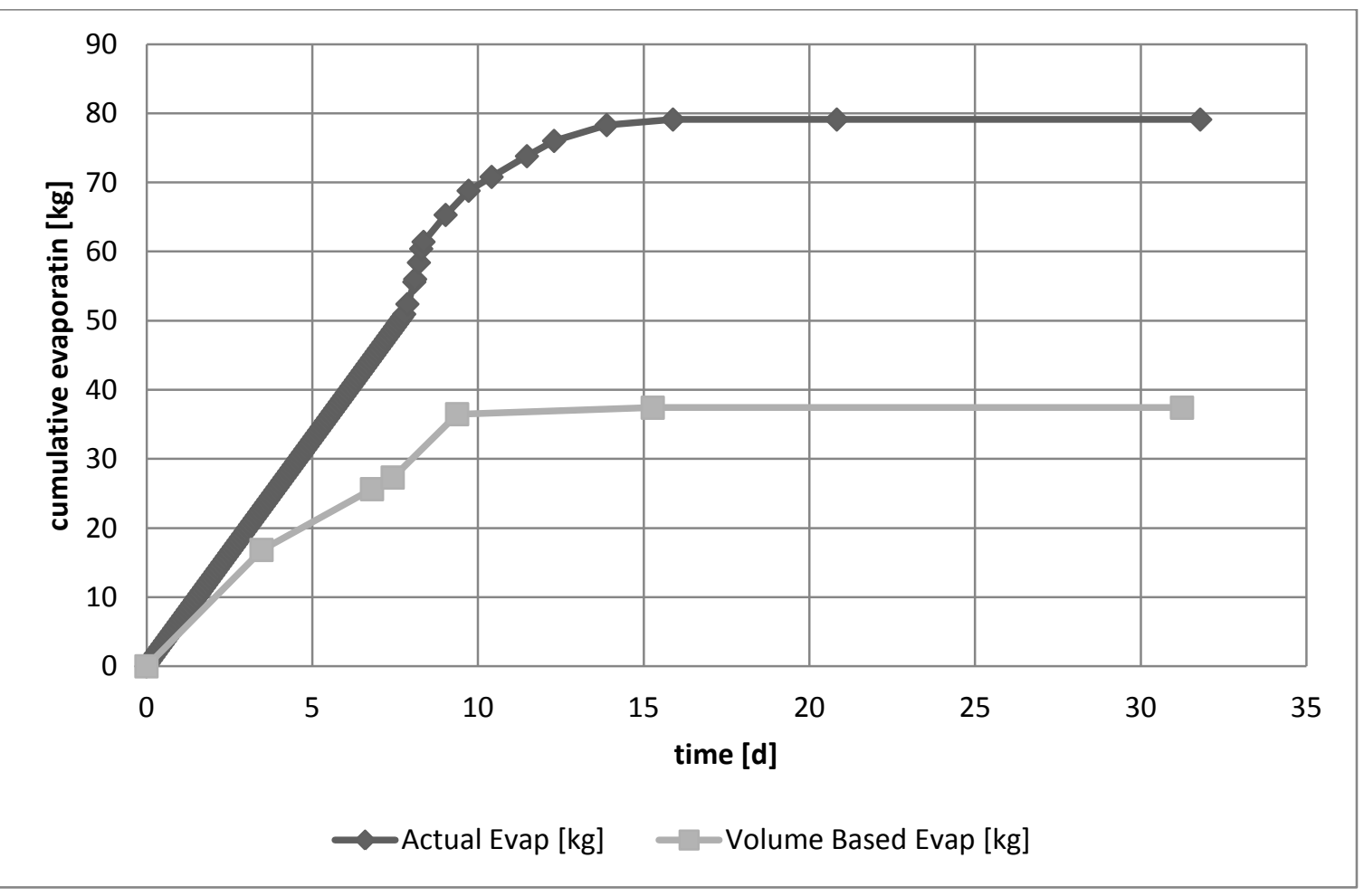

Figure 75 Cumulative evaporation 
At 3.47 days, 24 surface samples were taken from the desiccating clay and were analyzed for total suction measurements. The same was done at 6.81 days and 7.43 days. Contour maps of suction were then created in Matlab from which a total average surface suction was derived.

\begin{tabular}{|c|c|c|c|c|c|c|c|c|c|c|c|c|c|}
\hline & $\begin{array}{l}\text { Color } \\
1\end{array}$ & $\begin{array}{l}\text { Color } \\
2\end{array}$ & $\begin{array}{l}\text { Color } \\
3\end{array}$ & $\begin{array}{l}\text { Color } \\
4\end{array}$ & $\begin{array}{l}\text { Color } \\
5\end{array}$ & $\begin{array}{l}\text { Color } \\
6\end{array}$ & $\begin{array}{l}\text { Color } \\
7\end{array}$ & $\begin{array}{l}\text { Color } \\
8\end{array}$ & $\begin{array}{l}\text { Color } \\
9\end{array}$ & $\begin{array}{l}\text { Color } 1 \\
0\end{array}$ & $\begin{array}{l}\text { Color1 } \\
1\end{array}$ & Color 12 & total \\
\hline pt. $2 \Psi$ & 5.5 & 5 & 4.5 & 4 & 0 & 0 & 0 & 3.5 & 1.5 & 2 & 2.5 & 3 & \\
\hline $\begin{array}{l}\text { pt. } 2 \Psi \\
\text { pixel }\end{array}$ & 0.44 & 0.419 & 0.4618 & 0.476 & 0 & 0 & 0 & 0.5124 & 0.8098 & 0.8404 & 0.5875 & 0.5248 & 5.073 \\
\hline$\% \mathrm{col}$ & 0.086 & 0.082 & 0.0910 & 0.094 & 0 & 0 & 0 & 0.1009 & 0.1596 & 0.1656 & 0.1158 & 0.103441 & \\
\hline $\begin{array}{l}\text { weight } \\
\text { ed } \Psi\end{array}$ & 0.476 & 0.413 & 0.4096 & 0.376 & 0 & 0 & 0 & 0.3534 & 0.2394 & 0.3312 & 0.2895 & 0.310324 & 3.200 \\
\hline pt. $3 \Psi$ & 6.24 & 5.78 & 5.33 & null & 4.87 & null & 4.42 & 3.05 & 3.51 & 3.96 & 4.42 & total & \\
\hline $\begin{array}{l}\text { pt. } 3 \Psi \\
\text { pixel }\end{array}$ & 0.375 & 0.626 & 0.6122 & 0 & 0.4878 & 0 & 0.6974 & 0.2496 & 0.3356 & 0.5575 & 0.6581 & 4.6009 & \\
\hline$\% \mathrm{col}$ & 0.081 & 0.136 & 0.1330 & 0 & 0.1060 & 0 & 0.1515 & 0.0542 & 0.0729 & 0.1211 & 0.1430 & & \\
\hline $\begin{array}{l}\text { weight } \\
\text { ed } \Psi\end{array}$ & 0.509 & 0.787 & 0.7092 & 0 & 0.5163 & 0 & 0.6699 & 0.1654 & 0.2560 & 0.4798 & 0.6322 & 4.726321 & \\
\hline
\end{tabular}

Table 13 weighed color-coded suction

$$
\psi_{\text {normalized }}=\psi_{1} \bullet \% \text { Area }_{1} \ldots+\psi_{n} \bullet \% \text { Area }_{n} \ldots+\psi_{10} \bullet \% \text { Area }_{10}
$$

Equation 61

Surface total suction was color coded on the contour maps and the relative weight of each color was derived from Matlab. A weighted average suction was then calculated depending on the proportional area each color occupied on the surface contour maps (table 12). The weighted total average suction at 6.81 days was $3.20 \mathrm{MPa}$ while that at 7.43 days was $4.73 \mathrm{MPa}$. Two soil samples were taken from crack surfaces at 6.81 days 
and 7.43 days. 24 surface samples were taken at 3.47 days but analysis showed that suction in those samples was insignificant and far below $3 \mathrm{MPa}$.

In order to measure theoretical evaporation at these surface suction values, the soil's relative humidity was obtained (equation 63). Actual vapor pressure was calculated by first determining saturation vapor pressure through Teten's Equation (equation 62) then multiplying it by ambient relative humidity and dividing the whole by a hundred.

$$
\frac{e_{s}}{e_{s 0}}=\exp \left[\frac{17.27 T}{T+237.3}\right] \quad e_{s}=e_{s 0} \cdot \exp \left[\frac{17.27 T}{T+237.3}\right] \quad e_{s}=0.6108 \exp \left[\frac{17.27 T}{T+237.3}\right]
$$

Equation 62

$\mathrm{e}_{\mathrm{s}}$ : saturation vapor pressure $[\mathrm{kPa}]$

$\mathrm{e}_{\mathrm{s} 0}$ : saturation vapor pressure at $0^{\circledR} \mathrm{C}[0.6108 \mathrm{kPa}]$

$\mathrm{T}$ : temperature $\left[{ }^{\circledR} \mathrm{C}\right]$

$$
\begin{gathered}
e_{s}=0.6108 \exp \left[\frac{17.27 \cdot 23}{23+237.3}\right] e_{s}=2809[\mathrm{~Pa}] \\
R H=e^{\psi \omega / R T}
\end{gathered}
$$

Equation 63

$\mathrm{RH}$ : relative humidity

$\Psi$ : total soil suction [MPa]

$\omega$ : molecular mass of water vapor [18.016 kg/kmol]

$\mathrm{R}$ : universal gas constant $\left[8.31432 \mathrm{~J} /\left(\mathrm{mol}^{*} \mathrm{~K}\right)\right]$

$\mathrm{T}$ : temperature $\left[{ }^{\circledR} \mathrm{C}\right]$

$$
\begin{aligned}
& R H=e^{-4.726 \bullet 18.016 / 8.31432 \bullet(23+273.16)} \\
& R H=96.6 \% \\
& e_{a}=\frac{e_{S} \bullet R H \%}{100} \\
& e_{a}=\frac{2809[\mathrm{~Pa}] \cdot 59.5}{100} e_{a}=1672[\mathrm{~Pa}]
\end{aligned}
$$




$$
E_{\text {theoretical }}\left[\frac{m m}{d}\right]=f(w) e_{a}\left(\frac{1}{R H_{A}}-\frac{1}{R H_{S}}\right)
$$

Equation 64

$E_{\text {theoretical: }}$ Theoretical evaporation $[\mathrm{mm} / \mathrm{d}]$

$f(w)$ : wind factor [unitless]

$\mathrm{e}_{\mathrm{a}}$ : actual vapor pressure $[\mathrm{kPa}]$

$\mathrm{RH}_{\mathrm{A}}$ : ambient relative humidity

$\mathrm{RH}_{\mathrm{s}}$ : soil relative humidity

$$
\begin{aligned}
& E_{\text {theoretical }}\left[\frac{m m}{d}\right]=3.31 \bullet 1.672\left(\frac{1}{0.595}-\frac{1}{0.966}\right) \\
& E_{\text {theoretical }}\left[\frac{m m}{d}\right]=3.57\left[\frac{m m}{d}\right]
\end{aligned}
$$

With a wind factor of 3.31, the theoretical rate of evaporation emerged as $3.57 \mathrm{~mm} / \mathrm{d}$. By multiplying the theoretical rate of evaporation by the un-cracked top area, the theoretical rate of evaporation was obtained. The rate of evaporation from crack surfaces at 6.81 days $(9,800$ minutes) was obtained by subtracting the top rate of evaporation from the total recorded rate of evaporation as seen below.

$$
\begin{aligned}
& E_{T O P}\left[\frac{\mathrm{mm}^{3}}{d}\right]=E_{\text {theoretical }}\left[\frac{\mathrm{mm}}{d}\right] \bullet \text { TopArea }\left[\mathrm{mm}^{2}\right] \\
& E_{T O P}\left[\frac{\mathrm{mm}^{3}}{d}\right]=3.57 \bullet 1,497,549 \\
& E_{T O P}\left[\frac{\mathrm{mm}^{3}}{d}\right]=5,346,250\left[\frac{\mathrm{mm}^{3}}{d}\right] \\
& E_{T O P}\left[\frac{\mathrm{kg}}{\mathrm{d}}\right]=E_{T O P}\left[\frac{\mathrm{mm}^{3}}{\mathrm{~d}}\right] \bullet\left(\frac{1 \mathrm{~m}}{1000 \mathrm{~mm}}\right)^{3} \bullet \frac{1000 \mathrm{~kg}}{\mathrm{~m}^{3}}
\end{aligned}
$$




$$
\begin{aligned}
& E_{T O P}\left[\frac{\mathrm{kg}}{\mathrm{d}}\right]=5,346,250 \bullet \frac{1}{1000^{3}} \cdot \frac{1000 \mathrm{~kg}}{\mathrm{~m}^{3}} \\
& E_{T O P}\left[\frac{k g}{d}\right]=5.346250\left[\frac{k g}{d}\right] \\
& E_{9800}\left[\frac{k g}{d}\right]=\left(\frac{\text { Cum.Evap }}{9,8700-C u m \cdot \text { Evap }_{10600}}\right)\left[\frac{\mathrm{kg}}{\mathrm{min}}\right] \cdot 1440\left[\frac{\mathrm{min}}{\mathrm{d}}\right] \\
& E_{9800}\left[\frac{k g}{d}\right]=\left(\frac{53.8-52.8}{9,800-9,700}\right)\left[\frac{k g}{\min }\right] \bullet 1440\left[\frac{\min }{d}\right] \\
& E_{9800}\left[\frac{k g}{d}\right]=14.4\left[\frac{k g}{d}\right] \\
& E_{9800}\left[\frac{\mathrm{mm}}{\mathrm{d}}\right]=14.4\left[\frac{\mathrm{kg}}{\mathrm{d}}\right] \cdot \frac{1 \mathrm{~m}^{3}}{1000 \mathrm{~kg}} \cdot \frac{(1000 \mathrm{~mm})^{3}}{(1 \mathrm{~m})^{3}} \cdot \frac{1}{1290 \mathrm{~mm} \bullet 1450 \mathrm{~mm}} \\
& E_{9800}\left[\frac{m m}{d}\right]=7.70\left[\frac{m m}{d}\right] \\
& E_{\text {cracks }}\left[\frac{k g}{d}\right]=E_{\text {total }}\left[\frac{k g}{d}\right]-E_{T O P}\left[\frac{k g}{d}\right] \\
& E_{\text {cracks }}\left[\frac{\mathrm{kg}}{\mathrm{d}}\right]=14.4\left[\frac{\mathrm{kg}}{\mathrm{d}}\right]-5.35\left[\frac{\mathrm{kg}}{\mathrm{d}}\right] \\
& E_{\text {cracks }}\left[\frac{\mathrm{kg}}{\mathrm{d}}\right]=2.93\left[\frac{\mathrm{kg}}{\mathrm{d}}\right] \\
& E_{\text {cracks }}\left[\frac{\mathrm{mm}}{\mathrm{d}}\right]=2.93\left[\frac{\mathrm{kg}}{\mathrm{d}}\right] \cdot \frac{1 \mathrm{~m}^{3}}{1000 \mathrm{~kg}} \bullet \frac{(1000 \mathrm{~mm})^{3}}{(1 \mathrm{~m})^{3}} \cdot \frac{1}{1290 \mathrm{~mm} \bullet 1450 \mathrm{~mm}} \\
& E_{\text {cracks }}\left[\frac{m m}{d}\right]=1.57\left[\frac{m m}{d}\right] \\
& \% E_{\text {cracks }}\left[\frac{k g}{d}\right]=\frac{E_{\text {cracks }}}{E_{\text {total }}} \bullet 100 \\
& \% E_{\text {cracks }}\left[\frac{k g}{d}\right]=\frac{2.93}{8.28} \bullet 100 \\
& \% E_{\text {cracks }}\left[\frac{k g}{d}\right]=35.4 \%
\end{aligned}
$$


Once theoretical top evaporation was determined in $\mathrm{mm} / \mathrm{d}$, it was multiplied by the top exposed surface area for volumetric evaporation readings. These readings were then converted into gravimetric evaporation and subtracted from the known gravimetric evaporation, giving the gravimetric evaporation originating from crack surfaces. At 3.47 days, total gravimetric evaporation was $3.53 \mathrm{~mm} / \mathrm{d}(6.6 \mathrm{~kg} / \mathrm{d})$ of which $93.67 \%$ originated from top surface and $6.33 \%$ from crack surfaces. By 6.81 days, total evaporation had reached $7.70 \mathrm{~mm} / \mathrm{d}(14.4 \mathrm{~kg} / \mathrm{d})$, of which $64.6 \%$ originated from the top surface and $35.4 \%$ from crack surfaces. If we assume that surface total suction remained at $4.73 \mathrm{MPa}$ at 7.67 days, at peak evaporation, then out of a total evaporation of 11.55 $\mathrm{mm} / \mathrm{d}(15.36 \mathrm{~kg} / \mathrm{d}), 36.4 \%$ derived from top surface and $63.6 \%$ derived from crack surfaces, denoting the major role that cracks played in total evaporation at the turning point of de-saturation. It should be noted however, that top soil samples which were used to determine total suction, were about $1 \mathrm{~cm}$ deep which underestimated the real total suction on the actual surface, meaning, the top $2 \mathrm{~mm}$ layer. A more accurate evaporation would have thus been lower than that calculated. Moreover, no soil resistance term was integrated into Wilson's equation for evaporation, hence again underestimating the real evaporation.

Wind velocity is lower inside the crack openings than it is above it. Calculated gravimetric evaporation from crack surfaces demonstrated that the assumption of flat crack surfaces cannot be held to be true. For example, at 7.67 days, evaporation from crack surfaces surpasses surface potential evaporation, let alone potential evaporation using crack opening wind velocity. 
The crack surface was curved and hence its actual surface area was significantly greater than that calculated above. These curvatures form surface roughness, which indicates that evaporation emerges from the totality of the rough surface and not from the planar area. In other words, the greater the surface roughness, the greater the total exposed area, and hence, the higher the total evaporation. 


\section{Conclusion}

In the large scale drying test, it was shown that crack surfaces contributed at most, to $6.6 \%$ of total evaporation in the saturated stage. At point of surface de-saturation, a quick lateral realignment of moisture flow towards crack surfaces occurred and evaporation from crack openings came to represent $35 \%$ of total evaporation by 7.64 days, and at least $64 \%$ by 7.85 days. Following this quick realignment, crack surface total suction increased due to drying and salt accumulation, and total evaporation henceforth decreased. The increase in evaporation beginning at point of surface de-saturation more than doubled total evaporation from $3.50 \mathrm{~mm} / \mathrm{d}$ at 6.81 days to $15.4 \mathrm{~mm} / \mathrm{d}$ at its peak at 8.29 days. The scale of that increase invalidated the assumption of flat crack surfaces vertically piercing the specimen, for such surface area was too small to explain the scale of increase in evaporation. This proved that the observed curvatures and roughness of crack surfaces had to be taken into account for the determination of real surface area which would have to be multiple times greater than assumed area.

Chertkov's model was able to replicate most observed parameters of crack development, but only if i) a saturated hydraulic conductivity one magnitude lower and outside of the range of typical hydraulic conductivities for kaolinite clay was used, or ii) more realistic parameters are used, but then the model would predict a maximum depth greater than the thickness of the initial layer. Fractographic analysis showed that plastic deformation occurred, and that mixed-mode loading occurred, both of which violate assumptions of Chertkov's model, which is based on linear elastic fracture 
mechanics. Whether this rules out Chertkov's model as a useful tool, however, must be evaluated by future studies. 


\section{References}

Acker P, Colina H. (2000), Drying cracks: kinematics and scale laws, Materials and Structures, Matériaux et Constructions, Vol. 33, p 101-107

Adams JE., Hanks R.J. (1964), Evaporation from soil shrinkage cracks, Soil Science Society of America Journal, Vol. 28 No. 2, p. 281-284

Adams JE., Ritchie JT. (1974), Field Measurement of Evaporation from Soil Shrinkage Cracks, Soil Science Society of America Journal, Vol. 38 No. 1, p. 131-134

Arya, L.M., Tyner, J.S., Wright, W.C. (2006), The Dual Gravimetric Hot-Air Method for Measuring Soil Water Diffusivity, Vadose Zone Journal, 5:1281-1286

Barbour, S.L., Fredlund, D.G., Wilson, G.W. (1997), The effect of soil suction on evaporative fluxes from soil surfaces, Canadian Geotechnical Journal, 31(2), 151-161

Battistelli, A., Calore, C., \& Pruess, K. (1997). The simulator TOUGH2/EWASG for modelling geothermal reservoirs with brines and non-condensible gas.Geothermics, 26(4), 437-464.

Belyaev, V.V., Naimark OB., (1989), Kinetics of Accumulation of Mircrocracks and the Staged Nature of the Fracture Process Under shock Loading, Combustion, Explosion and Shock Waves, 25(4)

BGC Engineering Inc., 2010. Oil Sands Tailings Technology Review. OSRIN Report No. TR-1. 136 pp.http://hdl.handle.net/10402/era.17555

Bittelli, M., Ventura, F., Campbell, G. S., Snyder, R. L., Gallegati, F., \& Pisa, P. R. (2008). Coupling of heat, water vapor, and liquid water fluxes to compute evaporation in bare soils. Journal of hydrology, 362(3), 191-205.

Brooks, R.H., Borey, A.T. (1964), Hydraulic properties of porous media., Hydrology Paper 3, Civil Engineering Department, Colorado State University, Fort Collins

Camillo, P.J., Gurney, R.J., (1986). A resistance parameter for bare soil evaporation models. Soil Sci. 141, 95-105. 
Campbell, G. S. (1985). Soil physics with BASIC: transport models for soil-plant systems (Vol. 14). Elsevier.

Causarano, H. (1993). Factors affecting the tensile strength of soil aggregates.Soil and Tillage Research, 28(1), 15-25.

Chen, S., Feng, X. T., \& Li, S. (2001). Effects of water chemistry on microcracking and compressive strength of granite. International Journal of Rock Mechanics and Mining Sciences, 38(4), 557-568.

Chertkov, V. Y., \& Ravina, I. (1998). Modeling the crack network of swelling clay soils. Soil Science Society of America Journal, 62(5), 1162-1171.

Chertkov, V. Y. (2002). Modelling cracking stages of saturated soils as they dry and shrink. European Journal of Soil Science, 53(1), 105-118.

Chertkov, V. Y. (2002). Characteristic crack dimension of saturated drying soils: theory and applications. Agricultural Engineering International: CIGR EJournal.

Wang, J. J., Zhu, J. G., Chiu, C. F., \& Zhang, H. (2007). Experimental study on fracture toughness and tensile strength of a clay. Engineering Geology, 94(1), 65-75.

Colina, H., \& Roux, S. (2000). Experimental model of cracking induced by drying shrinkage. The European Physical Journal E, 1(2-3), 189-194.

Dalton., J. 1802. Experimental essays on the constitution of mixed gases; on the force of stream or vapour from water and other liquids in different temperatures, both in a Torricellian vacuum and in air; on evaporation and on the expansion of gases by heat, Mem. Manchester Lit. and Phil.Soc. 5: 535-602.

Hallettt, P. D., Dexter, A. R., \& Seville, J. P. K. (1995). The application of fracture mechanics to crack propagation in dry soil. European Journal of Soil Science, 46(4), 591 599.

Fang, Hsai-Yang. Daniels, J. (1997), Introduction to Environmental Geotechnology, Boca Raton, CRC Press LLC.

Fredlund, D. G., \& Rahardjo, H. (1993). Soil mechanics for unsaturated soils. John Wiley \& Sons. Fujiyasu, Y., Fahey, M., \& Newson, T. (2000). 
Field investigation of evaporation from freshwater tailings. Journal of geotechnical and geoenvironmental engineering, 126(6), 556-567.

Gardner, W. R., \& Hillel, D. I. (1962). The relation of external evaporative conditions to the drying of soils. Journal of Geophysical Research, 67(11), 4319-4325.

Gdoutos, E. E. Fracture Mechanics-An Introduction. 2005.

Graham, C. B., Dragila, M. I., Cooper, C. A., \& Weisbrod, N. (2005, May). Modeling Salt Redistribution in Fractured Porous Media Caused by Convection Driven Evaporation Within the Fracture. In AGU Spring Meeting Abstracts (Vol. 1, p. 02).

Hallett, P. D., \& Yoshida, S. (2008). Impact of hydraulic suction history on crack growth mechanics in soil. Water Resources Research, 44(5).

Hatano, R., Nakamoto, H., Sakuma, T. and Okajima, H. (1988). Evapotranspiration in cracked clay field soil. Soil sci. Plant Nutr., 34: 547-555.

Holtz, R. D., \& Kovacs, W. D. (1981). An introduction to geotechnical engineering (No. Monograph).

Horgan, G.W., Young, I.M. (2000). An empirical stochastic model for the geometry of two-dimensional crack growth in soil (with discussion). Geoderma 96, 263-276

Hull, D. (1999). Fractography: observing, measuring and interpreting fracture surface topography. Cambridge University Press.

Inci, G. (2008). Numerical Modeling of Desiccation Cracking in Compacted Soils. International Association for Computer Methods and Advances in Geomechanics (IACMAG). Goa, India.

Irwin, G. R. (1957). Analysis of stresses and strains near the end of a crack traversing a plate. J. appl. Mech.

Jayasinghe, P. "Prototype Testing of a Modified Poroelastic Matric Suction Sensor", M.A.Sc. thesis, Department of Civ. \& Env. Engineering, Carleton University, 2013 
Kirkham, D., \& Selim, H. M., (1970). Soil temperature and water content changes during drying as influenced by cracks: A laboratory experiment. Soil Science Society of America Journal, 34(4), 565-569.

Sugita, F., \& Kishii, T. (2002). Effect of roughness distribution on evaporation processes over non-homogeneous sand surfaces: a wind tunnel investigation. Hydrological processes, 16(11), 2141-2153.

Kodikara, J. K., \& Nahlawi, H. (2006). Laboratory experiments on desiccation cracking of thin soil layers. Geotechnical \& Geological Engineering, 24(6), 1641-1664.

Konrad, J. M., \& Ayad, R. (1997). A idealized framework for the analysis of cohesive soils undergoing desiccation. Canadian Geotechnical Journal, 34(4), 477-488.

Konrad, J. M., \& Ayad, R. (1997). Desiccation of a sensitive clay: field experimental observations. Canadian Geotechnical Journal, 34(6), 929-942.

Ledesma, A., Rodríguez, R., Sanchez, M., \& Lloret, A. (2007). Experimental and numerical analysis of desiccation of a mining waste. Canadian Geotechnical Journal, 44(6), 644658.

Liu, C., Tang, C., Shi, B., Zhao, L., \& Wang, B. (2008). Influencing factors of geometrical structure of surface shrinkage cracks in clayey soils. Engineering Geology, 101(3), 204217.

Menziani, M., Pugnaghi, S., Pilan, L., Santangelo, R., \& Vincenzi, S. (1999). Field experiments to study evaporation from a saturated bare soil. Physics and Chemistry of the Earth, Part B: Hydrology, Oceans and Atmosphere, 24(7), 813-818.

Miller, R. D., \& Snyder, V. A. (1985). Tensile strength of unsaturated soils. Soil Science Society of America Journal, 49(1), 58-65.

Miller, C. J., Mi, H., \& Yesiller, N. (1998). EXPERIMENTAL ANALYSIS OF DESICCATION CRACK PROPAGATION IN CLAY LINERS1. JAWRA Journal of the American Water Resources Association, 34(3), 677-686.

Mitchell, J. K. 1993, Fundamentals of Soil Behavior, John Wiley and Sons, Inc., New York. 
Neal-Sturgess, C. E. (2008). A Direct Derivation of the Griffith-Irwin Relationship using a Crack tip Unloading Stress Wave Model. arXiv preprint arXiv:0810.2218.

Pontius, F. (2012). An updated global energy balance. The Drinking Water Advisor. Retrieved April 21 $1^{\text {st }}, 2014$, from http://drinkingwateradvisor.com/2012/11/21/anupdated-global-energy-balance/

Prat, P. C., Ledesma, A., Lakshmikantha, M. R., Levatti, H., \& Tapia, J. (2008, October). Fracture mechanics for crack propagation in drying soils. InProceedings of the 12th International Conference of the International Association for Computer Methods and Advances in Geomechanics (IACMAG), Goa, India (pp. 1-6).

Rao, S. M., \& Shivananda, P. (2005). Role of osmotic suction in swelling of salt-amended clays. Canadian geotechnical journal, 42(1), 307-315.

Ritchie, J. T., Adams, J. E., Burnett, E., \& Fryrear, D. W. (1969). Evaporation from a simulated soil shrinkage crack. Soil Science Society of America Journal,33(4), 609-613.

Terzaghi, Karl. (1967), Soil Mechanics in Engineering Practice. NewYork, Wiley

Min, T. K., \& Vo-Dai, N. (2008). Kelvin-Voigt model for dynamics of crack opening in shrinkage cracking. KSCE Journal of Civil Engineering, 12(3), 149-154.

Min, T. K., \& Vo-Dai, N. (2008).A Graphical Method for Evaluation of Stages in Shrinkage cracking Using S-shape Curve Model. Journ. of the KGS, 24(9),41-48.

Van Genuchten, M. T. (1980). A closed-form equation for predicting the hydraulic conductivity of unsaturated soils. Soil Science Society of America Journal, 44(5), 892-898.

van Mier, J. G. (2008). Framework for a generalized four-stage fracture model of cement-based materials. Engineering Fracture Mechanics, 75(18), 5072-5086.

Weinberger, R. (1999). Initiation and growth of cracks during desiccation of stratified muddy sediments. Journal of Structural Geology, 21(4), 379-386.

Weinberger, R. (2001). Evolution of polygonal patterns in stratified mud during desiccation: The role of flaw distribution and layer boundaries. Geological Society of America Bulletin, 113(1), 20-31. 
Weisbrod, N., Pillersdorf, M., Dragila, M., Graham, C., Cassidy, J., \& Cooper, C. A. (2005). Evaporation from fractures exposed at the land surface: Impact of gas-phase convection on salt accumulation. Geophysical Monograph Series,162, 151-164.

Weisbrod, N., Nativh, R., Adar, K. M., \& Ronend, D. (2000). Salt accumulation and flushing in unsaturated fractures in an arid environment. Groundwater, 38(3), 452-461.

Weisbrod, N., Nachshon, U., Dragila, M. I. (2011, December). Fracture ventilation by surface winds. In AGU Fall Meeting Abstracts (Vol. 1, p. 1167).

Wilson, G.W., Fredlund,D.G., Barbour, S.L. (1994). Coupled soil-atmosphere modeling for soil-evaporation. Canadian Geotechnical Journal, 31: 151-161.

Yanful, E. K., Rayhani, M. HT, and A. Fakher. "Desiccation-induced cracking and its effect on the hydraulic conductivity of clayey soils from Iran." Canadian geotechnical journal 44.3 (2007): 276-283.

Yarema, S. (1995). History of Fracture Mechanics. On the contribution of GR Irwin to Fracture Mechanics.

Zhurkov, S. N., Kuksenko, V. S., Petrov, V. A., Savelijev, V. N., \& Sultanov, U. S. (1977). On the problem of prediction of rock fracture. Physics of the Solid Earth, 13(6), 374-379. 


\section{Appendix A: SWCC and Diffusivities}

\begin{tabular}{|lrc|}
\hline$\#$ & $\boldsymbol{\Psi}[\mathrm{Mpa}]$ & $\mathbf{w} \%$ \\
\hline 1 & 0.06 & 36.10921 \\
\hline 2 & 0 & 41.06833 \\
\hline 3 & 0.21 & 9.762406 \\
\hline 4 & 0 & 43.79511 \\
\hline 5 & 0.09 & 41.73656 \\
\hline 6 & 0.02 & 44.82161 \\
\hline 7 & 0.1 & 42.21883 \\
\hline 8 & 0.05 & 36.80456 \\
\hline 9 & 0.45 & 42.22087 \\
\hline 10 & 0 & 41.47721 \\
\hline 11 & 0.11 & 39.77981 \\
\hline 12 & 0.05 & 40.80765 \\
\hline 13 & 0.4 & 34.95823 \\
\hline
\end{tabular}

Table 14 Surface suction at 3.47 days

\begin{tabular}{rrr|}
\hline \# $\boldsymbol{\Psi}$ & $\begin{array}{c}\boldsymbol{\Psi} \\
{[\mathrm{Mpa}]}\end{array}$ & \multicolumn{1}{c|}{$\mathbf{w} \%$} \\
\hline 1 & -2.5 & 24.90566 \\
\hline 2 & -5.69 & -200 \\
\hline 3 & -1.67 & 27.98982 \\
\hline 4 & -5.35 & 22.58065 \\
\hline 5 & -4.09 & 24.50495 \\
\hline 6 & -2.1 & 27.8826 \\
\hline 7 & -4.73 & 23.7069 \\
\hline 8 & -3.58 & 24.73958 \\
\hline 9 & -5.24 & 22.22222 \\
\hline 10 & -5.18 & -293.333 \\
\hline 11 & -4.21 & 21.8638 \\
\hline 12 & -2.24 & 26.72897 \\
\hline 13 & -1.16 & 29.06977 \\
\hline 14 & -1.45 & 28.96936 \\
\hline 15 & -1.92 & 25.37879 \\
\hline 16 & -1.77 & 24.89177 \\
\hline 17 & -1.26 & 26.97368 \\
\hline 18 & -2.46 & 26.19048 \\
\hline $15 S 4$ & 5410 & 6.81 \\
\hline
\end{tabular}

Table 15 Surface suction at 6.81 days 


\begin{tabular}{|c|c|c|}
\hline$\# \Psi$ & $\begin{array}{c}\Psi \\
{[\mathrm{Mpa}]}\end{array}$ & $w \%$ \\
\hline 1 & -6.68 & 15.70827 \\
\hline 2 & -5.9 & 19.58637 \\
\hline 3 & -6.03 & 16.66667 \\
\hline 4 & -4.19 & 24.11765 \\
\hline 5 & -2.6 & 25.5688 \\
\hline 6 & -4.57 & 23.64621 \\
\hline 7 & -5.33 & 21.09005 \\
\hline 8 & -6.69 & 16.16314 \\
\hline 9 & -5.57 & 19.21296 \\
\hline 10 & -3.9 & 23.94068 \\
\hline 11 & -5.66 & 19.11469 \\
\hline 12 & -3.6 & 25.03277 \\
\hline 13 & -4.99 & 20.67594 \\
\hline 14 & -6.13 & 18.93333 \\
\hline 15 & -4.32 & 24.0458 \\
\hline 16 & -3.32 & 25.07837 \\
\hline 17 & -4.77 & 23.58318 \\
\hline 18 & -3.03 & 25.44379 \\
\hline 19 & -5.32 & 23.02905 \\
\hline 20 & -5.35 & 22.22222 \\
\hline
\end{tabular}

Table 16 Surface suction at 7.43 days

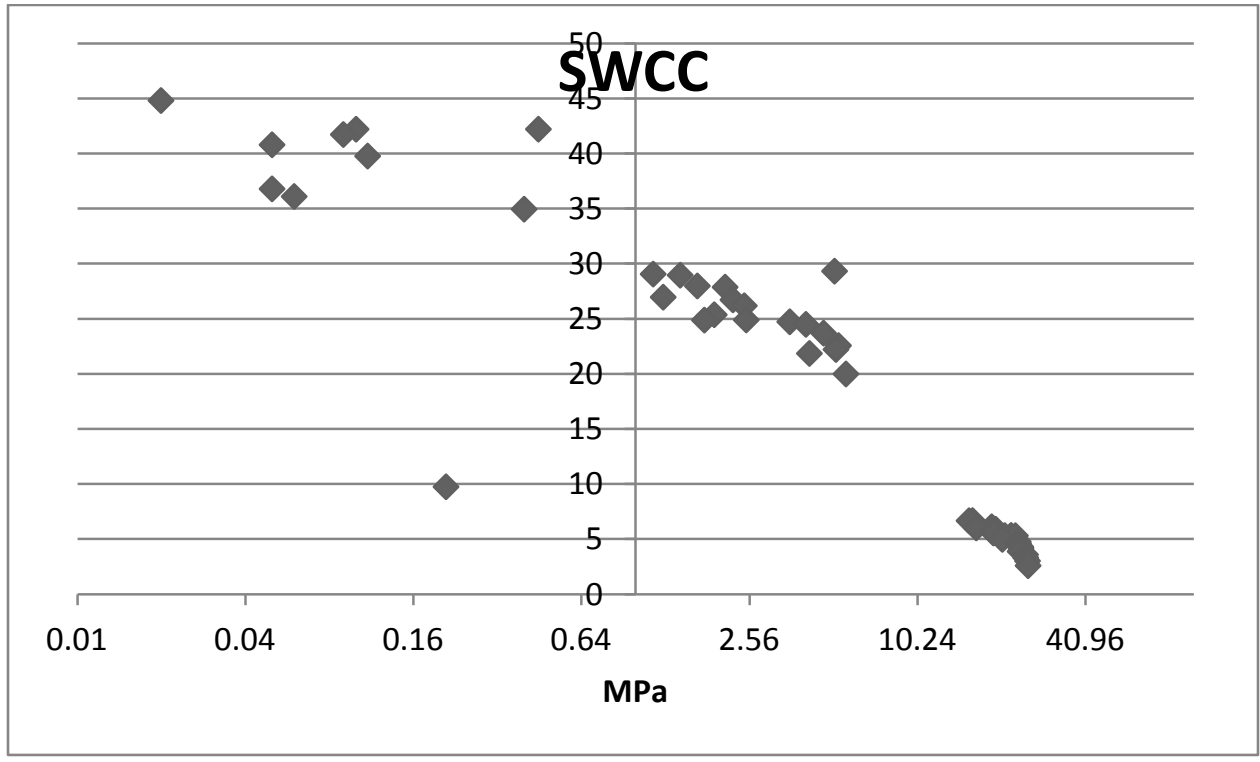

Figure 76 


$$
\begin{aligned}
& \text { slope }=\frac{\Delta w^{0} \%}{\Delta \psi} \\
& \text { slope }=0.011\left[\frac{}{\mathrm{kPa}}\right] \bullet 9.81\left[\frac{\mathrm{kPa}}{\mathrm{m}}\right] \\
& \text { slope }=0.010791\left[\frac{-}{\mathrm{m}}\right]
\end{aligned}
$$

Diffusivity obtained for a ksat=1*10-11 m/s:

$$
\begin{aligned}
& D=\frac{k_{\text {sat }}}{\text { slope }} \\
& D=\frac{1 \bullet 10^{-11}[\mathrm{~m} / \mathrm{s}]}{0.010791[\mathrm{~m}]} \\
& D=0.0556\left[\frac{\mathrm{mm}^{2}}{\mathrm{~min}}\right]
\end{aligned}
$$

Diffusivity obtained according to Gardner and Hillel's method:

According to Gardner and Hillel (1962), diffusivity can be tied to rate of evaporation . Rate of evaporation is expressed in terms of rate of moisture loss as a percentage over time. Moisture contents are taken at two times to calculate the rate of moisture loss during crack growth.

$$
\begin{aligned}
& E=\frac{D(\theta) W \pi^{2}}{4 L^{2}}=-\frac{d W}{d t} \\
& D(\theta)=-\frac{d W}{d t} \bullet \frac{4 L^{2}}{W \pi^{2}}
\end{aligned}
$$

Time 1: $\frac{59.94 \%}{20 \mathrm{~min}}$

Time 2: $\frac{45.73 \%}{4800 \mathrm{~min}}$ 
RateE $=\frac{59.94 \%-45.73 \%}{20 \min -4800 \min }$

RateE $=-0.00297 \frac{\%}{\min }$

RateE $=-4.28 \frac{\%}{d}$

The rate comes to $-4.28 \%$ éd. The average length is $8.3 \mathrm{~cm}$ while the average moisture is $53.8 \%$.

$D(\theta)=-\frac{d W}{d t} \cdot \frac{4 L^{2}}{W \pi^{2}}$

$D(\theta)=-\left(-4.28 \frac{\%}{d}\right) \cdot \frac{4 * 8.3^{2}}{53.8 \% \pi^{2}}$

$D(\theta)=222.1 \frac{\mathrm{cm}^{2}}{d}$

$D(\theta)=6 \frac{\mathrm{mm}^{2}}{\min }$

The 4 diffusivities are Chertkov's diffusivity of $15.4 \mathrm{~mm}^{2} / \mathrm{min}$, the diffusivity obtained according to Gardner and Hillel's (1962) method of $6 \mathrm{~mm}^{2} / \mathrm{min}$, the diffusivity obtained for a hydraulic conductivity of $1 * 10^{-11} \mathrm{~m} / \mathrm{s}\left(0.0556 \mathrm{~mm}^{2} / \mathrm{min}\right)$ and the final inputted diffusivity of $1.65 \mathrm{~mm}^{2} / \mathrm{min}$ which corresponds to a hydraulic conductivity within the accepted range for kaolinite clays. 


\section{Appendix B: Chertkov's Parameters}

Initial crack propagation velocities are the inverse of the slopes of the Chertkov curves below:

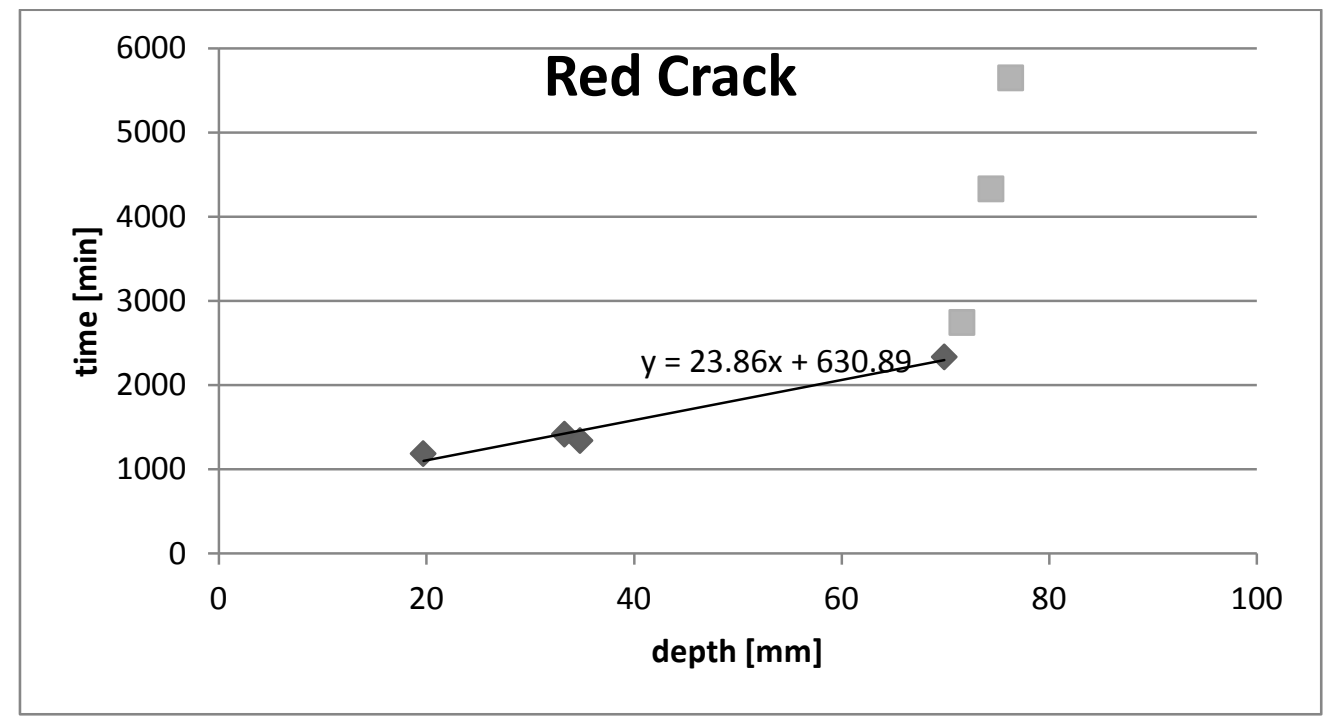

Figure 77

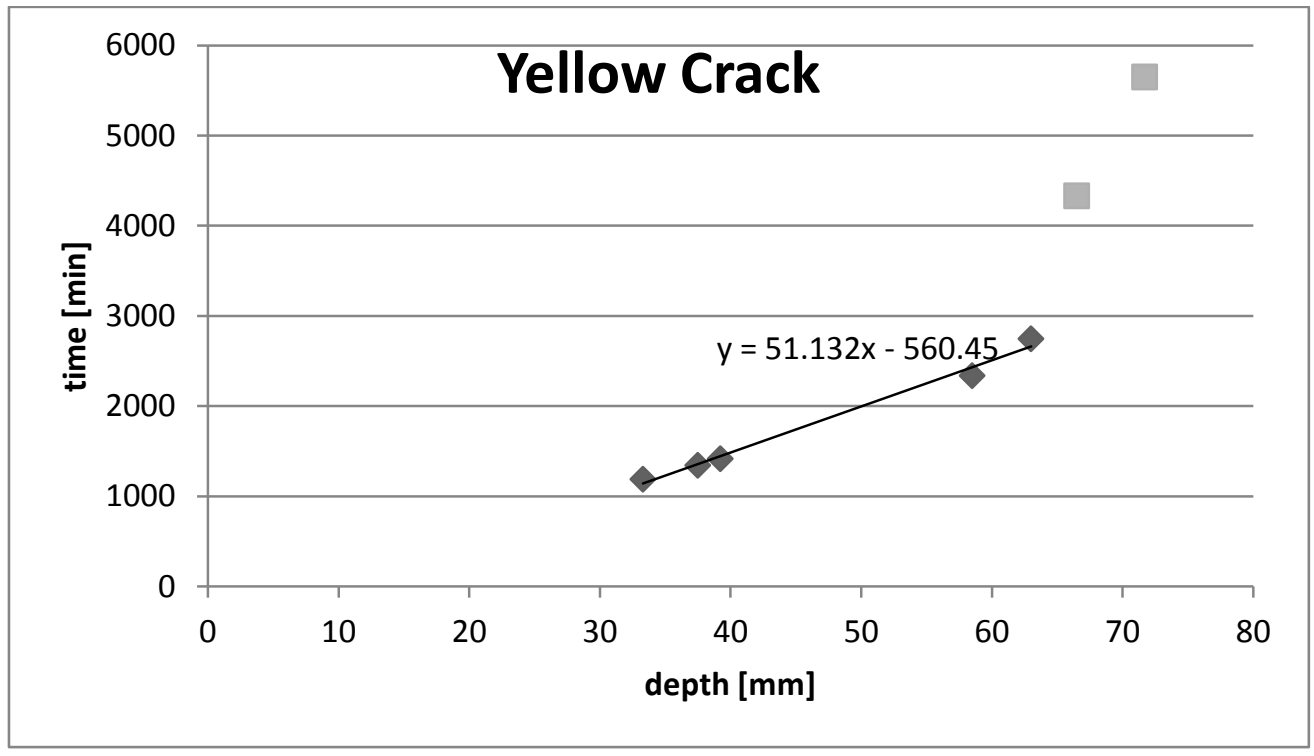

Figure 78 


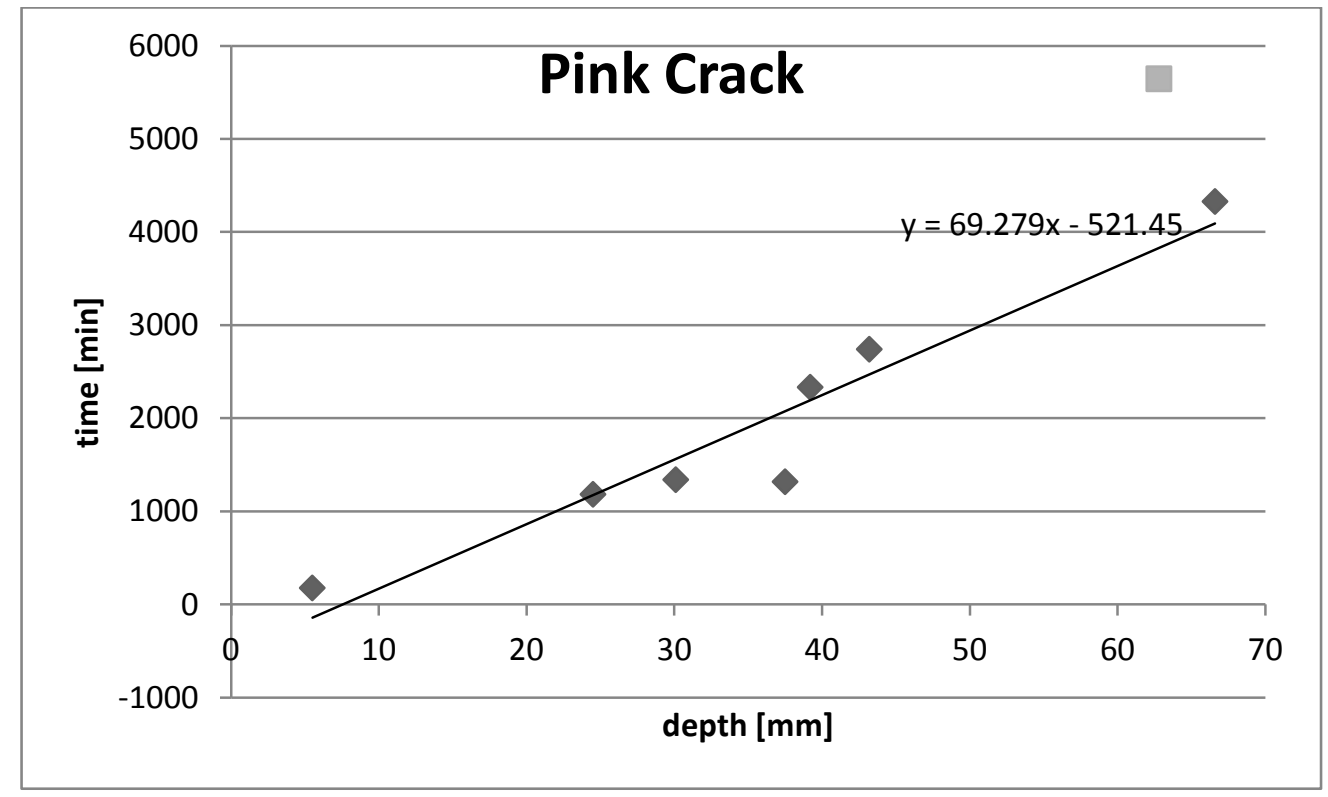

Figure 79

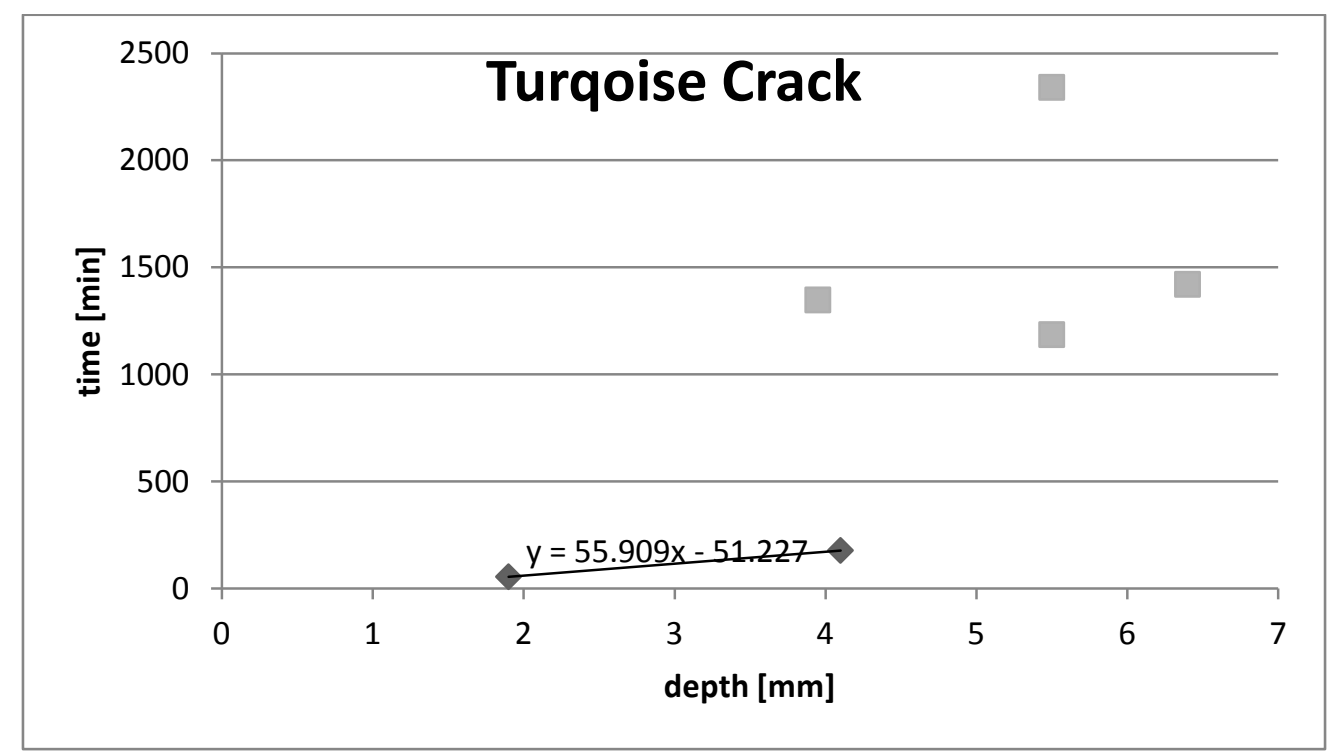

Figure 80 


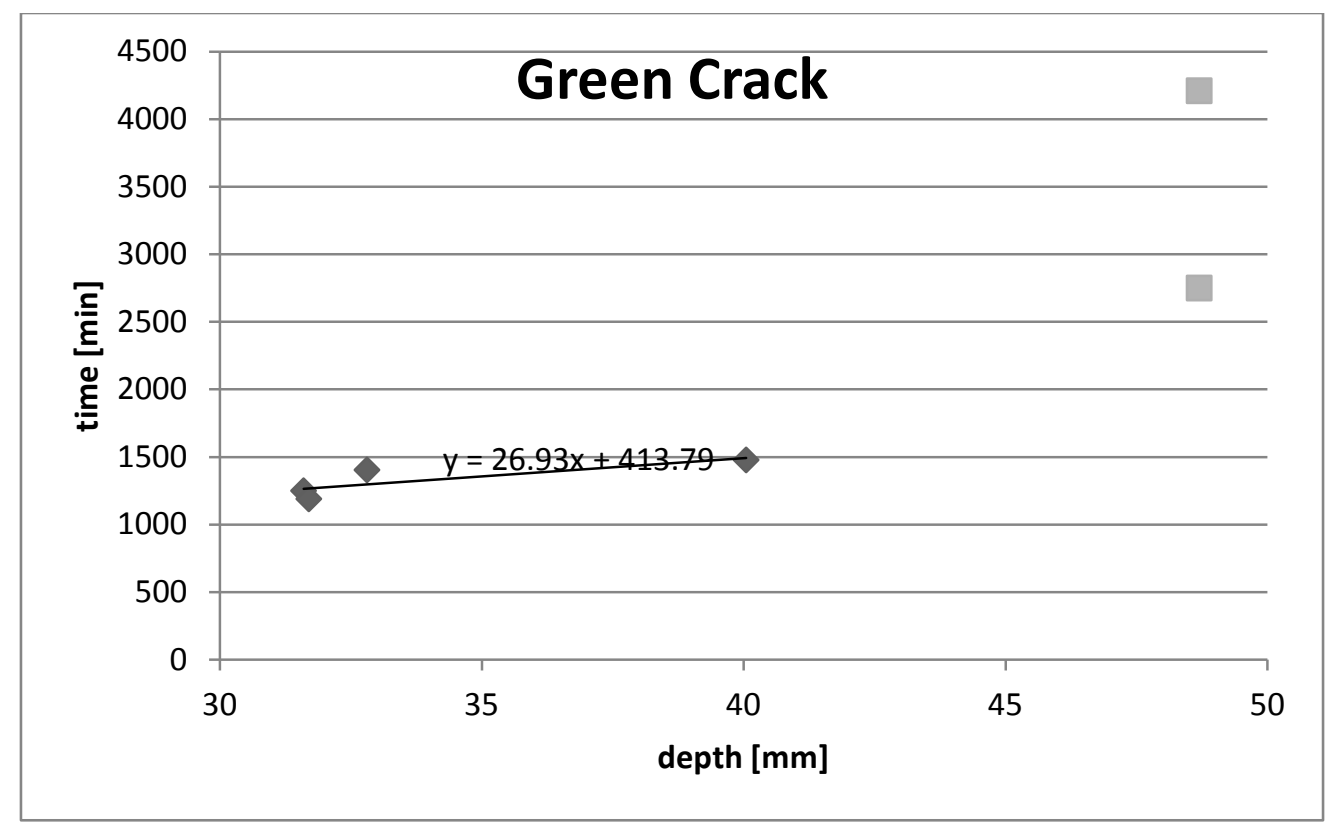

Figure 81

\begin{tabular}{|c|c|c|c|}
\hline & slope & $\begin{array}{l}\text { 1/slope } \\
\text { [mm/min] }\end{array}$ & $\mathrm{mm} / \mathrm{d}$ \\
\hline Red & 23.86 & 0.0419 & 60.35 \\
\hline Yellow & 51.13 & 0.0196 & 28.16 \\
\hline Pink & 69.28 & 0.0144 & 20.79 \\
\hline Turk & 55.91 & 0.0179 & 25.76 \\
\hline \multirow[t]{3}{*}{ Green } & 26.93 & 0.0371 & 53.47 \\
\hline & & $\operatorname{avg}[\mathrm{mm} / \mathrm{d}]$ & 37.71 \\
\hline & & $\begin{array}{l}\text { avg } \\
\mathrm{mm} / \mathrm{min}\end{array}$ & 0.0262 \\
\hline
\end{tabular}

\begin{tabular}{|c|c|c|}
\hline & $\begin{array}{l}\text { Lav } \\
\text { [mm] }\end{array}$ & $\begin{array}{l}\text { Tav } \\
\text { [min] }\end{array}$ \\
\hline Red & 19.69 & 1188 \\
\hline Yellow & 33.3 & 1190 \\
\hline Pink & 5.5 & 179 \\
\hline Turqoise & 1.9 & 55 \\
\hline Green & 31.6 & 1250 \\
\hline average & 18.398 & 772.4 \\
\hline
\end{tabular}




\begin{tabular}{cl}
\hline $\begin{array}{c}\text { Derived } \\
\text { Parameters }\end{array}$ & \multicolumn{1}{c}{ Transformation } \\
\hline $\mathrm{S}_{0}$ & $\mathrm{~S}_{0}=\left(\mathrm{K}_{*}+1\right) \mathrm{I}_{*} \approx 6 \mathrm{I}_{*}$ \\
$\mathrm{~L}_{\mathrm{avg}}$ & $\mathrm{L}_{\mathrm{avg}} \approx 5.72 \mathrm{I}_{*}$ \\
$\mathrm{~T}_{\mathrm{avg}}$ & $\mathrm{T}_{\mathrm{avg}}=11.10\left(\mathrm{I}^{2}{ }_{*} / \mathrm{D}\right)$ \\
$\mathrm{u}$ & $\mathrm{u}=16 \mathrm{D} /\left(\pi^{3} \mathrm{I}_{*}\right)$ \\
\hline
\end{tabular}

\begin{tabular}{|c|c|}
\hline $\begin{array}{l}\text { D } \\
{\left[\mathrm{mm}^{2} / \mathrm{min}\right]}\end{array}$ & $\begin{array}{l}\text { Tavg } \\
\text { [min] }\end{array}$ \\
\hline 15.4 & 0.72 \\
\hline 6 & 1.85 \\
\hline 0.0556 & 200 \\
\hline
\end{tabular}

\begin{tabular}{rr}
\hline D & \multicolumn{2}{l}{ U } \\
{$\left[\mathrm{mm}^{2} / \mathrm{min}\right]$} & {$[\mathrm{mm} / \mathrm{min}]$} \\
\hline $\mathbf{1 5 . 4}$ & 7.96 \\
$\mathbf{6}$ & 3.1 \\
$\mathbf{0 . 0 5 5 6}$ & 0.029 \\
\hline
\end{tabular}

\begin{tabular}{crr}
\hline & $I^{*}=\mathbf{1 m m}$ & $I^{*}=30 \mathrm{~mm}$ \\
\hline $\mathrm{S}_{0}$ & 6 & 180 \\
$\mathrm{~L}_{\text {avg }}$ & 5.71 & 171.6 \\
\hline
\end{tabular}

For a/ diffusivity of $1.65 \mathrm{~mm}^{2} / \mathrm{min}$ the resultant $T_{\text {avg }}$ was 370 minutes, $U$ was $0.028 \mathrm{~mm} / \mathrm{min}$, $\mathrm{L}_{\text {avg }}$ was $171.6 \mathrm{~mm}$ and $\mathrm{S}_{0}$ was $18 \mathrm{~cm}$. 

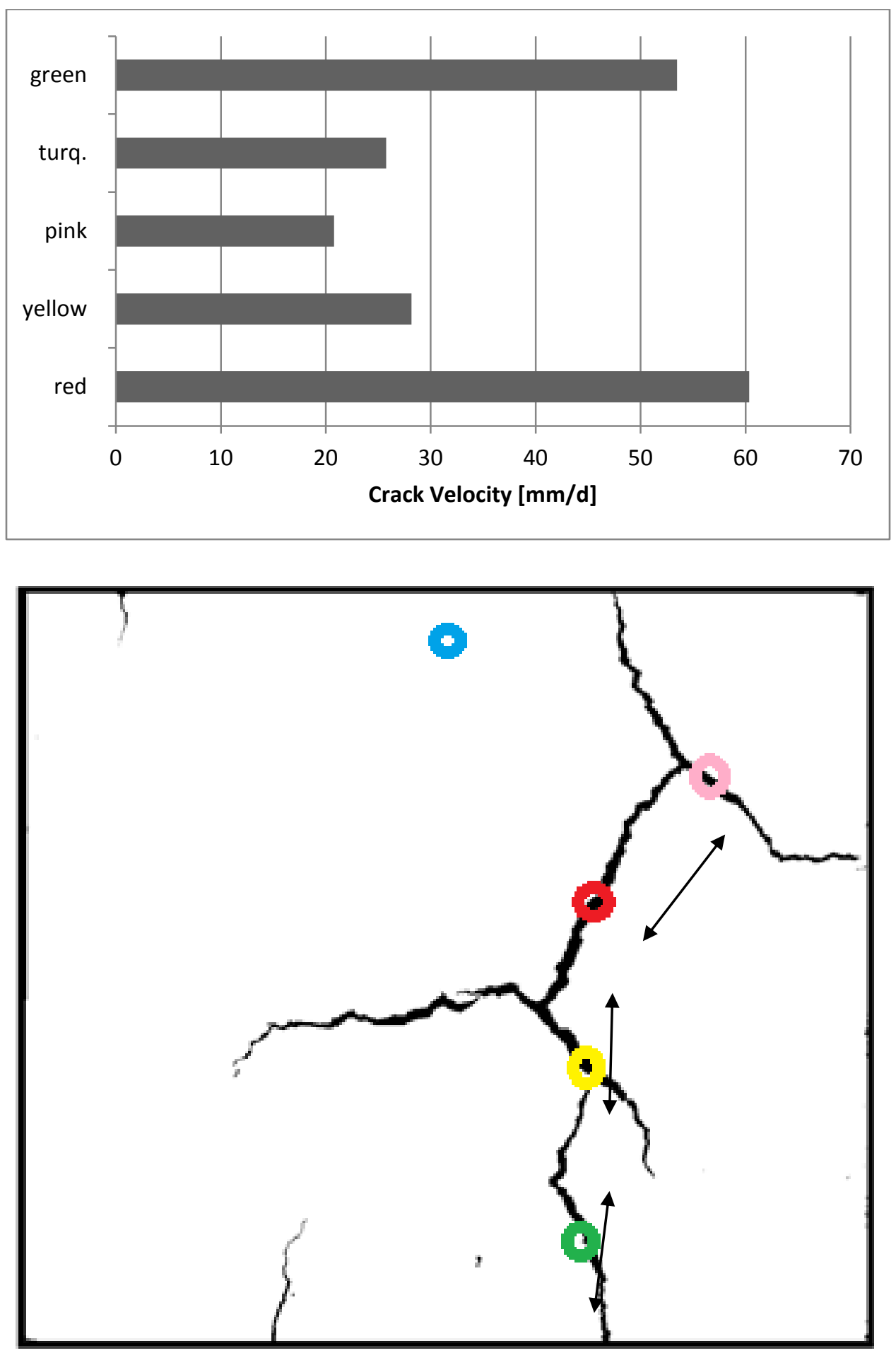

The average distance between primary crack nucleation sites is taken as the $\mathrm{S}_{0}$ value. The crack at the top center location is ignored because it did not nucleate into a macrocrack. 


\section{Appendix C: Drying Data}
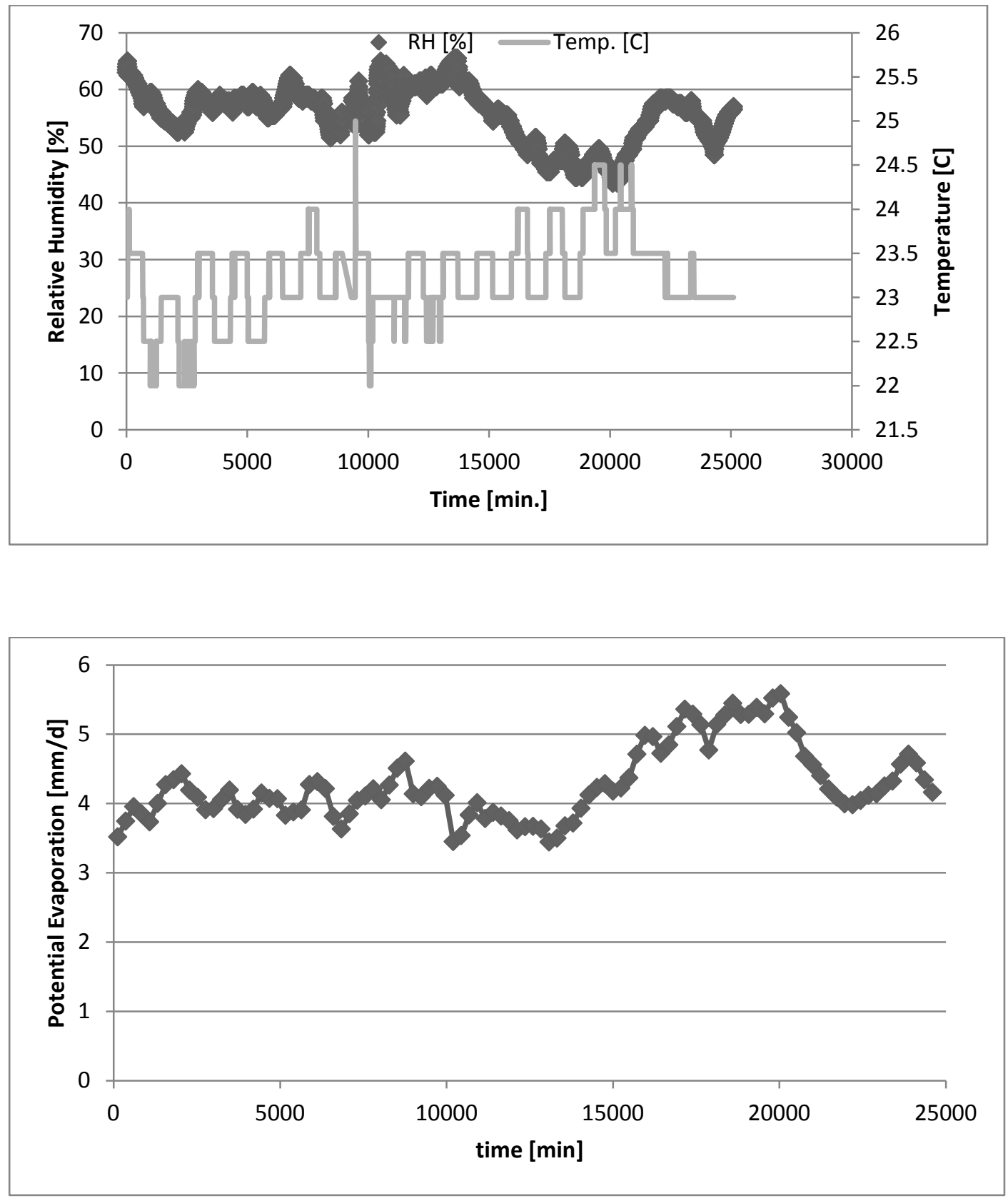
